\begin{tabular}{|l|l|}
\hline 2. To: (Receiving organization) & $\begin{array}{l}\text { 3. From: (Originating Organization) } \\
\text { Mechanical Systems Design }\end{array}$ \\
\hline 5. Proj./Prog./Dept./Div.: & $\begin{array}{l}\text { 6. Design Authority/ Design Agent/Cog } \\
\text { Engr.: } \\
\text { Waste Management }\end{array}$ \\
\hline
\end{tabular}

8. Originator Remarks:

This document is being processed for release.

11. Receiver Remarks: 11A. Design Baseline Document? [] Yes [X] No
4. Related EDT No.:
$N / A$
7. Purchase Order No.:
$\mathrm{N} / \mathrm{A}$

9. Equip./Component No.:

$\mathrm{N} / \mathrm{A}$

10. System/Bldg./Facility:

N/A

12. Major Assm. Dwg. No.:

$N / A$

13. Permit/Permit Application No.: $N / A$

14. Required Response Date: $\mathrm{N} / \mathrm{A}$

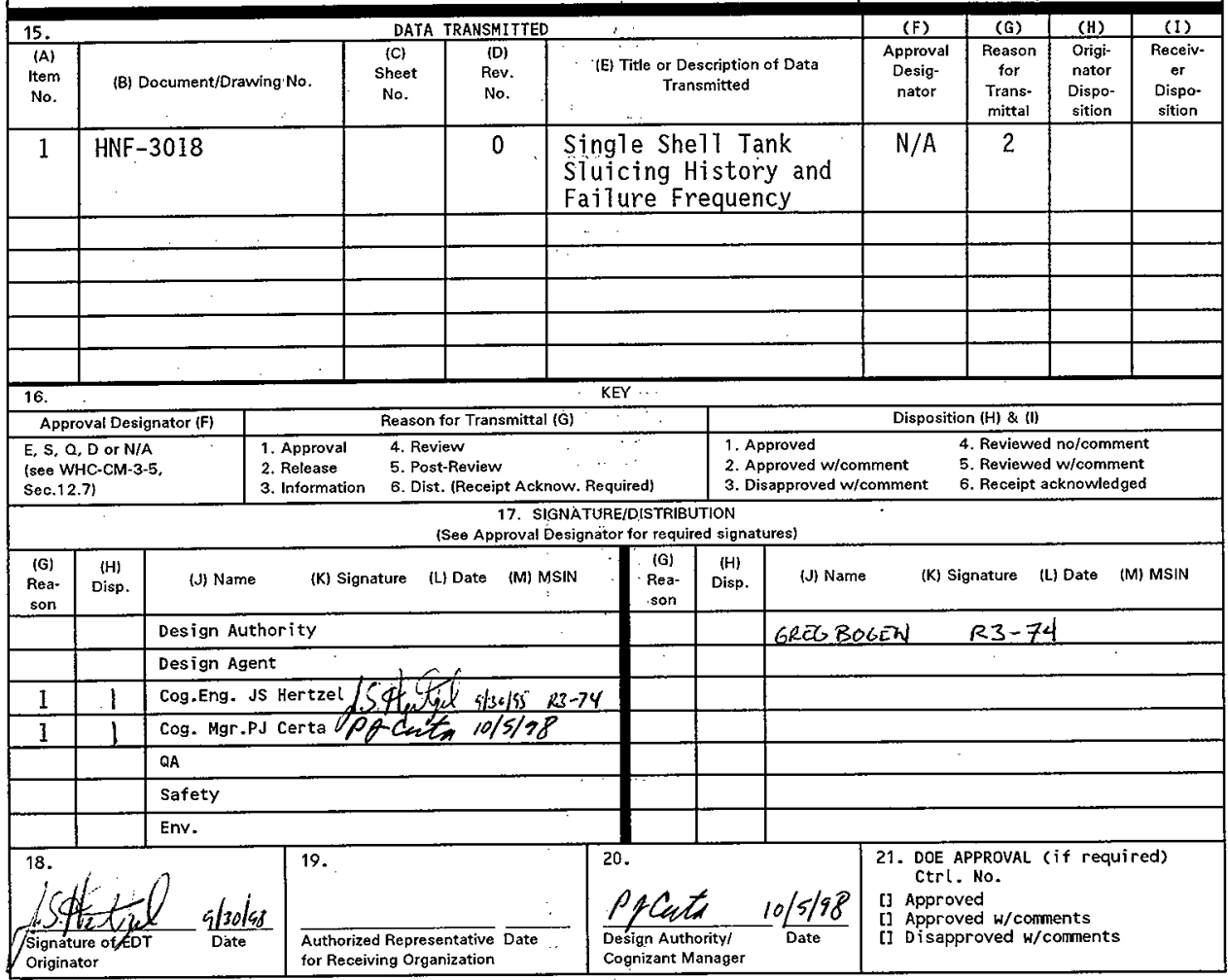

BD-7400-172-2(05/96) GEF097 


\section{Single Shell Tank Sluicing History and Failure Frequency}

\section{Jeffory S. Hertze1}

Numatec Hanford Corporation, Richland, WA 99352

U.S. Department of Energy Contract DE-AC06-96RL13200

EDT/ECN: 625701

Org Code: 81200

UC: 2030

Charge Code: 102631

B\&R Code: EW3130010 Total Pages: 530

Key Words: Leak Detection, Leak Monitoring, STuicing, SST

Abstract: This document assesses the potential for failure of the single-shell tanks (SSTs) that are presumably sound and helps to establish the retrieval priorities for these and the assumed leakers. Furthermore, this report examines probabilities of SST failure as a function of age and operational history, and provides a simple statistical summary of historical leak volumes, leak rates, and corrosion factor.

ENRAF is a trademark of ENRAF Corporation, Houston, Texas.

TRADEMARK DISCLALMER. Reference herein to any specific comercial product, process, or service by trade name, trademark, manufacturer, or otherwise, does not necessarily constitute or $i$ mply its endorsement, recommendation, or favoring by the United States Government or any agency thereof or $i$ ts contractors or subcontractors.

Printed in the United States of America. To obtain copies of this document, contact: Document Control Services, P.O. Box 950, Mailstop H6-08, Richland WA 99352, Phone (509) 372-2420;

Fax (509) 376-4989.
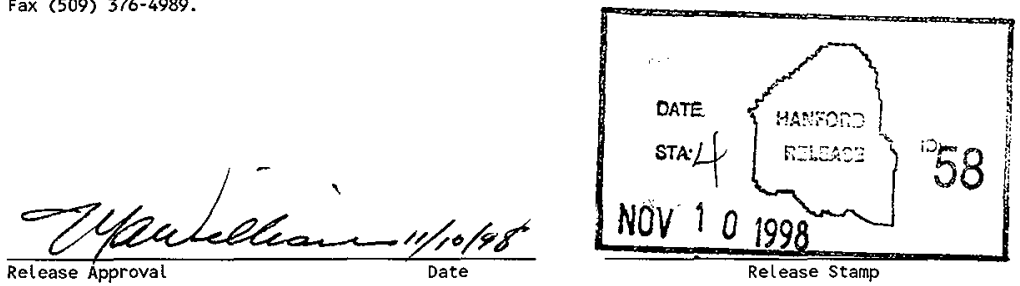


\section{ERRATA:}

Immediately after this report was submitted for duplication and distribution, it was learned that at least some, if not all, of the interstitial liquid level (ILL) measurements were suspect. It is possible, but undetermined at this time, that some of the ILL sensor data are measurements of the waste surface rather than an interstitial liquid interface. To the extent the $\mathrm{LL}$ data is not measuring the interstitial liquid level, the ILL-measured tank data and subsequent analysis shown in Appendix $E$ will be in error. The conclusions and recommendations described in this report are supported by the ENRAF and FIC data and remain valid. 


\section{Single-Shell Tank Sluicing History and Failure Frequency}

COGEMA Engineering Corporation Purchase Agreement C-98-P-PO1-0007

Vista Research Project No. F007

Prepared by:

Phillip C. Ohl

Dennis G. Douglas

Joseph W. Maresca, Jr.

Prepared for:

U.S. Department of Energy - Office of Environmental Restoration and Waste Management (EM-30)

c/o Lockheed Martin Hanford Corporation

P.O. Box 1500

Richland, Washington 99352-1505

3 September 1998 


\section{Executive Summary}

Single-shell tanks (SSTs) were initially constructed at Hanford in 1944 to store radioactive wastes resulting from plutonium/uranium separations processes necessary for plutonium production. The first SSTs to leak were TY-106 and U-101, in 1959. To date, 67 of the total of 149 single-shell tanks have been declared "confirmed or assumed leakers"; the other 82 tanks are deemed "presumably sound." While some of the SSTs have had the supernatant pumped off (or stabilized) many of the tanks contain significant volumes of supernatant, interstitial liquids, or both. These tanks represent a potential insult to the environment should a failure occur prior to or during the retrieval of their contents.

To assess the potential for failure of the SSTs that are presumably sound (at present) and to help establish retrieval priorities for these and the assumed leakers, this report examines several factors that can facilitate retrieval planning. First, this report reviews the probability of single-shell tank failure as a function of tank age and operational history. Second, it provides a simple statistical summary of historical leak volumes, leak rates, and corrosion factors.

A preliminary integrity assessment of the remaining useful life of the tanks is included. This assessment, which is based upon factors such as corrosiveness of the waste, maximum waste temperature, and lower-knuckle construction, is then used in conjunction with predicted failure frequencies to make an initial estimate of the remaining useful life of the SSTs. The end result is a preliminary screening of the single-shell tanks that may be candidates for initial hydraulic retrieval based on tank integrity. Accordingly, 12 presumably sound tanks are proposed as candidates for immediate detailed integrity assessment, 20 presumably sound tanks are proposed as contingency candidates for immediate detailed integrity assessment, and 52 presumably sound tanks and 62 assumed leakers are proposed for subsequent detailed integrity assessment.

For those SSTs with a reportable liquid level-supernatant measured with a level gauge or interstitial liquids measured by a gamma/neutron probe in the liquid observation wells-this report also provides a preliminary assessment of the significance of volume changes over month-long periods, and it provides a preliminary estimate of the minimum leak rates that could be detected in these tanks. Together with available data based on expected retrieval times, this estimate of minimum detectable leak rates was used to calculate a maximum undetected leak volume for each SST.

This preliminary screening of SST failure frequencies and sluicing histories concludes that for many SSTs, tank integrity indicators such as corrosiveness of the waste and maximum waste temperature are favorable. Furthermore, level data show that many tanks with a recordable liquid level are leak-tight today - within quantified criteria and probability of detection and probability of false alarm. Finally, methodologies are suggested for confirmatory tank integrity analysis and failure frequency predictions prior to the initiation of full-scale retrieval operations on the SSTs. 


\section{Table of Contents}

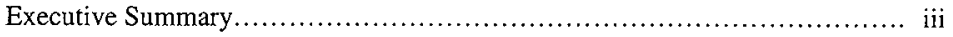

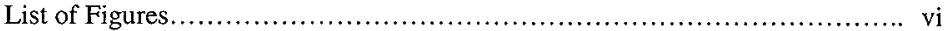

List of Tables............................................................ vii

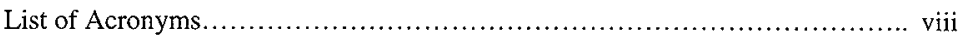

Acknowledgements............................................................ ix

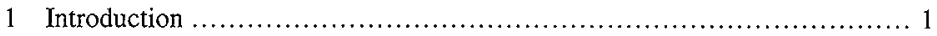

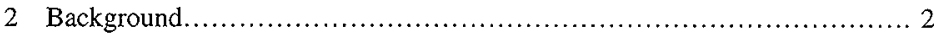

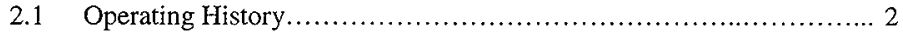

2.2 Failure Mechanisms.................................................. 2

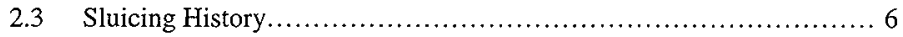

2.4 Failure Frequencies.............................................. 8

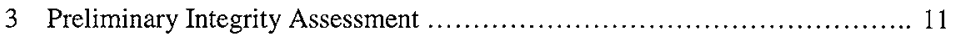

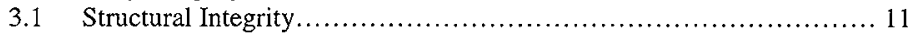

3.2 Liquid Integrity ................................................ 12

3.2.1 Selection of Level Data .................................. 13

3.2.2 Statistical Analysis of Level Data ........................... 14

3.2.2.1 Significance of the Average Volume Rate............ 19

3.2.2.2 Minimum Detectable Leak.......................... 19

4 Assessment of Remaining Useful Life ..................................... 23

4.1 Catastrophic Failure .............................................. 23

4.2 Loss of Containment............................................ 24

4.3 Tank-by-Tank Ranking ........................................... 26

5 Impact of Hydraulic Retrieval on Liquid Integrity ........................ 28

5.1 Calculated Flow Constant for Laminar Flow......................... 28

5.2 Maximum Undetected Leak Volume................................ 30

6. Conclusions and Recommendations................................... 33

6.1 Conclusions......................................................... 33

6.2 Recommendations................................................. 33

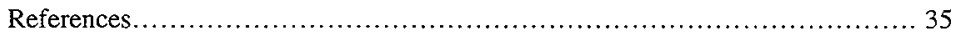

Appendix A: Single-Shell Tank Quick Reference Facts...................... A-1

Appendix B: SST Failure Frequencies.................................. B-1

Appendix C: SST Waste Tank Volumes and Available Liquid Level Data ....... C-1

Appendix D: Tank Level Data Obtained From TWINS ......................... D-1

Appendix E: Statistical Analyses of Level Data............................ E-1

Appendix F: Calculation of Potential Leaks................................. F-1 


\section{Figures}

Figure 1. Savannah River Site, Tank 14 (Photograph \# 4080-13)........... 3

Figure 2. Histogram of SST failure frequency based on the date at which the tank was declared an "assumed leaker"........................ 9

Figure 3. Histogram of SST failure frequency based on the date of level decrease

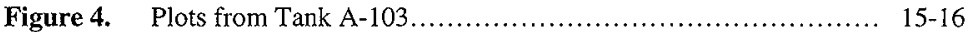

Figure 5. Plot used in the analysis of Tank A-103.................... 17

Figure 6. Impact of hydraulic retrieval.............................. 29

Figure 7. Fluid dynamics data for seven SSTs with "confirmed" leak rates... 30

Figure 8. Fluid dynamics data for "confirmed" and "postulated" leak rates of 10 leaking SSTs.......................................... 30

Figure 9. Baseline retrieval time history for Tank C-102, using Kirkbride's formula .................................................. 31 


\section{Tables}

Table 1. Waste Grouping vs. Leak Status and Corrosivity Factor.............. 4

Table 2. Corrosivity Factors for Primary Waste Types .................... 5

Table 3. Sluicing Campaigns for Strontium and Cesium Recovery ............6 6

Table 4. Sluicing Campaigns for Uranium Recovery .......................... 7

Table 5. A Comparison of Reported Tank Integrity with Analysis-Inferred

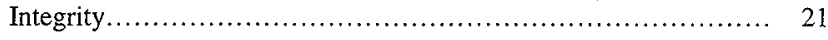

Table 6. Length of Service of SSTs according to Tank Farm Grouping ....... 23

Table 7. Catastrophic Leaks in SSTs.................................. 24

Table 8. Tank Groupings according to Category ......................... 26

Table 9. Relative Rankings of the Remaining Useful Lives of SSTs.......... 29

Table 10. Critical Flow Constant (k) Calculations for Known and Postulated Leak Rates...................................................... 29

Table 11. Average Retrieval Times and Potenital Undetected Leak Volumes for Tanks of Various Capacities..................................... 32 


\section{Acronyms}

CF Corrosivity factor (i.e., ratio of nitrate to nitrite-plus-hydroxide)

ILL Interstitial liquid level

LOW Liquid observation well

$\mathrm{L}_{\mathrm{MD}} \quad$ Minimum detectable leak

$P_{D} \quad$ Probability of detection

$P_{F} \quad$ Probability of failure

PFA Probability of false alarm

RCRA Resource Conservation Recovery Act

SCC Stress corrosion cracking

SST(s) Single-shell $\operatorname{tank}(\mathrm{s})$

SRS Savannah River Site 


\section{Acknowledgments}

The program sponsors for this report were Rob Marshall and Jeff Hertzel of Numatec Hanford Corporation and Jim Andersen of COGEMA Engineering Corporation. Additional technical contributors to this report through analysis, review and reference material include Steve Barcellos of Vista Research, George Crawford of Numatec Hanford Corporation, Mo Anantatmula and Dave Barnes of the Lockheed Martin Hanford Corporation, and Larry Julyk and Jim Truitt of Fluor Daniel Northwest. Technical editing was provided by Monique Seibel of Vista Research. 


\section{Introduction}

Under the Single-Shell Tank (SST) Retrieval Program Plan, the contents of the Hanford SSTs are scheduled for "retrieval" with various hydraulic (sluicing-based) technologies. A primary input to this plan is the characterization of the current condition of the SSTs.

Since the SSTs were taken out of service, a number of circumstances regarding SST retrieval have changed. First, some of the SSTs have been "stabilized"; that is, pumpable liquids have been removed, leaving sludge and salt cake in a stable condition while they await retrieval. Second, there has been some degradation of tank liners. Third, the "leak designation" of some SSTs has changed (i.e., whether they are considered leaking or not). And fourth, there have been changes in retrieval technology. All of these circumstances must be considered in context in order to devise a viable retrieval strategy-one that allows efficient waste retrieval and at the same time minimizes the risk of leaks into the vadose zone. As the condition of the tanks continues to degrade, retrieval options may become limited to technologies that would not cause further degradation (at least not to the point of creating new leaks).

Appendix A shows quick reference facts for SSTs. This appendix summarizes the SSTs in terms of the age of the tanks, the number of tanks assumed to be leaking, the number of sound tanks, and other pertinent information. A tank-by-tank ranking of integrity is shown in Appendix B. 


\section{Background}

\subsection{Operating History}

Single-shell tanks were initially constructed at Hanford in 1944 to store radioactive wastes resulting from plutonium/uranium separation processes necessary for plutonium production. The first SSTs known to leak were TY-106 and U-101, in 1959. To date, 67 out of a total of 149 SSTs have been declared "known leakers" or "assumed leakers." The approach used to determine what constitutes a "leaker" has not been consistent. Anecdotal information indicates that, in some circumstances, a leak was merely inferred-on the basis of partial or inconclusive data. Accordingly, not all "assumed leakers" may have actually leaked. The SSTs were formally removed from active service in 1981, but they still contain over 35 million gallons of radioactive waste that has not yet been retrieved [Hanlon, 1998].

During the 37 years that the SSTs were in active service, 13 different types of waste were generated [Hill, 1994] — the result of various processes for plutonium/uranium separation, uranium recovery, and cesium/strontium removal. These 13 distinct wastes have been mixed together as a result of consolidation efforts and the cascading of wastes to form 30 discrete tank groupings by specific waste chemistry [Anantatmula, 1994].

Since 1978, 119 SSTs have been "interim-stabilized." Interim stabilization is the process of removing pumpable liquids from the tanks, leaving the sludge and salt cake in a stable condition while they await retrieval. Even after the supernatant liquids have been pumped off, SSTs may contain significant volumes of interstitial liquids-liquids contained in the void space between the grains and particles that comprise the sludge and the wetted portions of the salt cake.

\subsection{Failure Mechanisms}

Aside from process upsets and structural/mechanical failures, the most likely failure mechanisms for SSTs are corrosion-related. It is important to note that any discussion of SST corrosion issues should be prefaced by the fact that nearly everything we know about SST corrosion is inferred from laboratory simulants or Savannah River data. There exist only limited data on the exposure of in-tank coupons to PUREX, Redox and $\mathrm{BiPO}_{4}$ wastes at Hanford.

The failure mechanisms applicable to the Hanford SSTs are ranked as follows, in decreasing order of importance [Edgemon, 1996]:

(1) stress-corrosion cracking (SCC)

(2) pitting/crevice corrosion

(3) uniform corrosion 
The most common, and most plausible, leakage mechanism for the Hanford SSTs is stresscorrosion cracking. SCC can occur when the tank's carbon-steel liner is exposed to aqueous solutions containing sodium hydroxide and sodium nitrate. Cracks form in and near the welds in the tank's sidewall, in the weld "heat-affected zones"-a region whose width is typically two to three times the thickness of the base material and where there is an accumulation of residual stresses from the welding that occurred during the tank's construction. (The Hanford SSTs were not treated for stress relief during construction.) The strongest evidence of stress-corrosion cracking comes from the failure of Tanks \#9, \#10, \#14 and \#16 at the Savannah River Site [Girdler, 1965; Poe, 1974]. Figure 1 shows a photograph of the exterior of Tank \#14 at the SRS-a tank that leaked as a result of SCC. The effects of the leaks are clearly evident in the photo. These leaks occurred along numerous cracks that appeared in the lower horizontal weld of the tank.

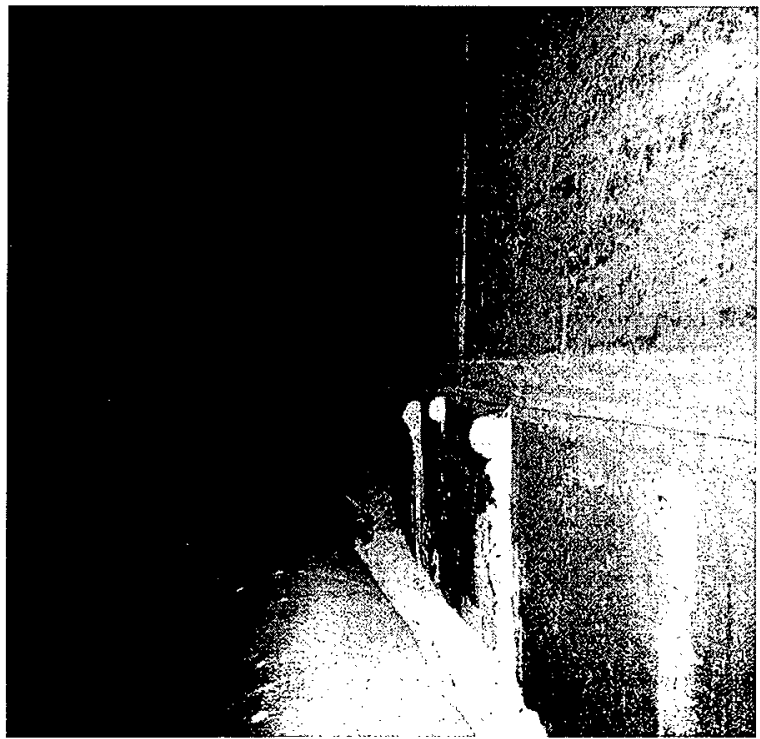

Figure 1. Savannah River Site, Tank \#14 (Photograph \#4080-13). In this non-stress-relieved tank, leaks due to nitrate-assisted, stress-corrosion cracking can be seen in the heat-affected zone near the weld. Note that the leaks appear to have self-sealed.
The time it takes for cracking to occur cannot be predicted; it may be anywhere from a few months to several years. A common tool for assessing SCC in the waste tanks at Hanford and Savannah River is the corrosivity factor (CF), which is the ratio of the molar concentrations of nitrate to nitrite-plushydroxide. In the present corrosion specifications for double-shell tanks, the CF is maintanied below 2.5. The calculation of the CFs is based on a rough approximation of the chemistry of the primary and secondary wastes $(70 \%$ and $30 \%$, respectively) [Anantatmula, 1994]. The CFs calculated for the SSTs are shown in Tables 1 and 2 . 
Table 1. Waste Grouping vs. Leak Status and Corrosivity Factor (Reprinted from Anantatmula, 1994)

\begin{tabular}{|c|c|c|c|}
\hline $\begin{array}{l}\text { Waste Group/ } \\
\text { Waste Type }\end{array}$ & Tanks & $\begin{array}{l}\text { Percent } \\
\text { Leaked }^{* *}\end{array}$ & CF \\
\hline TBP, EB-ITS & $\underline{B Y-109}, \underline{B Y-102}$ & 0 & 67.67 \\
\hline $\mathrm{CW}, \mathrm{TBP}$ & $\underline{\mathrm{C}-102}, \underline{\mathrm{C}-105}$ & 0 & 24.54 \\
\hline SS, TBP & $\underline{\mathrm{C}-103}, \underline{\mathrm{C}-106}$ & 0 & 24.53 \\
\hline $\mathrm{EB}, \mathrm{CW}$ & $\underline{\mathrm{U}-105}, \underline{\mathrm{U}-107}, \underline{\mathrm{U}-108}, \underline{\mathrm{U}-109}$ & 0 & 21.21 \\
\hline $\mathrm{CW}$ & U-201, U-202, U-203 & 0 & 0.05 \\
\hline $\mathrm{EB}, \mathrm{TBP}$ & TX-108, TX-118 & 0 & 45.70 \\
\hline REDOX, EB & $\begin{array}{l}\frac{S-102}{S-112}, \frac{S-111}{S-103}, \frac{S-106}{S-101}, \frac{S-105}{S-107}, \frac{S-109}{S X-105}, \frac{S-108}{S X-106}, \frac{S-110}{S-104}, \frac{S X-102}{S X}, \frac{S-101}{T X-102}, T X-104 \\
T X-105, T X-106, T X-107\end{array}$ & 14 & 13.66 \\
\hline EB, REDOX & $\underline{\mathrm{U}-103}, \underline{\mathrm{U}-102}, \underline{\mathrm{U}-111}, \underline{\mathrm{U}-106}, \mathrm{TX}-115$ & 20 & 23.16 \\
\hline $1 \mathrm{C}, \mathrm{EB}$ & B-107, B-108, B-109, BX-112 & 25 & 11.01 \\
\hline DSSF, NCPLX & $\underline{\mathrm{A}-101}, \mathrm{~A}-102, \mathrm{~A}-103, \mathrm{AX}-101$ & 25 & 0.77 \\
\hline $2 \mathrm{C}, 224$ & $\underline{T-110}, \mathrm{~T}-111, \mathrm{~T}-112$ & 33 & 4.04 \\
\hline 224 & $\begin{array}{l}\text { B-201, B-202, B-203, B-204, T-201, T-202, T-203, } \\
\text { T-204 }\end{array}$ & 37.5 & 1.80 \\
\hline Ungrouped & $\begin{array}{l}\text { A-104, A-105, A-106, AX-104, B-104, BX-109, } \\
\text { C-104, C-107, SX-103, T-109, T-104, TX-101, } \\
\text { TX-103, TX-112, TY-101, U-110, U-112, U-204 }\end{array}$ & 39 & $\begin{array}{l}0.85 \text { for } \mathrm{C}-107 \\
4.87 \text { for } \mathrm{SX}-103 \\
2.75 \text { for } \mathrm{T}-104\end{array}$ \\
\hline TBP-F, 1C & $\mathrm{C}-108, \mathrm{C}-109, \mathrm{C}-111, \mathrm{C}-112, \mathrm{~T}-107$ & 40 & 35.83 \\
\hline TBP, CW & $\begin{array}{l}\text { BX-101, BX-102, BX-103, BX-104, BX-105, } \\
\text { BX-106, C-101 }\end{array}$ & 43 & 57.18 \\
\hline TBP-F, EB-ITS & $\begin{array}{l}\text { BY-101, BY-103, BY-104, BY-105, BY-106, } \\
\text { BY-107, BY-108, BY-110, BY-111, BY-112 }\end{array}$ & 50 & 45.5 \\
\hline CCPLX, DSSF & $\mathrm{AX}-102, \mathrm{AX}-103$ & 50 & 1.10 \\
\hline $1 \mathrm{C}, \mathrm{CW}$ & $\mathrm{T}-105, \mathrm{~T}-106$ & 50 & 1.94 \\
\hline $1 \mathrm{C}, \mathrm{TBP}$ & B-106, BX-107, BX-108, C-110, T-108 & 60 & 26.43 \\
\hline $\mathrm{CW}, \mathrm{EB}$ & B-101, B-102, B-103 & 67 & 9.12 \\
\hline CW, MIX & $T-101, T-102, T-103$ & 67 & 0.10 \\
\hline $\mathrm{EB}, 1 \mathrm{C}$ & $\begin{array}{l}\text { B-105, TX-109, TX-110, TX-111, TX-113, } \\
\text { TX-114, TX-116, TX-117, TY-102 }\end{array}$ & 75 & 22.02 \\
\hline REDOX & $\begin{array}{l}\text { S-104, SX-107, SX-108, SX-109, SX-112, SX-115, } \\
\text { U-101 }\end{array}$ & 100 & 6.53 \\
\hline
\end{tabular}

continued 


\begin{tabular}{llcc}
\hline \multicolumn{1}{c}{$\begin{array}{c}\text { Waste Group/ } \\
\text { Waste Type }\end{array}$} & \multicolumn{1}{c}{ Tanks } & $\begin{array}{c}\text { Percent } \\
\text { Leaked }\end{array}$ & CF \\
\hline HS & C-201, C-202, C-203, C-204 & 100 & 1.59 \\
$2 C, 5-6$ & B-110, B-111, B-112 & 100 & 5.00 \\
REDOX, REDOX-IX & SX-110, SX-111, SX-114 & 100 & 6.07 \\
1C, EB-ITS & BX-110, BX-111 & 100 & 12.43 \\
TBP & TY-105, TY-106 & 100 & 81.67 \\
TBP, 1C-F & TY-103, TY-104 & 100 & 57.99 \\
REDOX, DIA & SX-113, U-104 & 100 & 4.57 \\
\hline
\end{tabular}

* Underline indicates tanks that were sound and not stabilized (as of 1994).

** Percentage of tanks, by waste group, that have leaked.

Table 2. Corrosivity Factors for Primary Waste Types [Anantatmula, 1994]

\begin{tabular}{lccc}
\hline Waste Type & $\begin{array}{c}\mathrm{OH}+\mathrm{NO}_{2} \\
\text { moles/liter }\end{array}$ & $\begin{array}{c}\mathrm{NO}_{3} \\
\text { moles/liter }\end{array}$ & $\begin{array}{c}\text { Corrosivity Factor } \\
\mathrm{NO}_{3} /\left(\mathrm{OH}+\mathrm{NO}_{2}\right)\end{array}$ \\
\hline REDOX & 0.74 & 4.83 & 6.53 \\
HS & 1.32 & 2.1 & 1.59 \\
$2 \mathrm{C}$ & $\mathrm{NR}$ & 1.27 & $5^{*}$ \\
OWW & $\mathrm{NR}$ & 0.06 & $1^{*}$ \\
$1 \mathrm{C}$ & 0.56 & 1.54 & 2.75 \\
EB & 0.57 & 17.26 & 30.28 \\
TBP & 0.09 & 7.35 & 81.67 \\
CW & 0.37 & 0.02 & 0.05 \\
CCPLX & 0.52 & 0.72 & 1.38 \\
DSSF & 6.05 & 2.72 & 0.45 \\
224 & 0.59 & 1.06 & 1.8 \\
NCPLX & 2.2 & 3.3 & 1.5 \\
SS & 5.74 & $\mathrm{NR}$ & $0.04^{*}$ \\
\hline
\end{tabular}

$* \quad=$ assumed value

$* *=$ assumed a density of $1.45 \mathrm{~g} / \mathrm{cc}$ for molarity calculation

$N R=$ none reported

Temperature also plays an important role in initiating SCC. A critical temperature of $122^{\circ} \mathrm{F}$ was discovered to be the threshold below which nitrate-assisted SCC would occur only at very low rates [Ondrejcian, 1978]. 
While stress-corrosion cracking is expected to be the dominant failure mechanism for the Hanford SSTs, pitting/crevice corrosion cannot be discounted. Pits often begin at the site of manganese sulfide $(\mathrm{MnS})$ precipitates prevalent in carbon steels. They result from a highly localized corrosion process that produces small-diameter holes in a solid metal structure. Once a pit begins, the local chemistry in the tank will cause it to grow. Typically, the growth rate accelerates as the pit grows deeper. Once initiated, the pitting can rapidly produce a hole in plate steels.

While uniform corrosion does occur in the SSTs, the corrosion rates are generally less than 1 mil $(0.001 \mathrm{in}$.) per year. Thinning to point of failure is highly unlikely. Accordingly, SST failures due to uniform corrosion are discounted in this report.

\subsection{Sluicing History}

Between 1952 and 1957, 43 SSTs in the B, BX, BY, C, T, TX, and U tank farms were sluiced to recover uranium and then returned to service. Between 1962 and 1978, an additional 10 tanks in the $\mathrm{A}$ and $\mathrm{AX}$ tank farms were sluiced to recover strontium and cesium. Of these, eight were returned to service; during the sluicing operations Tanks A-104 and A-105 were found to be leaking and were therefore removed from service at the completion of those operations [Rodenhizer, 1987]. (Tank A-105 was sluiced after the leak was discovered, so that high-heat-producing sludge could be removed. Tank A-104 started to leak during the sluicing operations, but no definitive relationship between the leak and these operations was established [Rasmussen, 1980].) Tables 3 and 4 list tanks and sludge volume retrieved during both the strontium and cesium and the uranium recovery campaigns.

With respect to leaks and sluicing, 53 tanks in total have been sluiced to empty or nearly empty levels. The bulk of sluicing operations took place in tanks that held the relatively benign bismuth-phosphate wastes as part of uranium recovery operations. The one tank that was identified as a leaker during sluicing operations (A-104) contained a mixture of wastes from the PUREX process and organic wash wastes [Brevick, 1994; Rodenhizer, 1987]. For this analysis, Tank A-105 was removed from the population of sluiced tanks because it had been identified as a leaker prior to sluicing; thus, 51 out of the 52 tanks that were sluiced $(98.1 \%)$ remained sound and were returned to service. Of the 51 tanks returned to service, $21(41.2 \%)$ were subsequently declared "assumed leakers." The remaining 30 tanks that have been sluiced and that have not produced indications of leaks may be candidates for early hydraulic retrieval.

Table 3. Sluicing Campaigns for Strontium and Cesium Recovery

\begin{tabular}{ccc}
\hline Tank & Sluicing Period & $\begin{array}{c}\text { Sludge Volume Retrieved } \\
\text { (Kgal) }\end{array}$ \\
\hline A-101 & $1968-1976$ & 107 \\
A-102 & $1964-1976$ & 170 \\
A-103 & $1962-1976$ & 116 \\
\hline \multicolumn{3}{c}{ continued }
\end{tabular}




\begin{tabular}{lcr} 
A-104 & $1969-1975$ & 223 \\
A-105 & $1968-1970$ & 147 \\
A-106 & $1969-1977$ & 237 \\
AX-101 & $1975-1976$ & 66 \\
AX-102 & 1976 & 66 \\
AX-103 & $1976-1977$ & 82 \\
AX-104 & 1977 & 52 \\
\hline
\end{tabular}

Table 4. Sluicing Campaigns for Uranium Recovery

\begin{tabular}{|c|c|c|}
\hline Tank & Sluicing Period & $\begin{array}{l}\text { Sludge Volume Retrieved } \\
\text { (Kgal) }\end{array}$ \\
\hline$U-101$ & $1952-1956$ & 132.5 \\
\hline U-102 & $1953-1957$ & 59.6 \\
\hline U-103 & $1952-1956$ & $0+132.5$ (from U-101) \\
\hline U-104 & $1953-1956$ & 132.5 \\
\hline U-105 & $1953-1957$ & 59.6 \\
\hline U-106 & 1956 & 0 \\
\hline U-107 & $1953-1957$ & 132.5 \\
\hline U- 108 & $1953-1956$ & 59.6 \\
\hline U-109 & $1953-1956$ & 0 \\
\hline C-101 & $1952-1953$ & 132.5 \\
\hline C-102 & 1953 & 59.6 \\
\hline$C-103$ & 1953 & 0 \\
\hline C-104 & $1953-1955$ & 132.5 \\
\hline C- 105 & 1953 & 59.6 \\
\hline$C-106$ & $n / a$ & 0 \\
\hline C-201 & 1954 & 16 \\
\hline C- 202 & 1954 & 8 \\
\hline C- 203 & 1954 & 0 \\
\hline C- 204 & $1954-1955$ & 0 \\
\hline B-101 & 1953 & 132.5 \\
\hline B-102 & 1953 & 59.6 \\
\hline B-103 & $\mathrm{n} / \mathrm{a}$ & 0 \\
\hline $\mathrm{BX}-101$ & $1953-1954$ & 280 \\
\hline BX-102 & 1954 & 134 \\
\hline $\mathrm{BX}-103$ & 1954 & 33 \\
\hline BX-104 & $1954-1955$ & 181.5 \\
\hline BX-105 & 1955 & 89 \\
\hline BX-106 & 1955 & 12.5 \\
\hline BY -101 & 1954 & 0 \\
\hline BY-102 & 1954 & 0 \\
\hline
\end{tabular}




\begin{tabular}{lcr} 
BY-103 & 1954 & 0 \\
BY-104 & $\mathrm{n} / \mathrm{a}$ & 0 \\
BY-105 & 1954 & - \\
BY-106 & $\mathrm{n} / \mathrm{a}$ & - \\
BY-111 & 1955 & -- \\
& & \\
BY-112 & 1955 & -- \\
T-101 & $1954-1956$ & 132.5 \\
T-102 & $1953-1956$ & 59.6 \\
T-103 & $1953-1957$ & 0 \\
TX-101 & $1954-1956$ & 259 \\
& & \\
TX-102 & $1954-1956$ & 121 \\
TX-103 & 1954 & 0 \\
TX-104 & $1954-1956$ & 0 \\
TX-105 & $1954-1957$ & 91 \\
TX-106 & 1955 & - \\
TX-107 & $1954-1957$ & -- \\
TX-108 & $1954-1957$ & - \\
\hline
\end{tabular}

\subsection{Failure Frequencies}

There are many methods of quantifying failure frequencies for a population of failed components. Three such methods are presented in this report:

- deterministic failure frequencies based on declaration date

- deterministic failure frequencies based on indications from liquid level data

- probabilistic failure frequencies based on corrosivity

In the case of the SSTs, it is possible to determine the age of the tank at the time it was declared leaking by subtracting its installation date from the raw "declared leaker date" published in the monthly Waste Tank Summary Report [Hanlon, 1998]. A histogram of tank age at (declared) failure is presented in Figure 2. The column plot in this figure shows the number of tanks that were declared "leakers" or presumed to be "leakers" as a function of their age at the declaration date. (The plot is "binned" at two-year intervals.) The line plot in Figure 2 shows the cumulative distribution of the failures. The cumulative distribution describes-for tanks that have actually leaked or that are presumed to have leaked (relative to the total number of tanks that were declared leaking)- the percentage of failures as a function of age. The average age-to-failure for the 67 SSTs that have leaked or are presumed to have leaked is about 24 years.

This simple estimation of failure frequency assumes that the tanks have common operational histories and are subjected to the same criteria when the "presumed leaker" designation is applied. There is a firmer criterion on which to base the decision that a leak has occurred or is occurring - a definite decrease in level that is not plausibly attributable to other sources. A histogram of tank age at failure for 24 such SSTs is shown in Figure 3. For these data, the 
average age-to-failure is about 28 years. When one compares these data to the ages of the tanks that exhibited unambiguous decreases in level, the implication is that the assignment of a "declared leaker" status to an SST may have been conservative.

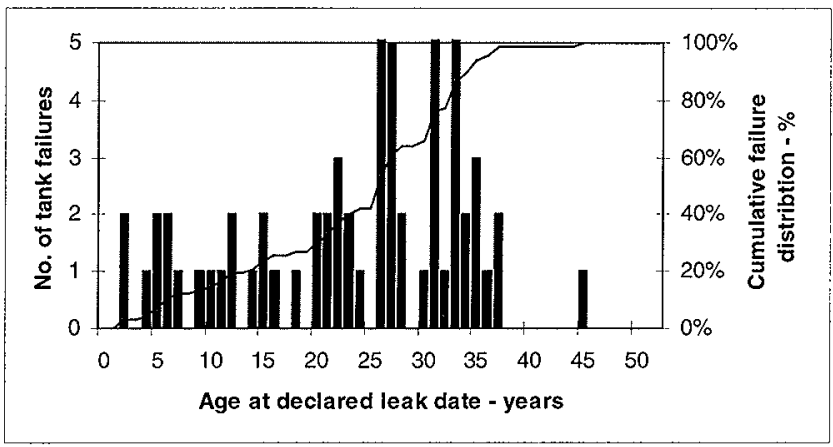

Figure 2. Histogram of SST failure frequency based on the date at which the tank was declared an "assumed leaker." Mean time to declaration is 24 years.

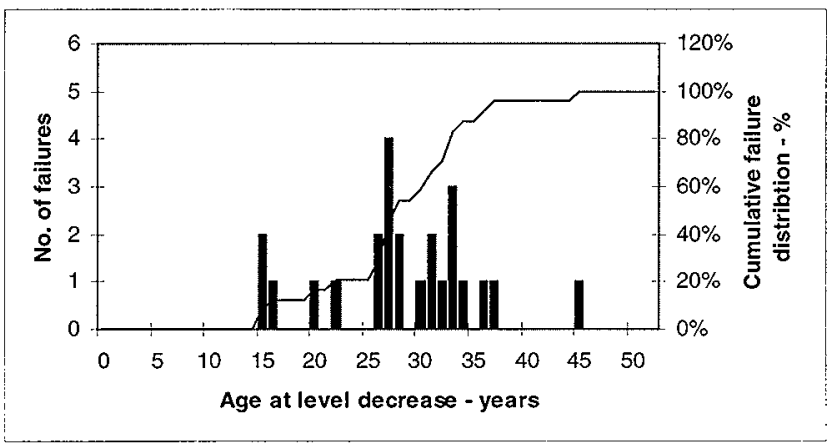

Figure 3. Histogram of SST failure frequency based on the date of level decrease. Mean time to level decrease is 28 years.

The final failure frequency method presented here is a probabilistic method based on expected corrosion-related failures for large, carbon-steel tanks. Information from both Hanford and the Savannah River Site suggests that the primary failure mode for SSTs is nitrate-assisted SCC [Edgemon, 1994; Girdler, 1965]. SCC is insidious and is difficult to predict because of the wide variability in the time it takes for a crack to appear. SCC requires an aggressive environment (enhanced by elevated temperatures), a high-stress state 
due either to residual fabrication stresses or applied loads, and a crack initiation site such as an impurity, a scratch, or a void in a weld.

The probability, $\mathrm{P}_{\mathrm{SCC}}$, that $\mathrm{SCC}$ will occur in a waste storage tank can be qualitatively defined as

$$
\mathrm{P}_{\mathrm{SCC}}=\mathrm{P}_{\mathrm{env}} \times \mathrm{P}_{\sigma}
$$

where $P_{\mathrm{env}}$ is the probability that the contents of the tank constitute an aggressive environment and $P_{\sigma}$ is the probability that the tank is subject to stresses above the $k_{I S C C}$ (the threshold stress for SCC) required to initiate cracking [Anantatmula in Abatt, 1996]. A third term (not shown in the equation) represents the probability that the tank has numerous crack initiation sites. Because of the way the tanks are constructed, this third term can be taken to be 1.0. In the case of the SSTs, $P_{\sigma}$ can also be taken to be 1.0 , because the SSTs were put into service without the benefit of a stress-relief annealing process.

This leaves $\mathrm{P}_{\mathrm{env}}$ as the controlling factor in the probability of the occurrence of SCC. In the case of the SSTs, environmental aggressiveness can be divided into two sub-parameters: (1) the corrosivity factor of the waste, and (2) temperature. Tanks with maximum temperatures less than $122^{\circ} \mathrm{F}$ would not be expected to experience significant SCC damage regardless of waste type. Tanks that have maximum temperatures above $122^{\circ} \mathrm{F}$ and $\mathrm{CFs}$ greater than 2.5 would be expected to suffer severe SCC-related damage. Based upon these values, a relative failure frequency can be assigned to each individual tank. Using these parameters for $\mathrm{CF}$ and temperature, relative failure frequencies were assigned quantitatively. This is described in Section 4.0 (Assessment of Remaining Useful Life). 


\section{Preliminary Integrity Assessment}

Tank integrity can be discussed on two levels: structural integrity and liquid integrity. Structural integrity addresses whether the tank is likely to collapse or rupture, whereas liquid integrity addresses whether it can maintain the confinement of liquids. The SSTs derive their structural integrity from their concrete encasements. They derive their liquid integrity from the carbon-steel liner that defines the confinement boundary. Although the SSTs are believed to be structurally sound, many of them are suspect in terms of liquid integrity.

The Tank Farms Surveillance Group at Hanford has established administrative controls on the allowable changes in liquid level in the SSTs; when levels go beyond these limits, some investigation is required. There are, however, no leak detection or reporting methods in place whose performance-in terms of probability of false alarm and probability of detection as measured against some specified criterion-has been evaluated and demonstrated. In this section of the report, we examine the SST level data in an attempt to (1) provide a statistical assessment of the significance of changes in tank volume over time; (2) assess the minimum leak rate that could be detected in these tanks using the existing level-sensing instruments and data systems; and (3) estimate the performance of an integrity monitoring system that is based upon the extant level sensors and data systems.

\subsection{Structural Integrity}

The structural integrity of the SSTs must be inferred from non-empirical data. There are no in-service inspection records for the SSTs. Thus, the structural integrity of the tank is established on the basis of its concrete encasement. In calculations performed for the Final Safety Analysis Report (FSAR)," the design of the SSTs showed an ample margin for tolerating operational loads and withstanding credible accident scenarios [Han, 1996a, 1996b]. Concentrated loads ranging from 100 tons over a $30-\mathrm{ft}$ radius to 200 tons over a 10 $\mathrm{ft}$ radius were considered. The most critical factor in assessing the structural integrity of the SSTs is dome loading. Based on a safety factor between 2 and 3, according to ACI code, the "100 series" of SSTs examined here are expected to withstand a concentrated load of 300 to 600 tons over an area with a 10-ft radius. Under these conditions, the predicted failure mode is a flattening of the tank dome and eventual shearing through the 10 -ft-radius area centered at the crown of the dome.

Dome loads for SSTs are rigorously enforced through OSD-T-151-00013 D-15, which limits static dome loads to 5 tons over a 12 -ft radius for "200 series" tanks, and 5 tons over a 10 -ft radius for " 100 series" tanks. Live loads are limited to 50 tons for " 200 series" tanks and 100 tons for "100 series" tanks. Based on Han's analyses [Han, 1996a, 1996b], it is not expected that the SSTs will collapse during interim storage, stabilization or retrieval operations as long as the dome loading limits are observed. 


\subsection{Liquid Integrity}

The liquid integrity assessment for each SST requires a measure of the liquid volume over time. Some tanks contain measurable amounts of supernatant, while others have had (most of) the supernatant liquids removed. These latter tanks can, however, contain a significant volume of interstitial liquid that is trapped in the sludge and that is not readily pumpable in large volumes. Since nearly all of the tanks can be considered as having some volume of liquid in them, any loss of liquid integrity poses a clear and present danger of insult to the environment, including the likelihood of groundwater contamination. This is an important issue now, and will be even more so during retrieval operations.

The single-shell tanks can be subdivided into two categories: interim-stabilized and nonstabilized. There are 119 tanks that have been interim-stabilized - that is, tanks whose supernatant liquid has been pumped off, leaving only sludge, interstitial liquids, and salt cake [Hanlon, 1998]. The level (volume) of the interstitial liquid in the stabilized tanks is measured with a gamma/neutron probe (or Interstitial Liquid Level [LL]) that is raised and lowered into a liquid observation well (LOW) located in the center of each tank. The liquidair interface is detected as a sudden and significant change in the activity monitored by the probe. ${ }^{1}$ There are also 30 tanks that are non-stabilized-meaning that they contain sludge, interstitial liquid, and supernatant liquids. The liquid level in these tanks is measured (typically) with a level gauge such as the ENRAF or FIC. (Note that the ILL probe will also provide a measure of the air/liquid interface in these tanks.) A number of the interimstabilized tanks are effectively empty; that is, most of the liquid and sludge has been removed during an earlier campaign. These tanks are nominally free of both liquids and sludge, except, perhaps, for a thin layer at the bottom, or scattered areas of dried or drying sludge.

A table of SST waste volumes as of 31 December 1997 is shown in Appendix C, a portion of which was abstracted from one of the monthly Hanlon reports. Included is the total volume in each tank, subdivided according to the volume of supernatant liquid, interstitial liquid, sludge and salt cake. The second-to-last column in this table indicates whether there is a sufficient volume of liquid to warrant a liquid integrity analysis of the tank, and the last column indicates whether that tank incorporates the instrumentation needed to obtain the measurements for such an analysis. Since the height-to-volume ratio of most of the SSTs is about 2,750 gal/in., a cutoff point of about 5,000 gal was established; tanks with volumes less than this amount were not analyzed. For tanks containing a significant volume of supernatant, level-measurement data from an ENRAF, FIC or equivalent sensor were used if such data were available and if these data were both recent and continuous. For tanks with significant volumes of interstitial liquid but little or no supernatant, data from the gamma/neutron probe, if available, were used.

\footnotetext{
${ }^{\mathrm{t}}$ The inferred volume of liquid will depend on both the depth of the liquid and the void fraction. The void fraction will vary depending upon the makeup of the sludge, and thus will be tank-specific. Values for the void fraction for each tank can be found, for example, in WHC-SD-WM-ER-349, "Historical Tank Content Estimates for the Northeast Quadrant of the Hanford 200 Area" [Brevick, 1994].
} 
The tank documents reviewed in this work show that there were a total of 102 SSTs that contain sufficient quantities of liquid (as defined above), either supernatant or interstitial, to warrant further analysis. Of these, 70 have data that are suitable for preliminary integrity assessment analysis. ${ }^{2}$ An important point is that this liquid can leak, regardless of which type it is. A statistical analysis of the data from a tank that presently contains liquid can be used to infer - in a very general sense-the liquid integrity of that tank, and to assess the leak detection performance of its extant level gauges.

The SST liquid level data are measured by any of several different methods. Early in the Hanford program, the method was a "stick" (or manual tape) inserted into the tank, and data were taken infrequently, several times per year or perhaps quarterly. These data are not very useful in a leak detection analysis because the sample frequency is too low to be of value on a reasonable time scale-say, a week to a month. Later, the stick method was replaced with automatic tank gauges such as the FIC and the ENRAF. Typically, these sensors measure and record the air/liquid interface once every $10 \mathrm{~min}$, with averages computed on an hourly and a daily basis ${ }^{3}$ [Barnes, 1998]. The daily averages were used in the analysis described below for the ENRAF and FIC data. In the case of the ILL probe, data are collected manually, using an instrumented van that is driven from tank to tank, approximately once per week. The ILL data were obtained from TWINS and were used in the same manner as the data from the ENRAF and FIC gauges.

\subsubsection{Selection of Level Data}

The data gathered in this report were obtained from TWINS - an interface to Hanford-related databases that is accessible from the Internet. ${ }^{4}$ Subsets of these data were used in the analysis. Appendix D includes a listing of the data that were obtained from TWINS, and those data selected for analysis. The entries in this appendix show the range, in terms of date, of the various sensor data that were available. As can be seen from the entries, some tanks have had several sensors installed, but some of the sensor data may be many years old. For the purposes of the analysis described below, we selected data that represented the most reliable, recent, and continuous set available. When more than one set met the selection criteria, the Auto ENRAF data, when available, were chosen over other data. If the Auto ENRAF data were not available (or were discontinuous), we selected the Manual ENRAF, then the Auto or Manual FIC data, and finally the Manual Tape data. In cases where there was interstitial liquid only, and the LOW data were available, the ILL probe data were selected.

\footnotetext{
${ }^{2}$ Thirty-two of the 102 tanks either exhibited liquid-level data that were erratic or otherwise not sufficiently continuous for use in the analysis, or were not equipped with a LOW sensor. Accordingly, the data from a total of 70 tanks have been analyzed for this report.

${ }^{3}$ To minimize the data storage requirements, a data compression technique is used whereby only level values that have changed more than $0.01 \mathrm{in}$. are actually recorded. There is no critical information lost when this technique is used.

${ }^{4}$ See http://twins.pnl.gov:8001/TCD/main.html, for example.
} 
To be useful for the analysis, the level data needed to be sampled over a long duration, at a more or less uniform frequency. Since hourly samples were not readily available for this analysis, we used daily samples, seeking block-lengths of at least two years. (This usually led to the selection of either the Auto ENRAF or Auto FIC data.) A second requirement for the analysis was that the level data needed to be more or less internally consistent with the other level measurements made on the tank. That is, if a tank had liquid level measurements made by several sensors, then a measure of the quality or reliability of the data would be how well the several independent data compared. For example, if two sensors measured (about) 118 in. of liquid, and the data from a third sensor was to be used in the analysis, it was expected that the value measured by the third sensor would be (about) $118 \mathrm{in}$. also.

To compare the similarity and potential temporal overlap of the various sensor sets, a plot of measured level as a function of time was made for each available sensor, for each of the tanks shown in the table in Appendix D. Figure 4 shows a series of plots from Tank A-103. As shown in Appendix D, the TWINS-accessible databases contain level data on Tank A-103 from six level sensing systems during various past years: Auto ENRAF, Auto FIC, Intrusion FIC, Manual ENRAF, Manual FIC, and Manual Tape. For this tank, the best and most reliable data appeared to be the Manual ENRAF data. These choices are illustrated in Appendix $\mathrm{D}$, and the data used in the analysis are denoted by boldface type. Note that for some of the tanks, no usable data were obtained. This was either because the data quality was too poor, or because there was no sensor installed on that tank to provide relevant data.

\subsubsection{Statistical Analysis of Level Data}

After the required data had been downloaded, it was analyzed with an Excel ${ }^{\mathrm{TM}}$ spreadsheet prepared for processing large quantities of data. The output is presented in Appendix E. The analysis technique is explained below, using the Auto ENRAF data from Tank A-103 as an example. ${ }^{5}$ The data plots shown in Figure 4 illustrate a data sample taken from Appendix E.

The first step in the data analysis was to convert level to volume, using the appropriate height-to-volume conversion factor, ${ }_{2}^{6}$ and then make a plot of the volume data. The plot used in the analysis of A-103 is shown at the top of Figure 5. In a few cases (including A-103), the data obtained through TWINS contained spurious points that could be edited without compromising the integrity of the data set. The spurious points edited out of the A-103 data set, although not plotted, are indicated at the lower right of the plot. A comparison of the Manual ENRAF plot in Figure 4 with the volume plot in Figure 5 reveals the three spurious points that were edited from the data: one point at the beginning of the record, one early in January 1997, and another early in 1998.

\footnotetext{
${ }^{5}$ Although Tank A-103 was declared an assumed leaker in 1987, and was administratively stabilized, it reportedly contains an estimated 4,000 gal of supernatant [Brevick, 1994]. Accordingly, changes in the level of the liquid surface can be analyzed. Because of the sludge and salt cake present in the tank, the absolute volume estimates will be in error, but the rate of change of volume will be correct.

${ }^{6}$ For the 100 -series tanks, the height-to-volume conversion is $2,753.8 \mathrm{gal} / \mathrm{in}$; for the 200 -series tanks, the height-to-volume conversion ratio is $195.7 \mathrm{gal} / \mathrm{in}$.
} 

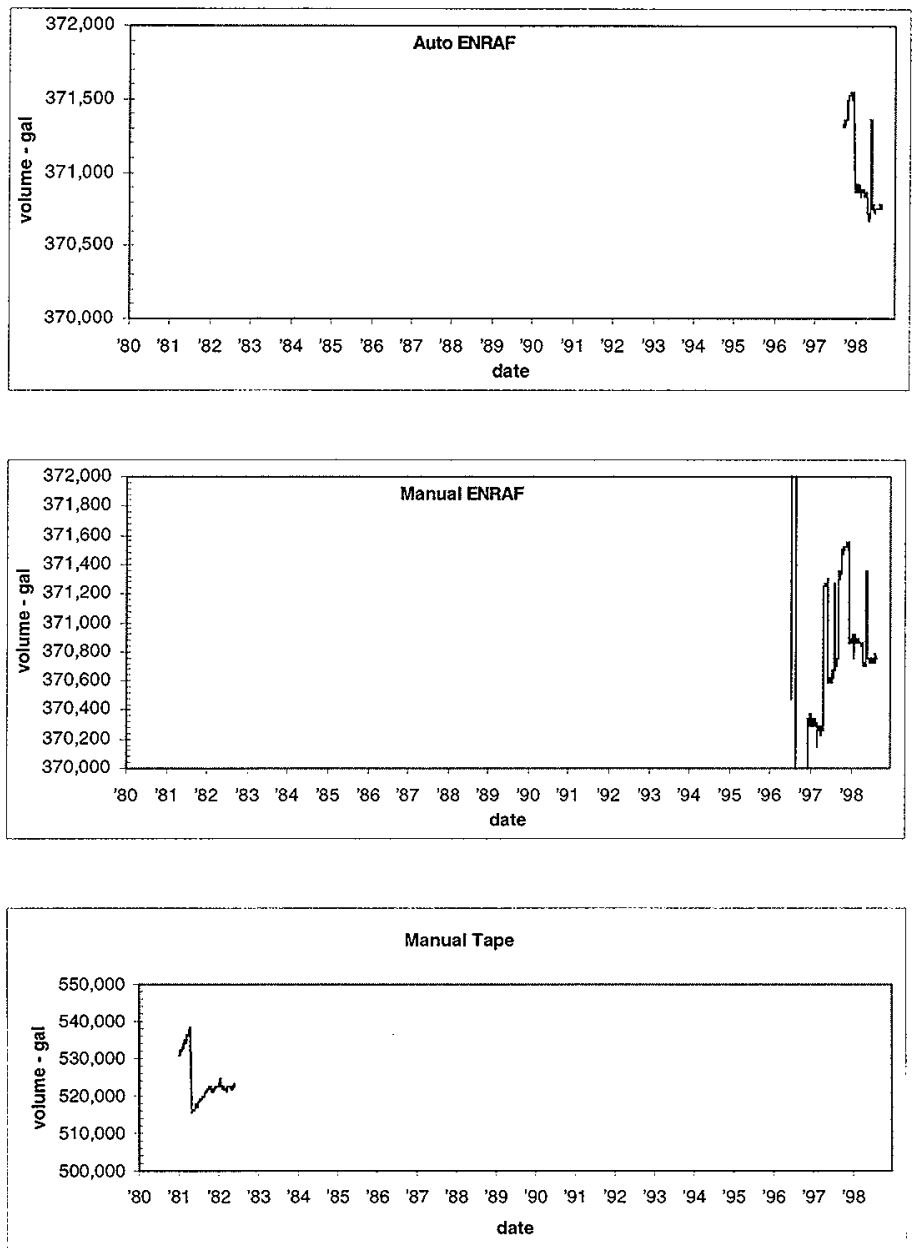

Figure 4. Plots from Tank A-103. 

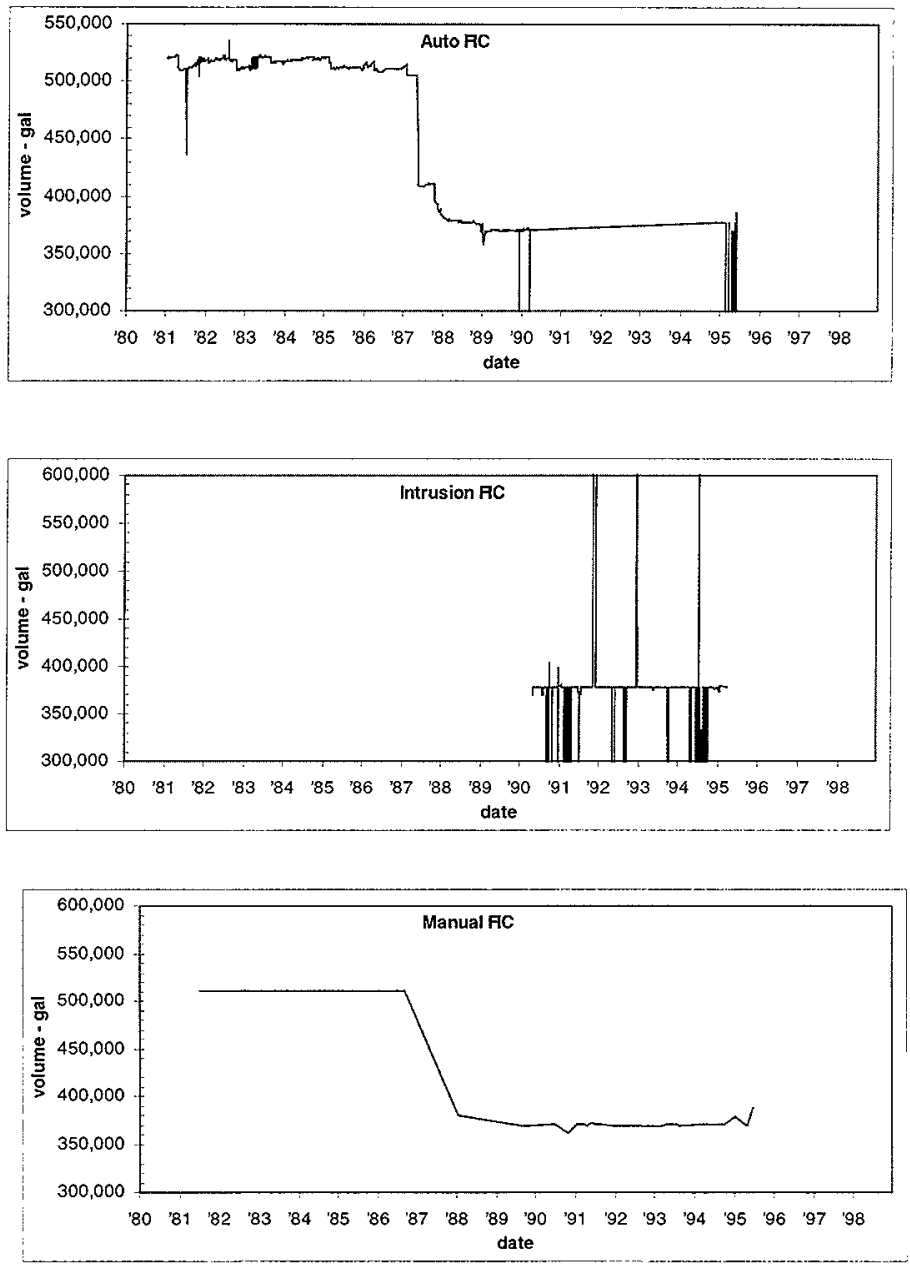

Figure 4 (concluded). Plots from Tank A-103. 


\section{Data File: A-103 Data is from sensor type: Manual ENRAF}

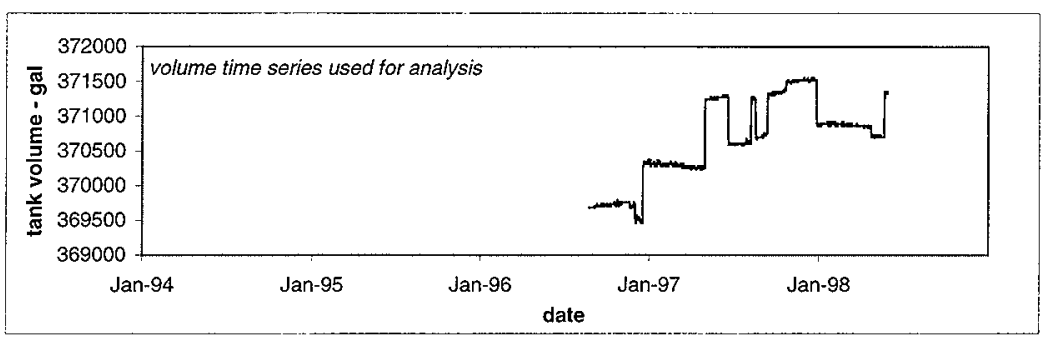

No. points edited from time series $=$

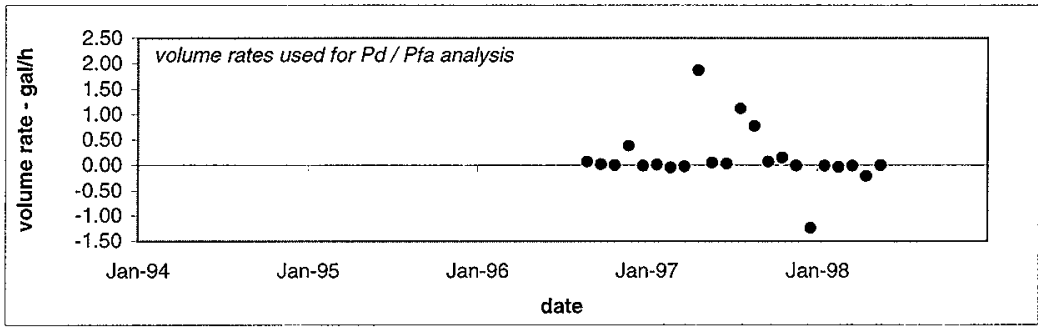

No. avg. vol rate estimates removed $=1$

During the analysis period, the average volume rate $=$ The standard deviation of the volume rate estimates =

For Pd $/ \mathrm{Pfa}=95 \% / 5 \%$ :

The mean volume rate is equivalent to $0 \mathrm{gal} / \mathrm{h}$

Threshold, T: $\quad-1.00 \mathrm{gal} / \mathrm{h}$

Min. Detectable Leak: $\quad-2.00 \mathrm{gal} / \mathrm{h}$

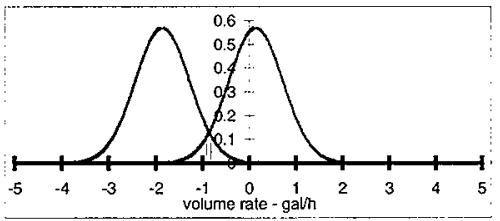

$0.14 \mathrm{gal} / \mathrm{h}$

$0.58 \mathrm{gal} / \mathrm{h}$

For Pd / Pfa $=99 \% / 1 \%$ :

The mean volume rate is equivalent to $0 \mathrm{gal} / \mathrm{h}$

Threshold, T: $\quad-1.46 \mathrm{gal} / \mathrm{h}$

Min. Detectable Leak: $\quad-2.92 \mathrm{gal} / \mathrm{h}$

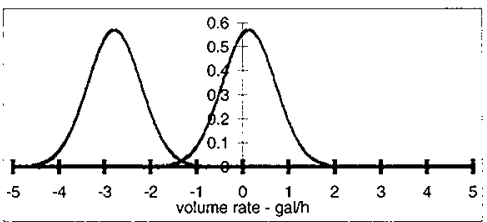

For this data, a threshold $=-1.84 \mathrm{gal} / \mathrm{h}$ will detect a tank release of $\quad 2.92 \mathrm{gal} / \mathrm{h}$ at a $\mathrm{Pd}=95 \%$ The corresponding $\mathrm{Pfa}$ is $\quad 0.16 \%$

Figure 5. Plots used in the analysis of Tank A-103. 
The volume plot in Figure 5 shows that Tank A-103 had seven or eight periods, lasting two to three months each, during which volume was more or less constant. Between these periods, there are also eight or nine places in the data where the volume changes abruptlyeither up or down. Since the character of the indicated positive and negative volume changes is suggestive of sensor adjustments, calibrations, or other non-actual volumetric changes, these data are retained in the analysis.

After generating the plot, the spreadsheet parsed the data into 30-day sets. ${ }^{7}$ As many of these (nominally) month-long data sets were parsed as could be obtained from the data. For example, in a case where $2 \frac{1}{2}$ years of sensor data were available, 30 (thirty) 30-day data sets could be obtained. After the data had been parsed, a least-squares linear regression fit was made to each of the 30-day data sets. The slope of the regression line, expressed in terms of gallons per hour, was saved as an estimate of the volume rate during the month-long period. The standard deviation of the y-estimate, which describes the fluctuations during the monthlong period (i.e., how well the data "behave"), was also saved. In the case of A-103, it was expected that the abrupt volume changes observed in the data set would cause unusually large and entirely spurious estimates of volume rate, standard deviation, or both. To provide a data quality filter, we rejected from the ensemble any data set having a standard deviation of more than $1,000 \mathrm{gal} / \mathrm{h}(2,000 \mathrm{gal} / \mathrm{h}$ for the $\mathrm{ILL}$ data). The final volume rate data set used in the analysis is plotted in Figure 5. It forms the basis for the performance and leak detection estimates. The number of volume rate estimates removed from the data set because of poor quality (i.e., high standard deviation) is shown at the lower right of the volume rate plot of Figure 5. Immediately below this is the number, $\mathrm{N}$, of data sets that were available for analysis for the tank in question. For A-103, for example, $\mathrm{N}$ was equal to 21 .

The EPA provides a concise approach for evaluating the performance of leak detection methods using a gaussian analysis ["Standard Test Procedures for Evaluating Leak Detection Methods: Automatic Tank Gauging Systems," 1990]. This evaluation procedure, applied to the Hanford tank data, allows an estimate to be made of the minimum leak that can be detected in each tank, assuming that the data sets used are representative of the liquid level data from that tank. Using the final analysis set, the EPA's gaussian analysis first calculates a test statistic, $t_{s}$, given as

$$
t_{s}=N^{1 / 2} \times\left(m / \sigma_{m}\right),
$$

where $\mathrm{N}$ is the number of data sets that are usable after the data have been culled and anomalous data points removed, $\mathrm{m}$ is the average volume rate over the entire analysis period (the average of the $N$ volume rate estimates), and $\sigma_{\mathrm{m}}$ is the standard deviation of the set of volume rate estimates. As described above, for the A-103 data, there were 21 data sets of volume rate data after culling. For a mean volume rate of $0.14 \mathrm{gal} / \mathrm{h}$ and a standard deviation of $\mathrm{m}$ of $0.58 \mathrm{gal} / \mathrm{h}$, the resulting test statistic is calculated to be 1.10 .

\footnotetext{
${ }^{7}$ Since the ILL data were recorded weekly, there are far fewer samples available, compared to the ENRAF or equivalent sensor. When the ILL data were used, 30 samples were taken; this typically corresponds to a record length of about seven months.
} 


\subsubsection{Significance of the Average Volume Rate}

To determine the statistical significance of the average volume rate, $\mathrm{m}$, a mull hypothesis test can be used. The null hypothesis states-in this case-that $\mathrm{m}$ is zero gallons per hour. The test compares the test statistic to a critical statistic, $t_{c}$, determined from a table of Student's $t$ values, for specified one-sided confidence intervals. Given the month-to-month fluctuations in the values of volume rate, the test determines whether the measured value of $\mathrm{m}$ is statistically different from 0 gal, or whether the observed value can be attributed to random occurrence. In the case of the analysis of the SST data, we test at two confidence intervals, $5 \%$ and $1 \%$. In the hypothesis test, these values are the probability of rejecting the null hypothesis when it is true -in other words, at $5 \%$ and $1 \%$ probabilities of false alarm. A Student's t-table gives a $t_{c}$ value of 1.729 at a $5 \%$ error, and a value of 2.539 for a $1 \%$ error. Since $t_{s}$ is less than $t_{c}$ in both cases, we conclude that, with only a $5 \%$ chance of error (or $1 \%$, depending upon the value used), the measured average volume rate, $\mathrm{m}=0.14 \mathrm{gal} / \mathrm{h}$, is due to pure chance and cannot be distinguished from $0 \mathrm{gal} / \mathrm{h}$. Had $\mathrm{t}_{\mathrm{s}}$ been greater than $\mathrm{t}_{\mathrm{c}}$ (as it is for some of the SST data analyzed below), we would conclude that, with only a $5 \%$ (or $1 \%$ ) chance of error, the mean volume rate could not be explained by random error. This does not mean the tank is leaking; it simply describes that the average volume rate is not likely attributable to random error. In the language of statistics, when $t_{s}$ is less than $t_{c}$, we say we "fail to reject the null hypothesis." While this statement is technically correct, it is obtuse; accordingly, we have shown the result in Figure 5 in terms of the statement "the mean volume rate is equivalent to $0 \mathrm{gal} / \mathrm{h}$."

\subsubsection{Minimum Detectable Leak}

Using the volume rate data for each tank, a threshold, $T$, can be determined that will specify the maximum likelihood of incorrectly detecting a leak, if a leak test were conducted on this tank; this is the probability of false alarm, $P_{\mathrm{FA}}$. The threshold will also allow us to estimate the minimum leak that would be correctly detected; this is the probability of detection, $\mathrm{P}_{\mathrm{D}}$. The relationship is

$$
\mathrm{T}_{\mathrm{PFA}}=-\mathrm{t}_{\mathrm{c}} \times \sigma_{\mathrm{m}}
$$

where $t_{c}$ is selected from a table of Student's t-values to match the desired $\mathrm{P}_{\mathrm{FA}}$ for the number of degrees of freedom available (N-1). Using these data, the minimum detectable leak, $\mathrm{L}_{\mathrm{MD}}$, at a probability of detection of $1-\mathrm{P}_{\mathrm{FA}}$, can be calculated simply as $2 \times \mathrm{T}$. Figure 5 shows these calculations for $\mathbf{P}_{\mathrm{D}} / \mathbf{P}_{\mathrm{FA}}$ of $95 \% / 5 \%$ and $99 \% / 1 \%$.

In the case of Tank A-103, for example, these calculations indicate that if we implement a leak detection threshold, $\mathrm{T}$, of $-1.00 \mathrm{gal} / \mathrm{h}$ on the Manual ENRAF data stream we can, by using a single month-long data period, detect a leak as small as $-2.00 \mathrm{gal} / \mathrm{h}$ with a $\mathrm{P}_{\mathrm{D}}$ of $95 \%$. Because the $P_{F A}$ is $5 \%$, we would also expect five false alarms for every 100 tests attempted. Since responding to false alarms is both expensive and time-consuming, it is of interest to lower the value of the $P_{F A}$. If we implement a leak detection threshold, $T$, of $-1.46 \mathrm{gal} / \mathrm{h}$ instead, we obtain a lowered $P_{F A}$ of $1 \%$ and can detect a leak of $-2.92 \mathrm{gal} / \mathrm{h}$ with a $P_{D}$ of 
$99 \%{ }^{8}$ These performance data are illustrated in Figure 5. The plots near the bottom of the figure show how the noise and signal-plus-noise data (assuming that these data were normally distributed) would be related to the $\mathrm{m}, \sigma_{\mathrm{m}}$, and $\mathrm{T}$ values in each case $\left(\mathrm{P}_{\mathrm{D}}\right.$ and $\mathrm{P}_{\mathrm{FA}}$ of $95 \%$ and $5 \%$, respectively, and $\mathrm{P}_{\mathrm{D}}$ and $\mathrm{P}_{\mathrm{FA}}$ of $99 \%$ and $1 \%$, respectively).

The selection of a threshold to match various $\mathrm{P}_{D}$ and $\mathrm{P}_{\mathrm{FA}_{A}}$ requirements invariably entails compromise: any attempt to reduce $\mathrm{P}_{\mathrm{FA}}$ also reduces $\mathrm{P}_{\mathrm{D}}$. Within the leak detection community, ${ }^{9}$ however, a $P_{D}$ of $95 \%$ is the commonly accepted standard. In order to improve the performance of the leak detection method, we can extend the statistical analysis used to make the performance estimates by finding a threshold that minimizes $\mathrm{P}_{\mathrm{FA}}$ yet is consistent with a $P_{D}$ of $95 \%$. When this tactic is applied to the data from Tank A-103, for example, we find that if we implement a leak detection threshold of $-1.84 \mathrm{gal} / \mathrm{h}$ we can detect a release of $-2.92 \mathrm{gal} / \mathrm{h}$ with a $\mathrm{P}_{\mathrm{D}}$ of $95 \%$ and a $\mathrm{P}_{\mathrm{FA}}$ of only $0.16 \%$. This represents approximately a sixfold increase in the leak detection capability for Tank A-103, with no concurrent loss of $P_{D}$. The results of the calculation for minimizing $P_{F A}$ are shown at the bottom of Figure 5 .

As noted at the beginning of Section 3.2.2, an analysis similar to that described above has been conducted for each of the SSTs that exhibited data of sufficient quality and duration to warrant such an analysis. The results are presented in Appendix E. Assuming that the data measured for each tank faithfully represents the liquid level in that tank, the essential conclusions from the work described above are several. First, the TWINS data show that 70 of the 149 SSTs have a sufficient volume of supernatant or interstitial liquids, and have liquid level data of sufficient quality, to be useful for a volumetric-based liquid integrity assessment method. Second, the analysis showed that the liquid integrity of those tanks could successfully be assessed. Third, the performance of a volumetric-based integrity assessment method is expected to be reasonably good (i.e., minimum detectable leaks of a few gallons per hour at a $\mathrm{P}_{\mathrm{D}}$ of $95 \%$, with a $\mathrm{P}_{\mathrm{FA}}$ typically much less than $1 \%$ ). This is an especially useful result when one considers integrity assessments for assigning retrieval priorities, considering that the installed level instruments were never designed for a "leak test" purpose.

Furthermore, the successful use of liquid-level data to assess tank integrity demonstrates the potential usefulness of this approach for periodic monitoring (for example, during waste retrieval operations). To achieve the degree of performance described above would require 30 daily measurements (or, for ILL measurements, weekly samples). Thus, a single test would last one month (seven months in the case of $\mathrm{LL}$ measurements) - too long a duration for most applications. A shorter test duration would be possible if the level data were based on hourly measurements; for example, a two-day test could be conducted using 48 hourly measurements. Such a test would require a separate performance assessment (since its performance would not necessarily be the same as that of the 30-day test). Given the

\footnotetext{
${ }^{8}$ Existing procedures at TMACS examine the liquid-level data stream for changes in volume of 3 standard deviations. This is roughly comparable to a $\mathrm{P}_{\mathrm{FA}}$ of $1 \%$. While the $\mathrm{P}_{\mathrm{FA}}$ of the existing procedures is comparable to the $1 \%$ described for the volume rate estimates, the $P_{D}$ inherent in the existing TMACS procedures has not been established, nor has the minimum detectable leak been established.

9 and many other detection-oriented communities as well, such as those using radar and sonar
} 
availability of hourly liquid-level data, this assessment could be accomplished through analysis of these data.

A final conclusion resulting from the statistical analysis of the level data was that, with only a few exceptions, this work confirms the DOE-published assumptions regarding tank integrity. In 40 of the cases where DOE determined that a particular tank is likely to be sound, this analysis confirmed that determination. The results of the analysis are tabulated in Table 5. It is important to note that the analysis described in this section did not attempt to identify phenomena that might affect the volume data or to correlate these phenomena with the data. For example, it is known that the measured volume in some tanks is strongly anticorrelated with barometric pressure. The identification of such influences, and compensation for their effects on the measured volume data, was beyond the scope of this work.

Table 5. A Comparison of Reported Tank Integrity with Analysis-Inferred Integrity

\begin{tabular}{|c|c|c|c|}
\hline $\begin{array}{l}\text { DOE-Reported } \\
\text { Integrity }\end{array}$ & $\begin{array}{l}\text { Analysis-Inferred } \\
\text { Integrity }\end{array}$ & $\begin{array}{l}\text { Number of } \\
\text { Tanks }\end{array}$ & Tank IDs \\
\hline Presumed sound & Volume rate $=0 \mathrm{gal} / \mathrm{h}$ & 40 & $\begin{array}{l}\text { A-101, B-102, B-104, BX-104, BX-105, BY-101, } \\
\text { BY-102, BY-104, BY-109, BY-110, BY-112, C- } \\
\text { 103, C-106, S-101, S-103, S-105, S-108, S-109, } \\
\text { S-110, S-111, SX-101, SX-102, SX-103, SX-105, } \\
\text { SX-106, T-102, T-104, T-110, T-112, TX-101, } \\
\text { TX-102, TX-106, TX-109, TX-118, U-102, U- } \\
\text { 103, U-107, U-108, U-109 }\end{array}$ \\
\hline Presumed sound & $\begin{array}{l}\text { Statistically significant } \\
\text { negative volume rate }\end{array}$ & 0 & - \\
\hline Presumed sound & $\begin{array}{l}\text { Statistically significant } \\
\text { positive volume rate }\end{array}$ & 9 & $\begin{array}{l}\text { BX-103, S-102, S-106, S-107, S-112, TX-111, } \\
\text { TX-112, U-105, U-106 }\end{array}$ \\
\hline Assumed leaker & Volume rate $=0 \mathrm{gal} / \mathrm{h}$ & 17 & $\begin{array}{l}\text { A-103, B-105, B-111, B-112, BX-110, BY-103, } \\
\text { BY-105, BY-106, BY-107, S-104, SX-104, T- } \\
111(>1995), \text { TX-114, TX-115, TY-103, TY-104, } \\
\text { U-101 }\end{array}$ \\
\hline Assumed leaker & $\begin{array}{l}\text { Statistically significant } \\
\text { negative volume rate }\end{array}$ & 1 & B-110 \\
\hline Assumed leaker & $\begin{array}{l}\text { Statistically significant } \\
\text { positive volume rate }\end{array}$ & 3 & TX-110, TX-113, TX-117 \\
\hline
\end{tabular}

Total of 70 tanks containing sufficient liquid and possessing functional instrumentation 


\section{Assessment of Remaining Useful Life}

All of the SSTs have been removed from active service. They are currently used to store waste that is awaiting retrieval under a RCRA Part A, interim-status permit. In other words, the SSTs have already reached the end of their useful lives in active service. The term "remaining useful life," as used in this report, refers to the SSTs' viability as interim storage receptacles for solid and liquid wastes awaiting retrieval. In the context of "remaining useful life," the definition of "failure" is the loss of liquid containment during the interim storage period or during subsequent retrieval operations. A corollary to this definition is that any tank that has been declared an "assumed leaker" is considered to have undergone failure.

The service life of all SSTs (grouped according to tank farm) is shown in Table 6. This table covers the period from 1998 to 2018 , the target date for SST closure.

Table 6. Length of Service of SSTs according to Tank Farm Grouping

\begin{tabular}{lccc}
\hline Tank Farm & In Service From/To & $\begin{array}{c}\text { Service Life in 1998 } \\
\text { (in Years) }\end{array}$ & $\begin{array}{c}\text { Service Life in 2018 } \\
\text { (in Years) }\end{array}$ \\
\hline A & $1956-57$ & 42 & 62 \\
AX & $1965-66$ & 33 & 53 \\
B & $1945-47$ & 53 & 73 \\
BX & $1948-50$ & 50 & 70 \\
BY & $1950-51$ & 48 & 68 \\
C & $1946-53$ & 52 & 72 \\
S & $1952-53$ & 46 & 66 \\
SX & $1954-60$ & 44 & 64 \\
T & & & 74 \\
TX & $1944-47$ & 54 & 69 \\
TY & $1949-51$ & 49 & 65 \\
U & 1953 & 45 & 72 \\
\hline
\end{tabular}

\subsection{Catastrophic Failure}

Catastrophic failure, defined in this analysis as either structural collapse or the loss of 50,000 gal or more, has a relatively low probability of occurrence. Table 7 presents information on the five tanks known to have leaked catastrophically. 
Table 7. Catastrophic Leaks in SSTs

\begin{tabular}{lcccl}
\hline Tank & Date & $\begin{array}{c}\text { Age of Tank } \\
\text { (Years) }\end{array}$ & Leak Volume (gal) & $\begin{array}{c}\text { Postulated } \\
\text { Failure Mechanism }\end{array}$ \\
\hline & & & & \\
A-105 & 1963 & 6 & 10,000 to 277,000 & Steam rupture \\
BX-102 & 1971 & 21 & 70,000 & Unknown \\
SX-115 & 1965 & 5 & 50,000 & Thermal cycling \\
T-106 & 1973 & 26 & 115,000 & Unknown \\
U-104 & 1961 & 12 & 55,000 & Unknown \\
& & & & \\
\hline
\end{tabular}

Minimizing catastrophic failures during retrieval operations will depend largely on the response time necessary to declare a leak and the ability of in-tank equipment to remove free liquids.

Based on the preliminary integrity assessment presented in Section 3, the SSTs can be qualified for interim storage of solids for the duration of the expected SST retrieval program, i.e., through the year 2028 .

\subsection{Loss of Containment}

An initial approach to estimating an SST's remaining useful life is to simply bound the expected time-to-failure and assign a probabilistic distribution within those bounds. As the carbon-steel liners of these tanks degrade over time, breaches are likely to occur. Time-tofailure can reasonably be bounded by the following:

- Minimum time-to-failure: 0 years (assuming some SSTs leak when placed into service )

- Maximum time-to-failure: 90 years (two times the longest known time-to-failure)

- Mean time-to-failure: $(90-0) / 2=45$ years

Once the minimum, maximum, and mean time-to-failures are defined, various probability distribution functions can be examined for utility as a reasonable remaining useful life estimator. A bounding estimator may be useful for the total population, but its utility for making remaining-useful-life estimates for individual tanks is limited.

A slightly more sophisticated approach to estimating a tank's remaining useful life is through the use of a simple linear likelihood estimator. Linear likelihood estimators are a common tool for predicting future component failures based on component failure histories. Sixtyseven SSTs have been declared "assumed leakers." Using the formula

Linear Likelihood Estimator (Tank Age) $\frac{\text { \# Failed }}{\text { Total Population }}=$ Probability of Failure 
we can develop a linear likelihood estimator based on the declaration date of the leak (as shown in Figures 2 and 3).

Tank AX-102, for example, went into service between 1965 and 1966. The linear estimator in Figure 2 shows that $70 \%$ of the 67 tanks that have been declared "leakers" had been in service between 30 and 35 years when that designation was applied. The estimated probability that Tank AX-102 would be declared an assumed leaker today is

$$
70 \% * 67 / 149=31 \%
$$

The probability of a level decrease can be estimated similarly, using the simple linear estimator in Figure 3. The probability of a level decrease for Tank AX-102 today is:

$$
60 \% * 24 / 149=10 \%
$$

These simple linear estimators have been applied to the remaining 82 SSTs-those that are considered sound. The results are shown in Table B-1 in Appendix B. Since the oldest SST to have been declared a leaker was Tank T-101, in 1992 (when it had been in service for 45 years), the linear estimators predict a "declared leaker" probability of $45 \%(100 \% * 67 / 149$ $=45 \%)$ and a probability of level decrease of $16 \%(100 \% * 24 / 149=16 \%)$ once a sound tank reaches a service life of 45 years.

Linear likelihood estimators are only as useful as the data used to develop them. Unfortunately, the protocols used to declare an SST an "assumed leaker" have not been consistent through the years, and tank-to-tank operations vary significantly. Linear estimator predictions should therefore be taken within the context of other predictors.

Any discussion of SSTs as a group is difficult because of the number of independent variables associated with each individual tank. The major variables affecting corrosionrelated failures include waste type, waste temperature, tank construction, and the percent of wetted surface time (i.e., how much time the interior surface of the liner has spent in contact with the contained liquids). All four of these four variables were qualitatively determined for the remaining 82 sound SSTs, according to the following protocols (and sorted in Appendix B):

$\begin{array}{lll}\text { Waste Type } & \bullet \text { 0\% leakers } & \text { Good } \\ & : \text { O-25\% leakers } & \text { Moderate } \\ & : \text { Over 25\% leakers } & \text { Bad } \\ & \text { 100\% leakers } & \text { Very bad } \\ \text { Corrosivity Factor } & : \text { Below 25 } & \text { Good } \\ & : 25 \text { to } 50 & \text { Moderate } \\ & \bullet \text { Above } 50 & \text { Bad }\end{array}$

continued 


\begin{tabular}{|c|c|c|}
\hline $\begin{array}{l}\text { Maximum Waste } \\
\text { Temperature }\end{array}$ & $\begin{array}{l}\text { - Below } 120^{\circ} \mathrm{F} \\
-120^{\circ} \mathrm{F} \text { to } 170^{\circ} \mathrm{F} \\
\text { - Over } 170^{\circ} \mathrm{F}\end{array}$ & $\begin{array}{l}\text { Good } \\
\text { Moderate } \\
\text { Bad }\end{array}$ \\
\hline & $\begin{array}{l}\text { - Radius knuckle } \\
\text { - Butt-weld knuckle }\end{array}$ & $\begin{array}{l}\text { Good } \\
\text { Bad }\end{array}$ \\
\hline
\end{tabular}

A common tool for screening the aggressiveness of a particular waste type is the corrosivity factor discussed in Section 2.2. It is important to note that the CF is most valid for nitricacid-based waste streams. There are many constituents comprising the 30 waste groupings used in this analysis [Anantatmula, 1994]. Appendix B shows the results of an initial screening of corrosive conditions based on waste type, maximum temperature, and tank construction.

\subsection{Tank-by-Tank Ranking}

Table 8 shows tank groupings according to five categories. It describes the characteristics of tanks in each category and gives the number of tanks in that category. Table 9 provides a relative ranking of the remaining useful lives of all the SSTs.

Table 8. Tank Groupings according to Category

\begin{tabular}{clc}
\hline Category & \multicolumn{1}{c}{ Characteristics } & Number of Tanks \\
\hline I. & $\begin{array}{l}\text { Benign waste type, low temperature, good to moderate corrosivity factor, } \\
\text { constant service history, consistent surface level }\end{array}$ \\
II. $\quad \begin{array}{l}\text { Inconsistent liquid level, benign waste type, elevated temperature, good } \\
\text { to moderate corrosivity factor, consistent service history, listed as sound, } \\
\text { may or may not have been stabilized }\end{array}$ & 20 \\
III. $\begin{array}{l}\text { Inconsistent liquid level or aggressive waste type, elevated temperature, } \\
\text { good to moderate corrosivity factor, inconsistent service history, listed as } \\
\text { sound, may or may not have been stabilized }\end{array}$ & 50 \\
IV. Listed as "assumed leaker," leaked less than 50,000 gal, may or may not \\
have been stabilized
\end{tabular}

The relative rankings provided here should be used for preliminary screening of SST candidates for early retrieval demonstrations. While qualitative rankings are indicative of trends, definitive conclusions regarding the structural and liquid integrity of individual tanks cannot be drawn from these limited data. 
Table 9. Relative Rankings of the Remaining Useful Lives of SSTs

\begin{tabular}{rlr}
\hline Category & \multicolumn{1}{c}{ Tank Name } & Number of Tanks \\
\hline I. & C-102, C-103, C-105, TX-108, TX-118, U-105, U-107, U-108, & 12 \\
& U-109, U-201, U-202, U-203 & \\
II. & BY-102, BY-109, C-106, S-112, S-111, S-102, SX-106, SX-101, & 20 \\
& SX-102, SX-105, S-101, S-103, S-105, S-106, S-107, S-108, S- \\
& 109, S-110, TX-102, TX-104 & \\
III. & TX-106, U-106, U-111, U-103, U-102, AX-101, A-101, A-102, \\
& B-108, B-109, BX-112, T-110, T-112, B-202, T-201, T-202, T- \\
& 203, T-204, U-204, SX-103, A-106, B-104, BX-109, C-104, C- \\
& 107, T-104, TX-101, TX-103, TX-112, C-108, C-109, C-112, \\
& BX-103, BX-104, BX-105, BX-106, BY-111, BY-112, AX-103, \\
BY-110, BY-104, BY-101, T-105, B-106, BX-107, B-102, T- & \\
& 102, TX-109, TX-111, TY-102 \\
& \\
A-103, A-104, AX-102, AX-104, B-101, B-103, B-105, B-107, & \\
B-110, B-111, B-112, B-201, B-203, B-204, BX-101, BX-108, \\
BX-110, BX-1 11, BY-103, BY-105, BY-106, BY-107, BY-108, \\
C-101, C-110, C-111, C-201, C-202, C-203, C-204, S-104, SX- \\
104, SX-107, SX-108, SX-109, SX-110, SX-111, SX-112, SX- \\
113, SX-114, T-101, T-103, T-107, T-108, T-109, T-111, TX- \\
105, TX-107, TX-110, TX-113, TX-114, TX-115, TX-116, TX- \\
117, TY-101, TY-103, TY-104, TY-105, TY-106, U-101, U-110, \\
U-112 \\
A-105, BX-102, SX-115, T-106, U-104 \\
V.
\end{tabular}




\section{Impact of Hydraulic Retrieval on Liquid Integrity}

During SST retrieval operations, the rate which liquid could potentially be released to the surrounding soils depends primarily on two parameters: (1) total hydraulic head and (2) leak path. The total volume of liquid that could be released to the soil depends on three additional parameters: (1) retrieval time, (2) detection time, and (3) response time. The impact of hydraulic retrieval is illustrated in Figure 6.

There are many theories regarding leak mechanisms for SSTs. One such theory says that leaking SSTs all have essentially the same flow area resulting from a similar distribution of stress corrosion cracks. A confident understanding of a leak's expected behavior will allow appropriate application of leak detection and leak response measures during retrieval operations in the SSTs.

\subsection{Calculated Flow Constant for Laminar Flow}

A detailed engineering study was conducted in 1993 to estimate leak rates associated with hydraulic retrieval of sludge from Tank C-106 [Lowe, 1993]. This study estimated leak rates from a distribution of 20 stress corrosion cracks to be as high as 40,000 gal over a 500 -h retrieval campaign, for an overall leak rate of $80 \mathrm{gal} / \mathrm{h}$. An earlier study [Isaacson, 1984] identified 13 SSTs with known or postulated leak rates. After declaring three of these tanks catastrophic leakers and removing them from the population, this study found (with $95 \%$ confidence) that $95 \%$ of the SSTs would leak at a rate less than $1.8 \mathrm{gal} / \mathrm{h}$. In an effort to reduce this 40 -fold difference between calculated and measured leak rates, a simple firstorder calculation was performed to quantify the relationship between leak rate and hydraulic head. For a specific fluid system, hydraulic head $(\mathrm{H})$ and volumetric flow $(\mathrm{Q})$ can be measured such that standard fluid dynamics equations reduce to

and

$$
\mathrm{Q}_{\text {turbulent }}=\mathrm{k}_{\text {turbulent }}(\mathrm{H})^{1 / 2}
$$

$$
\mathrm{Q}_{\text {laminar }}=\mathrm{k}_{\text {laminar }}
$$

where $k_{\text {furbulent }}$ and $k_{\text {laminar }}$ account for all constants like effective flow area, flow length, surface roughness, and fluid viscosity.

Laminar flow constants for seven tanks known to be leaking and six that were postulated leaking [Isaacson, 1981] were calculated; the results are shown in Table 10. Hydraulic head and leak rate data used for the calculations are plotted in Figures 7 and 8 . As is evident in both the table and the figures, it is not possible to postulate conclusively a relationship between leak rate and hydraulic head that would be common to all the tanks. Additional data and analyses are necessary before potential leak rates for SSTs undergoing retrieval operations can be estimated. Specifically, leak rate and hydraulic head data should be validated prior to further investigation. 


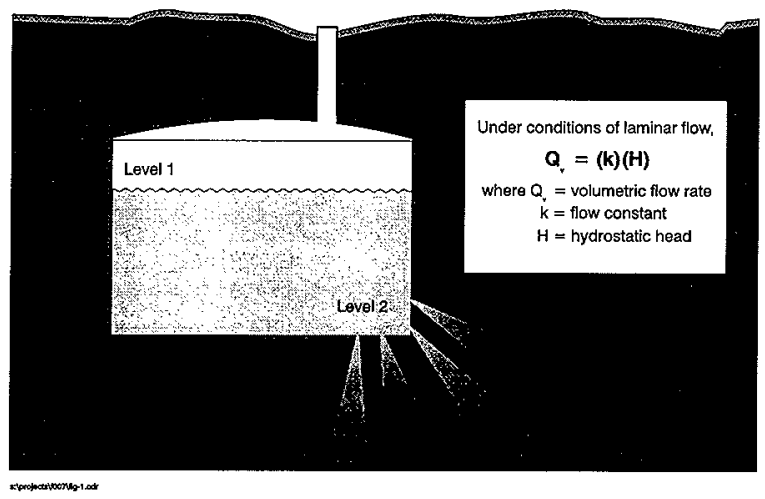

Figure 6. Impact of hydraulic retrieval.

Table 10. Laminar Flow Constant $\left(\mathrm{k}_{\mathrm{laminn}}\right)$ Calculations for Known and Postulated Leak Rates

\begin{tabular}{lcccc}
\hline \multicolumn{1}{c}{ Tank } & $\begin{array}{c}\text { Leak Rate } \\
\text { (gal/h) }\end{array}$ & Head (ft) & $\mathbf{k}_{\text {laminar }}$ & $\begin{array}{c}\text { Leak Rate } \\
\text { Confidence }\end{array}$ \\
\hline SX-115* & 306 & 22.0 & 13.91 & Confirmed \\
T-106* & 102 & 15.3 & 6.69 & Confirmed \\
B-201 & 0.30 & 12.5 & 0.02 & Confirmed \\
B-107 & 0.66 & 4.5 & 0.15 & Confirmed \\
C-101 & 1.14 & 2.0 & 0.57 & Confirmed \\
U-112 & 1.20 & 2.0 & 0.60 & Confirmed \\
U-110 & 1.38 & 11.0 & 0.13 & Confirmed \\
T-108 & 0.09 & 16.0 & 0.01 & Postulated \\
T-111 & 0.12 & 14.5 & 0.01 & Postulated \\
TX-107 & 0.36 & 2.0 & 0.18 & Postulated \\
TY-101 & 0.78 & 23.2 & 0.03 & Postulated \\
B-110 & 1.20 & 8.3 & 0.14 & Postulated \\
SX-110* & 12.00 & 13.0 & 0.92 & Postulated \\
\hline Average & 0.72 & 9.6 & 0.18 & \\
Std. Dev. & 0.46 & 6.8 & 0.21 & \\
\hline
\end{tabular}

Denotes a tank having a catastrophic leak rate. These tanks are not included in the average or in the standard deviation. 


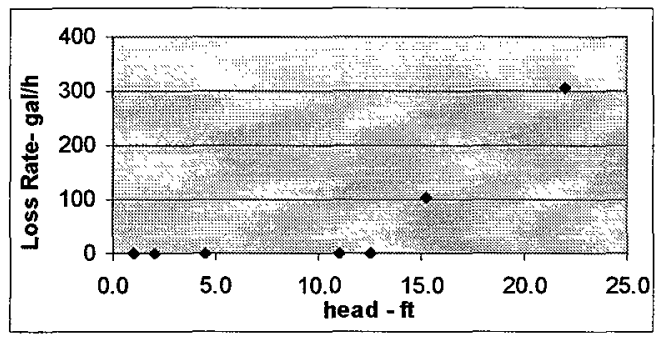

Figure 7. Fluid dynamics data for seven SSTs with "confirmed" leak rates.

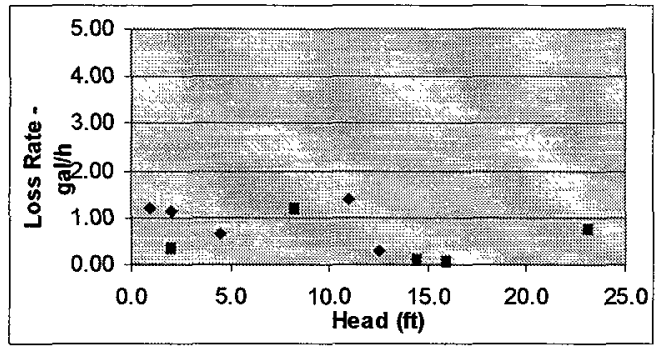

Figure 8. Fluid Dynamics data for "confirmed" and "postulated" leak rates of ten leaking SSTs. Squares indicate "confirmed" leak rates and diamonds indicate "postulated" leak rates. Three catastrophic leak rates are removed for scaling.

\subsection{Maximum Undetected Leak Volume}

Section 6.5 of the Tank Waste Remediation System Operation and Utilization Plan [Kirkbride, 1997] provides a formula that describes an estimated baseline retrieval time, $T_{r}$, as

$$
\begin{array}{lllrl}
\mathrm{T}_{\mathrm{r}}=0.72 \mathrm{~m}^{3} / \mathrm{d} & {[190.2 \mathrm{gal} / \mathrm{d}]} & \text { for } & 0.01>\mathrm{V}_{\mathrm{w}} / \mathrm{V}_{\mathrm{t}} \\
\mathrm{T}_{\mathrm{r}}=72 *\left(\mathrm{~V}_{\mathrm{w}} / \mathrm{V}_{\mathrm{t}}\right) \mathrm{m}^{3} / \mathrm{d} & {\left[19.02 *\left(\mathrm{~V}_{\mathrm{w}} / \mathrm{V}_{\mathrm{t}}\right) \mathrm{gal} / \mathrm{d}\right]} & \text { for } & 0.1 \geq \mathrm{V}_{\mathrm{w}} / \mathrm{V}_{\mathrm{t}} \geq 0.01 \\
\mathrm{~T}_{\mathrm{r}}=7.2 \mathrm{~m}^{3} / \mathrm{d} & {[1902 \mathrm{gal} / \mathrm{d}]} & \text { for } & & \mathrm{V}_{\mathrm{w}} / \mathrm{V}_{\mathrm{t}}>0.1
\end{array}
$$

where $V_{t}$ is the total volume capacity of the tank, and $V_{w}$ is the residual waste in the tank. Using this formula, we can estimate a time history for retrieval, and from this history we can estimate how much time will be required to retrieve any specified quantity of waste. This process is illustrated in Figure 9, an estimated retrieval time history for Tank C-102. Figure 9 shows that, beginning with the current volume of waste in C-102, 316,000 gal (see Appendix F), the waste removal operations proceed rapidly at a rate of about $1,900 \mathrm{gal} / \mathrm{day}$ 
until about Day 150 -at which time the retrieval rate begins to slow down. The calculations show that according to the baseline retrieval formula, it will take approximately 208 days to retrieve $99 \%$ of the wastes in C-102 and about 225 days to retrieve $100 \%$ of the wastes. The amount of time necessary to retrieve $99 \%$ of the wastes is tabulated, tank by tank, in Appendix B. (Based on the sum of the estimated retrieval times for all the SSTs, it is noted that if the retrieval program operated on each tank serially it would take 74.6 years to remove $99 \%$ of the wastes in the SSTs.)

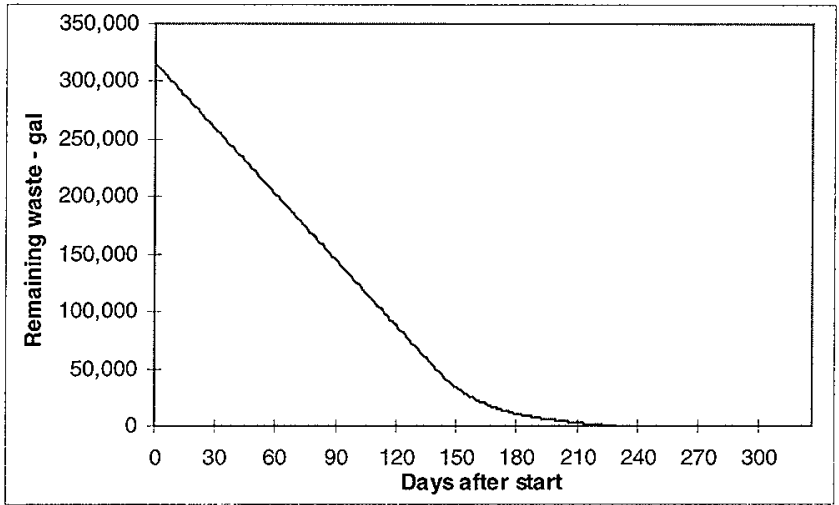

Figure 9. Baseline retrieval time history for Tank C-102, using Kirkbride's formula.

If, for a given tank, the onset of a leak occurs at the beginning of the retrieval campaign, and if the rate of that leak is just slightly less than the minimum detectable leak rate, the total volume of the undetected release will be no greater than the leak rate multiplied by the retrieval time. Thus, using the tank information, the known waste volumes, the minimum detectable leak rates calculated above (and listed for each tank in Appendix E), and the formula for estimating retrieval time, we can estimate the maximum volume of a potentially undetected leak from each tank as

\section{Retrieval Time $*$ Leak Rate $=$ Maximum Undetected Leak Volume}

The "maximum undetected leak volume" was calculated for each tank. (It is reported in the last column of the table in Appendix F.) Table 11 shows the average time necessary to retrieve $99 \%$ of the wastes and the average volume of a potentially undetected leak under three different conditions based on the volume of liquid in the tank (1,000,000 gal, 750,000 gal, and $500,000 \mathrm{gal}$ ). The table shows an average retrieval time of 14 days for tanks containing 55,000 gal, but since there were no level data available for these tanks that could be used to calculate a minimum detectable leak rate, it was not possible to determine a maximum undetected leak volume in this analysis. 
Table 11. Average Retrieval Times and Potential Undetected Leak Volumes for Tanks of Various Capacities

\begin{tabular}{ccc}
\hline $\begin{array}{c}\text { Tank Volume } \\
\text { (gal) }\end{array}$ & $\begin{array}{c}\text { Average Retrieval Time } \\
\text { (days) }\end{array}$ & $\begin{array}{c}\text { Average } \\
\text { Potentially Undetected Leak Volume } \\
\text { (Kgal) }\end{array}$ \\
\hline $1,000,000$ & 238 & 40 \\
750.000 & 261 & 20 \\
500,000 & 143 & 10 \\
55,000 & 14 & N/A \\
\hline
\end{tabular}




\section{Conclusions and Recommendations}

\subsection{Conclusions}

This work demonstrates that there are several techniques possible for screening the Hanford SSTs for liquid integrity. Much of the data employed by these techniques, however, are not readily available and are in many cases suspect. The use of multiple techniques in a way that exploits all of the available SST data, on the other hand, can facilitate a tank-by-tank understanding of liquid integrity and can foster a relative confidence in predictions of remaining useful life. Specifically, the following conclusions are presented.

- A qualitative tank integrity screening (based on engineering judgment using indicators such as corrosiveness of waste, maximum temperature, and lower-knuckle design) was prepared. SSTs can be grouped into relative rankings as candidates for early retrieval demonstrations.

- The analysis showed that volumetric methods can be applied to many of the SSTs as part of a regular test program to detect leaks in the range of regulatory interest (i.e., less than $5 \mathrm{gal} / \mathrm{h}$ ), using existing sensors. Performance specifications that include a probability of detection of $95 \%$ and a probability of false alarm of $1 \%$ or less can be developed for those tanks with measurable liquid levels. Test times of 24- to 48hours are likely for many of the SSTs.

- For many SSTs, tank liquid integrity indicators such as corrosiveness of the waste and maximum waste temperature are favorable.

- A maximum leak rate for "known leakers" was calculated as $1.8 \mathrm{gal} / \mathrm{h}$ [Isaacson, 1981]. A common relationship between fluid level and leak rate (critical flow constant) in SSTs could not be established with the data reviewed. Additional data and further analysis are necessary for such correlations to be established and justified.

\subsection{Recommendations}

The following recommendations are submitted for consideration in future SST tank integrity reviews.

(1) Perform detailed tank integrity assessments on the following candidate SSTs:
C-102
TX-118
U-107
U-201
C-103
TX-108
$\mathrm{U}-108$
U-202
C-105
U-105
U-109
$\mathrm{U}-203$

Detailed integrity assessments should include a critical review of waste chemistry and a calculation of the corrosivity factor throughout the life of the tank, a critical 
review of all tank temperature and level data from tank-farm operations logs, and a review of tank construction reports.

(2) Establish leak test protocols for SSTs for each retrieval methodology based on a statistically significant sample period and frequency.

(3) Review archived tank-farm operations logs for leak dates and level recordings to establish expected leak rates from SSTs. 


\section{References}

Abatt, F. G., 1996, "Double-Shell Tank Useful Life Analysis," WHC-SD-WM-ER-556, Rev. 0, Westinghouse Hanford Company, Richland, Washington.

Anantatmula, R. P., 1994, "Characterization of the Corrosion Behavior of the Carbon Steel Liner in Hanford Site Single-Shell Tanks," WHC-EP-0772, Rev. 1, Westinghouse Hanford Company, Richland, Washington.

Barnes, David, Lockheed Martin Hanford Corporation, conversation with authors, 3 June 1998

Brevick, C. H., 1994, "Historical Tank Content Estimate for the Northeast Quadrant of the Hanford 200 East Area," WHC-SD-WM-ER-349, Rev. 0, Westinghouse Hanford Company, Richland, Washington.

Edgemon, G. L., 1995, "Hanford Waste Tank System Degradation Mechanisms," WHC-SDWM-ER-414, Rev. 1, Westinghouse Hanford Company, Richland, Washington.

Girdler, R. M., 1965, "Leaks in Radioactive Waste Tanks," DP-990, E. I. Du Pont De Nemours \& Company, Aiken, South Carolina.

Han, F. C., 1996a, "Structural Integrity and Potential Failure Modes of the Hanford HighLevel Waste Tanks," WHC-SD-TWR-RPT-002, Rev. 0, Westinghouse Hanford Company, Richland, Washington.

Han, F. C., 1996b, "DELPHI Expert Panel Evaluation of Hanford High-Level Waste Tank Failure Modes and Release Quantities," WHC-SD-TWR-RPT-003, Rev. 0, Westinghouse Hanford Company, Richland, Washington.

Hanlon, B. M., 1998, "Waste Tank Summary Report for Month Ending March 31, 1998," HNF-EP-0182-120, Rev. 0, Fluor Daniel Hanford, Inc., Richland, Washington.

Hill, J. G., 1994, "SORT on Radioactive Waste Tanks at Hanford," WHC-PNL-90814, Rev. 2, Westinghouse Hanford Company, Richland, Washington.

Isaacson, R. E., 1981, "A Scientific Basis for Establishing Dry Well-Monitoring Frequencies," RHO-ST-34-201, Rockwell Hanford Operations, Richland, Washington.

Kirkbride, R. A., 1997, "Tank Waste Remediation System Operation and Utilization Plan," HNF-SD-WM-SP-012, Rev. 0, Numatec Hanford Corporation, Richland, Washington. 
Lowe, S. S., 1993, "Engineering Study of Tank Leaks Related to Retrieval of Sludge from Tank 241-C-106," WHC-SD-WM-ES-218, Rev. 0, Westinghouse Hanford Company, Richland, Washington.

Ondrejcin, R. S., 1978, "Prediction of Stress Corrosion of Carbon Steel by Nuclear Process Liquid Wastes," DP-1478, E. I. Du Pont de Nemours \& Co., Aiken, South Carolina.

Poe, W. L., 1974, "Leakage from Waste Tank 16, Amount, Fate, and Impact," DP-1358, E. I. Du Pont de Nemours \& Co., Aiken, South Carolina.

Rasmussen, O. R., 1980, "Hanford Radioactive Tank Cleanout and Sludge Processing," RHO-ST-30, Rev. 0, Rockwell Hanford Operations, Richland, Washington.

Rodenhizer, D. G., 1987, "Hanford Waste Tank Sluicing Fistory," WHC-TI-302, Rev. 0, Westinghouse Hanford Company, Richland, Washington.

"Standard Test Procedures for Evaluating Leak Detection Methods: Automatic Tank Gauging Systems," 1990, EPA Report No. EPA/530/UST-90/006, US Environmental Protection Agency, Washington, D.C.

“Tank Waste Support Table," Tank Waste Information Network System 2 (TWINS), cited 31 December 1997, available from http://twins.pnl.gov:8001. 
Appendix A

Single-Shell Tank Quick Reference Facts 


\section{Single-Shell Tank Quick Reference Facts}

- The first single-shell tanks were constructed in 1943-1944

- The last SST was placed in service in 1964

- In 1959, the first single-shell tank was confirmed to have leaked

- 32 of the 66 SSTs located in the East area are assumed leakers [Hanlon]

- 35 of the 83 SSTs located in the West area are assumed leakers [Hanlon]

- The SSTs contain $\sim 550,000$ gal of supernate [Hanlon]

- The SSTs contain $\sim 5,700,000$ gal of pumpable liquid [Hanlon]

- The SSTs contain $~ 5,800,000$ gal of drainable interstitial liquid [Hanlon]

- There is a total of 149 SSTs ( 67 of which, or $45 \%$, have been declared leakers)

- There is a total of $251,000,000$-gal tanks (15 of which, or $60 \%$, have been declared leakers)

- There is a total of 48758,000 gal tanks (19 of which, or 39\%, have been declared leakers)

- There is a total of 64530,000 gal tanks (26 of which, or $41 \%$, have been declared leakers)

- There is a total of 1255,000 gal tanks ( 7 of which, or $58 \%$, have been declared leakers)

- Only 24 of the declared "leakers" have shown a detectable decrease in surface level

- The total leakage from SSTs to date is $\sim 750,000$ gallons

- 9 out of 10 high-heat tanks have leaked (C-106 is the only non-leaker) [Hanlon]

- 3 out of $19 \mathrm{H}_{2}$ tanks have leaked [Hanlon]

- 5 out of 20 organic tanks have leaked [Hanlon]

- 2 out of 11 tanks with DSSF waste have leaked (A-103, SX-104) [Hanlon]

- 27 sound SSTs have not be stabilized; 55 sound tanks have been stabilized [Hanlon] 


\section{Appendix B}

\section{SST Failure Frequencies}




\begin{tabular}{|c|c|c|c|c|c|c|c|c|c|c|c|c|c|}
\hline Tank & 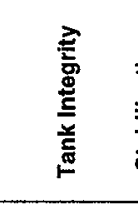 & 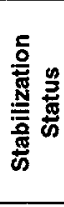 & 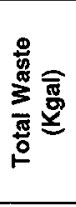 & 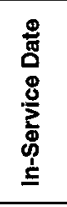 & 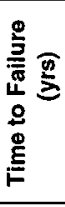 & 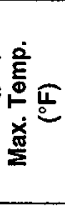 & 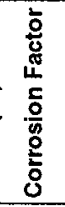 & 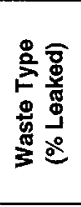 & 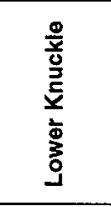 & 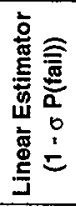 & 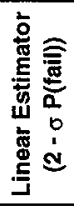 & 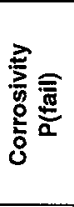 & $\begin{array}{l}\text { 경 } \\
\text { 용 } \\
\text { J }\end{array}$ \\
\hline $\mathrm{A}-101(\mathrm{~T}, \mathrm{H}, \mathrm{O})$ & SOUND & $/ \mathrm{PI}$ & 953 & 1957 & $n / a$ & 153 & 0.77 & $25 \%$ & Radius & $43 \%$ & $15 \%$ & Low & 3 \\
\hline $\mathrm{A}-102(\mathrm{~T})$ & SOUND & $|\mathrm{S} / \mathrm{P}|$ & 41 & 1957 & $\mathrm{n} / \mathrm{a}$ & & 0.77 & $25 \%$ & Radius & $43 \%$ & $15 \%$ & Low & 3 \\
\hline$A-103(T)$ & ASMD LKR & $|S / I|$ & 371 & 1957 & 30 & & 0.77 & $25 \%$ & Radius & $43 \%$ & $15 \%$ & Low & 4 \\
\hline$A-104(T)$ & ASMD LKR & $|S / I|$ & 28 & 1957 & 18 & 187 & 0 & $39 \%$ & Radius & $43 \%$ & $15 \%$ & Low & 4 \\
\hline$A-105$ & ASMD LKR & IS/I & 19 & 1957 & 6 & 141 & 0 & $39 \%$ & Radius & $43 \%$ & $15 \%$ & Low & 5 \\
\hline$A-106(T)$ & SOUND & $|S /| \mid$ & 125 & 1957 & $\mathrm{n} / \mathrm{a}$ & & 0 & $39 \%$ & Radius & $43 \%$ & $15 \%$ & Low & 3 \\
\hline$A X-101(T, H)$ & SOUND & $/ \mathrm{PI}$ & 748 & 1966 & $n a$ & 134 & 0.77 & $25 \%$ & Butt-weld & $31 \%$ & $10 \%$ & Low & 3 \\
\hline$A X-102(T, H)$ & ASMD LKR & IS/II & 39 & 1966 & 22 & 78 & 1.1 & $50 \%$ & Butt-weld & $31 \%$ & $10 \%$ & Low & 4 \\
\hline$A X-103(H)$ & SOUND & $\mid \mathrm{IS} / \mathrm{I}$ & 112 & 1966 & $\mathrm{n} / \mathrm{a}$ & 115 & 1.1 & $50 \%$ & Butt-weld & $31 \%$ & $10 \%$ & Low & 3 \\
\hline$A X-104(T)$ & ASMD LKR & IS/II & 7 & 1966 & 11 & & 0 & $39 \%$ & Butt-weld & $31 \%$ & $10 \%$ & Low & 4 \\
\hline B-101 (T) & ASMD LKR & IS/II & 113 & 1947 & 27 & & 9.12 & $67 \%$ & Radius & $45 \%$ & $16 \%$ & Low & 4 \\
\hline $\mathrm{B}-102(\mathrm{~T})$ & SOUND & IS/II & 32 & 1947 & $n / a$ & & 9.12 & $67 \%$ & Radius & $45 \%$ & $16 \%$ & Low & 3 \\
\hline B-103 (T) & ASMD LKR & $1 S / 11$ & 59 & 1947 & 31 & 66 & 9.12 & $67 \%$ & Radius & $45 \%$ & $16 \%$ & Low & 4 \\
\hline B-104 & SOUND & IS/II & 371 & 1947 & $\mathrm{n} / \mathrm{a}$ & & 0 & $39 \%$ & Radius & $45 \%$ & $16 \%$ & Low & 3 \\
\hline B-105 & ASMD LKR & $1 S / 11$ & 306 & 1947 & 31 & & 22 & $75 \%$ & Radius & $45 \%$ & $16 \%$ & Low & 4 \\
\hline B-106 & SOUND & IS/II & 117 & 1947 & $\mathrm{n} / \mathrm{a}$ & & 26.4 & $60 \%$ & Radius & $45 \%$ & $16 \%$ & Med & 3 \\
\hline B-107 & ASMD LKR & IS/II & 165 & 1947 & 33 & & 11 & $25 \%$ & Radius & $45 \%$ & $16 \%$ & Low & 4 \\
\hline B-108 & SOUND & IS/II & 94 & 1947 & $n / a$ & & 11 & $25 \%$ & Radius & $45 \%$ & $16 \%$ & Low & 3 \\
\hline B-109 & SOUND & IS/II & 127 & 1947 & $\mathrm{n} / \mathrm{a}$ & & 11 & $25 \%$ & Radius & $45 \%$ & $16 \%$ & Low & 3 \\
\hline$B-110(T)$ & ASMD LKR & IS/II & 246 & 1947 & 34 & & 5 & $100 \%$ & Radius & $45 \%$ & $16 \%$ & Low & 4 \\
\hline B-111 & ASMD LKR & IS/II & 237 & 1947 & 31 & & 5 & $100 \%$ & Radius & $45 \%$ & $16 \%$ & Low & 4 \\
\hline $\mathrm{B}-112(\mathrm{~T})$ & ASMD LKR & IS/II & 33 & 1947 & 31 & & 5 & $100 \%$ & Radius & $45 \%$ & $16 \%$ & Low & 4 \\
\hline B-201 & ASMD LKR & IS/II & 29 & 1947 & 33 & & 1.8 & $37 \%$ & Radius & $45 \%$ & $16 \%$ & Low & 4 \\
\hline $\mathrm{B}-202(\mathrm{~T})$ & SOUND & IS/II & 27 & 1947 & $\mathrm{n} / \mathrm{a}$ & & 1.8 & $37 \%$ & Radius & $45 \%$ & $16 \%$ & Low & 3 \\
\hline $\mathrm{B}-203$ & ASMD LKR & IS/II & 51 & 1947 & 36 & & 1.8 & $37 \%$ & Radius & $45 \%$ & $16 \%$ & Low & 4 \\
\hline B-204 & ASMD LKA & IS/II & 50 & 1947 & 37 & & 1.8 & $37 \%$ & Radius & $45 \%$ & $16 \%$ & Low & 4 \\
\hline$B X-101(T)$ & ASMD LKR & IS/II & 43 & 1950 & 22 & & 57.2 & $43 \%$ & Radius & $45 \%$ & $16 \%$ & High & 4 \\
\hline $\mathrm{BX}-102(\mathrm{~T})$ & ASMD LKR & IS/II & 96 & 1950 & 21 & & 57.2 & $43 \%$ & Radius & $45 \%$ & $16 \%$ & High & 5 \\
\hline BX-103 & SOUND & IS/II & 66 & 1950 & $n / a$ & & 57.2 & $43 \%$ & Radius & $45 \%$ & $16 \%$ & High & 3 \\
\hline BX-104 (T) & SOUND & IS/II & 99 & 1950 & $n / a$ & & 57.2 & $43 \%$ & Radius & $45 \%$ & $16 \%$ & High & 3 \\
\hline $\mathrm{BX}-105(\mathrm{~T})$ & SOUND & IS/II & 51 & 1950 & $n / a$ & & 57.2 & $43 \%$ & Radius & $45 \%$ & $16 \%$ & High & 3 \\
\hline$B X-106(T)$ & SOUND & $\mid \mathrm{PI}$ & 46 & 1950 & $\mathrm{n} / \mathrm{a}$ & & 57.2 & $43 \%$ & Radius & $45 \%$ & $16 \%$ & High & 3 \\
\hline$B X-107$ & SOUND & IS/PI & 345 & 1950 & $\mathrm{n} / \mathrm{a}$ & & 26.4 & $60 \%$ & Radius & $45 \%$ & $16 \%$ & Med & 3 \\
\hline$B X-108$ & ASMD LKR & IS/II & 26 & 1950 & 24 & & 26.4 & $60 \%$ & Radius & $45 \%$ & $16 \%$ & Med & 4 \\
\hline$B X-109$ & SOUND & IS/PI & 193 & 1950 & n/a & & 0 & $39 \%$ & Radius & $45 \%$ & $16 \%$ & Low & 3 \\
\hline$B X-110$ & ASMD LKR & IS/PI & 207 & 1950 & 26 & & 12.4 & $100 \%$ & Radius & $45 \%$ & $16 \%$ & Low & 4 \\
\hline$B X-111$ & ASMD LKR & $/ \mathrm{PI}$ & 162 & 1950 & 34 & & 12.4 & $100 \%$ & Radius & $45 \%$ & $16 \%$ & Low & 4 \\
\hline$B X-112$ & SOUND & $|S / P|$ & 165 & 1950 & $\mathrm{n} / \mathrm{a}$ & & 11 & $25 \%$ & Radius & $45 \%$ & $16 \%$ & Low & 3 \\
\hline
\end{tabular}




\begin{tabular}{|c|c|c|c|c|c|c|c|c|c|c|c|c|c|}
\hline Tank & 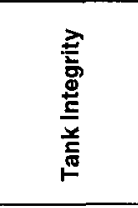 & 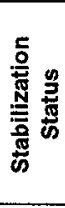 & 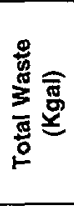 & 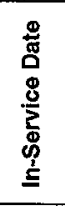 & 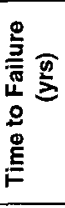 & 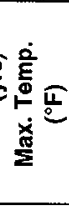 & 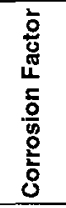 & 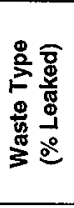 & 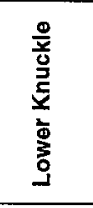 & 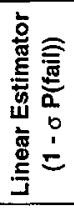 & 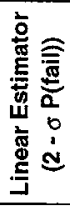 & 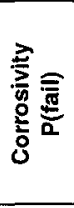 & 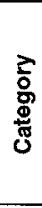 \\
\hline BY-101 & SOUND & IS/II & 387 & 1951 & Na & & 45.5 & $50 \%$ & Radius & $45 \%$ & $16 \%$ & Med & 3 \\
\hline BY -102 & SOUND & $|P|$ & 341 & 1951 & $n / a$ & & 67.7 & $0 \%$ & Radius & $45 \%$ & $16 \%$ & High & 2 \\
\hline $\mathrm{BY}-103(\mathrm{~T}, \mathrm{Fe})$ & ASMD LKR & $/ P I$ & 400 & 1951 & 22 & 81 & 45.5 & $50 \%$ & Radius & $45 \%$ & $16 \%$ & Med & 4 \\
\hline $\mathrm{BY}-104(\mathrm{~T}, \mathrm{Fe})$ & SOUND & IS/II & 406 & 1951 & $\mathrm{n} / \mathrm{a}$ & 125 & 45.5 & $50 \%$ & Radius & $45 \%$ & $16 \%$ & Med & 3 \\
\hline $\mathrm{BY}-105(\mathrm{~T}, \mathrm{Fe})$ & ASMD LKR & $/ \mathrm{Pl}$ & 503 & 1951 & 33 & 118 & 45.5 & $50 \%$ & Radius & $45 \%$ & $16 \%$ & Med & 4 \\
\hline BY-106 & ASMD LKR & IPI & 642 & 1951 & 33 & 122 & 45.5 & $50 \%$ & Radius & $45 \%$ & $16 \%$ & Med & 4 \\
\hline $\mathrm{BY}-107(\mathrm{Fe})$ & ASMD LKR & $|S /|$ & 266 & 1951 & 33 & 95 & 45.5 & $50 \%$ & Radius & $45 \%$ & $16 \%$ & Med & 4 \\
\hline $\mathrm{BY}-108(\mathrm{Fe})$ & ASMD LKR & IS/II & 228 & 1951 & 21 & 108 & 45.5 & $50 \%$ & Radius & $45 \%$ & $16 \%$ & Med & 4 \\
\hline BY-109 & SOUND & $/ \mathrm{PI}$ & 423 & 1951 & $n / a$ & & 67.7 & $0 \%$ & Radius & $45 \%$ & $16 \%$ & High & 2 \\
\hline $\mathrm{BY}-110(\mathrm{Fe})$ & SOUND & IS/II & 398 & 1951 & $\mathrm{n} / \mathrm{a}$ & 116 & 45.5 & $50 \%$ & Radius & $45 \%$ & $16 \%$ & Med & 3 \\
\hline BY-111 (Fe) & SOUND & IS/II & 459 & 1951 & n/a & 87 & 45.5 & $50 \%$ & Radius & $45 \%$ & $16 \%$ & Med & 3 \\
\hline $\mathrm{BY}-112(\mathrm{Fe})$ & SOUND & IS/II & 291 & 1951 & $n / a$ & 90 & 45.5 & $50 \%$ & Radius & $45 \%$ & $16 \%$ & Med & 3 \\
\hline $\mathrm{C}-101(\mathrm{~T})$ & ASMD LKR & $|S / I|$ & 88 & 1953 & 27 & & 57.2 & $43 \%$ & Radius & $45 \%$ & $16 \%$ & High & 4 \\
\hline $\mathrm{C}-102(\mathrm{~T}, \mathrm{O})$ & SOUND & /PI & 423 & 1953 & $\mathrm{n} / \mathrm{a}$ & 86 & 24.5 & $0 \%$ & Radius & $45 \%$ & $16 \%$ & Low & 1 \\
\hline C-103 $(T, O)$ & SOUND & /PI & 195 & 1953 & $\mathrm{n} / \mathrm{a}$ & 120 & 24.5 & $0 \%$ & Radius & $45 \%$ & $16 \%$ & Low & 1 \\
\hline C-104 (T) & SOUND & $\mid \mathrm{S} / \mathrm{I}$ & 295 & 1953 & $\mathrm{n} / \mathrm{a}$ & & 0 & $39 \%$ & Radius & $45 \%$ & $16 \%$ & Low & 3 \\
\hline $\mathrm{C}-105(\mathrm{Sn}, \mathrm{T})$ & SOUND & $/ \mathrm{PI}$ & 135 & 1953 & $\mathrm{n} / \mathrm{a}$ & & 24.5 & $0 \%$ & Radius & $45 \%$ & $16 \%$ & Low & 1 \\
\hline C-106 (T, HL) & SOUND & $/ \mathrm{Pl}$ & 229 & 1953 & na & 154 & 24.5 & $0 \%$ & Radius & $45 \%$ & $16 \%$ & Low & 2 \\
\hline $\mathrm{C}-107(\mathrm{~T})$ & SOUND & $/ \mathrm{PI}$ & 275 & 1953 & na & & 0.85 & $39 \%$ & Radius & $45 \%$ & $16 \%$ & Low & 3 \\
\hline $\mathrm{C}-108(\mathrm{~T}, \mathrm{Fe})$ & SOUND & IS/II & 66 & 1953 & $\mathrm{n} / \mathrm{a}$ & 78 & 35.8 & $40 \%$ & Radius & $45 \%$ & $16 \%$ & Med & 3 \\
\hline $\mathrm{C}-109(\mathrm{Fe})$ & SOUND & IS/II & 66 & 1953 & $\mathrm{n} / \mathrm{a}$ & 81 & 35.8 & $40 \%$ & Radius & $45 \%$ & $16 \%$ & Med & 3 \\
\hline $\mathrm{C}-110(\mathrm{~T})$ & ASMD LKR & $\mid \mathrm{Pl}$ & 187 & 1953 & 31 & & 26.4 & $60 \%$ & Radius & $45 \%$ & $16 \%$ & Med & 4 \\
\hline$C-111(T)$ & ASMD LKR & IS/II & 57 & 1953 & 15 & 77 & 35.8 & $40 \%$ & Radius & $45 \%$ & $16 \%$ & Med & 4 \\
\hline$C=112(T)$ & SOUND & IS/PI & 104 & 1953 & $\mathrm{n} / \mathrm{a}$ & 84 & 35.8 & $40 \%$ & Radius & $45 \%$ & $16 \%$ & Med & 3 \\
\hline $\mathrm{C}-201$ & ASMD LKR & IS/II & 2 & 1953 & 35 & & 1.59 & $100 \%$ & Radius & $45 \%$ & $16 \%$ & Low & 4 \\
\hline C-202 & ASMD LKR & IS/II & 1 & 1953 & 35 & & 1.59 & $100 \%$ & Radius & $45 \%$ & $16 \%$ & Low & 4 \\
\hline$C-203$ & ASMD LKR & $|S /| \mid$ & 5 & 1953 & 31 & & 1.59 & $100 \%$ & Radius & $45 \%$ & $16 \%$ & Low & 4 \\
\hline C-204 & ASMD LKR & IS/II & 3 & 1953 & 35 & & 1.59 & $100 \%$ & Radius & $45 \%$ & $16 \%$ & Low & 4 \\
\hline $\mathrm{S}-101(\mathrm{~T})$ & SOUND & /PI & 427 & 1953 & $\mathrm{~N} / \mathrm{a}$ & & 13.7 & $14 \%$ & Radius & $45 \%$ & $16 \%$ & Low & 2 \\
\hline S-102 $(H, O)$ & SOUND & $/ \mathrm{PI}$ & 549 & 1953 & $\mathrm{n} / \mathrm{a}$ & 110 & 13.7 & $14 \%$ & Radius & $45 \%$ & $16 \%$ & Low & 2 \\
\hline$S-103$ & SOUND & IPI & 248 & 1953 & n/a & & 13.7 & $14 \%$ & Radius & $45 \%$ & $16 \%$ & Low & 2 \\
\hline S-104 (T) & ASMD LKR & IS/II & 294 & 1953 & 15 & & 6.53 & $100 \%$ & Radius & $45 \%$ & $16 \%$ & Low & 4 \\
\hline S-105 & SOUND & $|S /| \mid$ & 456 & 1953 & $\mathrm{n} / \mathrm{a}$ & & 13.7 & $14 \%$ & Radius & $45 \%$ & $16 \%$ & Low & 2 \\
\hline S-106 & SOUND & $/ \mathrm{PI}$ & 479 & 1953 & $\mathrm{Na}$ & & 13.7 & $14 \%$ & Radius & $45 \%$ & $16 \%$ & Low & 2 \\
\hline S-107 (T) & SOUND & $/ \mathrm{PI}$ & 376 & 1953 & $\mathrm{n} / \mathrm{a}$ & & 13.7 & $14 \%$ & Radius & $45 \%$ & $16 \%$ & Low & 2 \\
\hline S-108 & SOUND & $/ \mathrm{PI}$ & 604 & 1953 & $\mathrm{~N} / \mathrm{a}$ & & 13.7 & $14 \%$ & Radius & $45 \%$ & $16 \%$ & Low & 2 \\
\hline S-109 & SOUND & $/ \mathrm{Pl}$ & 568 & 1953 & $\mathrm{Na}$ & & 13.7 & $14 \%$ & Radius & $45 \%$ & $16 \%$ & Low & 2 \\
\hline
\end{tabular}




\begin{tabular}{|c|c|c|c|c|c|c|c|c|c|c|c|c|c|}
\hline Tank & 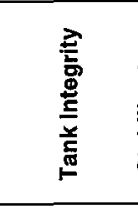 & 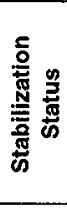 & 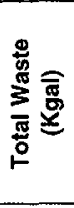 & 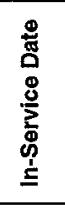 & 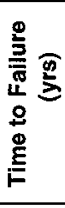 & 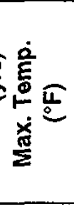 & 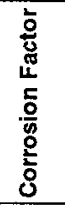 & 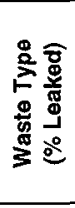 & 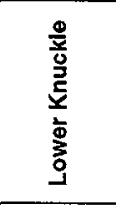 & 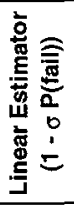 & 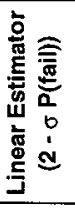 & $\begin{array}{l}\frac{2}{5} \\
\frac{1}{5} \\
\frac{5}{0}\end{array}$ & 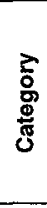 \\
\hline$S-110$ & SOUND & $/ \mathrm{PI}$ & 390 & 1953 & na & & 13.7 & $14 \%$ & Radius & $45 \%$ & $16 \%$ & Low & 2 \\
\hline $\mathrm{S}-111(\mathrm{H}, \mathrm{O})$ & SOUND & $/ \mathrm{PI}$ & 596 & 1953 & $\mathrm{n} / \mathrm{a}$ & 94 & 13.7 & $14 \%$ & Radius & $45 \%$ & $16 \%$ & Low & 2 \\
\hline $\mathrm{S}-112(\mathrm{~T}, \mathrm{H})$ & SOUND & $/ \mathrm{PI}$ & 523 & 1953 & $\mathrm{n} / \mathrm{a}$ & 87 & 13.7 & $14 \%$ & Radius & $45 \%$ & $16 \%$ & Low & 2 \\
\hline$S X-101(T)$ & SOUND & $/ \mathrm{PI}$ & 456 & 1960 & $\mathrm{n} / \mathrm{a}$ & 137 & 13.7 & $14 \%$ & Butt-weld & $43 \%$ & $15 \%$ & Low & 2 \\
\hline SX-102(H) & SOUND & $/ \mathrm{PI}$ & 543 & 1960 & $\mathrm{n} / \mathrm{a}$ & 150 & 13.7 & $14 \%$ & Butt-weld & $43 \%$ & $15 \%$ & Low & 2 \\
\hline$S X-103(T, H, O)$ & SOUND & $/ \mathrm{Pl}$ & 652 & 1960 & $\mathrm{n} / \mathrm{a}$ & 172 & 4.87 & $39 \%$ & Butt-weld & $43 \%$ & $15 \%$ & Low & 3 \\
\hline$S X-104(T)$ & ASMD LKR & $/ \mathrm{PI}$ & 614 & 1960 & 28 & 166 & 13.7 & $14 \%$ & Butt-weld & $43 \%$ & $15 \%$ & Low & 4 \\
\hline SX-105 (T, H) & SOUND & $/ \mathrm{PI}$ & 683 & 1960 & n/a & 181 & 13.7 & $14 \%$ & Butt-weld & $43 \%$ & $15 \%$ & Low & 2 \\
\hline$S X-106(T, H)$ & SOUND & /PI & 538 & 1960 & $\mathrm{n} / \mathrm{a}$ & 112 & 13.7 & $14 \%$ & Butt-weld & $43 \%$ & $15 \%$ & Low & 2 \\
\hline$S X-107(T)$ & ASMD LKR & IS/II & 104 & 1960 & 4 & 170 & 6.53 & $100 \%$ & Butt-weld & $43 \%$ & $15 \%$ & Low & 4 \\
\hline$S X-108(T)$ & ASMD LKR & $1 S / 1$ & 87 & 1960 & 2 & 197 & 6.53 & $100 \%$ & Butt-weld & $43 \%$ & $15 \%$ & Low & 4 \\
\hline$S X-109(T)$ & ASMD LKR & IS/II & 250 & 1960 & 5 & 151 & 6.53 & $100 \%$ & Butt-weld & $43 \%$ & $15 \%$ & Low & 4 \\
\hline$s X-110(T)$ & ASMD LKR & $1 S / 11$ & 62 & 1960 & 16 & 170 & 6.07 & $100 \%$ & Butt-weld & $43 \%$ & $15 \%$ & Low & 4 \\
\hline$S X-111(T)$ & ASMD LKR & $1 S / 11$ & 125 & 1960 & 14 & 194 & 6.07 & $100 \%$ & Butt-weld & $43 \%$ & $15 \%$ & Low & 4 \\
\hline$s X-112(T)$ & ASMD LKR & IS/II & 92 & 1960 & 9 & 155 & 6.53 & $100 \%$ & Butt-weld & $43 \%$ & $15 \%$ & Low & 4 \\
\hline$S X-113(T)$ & ASMD LKR & IS/II & 26 & 1960 & 2 & & 4.57 & $100 \%$ & Butt-weld & $43 \%$ & $15 \%$ & Low & 4 \\
\hline$S X-114(T)$ & ASMD LKR & IS/II & 181 & 1960 & 12 & 188 & 6.07 & $100 \%$ & Butt-weld & $43 \%$ & $15 \%$ & Low & 4 \\
\hline$S X-115(T)$ & ASMD LKR & $|S /| \mid$ & 12 & 1960 & 5 & & 6.53 & $100 \%$ & Butt-weld & $43 \%$ & $15 \%$ & Low & 5 \\
\hline $\mathrm{T}-101(\mathrm{~T})$ & ASMD LKR & IS/PI & 102 & 1947 & 45 & & 0.1 & $67 \%$ & Radius & $45 \%$ & $16 \%$ & Low & 4 \\
\hline $\mathrm{T}-102$ & SOUND & $|S /| \mid$ & 32 & 1947 & n/a & & 0.1 & $67 \%$ & Radius & $45 \%$ & $16 \%$ & Low & 3 \\
\hline$T-103$ & ASMD LKR & $|S /| \mid$ & 27 & 1947 & 27 & & 0.1 & $67 \%$ & Radius & $45 \%$ & $16 \%$ & Low & 4 \\
\hline$T-104$ & SOUND & $/ \mathrm{PI}$ & 445 & 1947 & $n / a$ & & 2.75 & $39 \%$ & Radius & $45 \%$ & $16 \%$ & Low & 3 \\
\hline$T-105(T)$ & SOUND & IS/II & 98 & 1947 & $\mathrm{n} / \mathrm{a}$ & & 1.94 & $50 \%$ & Radius & $45 \%$ & $16 \%$ & Low & 3 \\
\hline $\mathrm{T}-106(\mathrm{~T})$ & ASMD LKR & IS/II & 21 & 1947 & 26 & & 1.94 & $50 \%$ & Radius & $45 \%$ & $16 \%$ & Low & 5 \\
\hline$T-107$ & ASMD LKR & $/ \mathrm{PI}$ & 180 & 1947 & 37 & 70 & 35.8 & $40 \%$ & Radius & $45 \%$ & $16 \%$ & Med & 4 \\
\hline$T-108$ & ASMD LKR & IS/II & 44 & 1947 & 27 & & 26.4 & $60 \%$ & Radius & $45 \%$ & $16 \%$ & Med & 4 \\
\hline $\mathrm{T}-109$ & ASMD LKR & IS/II & 58 & 1947 & 27 & & 0 & $39 \%$ & Radius & $45 \%$ & $16 \%$ & Low & 4 \\
\hline $\mathrm{T}-110(\mathrm{~T}, \mathrm{H})$ & SOUND & $/ \mathrm{PI}$ & 379 & 1947 & $n / a$ & 66 & 4.04 & $33 \%$ & Radius & $45 \%$ & $16 \%$ & Low & 3 \\
\hline $\mathrm{T}-111$ & ASMD LKR & $/ \mathrm{PI}$ & 446 & 1947 & 32 & 67 & 4.04 & $33 \%$ & Radius & $45 \%$ & $16 \%$ & Low & 4 \\
\hline$T-112(T)$ & SOUND & $1 S / 11$ & 67 & 1947 & $\mathrm{n} / \mathrm{a}$ & & 4.04 & $33 \%$ & Radius & $45 \%$ & $16 \%$ & Low & 3 \\
\hline T-201 & SOUND & {$[S /]$} & 29 & 1947 & Na & & 1.8 & $37 \%$ & Radius & $45 \%$ & $16 \%$ & Low & 3 \\
\hline $\mathrm{T}-202$ & SOUND & IS/II & 21 & 1947 & $\mathrm{n} / \mathrm{a}$ & & 1.8 & $37 \%$ & Radius & $45 \%$ & $16 \%$ & Low & 3 \\
\hline T-203 & SOUND & IS/II & 35 & 1947 & $\mathrm{n} / \mathrm{a}$ & & 1.8 & $37 \%$ & Radius & $45 \%$ & $16 \%$ & Low & 3 \\
\hline T-204 & SOUND & IS/II & 38 & 1947 & $\mathrm{n} / \mathrm{a}$ & & 1.8 & $37 \%$ & Radius & $45 \%$ & $16 \%$ & Low & 3 \\
\hline TX-101 & SOUND & $|S / 1|$ & 87 & 1951 & $\mathbf{n} / \mathbf{a}$ & & 0 & $39 \%$ & Radius & $45 \%$ & $16 \%$ & Low & 3 \\
\hline$T X-102$ & SOUND & IS/II & 217 & 1951 & Na & & 13.7 & $14 \%$ & Radius & $45 \%$ & $16 \%$ & Low & 2 \\
\hline$T X-103$ & SOUND & $|S / I|$ & 157 & 1951 & $\mathrm{Na}$ & & 0 & $39 \%$ & Radius & $45 \%$ & $16 \%$ & Low & 3 \\
\hline TX-104 & SOUND & $|S /| \mid$ & 65 & 1951 & $\mathrm{na}$ & & 13.7 & $14 \%$ & Radius & $45 \%$ & $16 \%$ & Low & 2 \\
\hline
\end{tabular}




\begin{tabular}{|c|c|c|c|c|c|c|c|c|c|c|c|c|c|}
\hline Tank & 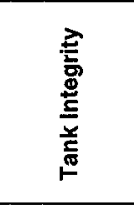 & 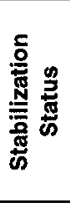 & 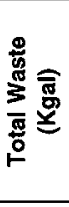 & 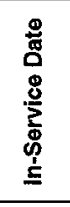 & 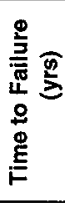 & 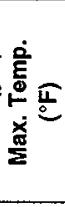 & 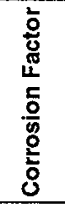 & 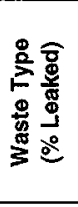 & 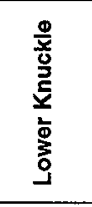 & 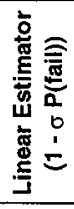 & 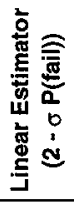 & 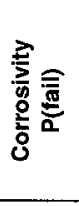 & 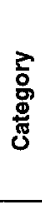 \\
\hline TX-105 (O) & ASMD LKR & IS/II & 609 & 1951 & 26 & 99 & 13.7 & $14 \%$ & Radius & $45 \%$ & $16 \%$ & Low & 4 \\
\hline TX-106 & SOUND & IS/II & 453 & 1951 & $n / a$ & & 13.7 & $14 \%$ & Radius & $45 \%$ & $16 \%$ & Low & 3 \\
\hline TX-107 & ASMD LKR & IS/II & 36 & 1951 & 33 & & 13.7 & $14 \%$ & Radius & $45 \%$ & $16 \%$ & Low & 4 \\
\hline TX-108 & SOUND & IS/I & 134 & 1951 & $n / a$ & & 45.7 & $0 \%$ & Radius & $45 \%$ & $16 \%$ & Med & 1 \\
\hline TX-109 (T) & SOUND & $|S /| \mid$ & 384 & 1951 & $\mathrm{n} / \mathrm{a}$ & & 22 & $75 \%$ & Radius & $45 \%$ & $16 \%$ & Low & 3 \\
\hline TX-110 & ASMD LKR & $|S / I|$ & 462 & 1951 & 26 & & 22 & $75 \%$ & Radius & $45 \%$ & $16 \%$ & Low & 4 \\
\hline$T X-111$ & SOUND & $|S /| \mid$ & 370 & 1951 & $\mathrm{n} / \mathrm{a}$ & & 22 & $75 \%$ & Radius & $45 \%$ & $16 \%$ & Low & 3 \\
\hline TX-112 & SOUND & IS/II & 649 & 1951 & $\mathrm{n} / \mathrm{a}$ & & 0 & $39 \%$ & Radius & $45 \%$ & $16 \%$ & Low & 3 \\
\hline$T X-113$ & ASMD LKR & $1 S / \mid 1$ & 607 & 1951 & 23 & & 22 & $75 \%$ & Radius & $45 \%$ & $16 \%$ & Low & 4 \\
\hline TX-114 & ASMD LKR & $1 S / I$ & 535 & 1951 & 23 & & 22 & $75 \%$ & Radius & $45 \%$ & $16 \%$ & Low & 4 \\
\hline TX-115 & ASMD LKR & IS/II & 640 & 1951 & 26 & & 23.2 & $20 \%$ & Radius & $45 \%$ & $16 \%$ & Low & 4 \\
\hline TX-116 & ASMD LKR & $\mid \mathrm{S} / \mathrm{I}$ & 631 & 1951 & 26 & & 22 & $75 \%$ & Radius & $45 \%$ & $16 \%$ & Low & 4 \\
\hline TX-117 & ASMD LKR & IS/II & 626 & 1951 & 26 & & 22 & $75 \%$ & Radius & $45 \%$ & $16 \%$ & Low & 4 \\
\hline $\mathrm{TX}-118(\mathrm{~T})$ & SOUND & IS/II & 347 & 1951 & $n / a$ & 77 & 45.7 & $0 \%$ & Radius & $45 \%$ & $16 \%$ & Med & 1 \\
\hline TY-101 (T) & ASMD LKR & IS/II & 118 & 1953 & 20 & 65 & 0 & $39 \%$ & Radius & $45 \%$ & $16 \%$ & Low & 4 \\
\hline TY-102 & SOUND & IS/II & 64 & 1953 & $n / a$ & & 22 & $75 \%$ & Radius & $45 \%$ & $16 \%$ & Low & 3 \\
\hline$T Y-103(T)$ & ASMD LKR & IS/II & 162 & 1953 & 20 & 70 & 58 & $100 \%$ & Radius & $45 \%$ & $16 \%$ & High & 4 \\
\hline TY-104 (O) & ASMD LKR & $|S /| \mid$ & 46 & 1953 & 28 & 71 & 58 & $100 \%$ & Radius & $45 \%$ & $16 \%$ & High & 4 \\
\hline TY-105 & ASMD LKR & IS/II & 231 & 1953 & 7 & & 81.7 & $100 \%$ & Radius & $45 \%$ & $16 \%$ & High & 4 \\
\hline TY-106 & ASMD LKR & $\mid S / I I$ & 17 & 1953 & 6 & & 81.7 & $100 \%$ & Radius & $45 \%$ & $16 \%$ & High & 4 \\
\hline U-101 & ASMD LKR & IS/II & 25 & 1949 & 10 & & 6.53 & $100 \%$ & Radius & $45 \%$ & $16 \%$ & Low & 4 \\
\hline U-102 & SOUND & $/ \mathrm{PI}$ & 374 & 1949 & $n / a$ & & 23.2 & $20 \%$ & Radius & $45 \%$ & $16 \%$ & Low & 3 \\
\hline $\mathrm{U}-103(\mathrm{H}, \mathrm{O})$ & SOUND & $/ \mathrm{PI}$ & 468 & 1949 & $\mathrm{r} / \mathrm{a}$ & 89 & 23.2 & $20 \%$ & Radius & $45 \%$ & $16 \%$ & Low & 3 \\
\hline$U-104$ & ASMD LKR & IS/II & 122 & 1949 & 12 & & 4.57 & $100 \%$ & Radius & $45 \%$ & $16 \%$ & Low & 5 \\
\hline $\mathrm{U}-105(\mathrm{H}, \mathrm{O})$ & SOUND & $/ \mathrm{PI}$ & 418 & 1949 & $\mathrm{n} / \mathrm{a}$ & 92 & 21.2 & $0 \%$ & Radius & $45 \%$ & $16 \%$ & Low & 1 \\
\hline U-106 (O) & SOUND & $/ \mathrm{PI}$ & 226 & 1949 & na & 82 & 23.2 & $20 \%$ & Radius & $45 \%$ & $16 \%$ & Low & 3 \\
\hline $\mathrm{U}-107(\mathrm{~T}, \mathrm{O})$ & SOUND & $/ \mathrm{Pl}$ & 406 & 1949 & $n / a$ & 83 & 21.2 & $0 \%$ & Radius & $45 \%$ & $16 \%$ & Low & 1 \\
\hline $\mathrm{U}-108(\mathrm{H})$ & SOUND & $\mid \mathrm{PI}$ & 468 & 1949 & $\mathrm{n} / \mathrm{a}$ & 89 & 21.2 & $0 \%$ & Radius & $45 \%$ & $16 \%$ & Low & 1 \\
\hline U-109 (H) & SOUND & /PI & 463 & 1949 & n/a & 87 & 21.2 & $0 \%$ & Radius & $45 \%$ & $16 \%$ & Low & 1 \\
\hline $\mathrm{U}-110(\mathrm{~T})$ & ASMD LKR & $|S / P|$ & 186 & 1949 & 26 & & 0 & $39 \%$ & Radius & $45 \%$ & $16 \%$ & Low & 4 \\
\hline$U-111(0)$ & SOUND & /PI & 329 & 1949 & $\mathrm{n} / \mathrm{a}$ & 82 & 23.2 & $20 \%$ & Radius & $45 \%$ & $16 \%$ & Low & 3 \\
\hline U-112 & ASMD LKR & $|S /| \mid$ & 49 & 1949 & 31 & & 0 & $39 \%$ & Radius & $45 \%$ & $16 \%$ & Low & 4 \\
\hline U-201 & SOUND & $|S /| \mid$ & 5 & 1949 & $\mathrm{Na}$ & & 0.05 & $0 \%$ & Radius & $45 \%$ & $16 \%$ & Low & 1 \\
\hline U-202 (O) & SOUND & IS/II & 5 & 1949 & n/a & & 0.05 & $0 \%$ & Radius & $45 \%$ & $16 \%$ & Low & 1 \\
\hline U-203 (O) & SOUND & IS/II & 3 & 1949 & $\mathrm{n} / \mathrm{a}$ & 66 & 0.05 & $0 \%$ & Radius & $45 \%$ & $16 \%$ & Low & 1 \\
\hline U-204 (O) & SOUND & IS/II & 3 & 1949 & $n / a$ & 63 & 0 & $39 \%$ & Radius & $45 \%$ & $16 \%$ & Low & 3 \\
\hline
\end{tabular}


Appendix C

SST Waste Tank Volumes

Available Liquid Level Data 


\begin{tabular}{|c|c|c|c|c|c|c|c|c|c|c|c|}
\hline Tank & 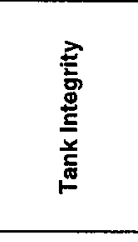 & 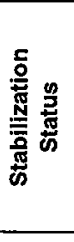 & $\begin{array}{l}\frac{9}{5} \\
\frac{\pi}{3} \\
\frac{\sqrt{\pi}}{0} \\
\frac{0}{5}\end{array}$ & 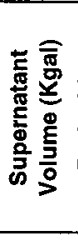 & 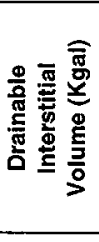 & 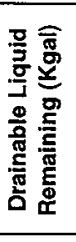 & 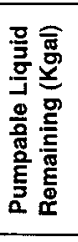 & 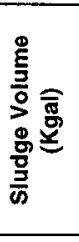 & 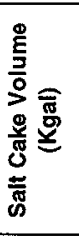 & 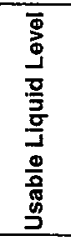 & 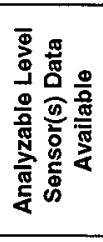 \\
\hline $241-A-101$ & SOUND & $/ \mathrm{PI}$ & 953 & 0 & 464 & 464 & 441 & 3 & 950 & YES & ILL \\
\hline $241-A-102$ & SOUND & $|S / P|$ & 41 & 4 & 2 & 6 & 0 & 15 & 22 & NO & NONE $^{2}$ \\
\hline $241-A-103$ & ASMD LKR & $|S /| \mid$ & 371 & 5 & 15 & 20 & 0 & 366 & 0 & YES & ENRAF \\
\hline $241-A-104$ & ASMD LKR & IS/II & 28 & 0 & 0 & 0 & 0 & 28 & 0 & NO & NONE $^{3,4}$ \\
\hline $241-A-105$ & ASMD LKR & IS/II & 19 & 0 & 4 & 4 & 0 & 19 & 0 & NO & NONE $^{3}$ \\
\hline $241-A-106$ & SOUND & IS/II & 125 & 0 & 7 & 7 & 0 & 125 & 0 & YES & NONE $^{2}$ \\
\hline $241-A X-101$ & SOUND & $/ \mathrm{PI}$ & 748 & 0 & 359 & 359 & 338 & 3 & 745 & YES & NONE $^{2}$ \\
\hline $241-A X-102$ & ASMD LKR & IS/II & 39 & 3 & 14 & 17 & 3 & 7 & 29 & YES & $M T^{7}$ \\
\hline $241-A X-103$ & SOUND & IS/II & 112 & 0 & 36 & 36 & 3 & 2 & 110 & YES & NONE ${ }^{5}$ \\
\hline $241-A X-104$ & ASMD LKR & IS/II & 7 & 0 & 0 & 0 & 0 & 7 & 0 & NO & ENRAF \\
\hline 241-B-101 & ASMD LKR & $|S /| \mid$ & 113 & 0 & 6 & 6 & 0 & 113 & 0 & YES & NONE $^{8}$ \\
\hline 241-B-102 & SOUND & IS/II & 32 & 4 & 0 & 4 & 0 & 18 & 10 & YES & ENRAF \\
\hline 241-B-103 & ASMD LKR & IS/II & 59 & 0 & 0 & 0 & 0 & 59 & 0 & NO & NONE \\
\hline 241-B-104 & SOUND & IS/II & 371 & 1 & 46 & 47 & 40 & 301 & 69 & YES & ILL \\
\hline 241-B-105 & ASMD LKR & IS/II & 306 & 0 & 23 & 23 & 0 & 40 & 266 & YES & ILL, MT \\
\hline $241-B-106$ & SOUND & IS/II & 117 & 1 & 6 & 7 & 0 & 116 & 0 & YES & NONE $^{8}$ \\
\hline 241-B-107 & ASMD LKR & $|S /|$ & 165 & 1 & 12 & 13 & 7 & 164 & 0 & YES & $N^{N O N E}{ }^{8}$ \\
\hline 241-B-108 & SOUND & $|\mathrm{S} /| \mid$ & 94 & 0 & 4 & 4 & 0 & 94 & 0 & NO & NONE \\
\hline 241-B-109 & SOUND & {$[S / I]$} & 127 & 0 & 8 & 8 & 0 & 127 & 0 & YES & NONE $^{8}$ \\
\hline $241-B-110$ & ASMD LKR & $|S /| \mid$ & 246 & 1 & 22 & 23 & 17 & 245 & 0 & YES & ILLL, MT \\
\hline $241-B-111$ & ASMD LKR & IS/II & 237 & 1 & 21 & 22 & 16 & 236 & 0 & YES & ILL, FIC \\
\hline $241-B-112$ & ASMD LKR & $I S / I I$ & 33 & 3 & 0 & 3 & 0 & 30 & 0 & YES & ENRAF \\
\hline 241-B-201 & ASMD LKR & IS/II & 29 & 1 & 3 & 4 & 0 & 28 & 0 & NO & NONE \\
\hline 241-B-202 & SOUND & IS/II & 27 & 0 & 3 & 3 & 0 & 27 & 0 & NO & NONE \\
\hline $241-\mathrm{B}-203$ & ASMD LKR & $1 S / 11$ & 51 & 1 & 5 & 6 & 0 & 50 & 0 & YES & NONE $^{8}$ \\
\hline 241-B-204 & ASMD LKR & IS/II & 50 & 1 & 5 & 6 & 0 & 49 & 0 & YES & NONE $^{8}$ \\
\hline $241-B X-101$ & ASMD LKR & $|S / I|$ & 43 & 1 & 0 & 1 & 0 & 42 & 0 & NO & NONE \\
\hline $241-B X-102$ & ASMD LKR & IS/II & 96 & 0 & 4 & 4 & 0 & 96 & 0 & NO & NONE \\
\hline 241-BX-103 & SOUND & IS/II & 68 & 6 & 0 & 6 & 0 & 62 & 0 & YES & ENRAF \\
\hline $241-B X-104$ & SOUND & IS/II & 99 & 3 & 30 & 33 & 27 & 96 & 0 & YES & ENRAF \\
\hline $241-B X-105$ & SOUND & IS/II & 51 & 5 & 6 & 11 & 4 & 43 & 3 & YES & ENRAF \\
\hline $241-B X-106$ & SOUND & $/ \mathrm{PI}$ & 38 & 0 & 0 & 0 & 0 & 38 & 0 & NO & NONE \\
\hline
\end{tabular}




\begin{tabular}{|c|c|c|c|c|c|c|c|c|c|c|c|}
\hline Tank & 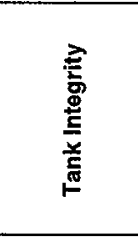 & 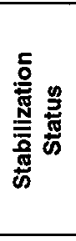 & 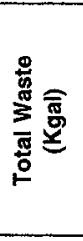 & 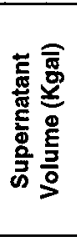 & 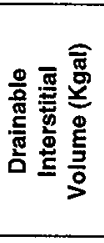 & 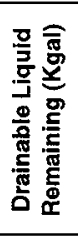 & 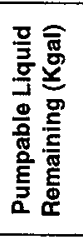 & 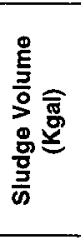 & 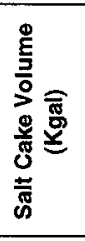 & 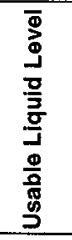 & 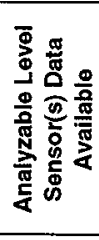 \\
\hline $241-B X-107$ & SOUND & IS/PI & 345 & 1 & 29 & 30 & 23 & 344 & 0 & YES & NONE $^{8}$ \\
\hline $241-B X-108$ & 3 ASMD LKR & IS/II & 26 & 0 & 1 & 1 & 0 & 26 & 0 & NO & NONE \\
\hline $241-B X-109$ & SOUND & IS/PI & 193 & 0 & 13 & 13 & 8 & 193 & 0 & YES & NONE ${ }^{8}$ \\
\hline $241-B X-110$ & ASMD LKR & $|S / P|$ & 207 & 3 & 16 & 19 & 13 & 195 & 9 & YES & ENRAF \\
\hline $241-B X-111$ & ASMD LKR & $/ P I$ & 162 & 1 & 1 & 3 & 1 & 52 & 109 & NO & NONE \\
\hline $241-B X-112$ & SOUND & $\mid \mathrm{S} / \mathrm{PI}$ & 165 & 1 & 7 & 8 & 2 & 164 & 0 & YES & NONE $^{8}$ \\
\hline 241-BY-101 & SOUND & $|S /| \mid$ & 387 & 0 & 5 & 5 & 0 & 109 & 278 & YES & ILL \\
\hline $241-B Y-102$ & SOUND & $\mid \mathrm{PI}$ & 277 & 0 & 11 & 11 & 0 & 0 & 277 & YES & ILLL \\
\hline $241-B Y-103$ & ASMD LKR & $/ P I$ & 414 & 0 & 38 & 38 & 32 & 5 & 409 & YES & ILL \\
\hline $241-B Y-104$ & SOUND & IS/II & 406 & 0 & 18 & 18 & 0 & 40 & 366 & YES & ILL \\
\hline 241-BY-105 & ASMD LKR & $/ \mathrm{PI}$ & 503 & 0 & 228 & 228 & 216 & 44 & 459 & YES & ILL. \\
\hline 241-BY-106 & ASMD LKR & $/ \mathrm{PI}$ & 642 & 0 & 200 & 200 & 163 & 95 & 547 & YES & ILL. \\
\hline $241-B Y-107$ & ASMD LKR & IS/II & 266 & 0 & 25 & 25 & 0 & 60 & 206 & YES & ILLL \\
\hline $241-B Y-108$ & ASMD LKR & IS/II & 228 & 0 & 9 & 9 & 0 & 154 & 74 & YES & NONE $^{8}$ \\
\hline $241-B Y-109$ & SOUND & $/ \mathrm{PI}$ & 290 & 0 & 37 & 37 & 20 & 57 & 233 & YES & ILL \\
\hline $241-B Y-110$ & SOUND & IS/II & 398 & 0 & 9 & 9 & 0 & 103 & 295 & YES & ILL \\
\hline $241-B Y-111$ & SOUND & IS/II & 459 & 0 & 0 & 0 & 0 & 21 & 438 & NO & NONE \\
\hline $241-B Y-112$ & SOUND & IS/II & 291 & 0 & 8 & 8 & 0 & 5 & 286 & YES & ILL. \\
\hline 241-C-101 & ASMD LKR & IS/II & 88 & 0 & 3 & 3 & 0 & 88 & 0 & No & NONE \\
\hline 241-C-102 & SOUND & $/ \mathrm{PI}$ & 316 & 0 & 46.7 & 30 & 17 & 316 & 0 & YES & NONE $^{B}$ \\
\hline $241-C-103$ & SOUND & $/ \mathrm{PI}$ & 195 & 133 & 0 & 135 & 133 & 62 & 0 & YES & ENRAF \\
\hline 241-C-104 & SOUND & IS/II & 295 & 0 & 0 & 11 & 5 & 295 & 0 & NO & NONE \\
\hline $241-C-105$ & SOUND & $/ \mathrm{PI}$ & 134 & 2 & 0 & 32 & 9 & 132 & 0 & NO & NONE \\
\hline $241-\mathrm{C}-106$ & SOUND & $\mid \mathrm{PI}$ & 229 & 32 & 0 & 62 & 52 & 197 & 0 & YES & ENRAF \\
\hline $241-C-107$ & SOUND & $/ \mathrm{PI}$ & 237 & 0 & 40.8 & 24 & 15 & 237 & 0 & YES & NONE $^{8}$ \\
\hline $241-C-108$ & SOUND & $|S /| \mid$ & 66 & 0 & 0 & 0 & 0 & 66 & 0 & NO & NONE \\
\hline 241-C-109 & SOUND & IS/II & 66 & 4 & 0 & 4 & 0 & 62 & 0 & NO & NONE \\
\hline $241-C-110$ & ASMD LKR & /PI & 178 & 1 & 28 & 29 & 15 & 177 & 0 & YES & $N_{O N E}{ }^{8}$ \\
\hline $241-\mathrm{C}-111$ & ASMD LKR & IS/II & 57 & 0 & 0 & 0 & 0 & 57 & 0 & NO & NONE \\
\hline $241-C-112$ & SOUND & $|S / P|$ & 104 & 0 & 0 & 32 & 26 & 104 & 0 & NO & NONE \\
\hline $241-C-201$ & ASMD LKR & IS/II & 2 & 0 & 0 & 0 & 0 & 2 & 0 & NO & NONE \\
\hline $241-C-202$ & ASMD LKR & $|S /| \mid$ & 1 & 0 & 0 & 0 & 0 & 1 & 0 & NO & NONE \\
\hline $241-\mathrm{C}-203$ & ASMD LKR & IS/II & 5 & 0 & 0 & 0 & 0 & 5 & 0 & NO & NONE \\
\hline
\end{tabular}


Tank
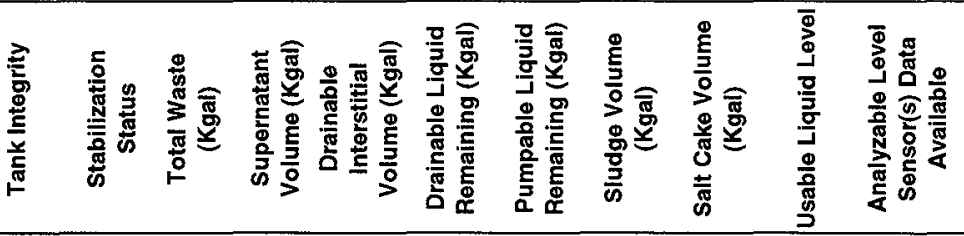

\begin{tabular}{|c|c|c|c|c|c|c|c|c|c|c|c|}
\hline 241-C-204 & ASMD LKR & IS/II & 3 & 0 & 0 & 0 & 0 & 3 & 0 & NO & NONE \\
\hline $241-S-101$ & SOUND & $/ \mathrm{PI}$ & 427 & 12 & 126 & 138 & 127 & 244 & 171 & YES & ENRAF \\
\hline $241-S-102$ & SOUND & $/ \mathrm{PI}$ & 549 & 0 & 262 & 262 & 239 & 4 & 545 & YES & ILL \\
\hline $241-5-103$ & SOUND & $/ \mathrm{PI}$ & 248 & 17 & 101 & 118 & 97 & 10 & 221 & YES & ENRAF \\
\hline $241-S-104$ & ASMD LKR & $\cdot|S /| \mid$ & 294 & 1 & 28 & 29 & 23 & 293 & 0 & YES & ILL \\
\hline $241-S-105$ & SOUND & IS/II & 456 & 0 & 35 & 35 & 13 & 2 & 454 & YES & ILL \\
\hline $241-5-106$ & SOUND & /PI & 479 & 4 & 186 & 190 & 168 & 28 & 447 & YES & ENRAF \\
\hline $241-5-107$ & SOUND & $/ \mathrm{PI}$ & 376 & 14 & 85 & 99 & 88 & 293 & 69 & YES & ENRAF \\
\hline $241-5-108$ & SOUND & $/ \mathrm{PI}$ & 450 & 0 & 4 & 4 & 0 & 4 & 446 & YES & ILL \\
\hline $241-S-109$ & SOUND & $/ \mathrm{PI}$ & 568 & 0 & 141 & 141 & 119 & 13 & 555 & YES & ILL \\
\hline $241-S-110$ & SOUND & $/ \mathrm{PI}$ & 390 & 0 & 30 & 30 & 23 & 131 & 259 & YES & ILL \\
\hline $241-S-111$ & SOUND & $/ \mathrm{PI}$ & 540 & 23 & 195 & 205 & 134 & 139 & 378 & YES & ENRAF \\
\hline $241-S-112$ & SOUND & $/ \mathrm{PI}$ & 523 & 0 & 110 & 110 & 107 & 5 & 517.7 & YES & ILL \\
\hline $241-S X-101$ & SOUND & $/ \mathrm{PI}$ & 456 & 1 & 184 & 185 & 174 & 112 & 343 & YES & ILL \\
\hline $241-S X-102$ & SOUND & $/ \mathrm{PI}$ & 543 & 0 & 226 & 226 & 216 & 117 & 426 & YES & ILL \\
\hline $241-5 X-103$ & SOUND & $/ \mathrm{PI}$ & 652 & 1 & 281 & 282 & 272 & 115 & 536 & YES & ILL. \\
\hline 241-SX-104 & ASMD LKR & $/ \mathrm{PI}$ & 614 & 0 & 201 & 201 & 195 & 136 & 477.9 & YES & ILL \\
\hline $241-S X-105$ & SOUND & /PI & 683 & 0 & 309 & 309 & 299 & 73 & 610 & YES & ILL \\
\hline 241-SX-106 & SOUND & $/ \mathrm{PI}$ & 538 & 61 & 224 & 285 & 264 & 12 & 465 & YES & ENRAF \\
\hline $241-5 x-107$ & ASMD LKR & IS/II & 104 & 0 & 5 & 5 & 0 & 104 & 0 & YES & NONE ${ }^{8}$ \\
\hline 241-SX-108 & ASMD LKR & IS/II & 87 & 0 & 5 & 5 & 0 & 87 & 0 & YES & NONE $^{8}$ \\
\hline $241-5 X-109$ & ASMD LKR & ISIII & 244 & 0 & 48 & 48 & 25 & 0 & 244 & YES & NONE $^{8}$ \\
\hline $241-S X-110$ & ASMD LKR & IS/II & 62 & 0 & 0 & 0 & 0 & 62 & 0 & NO & NONE \\
\hline $241-5 X-111$ & ASMD LKR & IS/II & 125 & 0 & 7 & 7 & 0 & 125 & 0 & YES & NONE $E^{8}$ \\
\hline $241-s X-112$ & ASMD LKR & IS/II & 92 & 0 & 3 & 3 & 0 & 92 & 0 & NO & NONE \\
\hline $241-5 X-113$ & ASMD LKR & IS/II & 26 & 0 & 0 & 0 & 0 & 26 & 0 & No & NONE \\
\hline $241-S X-114$ & ASMD LKR & $|\mathrm{IS} /| \mid$ & 181 & 0 & 14 & 14 & 0 & 181 & 0 & YES & NONE $^{8}$ \\
\hline $241-S X-115$ & ASMD LKR & IS/II & 12 & 0 & 0 & 0 & 0 & 12 & 0 & NO & NONE \\
\hline $241-T-101$ & ASMD LKR & IS/PI & 102 & 1 & 16 & 17 & 0 & 101 & 0 & YES & NONE $^{8}$ \\
\hline $241-T-102$ & SOUND & IS/II & 32 & 13 & 0 & 13 & 13 & 19 & 0 & YES & ENRAF \\
\hline $241-T-103$ & ASMD LKR & $|S /| \mid$ & 27 & 4 & 0 & 4 & 0 & 23 & 0 & NO & NONE $^{6}$ \\
\hline 241-T-104 & SOUND & $/ \mathrm{PI}$ & 343 & 0 & 67 & 67 & 64 & 343 & 0 & YES & ILL \\
\hline
\end{tabular}




\begin{tabular}{|c|c|c|c|c|c|c|c|c|c|c|}
\hline 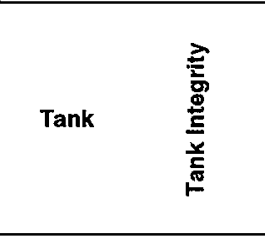 & 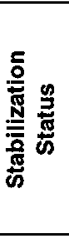 & 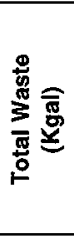 & 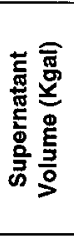 & 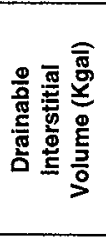 & 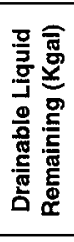 & 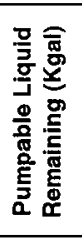 & 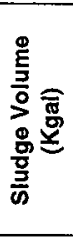 & 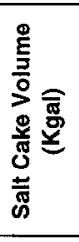 & 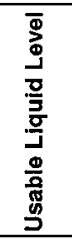 & 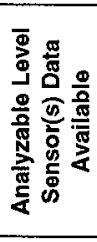 \\
\hline $241-\mathrm{T}-105$ & $|S /| \mid$ & 98 & 0 & 23 & 23 & 17 & 98 & 0 & YES & NONE $^{8}$ \\
\hline 241-T-106 ASMD LKR & IS/II & 21 & 2 & 0 & 2 & 0 & 19 & 0 & NO & NONE \\
\hline 241-T-107 ASMD LKR & $/ \mathrm{PI}$ & 173 & 0 & 22 & 22 & 12 & 173 & 0 & YES & NONE $^{8}$ \\
\hline 241-T-108 ASMD LKR & IS/II & 44 & 0 & 0 & 0 & 0 & 44 & 0 & No & NONE \\
\hline 241-T-109 ASMD LKR & IS/II & 58 & 0 & 0 & 0 & 0 & 58 & 0 & NO & NONE \\
\hline 241-T-110 SOUND & $/ \mathrm{PI}$ & 369 & 0 & 26 & 26 & 23 & 369 & 0 & YES & ILL \\
\hline 241-T-111 ASMD LKR & $/ \mathrm{PI}$ & 446 & 0 & 34 & 34 & 29 & 446 & 0 & YES & ILL \\
\hline 241-T-112 SOUND & $1 \mathrm{~S} / 11$ & 67 & 7 & 0 & 7 & 7 & 60 & 0 & YES & ENRAF \\
\hline $241-\mathrm{T}-201$ & IS/II & 29 & 1 & 3 & 4 & 0 & 28 & 0 & NO & NONE \\
\hline $241-\mathrm{T}-202$ & $|S / I|$ & 21 & 0 & 2 & 2 & 0 & 21 & 0 & NO & NONE \\
\hline $241-\mathrm{T}-203$ & IS/II & 35 & 0 & 4 & 4 & 0 & 35 & 0 & No & NONE \\
\hline $241-T-204$ & IS/II & 38 & 0 & 4 & 4 & 0 & 38 & 0 & NO & NONE \\
\hline $241-T X-101$ & IS/II & 87 & 3 & 2 & 5 & 0 & 84 & 0 & YES & ENRAF \\
\hline $241-T X-102$ & IS/II & 217 & 0 & 22 & 22 & 0 & 0 & 217 & YES & ILL \\
\hline $241-T X-103$ SOUND & IS/II & 157 & 0 & 15 & 15 & 0 & 157 & 0 & YES & NONE $^{8}$ \\
\hline 241-TX-104 & IS/II & 65 & 1 & 14 & 15 & 0 & 0 & 64 & YES & NONE $^{8}$ \\
\hline 241-TX-105 ASMD LKR & IS/II & 609 & 0 & 20 & 20 & 0 & 0 & 609 & YES & NONE $^{8}$ \\
\hline 241-TX-106 SOUND & IS/II & 453 & 0 & 10 & 10 & 0 & 0 & 453 & YES & ILL \\
\hline 241-TX-107 ASMD LKR & IS/II & 36 & 1 & 1 & 2 & 0 & 0 & 35 & NO & NONE \\
\hline 241-TX-108 SOUND & IS/II & 134 & 0 & 0 & 0 & 0 & 0 & 134 & No & NONE \\
\hline 241-TX-109 SOUND & $1 S / 11$ & 384 & 0 & 10 & 10 & 0 & 0 & 384 & YES & ILL \\
\hline 241-TX-110 ASMD LKR & IS/II & 462 & 0 & 15 & 15 & 0 & 0 & 462 & YES & ILL \\
\hline $241-T X-111$ SOUND & IS/II & 370 & 0 & 9 & 9 & 0 & 0 & 370 & YES & ILL \\
\hline 241-TX-112 SOUND & IS/II & 649 & 0 & 24 & 24 & 0 & 0 & 649 & YES & ILL \\
\hline 241-TX-113 ASMD LKR & IS/II & 607 & 0 & 16 & 16 & 0 & 0 & 607 & YES & ILL \\
\hline $241-T X-114$ ASMD LKR & IS/II & 535 & 0 & 15 & 15 & 0 & 0 & 535 & YES & ILL \\
\hline 241-TX-115 ASMD LKR & IS/II & 640 & 0 & 19 & 19 & 0 & 0 & 640 & YES & ILL \\
\hline 241-TX-116 ASMD LKR & IS/II & 631 & 0 & 23 & 23 & 0 & 0 & 631 & YES & NONE $^{8}$ \\
\hline 241-TX-117 ASMD LKR & IS//I & 626 & 0 & 8 & 8 & 0 & 0 & 626 & YES & ILL \\
\hline $241-T X-118$ SOUND & IS/II & 347 & 0 & 27 & 27 & 0 & 0 & 347 & YES & ILL \\
\hline 241-TY-101 ASMD LKR & IS/II & 118 & 0 & 0 & 0 & 0 & 118 & 0 & NO & NONE \\
\hline $241-T Y-102$ SOUND & $|S / I|$ & 64 & 0 & 14 & 14 & 0 & 0 & 64 & YES & NONE \\
\hline 241-TY-103 ASMD LKR & IS/II & 162 & 0 & 5 & 5 & 0 & 162 & 0 & YES & ILL \\
\hline
\end{tabular}




\begin{tabular}{|c|c|c|c|c|c|c|c|c|c|c|c|}
\hline Tank & 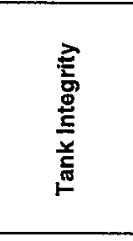 & 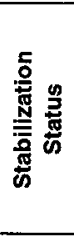 & 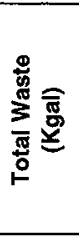 & 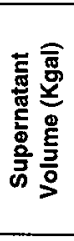 & 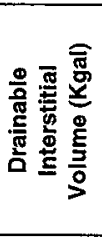 & 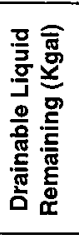 & 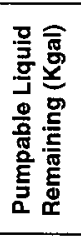 & 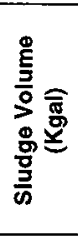 & 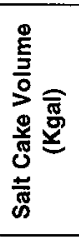 & 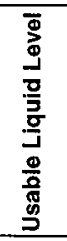 & 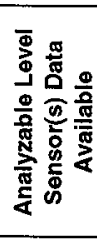 \\
\hline 241-TY-104 & ASMD LKR & IS/II & 46 & 3 & 12 & 15 & 0 & 43 & 0 & YES & ENRAF \\
\hline $241-T Y-105$ & ASMD LKR & $I S / I$ & 231 & 0 & 0 & 0 & 0 & 231 & 0 & NO & NONE \\
\hline 241-TY-106 & ASMD LKR & IS/II & 17 & 0 & 0 & 0 & 0 & 17 & 0 & NO & NONE \\
\hline $241-U-101$ & ASMD LKR & IS/II & 25 & 3 & 0 & 3 & 0 & 22 & 0 & YES & MT \\
\hline $241-U-102$ & SOUND & /PI & 374 & 18 & 154 & 172 & 160 & 43 & 313 & YES & ILL \\
\hline $241-U-103$ & SOUND & $/ \mathrm{PI}$ & 468 & 13 & 207 & 220 & 205 & 32 & 423 & YES & ENRAF \\
\hline 241-U-104 & ASMD LKR & IS/II & 122 & 0 & 7 & 7 & 0 & 122 & 0 & YES & NONE ${ }^{8}$ \\
\hline $241-U-105$ & SOUND & $/ \mathrm{PI}$ & 418 & 37 & 170 & 207 & 192 & 32 & 349 & YES & ENRAF \\
\hline 241-U-106 & SOUND & /PI & 226 & 15 & 87 & 102 & 85 & 26 & 185 & YES & ENRAF \\
\hline $241-U-107$ & SOUND & $/ P I$ & 406 & 31 & 172 & 203 & 183 & 15 & 360 & YES & ENRAF \\
\hline $241-U-108$ & SOUND & $/ \mathrm{PI}$ & 468 & 24 & 202 & 226 & 209 & 29 & 415 & YES & ILL \\
\hline $241-U-109$ & SOUND & $/ P I$ & 463 & 19 & 197 & 216 & 205 & 48 & 396 & YES & ENRAF \\
\hline $241-U-110$ & ASMD LKR & IS/PI & 186 & 0 & 15 & 15 & 9 & 186 & 0 & YES & NONE $^{8}$ \\
\hline $24 t-U-111$ & SOUND & $\mid \mathrm{PI}$ & 329 & 0 & 146 & 146 & 129 & 26 & 303 & YES & ILL \\
\hline $241-U-112$ & ASMD LKR & IS/II & 49 & 4 & 0 & 4 & 0 & 45 & 0 & NO & NONE \\
\hline $241-U-201$ & SOUND & IS/II & 5 & 1 & 0 & 1 & 0 & 4 & 0 & NO & NONE \\
\hline $241-U-202$ & SOUND & IS/II & 5 & 1 & 0 & 1 & 0 & 4 & 0 & NO & NONE \\
\hline $241-U-203$ & SOUND & IS/II & 3 & 1 & 0 & 1 & 0 & 2 & 0 & NO & NONE \\
\hline $241-U-204$ & SOUND & IS/II & 3 & 1 & 0 & 1 & 0 & 2 & 0 & NO & NONE \\
\hline
\end{tabular}

Notes:

1: Stabilization Status: "IS" = interim stabilized; "II" = interim isolated; "PI" = partially interim isolated

2: Liquid volumes determined from photos.

3: Manual Tape data.

4: Monthly ENRAF data.

5: Monthly FIC data.

6: Discontinuous data

7: Only old data available ('81 - '89)

8: No Neutron ILL data 
Appendix D

\section{Tank Level Data Obtained from TWINS}




\begin{tabular}{|c|c|c|c|c|c|c|c|}
\hline Tank & $\frac{g}{\frac{4}{3}} \frac{4}{4}$ & $\stackrel{8}{3} \frac{0}{4}$ & $\begin{array}{l}\frac{5}{0} \\
\frac{9}{2} \\
\underline{\underline{t}}\end{array}$ & 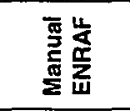 & 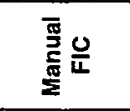 & 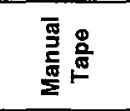 & 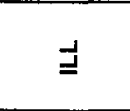 \\
\hline 241-A-101 & $9 / 97-5 / 98$ & $1 / 81-5-82$ & & $9 / 95-5 / 98$ & & $1 / 81-7 / 95$ & $3 / 86-2 / 98$ \\
\hline 241-A-102 & & $1 / 81-10 / 89$ & $5 / 90-5 / 98$ & & $8 / 83-5 / 98$ & & \\
\hline $241-A-103$ & $9 / 97-5 / 98$ & $1 / 81-5 / 96$ & $5 / 90-4 / 95$ & $7 / 96-5 / 98$ & $7 / 81-7 / 95$ & $1 / 81-5 / 82$ & \\
\hline $241-A-104$ & & & & $6 / 96-4 / 98$ & & $5 / 78-4 / 96$ & \\
\hline 241-A-105 & & & & & & $1 / 80-4 / 98$ & \\
\hline $241-A-106$ & $9 / 97-5 / 98$ & $1 / 81-4 / 84$ & $4 / 84-1 / 96$ & $1 / 96-4 / 98$ & $1 / 87-7 / 95$ & & \\
\hline 241-AX-101 & $9 / 97-5 / 98$ & $1 / 81-4 / 84$ & $4 / 84-9 / 95$ & $9 / 95-5 / 98$ & $7 / 84-9 / 95$ & & \\
\hline $241-A X-102$ & $12 / 97-5 / 98$ & & & & & $1 / 81-4 / 98$ & \\
\hline $241-A X-103$ & $9 / 97-5 / 98$ & $1 / 81-1 / 92$ & $1 / 92-9 / 95$ & $9 / 95-5 / 98$ & $8 / 98-9 / 95$ & $11 / 90-9 / 94$ & \\
\hline 241-AX-104 & $9 / 97-5 / 98$ & & & $10 / 86-4 / 98$ & & $1 / 81-10 / 96$ & \\
\hline $241-B-101$ & & $1 / 81-1 / 84$ & $2 / 84-6 / 98$ & & $11 / 81-4-98$ & & \\
\hline $241-B-102$ & & $1 / 81-3 / 95$ & & $3 / 95-5 / 98$ & $9 / 83-12 / 94$ & $1 / 81-1 / 83$ & \\
\hline $241-B-103$ & & $1 / 81-5 / 90$ & $5 / 90-6 / 98$ & & $12 / 81-4 / 96$ & & \\
\hline 241-B-104 & & & & & & $1 / 79-4 / 98$ & $3 / 86-2 / 98$ \\
\hline $241-B-105$ & & & & & & $1 / 81-4 / 98$ & \\
\hline $241-B-106$ & & $1 / 79-10 / 96$ & & & $10 / 90-5 / 98$ & & \\
\hline 241-B-107 & & $1 / 84-1 / 84$ & & & & $1 / 81-4 / 98$ & \\
\hline $241-B-108$ & & $1 / 81-5 / 90$ & $5 / 90-6 / 98$ & & $10 / 84-4 / 98$ & & \\
\hline $241-B-109$ & & & & & & $1 / 81-4 / 98$ & \\
\hline $241-B-110$ & & & & & & $1 / 81-4 / 98$ & $11 / 94-2 / 98$ \\
\hline $241-B-111$ & & $1 / 81-5 / 90$ & $5 / 90-6 / 98$ & & $8 / 82-4 / 98$ & & $11 / 94-2 / 98$ \\
\hline 241-B-112 & & $1 / 81-3 / 95$ & & $3 / 95-5 / 98$ & $9 / 84-11 / 94$ & $1 / 81-2 / 83$ & \\
\hline 241-B-201 & & & & & & $5 / 78-5 / 98$ & \\
\hline $241-B-202$ & & & & & & ป/79-5/98 & \\
\hline $241-B-203$ & & & & & & $1 / 81-5 / 98$ & \\
\hline $241-B-204$ & & & & & & $1 / 81-5 / 98$ & \\
\hline $241-B X-101$ & $5 / 96-5 / 98$ & & & $12 / 95-5 / 98$ & & $1 / 81-4 / 96$ & \\
\hline $241-B X-102$ & $5 / 96-5 / 98$ & & & $7 / 96-4 / 98$ & & $1 / 81-4 / 96$ & \\
\hline $241-B X-103$ & $5 / 96-5 / 98$ & $1 / 81-4 / 96$ & & $12 / 95-5 / 98$ & $4 / 84-4 / 96$ & & \\
\hline $241-B X-104$ & $5 / 96-5 / 98$ & $1 / 81-4 / 96$ & & $12 / 95-5 / 98$ & $1 / 82-12 / 95$ & $1 / 81-2 / 84$ & \\
\hline $241-B X-105$ & $5 / 96-5 / 98$ & $1 / 82-12 / 88$ & $5 / 90-3 / 96$ & $3 / 96-4 / 98$ & $1 / 81-1 / 96$ & $1 / 81-1 / 83$ & \\
\hline 241-BX-106 & $10 / 94-5 / 98$ & $1 / 79-12 / 83$ & & $7 / 94-4 / 98$ & $1 / 84-7 / 94$ & $1 / 81-1 / 83$ & \\
\hline $241-B X-107$ & $5 / 96-5 / 98$ & $1 / 81-6 / 96$ & & $12 / 95-5 / 98$ & $4 / 83-5 / 96$ & & \\
\hline $241-B X-108$ & $5 / 96-5 / 98$ & & & $6 / 96-4 / 98$ & & $1 / 81-4 / 96$ & \\
\hline $241-B X-109$ & $5 / 96-5 / 98$ & $1 / 81-5 / 95$ & $5 / 90-8 / 95$ & $8 / 95-4 / 98$ & $3 / 81-8 / 95$ & & \\
\hline $241-B X-110$ & $5 / 96-4 / 98$ & & & & & $1 / 81-12 / 96$ & \\
\hline $241-B X-111$ & & $1 / 81-5 / 90$ & $5 / 90-6 / 98$ & & $8 / 82-4 / 98$ & & \\
\hline $241-B X-112$ & $5 / 96-5 / 98$ & $1 / 81-3 / 96$ & & $12 / 95-5 / 98$ & $6 / 88-2 / 96$ & $1 / 81-5 / 83$ & \\
\hline
\end{tabular}




\begin{tabular}{|c|c|c|c|c|c|c|c|}
\hline Tank & $\stackrel{\circ}{\frac{u}{2}} \frac{\underline{\alpha}}{\frac{\alpha}{z}}$ & $\frac{}{3} \frac{0}{4}$ & 흘 은 & 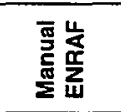 & 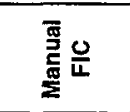 & $\begin{array}{l}\text { 䨔 } \\
\text { 害 } \\
\text { 畐 }\end{array}$ & 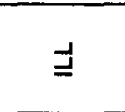 \\
\hline $241-B Y-101$ & & & & & & $1 / 81-4 / 98$ & $3 / 86-2 / 98$ \\
\hline $241-B Y-102$ & & & & & & $7 / 79-3 / 98$ & $3 / 86-2 / 98$ \\
\hline $241-B Y-103$ & $12 / 96-5 / 98$ & & & & & & $3 / 86-2 / 98$ \\
\hline $241-B Y-104$ & & & & & & $1 / 81-4 / 98$ & $3 / 86-2 / 98$ \\
\hline $241-B Y-105$ & & & & & & $1 / 81-5 / 98$ & $3 / 86-2 / 98$ \\
\hline $241-B Y-106$ & & & & & & $1 / 81-5 / 98$ & $3 / 86-2 / 98$ \\
\hline $241-B Y-107$ & & & & & & $1 / 81-4 / 98$ & $3 / 86-2 / 98$ \\
\hline $241-B Y-108$ & & & & & & $1 / 81-4 / 98$ & \\
\hline $241-B Y-109$ & & $2 / 79-3 / 96$ & & & $1 / 83-2 / 98$ & & $3 / 86-2 / 98$ \\
\hline $241-B Y-110$ & & & & $7 / 97-4 / 98$ & & $1 / 81-4 / 97$ & $3 / 86-2 / 98$ \\
\hline $241-B Y-111$ & & & & $4 / 97-5 / 98$ & & $1 / 81-11 / 96$ & \\
\hline $241-B Y-112$ & & & & & & $1 / 81-4 / 98$ & $3 / 86-2 / 98$ \\
\hline $241-C-101$ & & & & & & $1 / 81-4 / 98$ & \\
\hline 241-C-102 & & & & & & $1 / 81-4 / 98$ & \\
\hline $241-C-103$ & $10 / 94-5 / 98$ & $8 / 79-8 / 94$ & & $8 / 94-6 / 98$ & $7 / 79-7 / 94$ & & \\
\hline $241-C-104$ & & $1 / 81-3 / 96$ & & & $7 / 89-6 / 98$ & $1 / 81-4 / 81$ & \\
\hline $241-C-105$ & & $1 / 81-3 / 96$ & & $7 / 96-6 / 98$ & $1 / 83-7 / 96$ & $1 / 81-7 / 82$ & \\
\hline $241-C-106$ & $10 / 94-5 / 98$ & $1 / 81-9 / 96$ & & $9 / 94-6 / 98$ & $5 / 84-11 / 95$ & & \\
\hline $241-C-107$ & $6 / 95-5 / 98$ & $1 / 81-4 / 95$ & & $4 / 95-6 / 98$ & $7 / 85-4 / 95$ & $1 / 81-1 / 81$ & \\
\hline $241-C-108$ & & & & & & $1 / 81-4 / 98$ & \\
\hline $241-C-109$ & & & & & & $1 / 81-4 / 98$ & \\
\hline $241-C-110$ & & & & & & $1 / 81-6 / 98$ & \\
\hline $241-C-111$ & & & & & & $1 / 81-4 / 98$ & \\
\hline $241-C-112$ & & & & $3 / 96-4 / 98$ & & $1 / 81-2 / 96$ & \\
\hline 241-C-201 & & & & & & $1 / 81-4 / 98$ & \\
\hline $241-C-202$ & & & & & & $1 / 81-4 / 98$ & \\
\hline $241-C-203$ & & & & & & $1 / 81-4 / 98$ & \\
\hline $241-C-204$ & & & & & & $1 / 81-4 / 98$ & \\
\hline $241-S-101$ & & $1 / 81-4 / 93$ & $8 / 84-2 / 95$ & 2/95-6/98 & $1 / 81-1 / 95$ & $1 / 81-12 / 84$ & \\
\hline $241-S-102$ & & $1 / 81-5 / 95$ & & $5 / 95-6 / 98$ & $1 / 81-1 / 95$ & $1 / 81-6 / 81$ & $3 / 86-2 / 98$ \\
\hline $241-S-103$ & $12 / 95-5 / 98$ & $1 / 81-7 / 94$ & & $5 / 94-6 / 98$ & $1 / 81-3 / 94$ & $1 / 81-6 / 81$ & \\
\hline $241-S-104$ & & & & & & $1 / 81-4 / 98$ & $10 / 94-2 / 98$ \\
\hline $241-S-105$ & & $1 / 81-10 / 90$ & $6 / 89-7 / 95$ & $7 / 95-4 / 98$ & $4 / 81-4 / 95$ & $1 / 81-6 / 81$ & $3 / 86-2 / 98$ \\
\hline $241-S-106$ & $12 / 95-5 / 98$ & $1 / 8 t-7 / 94$ & & $6 / 94-6 / 98$ & $6 / 83-7 / 94$ & $1 / 81-3 / 85$ & \\
\hline $241-S-107$ & 12/95-5/98 & $1 / 81-7 / 94$ & & $6 / 94-6 / 98$ & $12 / 90-6 / 94$ & $1 / 81-6 / 81$ & \\
\hline $241-S-108$ & & $1 / 81-6 / 90$ & $6 / 90-7 / 95$ & $7 / 95-5 / 98$ & $10 / 86-4 / 95$ & $1 / 81-7 / 95$ & $3 / 86-2 / 98$ \\
\hline $241-S-109$ & & $1 / 81-6 / 90$ & $1 / 90-8 / 95$ & $8 / 95-5 / 98$ & $9 / 82-7 / 95$ & $1 / 81-6 / 81$ & $3 / 86-2 / 98$ \\
\hline
\end{tabular}




\begin{tabular}{|c|c|c|c|c|c|c|c|}
\hline Tank & 造紊章 & $\frac{9}{\frac{3}{4}} \frac{0}{4}$ & 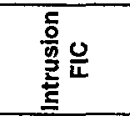 & $\begin{array}{l}\text { 西岁 } \\
\text { 至 } \\
\text { 至 }\end{array}$ & 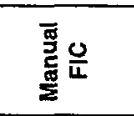 & 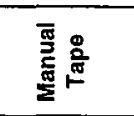 & $\sqsupseteq$ \\
\hline $241-S-110$ & & $1 / 81-6 / 90$ & $1 / 90-9 / 95$ & $8 / 95-5 / 98$ & $3 / 81-7 / 95$ & $1 / 81-6 / 81$ & $3 / 86-2 / 98$ \\
\hline $241-S-111$ & $12 / 95-5 / 98$ & $1 / 81-8 / 94$ & & $8 / 94-6 / 98$ & $5 / 84-8 / 94$ & $1 / 81-6 / 81$ & \\
\hline $241-S-112$ & & $1 / 81-6 / 90$ & $6 / 90-5 / 95$ & $5 / 95-5 / 98$ & $3 / 81-4 / 95$ & $1 / 81-12 / 81$ & $3 / 86-2 / 98$ \\
\hline $241-S X-101$ & & $1 / 81-5 / 84$ & $5 / 84-5 / 95$ & $5 / 95-5 / 98$ & $4 / 82-4 / 95$ & $1 / 81-1 / 85$ & $3 / 86-2 / 98$ \\
\hline $241-\$ X-102$ & & $1 / 80-5 / 95$ & $5 / 84-11 / 94$ & $5 / 95-5 / 98$ & $10 / 83-4 / 95$ & $1 / 81-8 / 83$ & $3 / 86-2 / 98$ \\
\hline $241-S X-103$ & & $1 / 80-4 / 93$ & $4 / 93-5 / 95$ & $5 / 95-5 / 98$ & $7 / 87-4 / 95$ & $1 / 81-1 / 85$ & $3 / 86-2 / 98$ \\
\hline $241-5 X-104$ & & $1 / 80-5 / 95$ & $6 / 90-12 / 94$ & $5 / 95-5 / 98$ & $1 / 85-4 / 95$ & $1 / 81-5 / 82$ & $3 / 86-2 / 98$ \\
\hline $241-S X-105$ & & $1 / 80-6 / 89$ & $5 / 84-5 / 95$ & $5 / 95-5 / 98$ & $7 / 84-4 / 95$ & $1 / 81-5 / 84$ & $3 / 86-2 / 98$ \\
\hline $241-S X-106$ & $12 / 95-5 / 98$ & $1 / 81-8 / 94$ & $5 / 84-4 / 86$ & $8 / 94-6 / 98$ & $6 / 84-8 / 94$ & $1 / 81-7 / 95$ & \\
\hline $241-S X-107$ & & & & & & $1 / 81-4 / 98$ & \\
\hline $241-S X-108$ & & & & & & $1 / 81-4 / 98$ & \\
\hline $241-5 X-109$ & & & & & & $1 / 81-4 / 98$ & \\
\hline $241-S X-110$ & & & & & & $t / 81-4 / 98$ & \\
\hline $241-S X-111$ & & & & & & $1 / 81-4 / 98$ & \\
\hline $241-S X-112$ & & & & & & $1 / 81-4 / 98$ & \\
\hline $241-S X-113$ & & & & & & $1 / 81 \cdot 4 / 98$ & \\
\hline $241-S X-114$ & & & & & & $1 / 81-4 / 98$ & \\
\hline $241-S X-115$ & & & & & & $1 / 81-4 / 98$ & \\
\hline $241-T-101$ & & $1 / 81-12 / 93$ & $7 / 93-5 / 95$ & $6 / 95-5 / 98$ & $6 / 97-6 / 95$ & $1 / 81-4 / 95$ & \\
\hline $241-T-102$ & $10 / 94-5 / 98$ & $1 / 81-7 / 94$ & & $6 / 94-6 / 98$ & $7 / 89-6 / 94$ & & \\
\hline $241-T-103$ & & $1 / 81-11 / 93$ & $7 / 93-7 / 95$ & $7 / 95-4 / 98$ & $3 / 82-7 / 95$ & & \\
\hline $241-T-104$ & & & & $1 / 96-5 / 98$ & & $1 / 80-12 / 96$ & $3 / 86-2 / 98$ \\
\hline $241-T-105$ & & $1 / 81-12 / 84$ & $1 / 81-8 / 95$ & $8 / 95-4 / 98$ & $7 / 84-7 / 95$ & $1 / 81-2 / 82$ & \\
\hline $241-T-106$ & & $1 / 81-2 / 84$ & $7 / 84-8 / 95$ & $8 / 95-4 / 98$ & $6 / 83-7 / 95$ & & \\
\hline $241-\mathrm{T}-107$ & $10 / 94-5 / 98$ & $1 / 84-7 / 94$ & & $6 / 94-5 / 98$ & $1 / 81-7 / 94$ & & \\
\hline $241-T-108$ & & & & $10 / 95-6 / 98$ & & $t / 81-9 / 95$ & \\
\hline $241-T-109$ & $10 / 94-8 / 95$ & $1 / 81-9 / 94$ & $6 / 84-8 / 94$ & $9 / 94-5 / 98$ & $9 / 81-4 / 94$ & & \\
\hline $241-T-110$ & $5 / 97-5 / 98$ & $1 / 81-5 / 95$ & $6 / 90-9 / 94$ & $6 / 95-5 / 98$ & $1 / 89-4 / 95$ & & $3 / 86-2 / 98$ \\
\hline $241-T-111$ & & $1 / 84-7 / 95$ & & $7 / 95-5 / 98$ & $1 / 81-7 / 95$ & & $3 / 86-2 / 98$ \\
\hline $241-T-112$ & & $1 / 81-10 / 95$ & & $9 / 95-6 / 98$ & $5 / 82-9 / 95$ & & \\
\hline $241-T-201$ & & & & & & $1 / 86-12 / 96$ & \\
\hline $241-T-202$ & & & & & & $1 / 81-6 / 98$ & \\
\hline $241-T-203$ & & & & & & $1 / 81-4 / 98$ & \\
\hline 241-T-204 & & & & & & $1 / 81-6 / 98$ & \\
\hline 241-TX-101 & $7 / 96-6 / 98$ & $1 / 81-10 / 95$ & & $10 / 95-6 / 98$ & $4 / 89-8 / 95$ & & \\
\hline $241-T X-102$ & $5 / 96-4 / 98$ & & & & & $1 / 81-4 / 96$ & $3 / 86-2 / 98$ \\
\hline $241-T X-103$ & $5 / 96-6 / 98$ & $1 / 84-9 / 88$ & $7 / 84-3 / 96$ & $1 / 96-4 / 98$ & $1 / 81-10 / 95$ & & \\
\hline 241-TX-104 & $5 / 96-6 / 98$ & $1 / 84-7 / 93$ & $7 / 93-3 / 96$ & 4/96-4/98 & $1 / 81-1 / 96$ & & \\
\hline
\end{tabular}




\begin{tabular}{|c|c|c|c|c|c|c|c|}
\hline Tank & $\stackrel{\frac{u}{3}}{\frac{\pi}{2}}$ & 온 & 듬 & 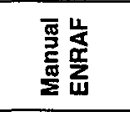 & 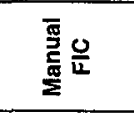 & $\begin{array}{l}\overline{\mathbf{E}} \\
\text { 总 } \\
\text { 焉 }\end{array}$ & $\stackrel{J}{=}$ \\
\hline 241-TX-105 & $5 / 96-6 / 98$ & & & $6 / 96-4 / 98$ & & $1 / 81-10 / 96$ & \\
\hline $241-T X-106$ & $5 / 96-6 / 98$ & & & $6 / 96-4 / 98$ & & $1 / 81-10 / 96$ & $3 / 86-2 / 98$ \\
\hline 241-TX-107 & $5 / 96-6 / 98$ & $1 / 79-3 / 96$ & & $5 / 96-4 / 98$ & $4 / 84-4 / 96$ & & \\
\hline $241-T X-108$ & $5 / 96-6 / 98$ & $1 / 81-7 / 90$ & $7 / 84-4 / 96$ & $5 / 96-4 / 98$ & $3 / 81-4 / 96$ & & \\
\hline 241-TX-109 & $5 / 96-6 / 98$ & $1 / 84-6 / 84$ & $9 / 84-1 / 96$ & $1 / 96-4 / 98$ & $1 / 81-10 / 95$ & & $3 / 86-2 / 98$ \\
\hline $241-T X-110$ & $5 / 96-6 / 98$ & & & $6 / 96-4 / 98$ & & $1 / 81-10 / 96$ & $3 / 86-2 / 98$ \\
\hline $241-T X-111$ & $5 / 96-6 / 98$ & & & $7 / 96-4 / 98$ & & $1 / 81-4 / 96$ & $3 / 86-2 / 98$ \\
\hline $241-T X-112$ & $5 / 96-6 / 98$ & & & $7 / 96-4 / 98$ & & $1 / 81-10 / 96$ & $3 / 86-2 / 98$ \\
\hline 241-TX-113 & $5 / 96-6 / 98$ & & & $6 / 96-4 / 98$ & & $1 / 81-10 / 96$ & $3 / 86-2 / 98$ \\
\hline $241-T X-114$ & $5 / 96-6 / 98$ & & & $6 / 96-4 / 98$ & & $1 / 81-10 / 96$ & $3 / 86-2 / 98$ \\
\hline $241-T X-115$ & $5 / 96-6 / 98$ & & & $4 / 96-4 / 98$ & & & $3 / 86-2 / 98$ \\
\hline $241-T X-116$ & $5 / 96-6 / 98$ & & & $6 / 96-4 / 98$ & & $1 / 81-10 / 96$ & $3 / 86-2 / 98$ \\
\hline $241-\mathrm{TX}-117$ & $5 / 96-6 / 98$ & & & $6 / 96-4 / 98$ & & $1 / 81-10 / 96$ & $3 / 86-2 / 98$ \\
\hline $241-T X-118$ & $5 / 96-6 / 98$ & & & $2 / 96-4 / 98$ & & & $3 / 86-2 / 98$ \\
\hline $241-T Y-101$ & $12 / 95-6 / 98$ & $1 / 81-2 / 85$ & $7 / 84-7 / 95$ & $7 / 95-4 / 98$ & $8 / 81-7 / 95$ & & \\
\hline $241-T Y-102$ & $12 / 95-6 / 98$ & $1 / 81-10 / 95$ & & $9 / 95-6 / 98$ & $9 / 81-9 / 95$ & & \\
\hline $241-T Y-103$ & $12 / 95-6 / 98$ & $1 / 81-6 / 84$ & $7 / 84-10 / 95$ & $10 / 95-4 / 98$ & $8 / 84-8 / 95$ & & $3 / 86-2 / 98$ \\
\hline $241-T Y-104$ & $12 / 95-6 / 98$ & $1 / 81-6 / 95$ & & $7 / 95-6 / 98$ & $1 / 81-7 / 95$ & & \\
\hline 241-TY-105 & $12 / 95-6 / 98$ & & & $4 / 96-4 / 98$ & & & \\
\hline $241-T Y-106$ & $12 / 95-6 / 98$ & & & $11 / 96-4 / 98$ & & & \\
\hline $241-U-101$ & & & & & & $1 / 81-6 / 98$ & \\
\hline $241-U-102$ & & $1 / 81-6 / 84$ & $6 / 84-3 / 96$ & $1 / 96-6 / 98$ & $6 / 83-10 / 95$ & & $3 / 86-2 / 98$ \\
\hline $241-U-103$ & $8 / 95-9 / 98$ & $1 / 81-7 / 94$ & & 7/94-6/98 & $12 / 84-7 / 94$ & & \\
\hline $241-U-104$ & & & & & & $1 / 81-4 / 98$ & \\
\hline $241-U-105$ & $12 / 95-6 / 98$ & $1 / 81 \cdot 7 / 94$ & & $7 / 94-6 / 98$ & $9 / 83-7 / 94$ & $1 / 81-9 / 85$ & \\
\hline 241-U-106 & $8 / 95-6 / 98$ & $1 / 79-8 / 94$ & & $8 / 94-6 / 98$ & $9 / 89-8 / 94$ & & \\
\hline $241-U-107$ & $8 / 95-6 / 98$ & $1 / 81-7 / 94$ & & $7 / 94-6 / 98$ & $1 / 90-7 / 94$ & & \\
\hline $241-U-108$ & & $1 / 81-1 / 93$ & $6 / 84-5 / 95$ & $5 / 95-6 / 98$ & $1 / 90-1 / 95$ & & $3 / 86-2 / 98$ \\
\hline $241-U-109$ & $8 / 95-6 / 98$ & $5 / 78-5 / 94$ & & $7 / 94-6 / 98$ & $10 / 85-7 / 94$ & & \\
\hline $241-U-110$ & & $1 / 81-6 / 84$ & $6 / 84-1 / 96$ & $1 / 96-6 / 98$ & $4 / 84-10 / 95$ & & \\
\hline $241-U-111$ & & $1 / 84-7 / 84$ & $7 / 89-1 / 96$ & $1 / 96-6 / 98$ & $1 / 81-10 / 95$ & & $3 / 86-2 / 98$ \\
\hline $241-U-112$ & & & & & & $1 / 81-4 / 98$ & \\
\hline $241-U-201$ & & & & & & $1 / 81-6 / 98$ & \\
\hline $241-U-202$ & & & & & & $1 / 81-6 / 98$ & \\
\hline $241-U-203$ & & & & & & $1 / 81-4 / 98$ & \\
\hline $241-U-204$ & & & & & & $1 / 81-6 / 98$ & \\
\hline
\end{tabular}




\section{Appendix E}

\section{Statistical Analyses of Level Data}

This appendix presents a statistical analysis of 70 SSTs that supports the preliminary integrity assessment. In these analyses, a result that "the mean volume rate is NOT equivalent to $0 \mathrm{gal} / \mathrm{h}$ " does not imply that the tank is leaking. Rather, it indicates that, in applying a null hypothesis test to the ensemble of volume rate data, the mean value cannot be explained simply by random occurrence. Similarly, a result that "the mean volume rate is equivalent to $0 \mathrm{gal} / \mathrm{h}$ " does not necessarily imply that the tank is leaktight; it just describes that, as a result of the variability of the data, the mean volume rate cannot be distinguished from $0 \mathrm{gal} / \mathrm{h}$.

The minimum detectable leak values reported in this appendix describe the smallest leak that could be reliably detected (at a $\mathrm{P}_{\mathrm{D}}$ of $95 \%$ and $99 \%$ ), if a leak test were conducted on that tank using the level sensor described and the 30-day test periods. These data demonstrate the performance potential for a possible future leak test program, and provide a preliminary liquid integrity assessment "baseline" for such a program. 


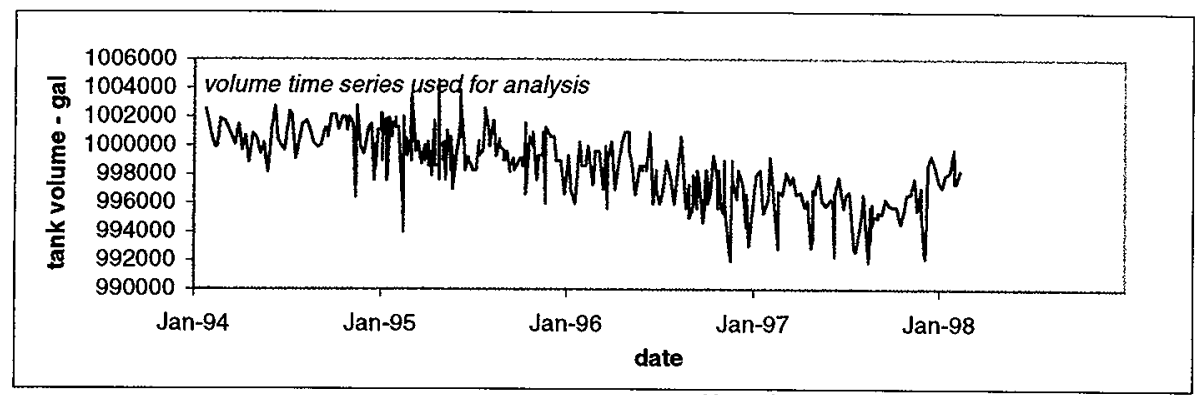

No. points edited from time series =

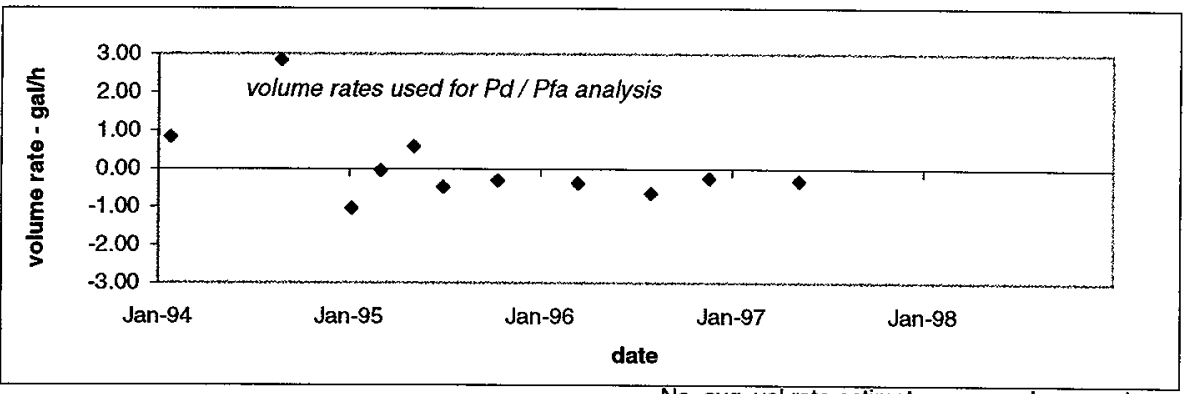

During the analysis period, the average volume rate $=$ The standard deviation of the volume rate estimates $=$

For Pd $/ \mathrm{Pfa}=95 \% / 5 \%$ :

The mean volume rate is equivalent to $0 \mathrm{gal} / \mathrm{h}$ Threshold, T: $-1.92 \mathrm{ga} / \mathrm{h}$ Min. Detectable Leak: $\quad-3.83 \mathrm{gal} / \mathrm{h}$

Gaussian Plots Not Representative Due to small N....
No. avg. vol rate estimates removed $=\quad \begin{array}{cc}1 \\ N= & 11\end{array}$

$0.07 \mathrm{gal} / \mathrm{h}$

$1.06 \mathrm{gal} / \mathrm{h}$

For Pd / Pfa $=99 \% / 1 \%$ :

The mean volume rate is equivalent to $0 \mathrm{gal} / \mathrm{h}$

Threshold, T: $\quad-2.92 \mathrm{gal} / \mathrm{h}$

Min. Detectable Leak: $\quad-5.85 \mathrm{gal} / \mathrm{h}$

\begin{tabular}{c}
\hline Gaussian Plots Not Representative \\
Due to small N.... \\
\end{tabular}

Gaussian Plots Not Representative Due to small N... 


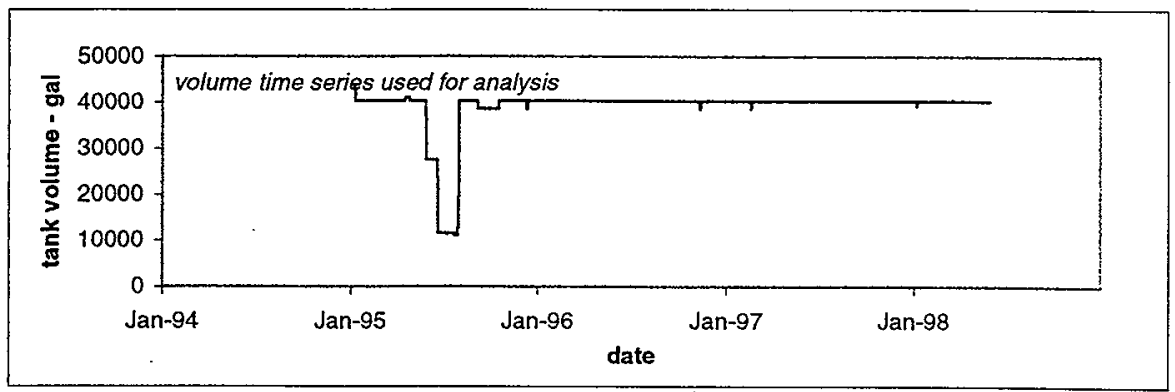

No. points edited from time series =

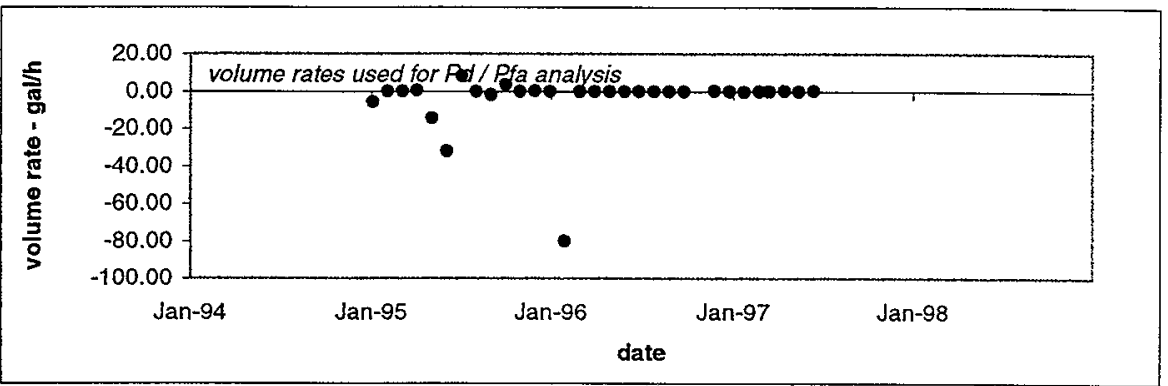

During the analysis period, the average volume rate $=$ The standard deviation of the volume rate estimates $=$

For Pd $/ \mathrm{Pta}=95 \% / 5 \%$ :

The mean volume rate is equivalent to $0 \mathrm{gal} / \mathrm{h}$ Threshold, T: $-29.03 \mathrm{gal} / \mathrm{h}$ Min. Detectable Leak: $\quad-58.06 \mathrm{gal} / \mathrm{h}$

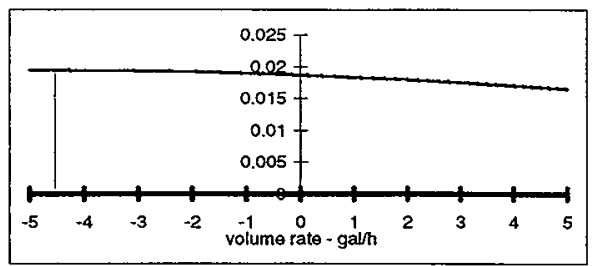

$-4.73 \mathrm{gal} / \mathrm{h}$

No. avg. vol rate estimates removed $=4$
For $\mathrm{Pd} / \mathrm{Pfa}=99 \% / 1 \%$ :

The mean volume rate is equivalent to $0 \mathrm{gal} / \mathrm{h}$ Threshold, T:

$-42.24 \mathrm{gal} / \mathrm{h}$ Min. Detectable Leak: $\quad-84.48 \mathrm{gal} / \mathrm{h}$
For this data, a threshold= The corresponding Pfa is
$5.00 \mathrm{ga} / \mathrm{h}$ will detect a tank release of $1.64 \%$

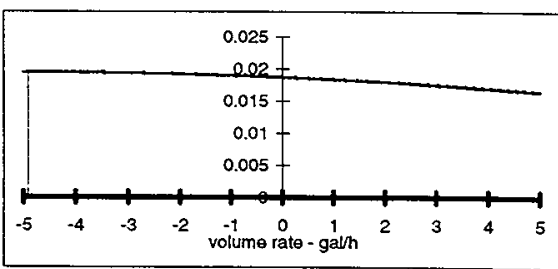

$84.48 \mathrm{gal} / \mathrm{h}$ at a $\mathrm{Pd}=95 \%$ 


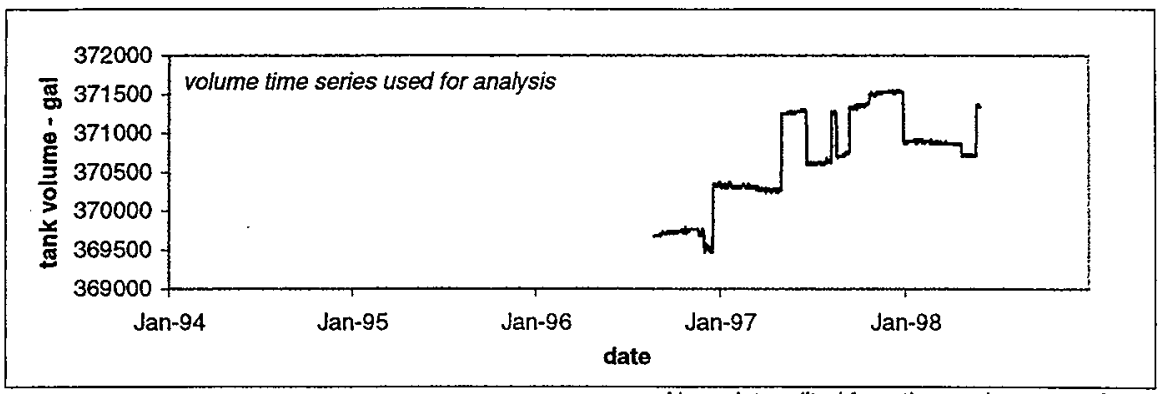

No. points edited from time series $=$

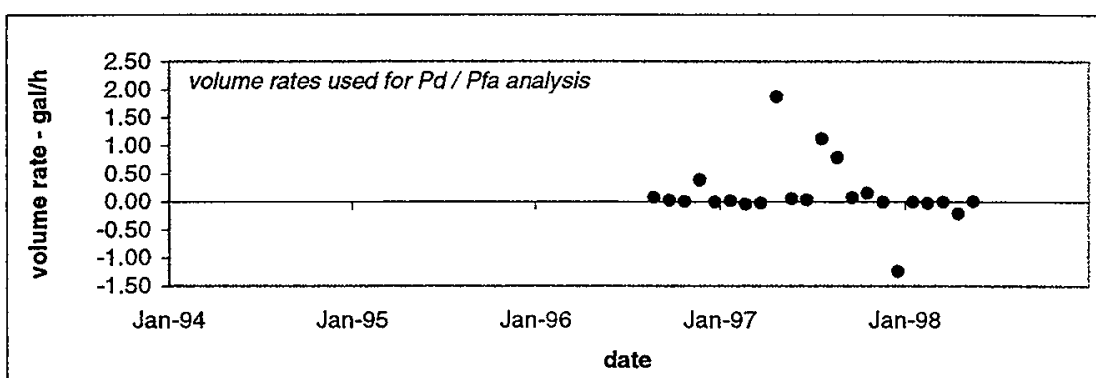

During the analysis period, the average volume rate =

No. avg. vol rate estimates removed $=$ 9

The standard deviation of the volume rate estimates =

$0.14 \mathrm{ga} / \mathrm{h}$

$N=$

21

$0.58 \mathrm{gal} / \mathrm{h}$

For $\mathrm{Pd} / \mathrm{Pfa}=95 \% / 5 \%$ :

The mean volume rate is equivalent to $0 \mathrm{gal} / \mathrm{h}$

Threshold, T: $\quad-1.00 \mathrm{gal} / \mathrm{h}$

Min. Detectable Leak: $\quad-2.00 \mathrm{gal} / \mathrm{h}$

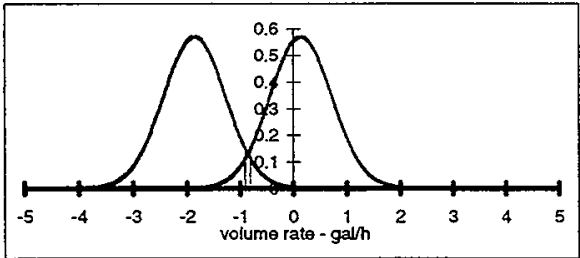

For $\mathrm{Pd} / \mathrm{Pfa}=99 \% / 1 \%$ :

The mean volume rate is equivalent to $0 \mathrm{gal} / \mathrm{h}$

Threshold, T: $\quad-1.46 \mathrm{gal} / \mathrm{h}$

Min. Detectable Leak: $\quad-2.92 \mathrm{gal} / \mathrm{h}$

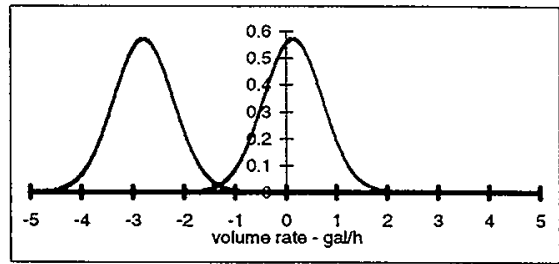

For this data, a threshold $=\quad-1.84 \mathrm{gal} / \mathrm{h}$ will detect a tank release of $2.92 \mathrm{gal} / \mathrm{h}$ at a $\mathrm{Pd}=95 \%$ The corresponding $\mathrm{Pfa}$ is $\quad 0.16 \%$ 
Data File: B-102 Data is from sensor type: Manual ENRAF

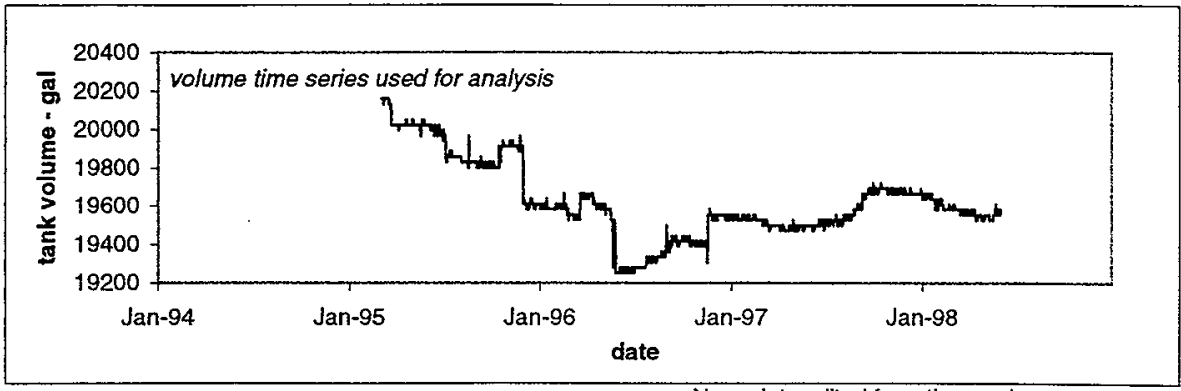

No. points edited from time series $=$

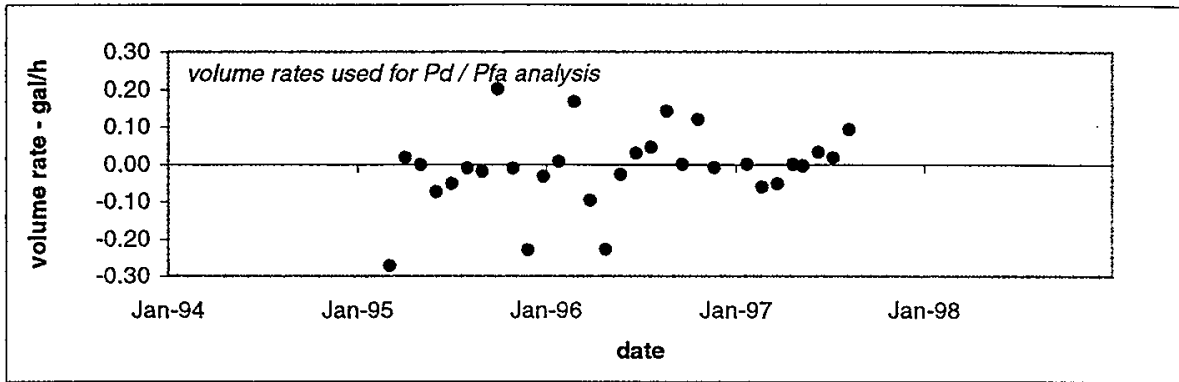

During the anaiysis period, the average volume rate =

No. avg. vol rate estimates removed $=$

The standard deviation of the volume rate estimates =

$$
-0.01 \mathrm{gal} / \mathrm{h}
$$$$
\mathrm{N}=
$$

For Pd $/ \mathrm{Pfa}=95 \% / 5 \%$ :

The mean volume rate is equivalent to $0 \mathrm{gal} / \mathrm{h}$

Threshold, T:

Min. Detectable Leak: $\quad-0.37 \mathrm{gal} / \mathrm{h}$

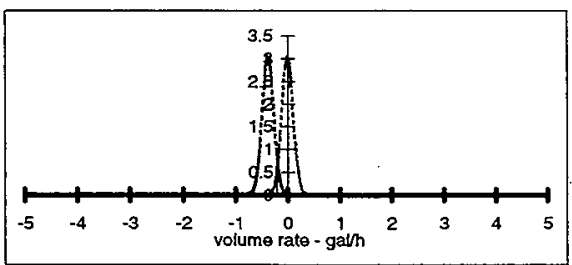

For this data, a threshold= The corresponding $\mathrm{Pfa}$ is
$-0.18 \mathrm{gal} / \mathrm{h}$

\section{$-0.38 \mathrm{ga} / \mathrm{h}$ will detect a tank release of} $0.95 \%$
For Pd $/ \mathrm{Pfa}=99 \% / 1 \%$ :

The mean volume rate is equivalent to $0 \mathrm{gal} / \mathrm{h}$

Threshold, T:

$-0.27 \mathrm{gaV} / \mathrm{h}$

Min. Detectable Leak:

$-0.54 \mathrm{gal} / \mathrm{h}$

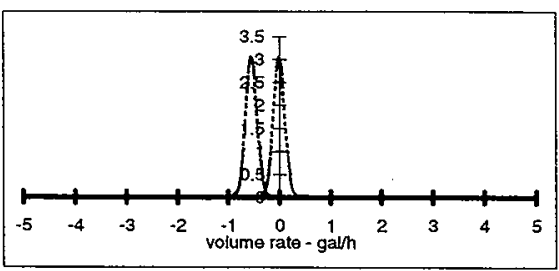

$0.54 \mathrm{ga} / \mathrm{h}$ at a $P d=95 \%$ 


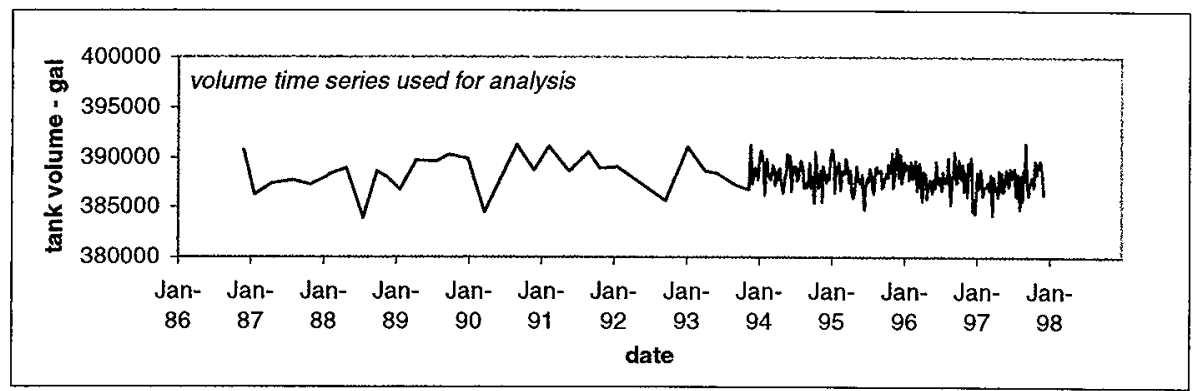

No. points edited from time series =

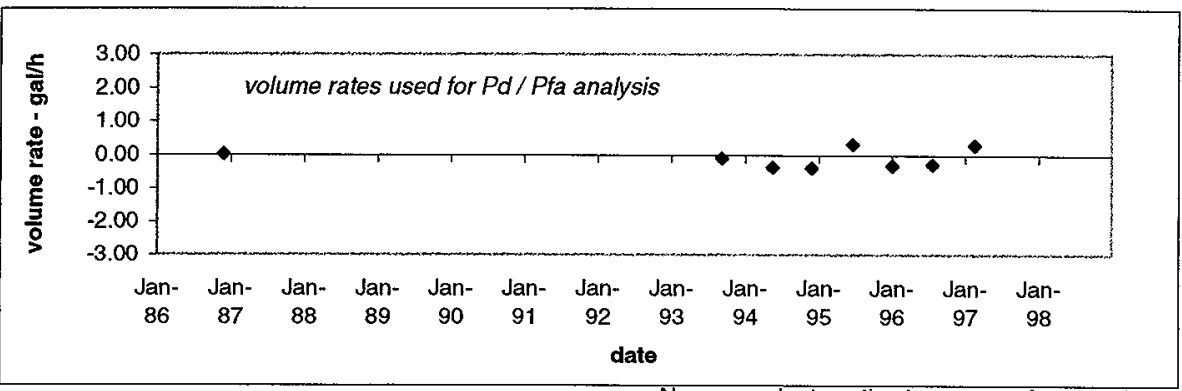

\begin{tabular}{ccccccccccccc} 
Jan- & Jan- & Jan- & Jan- & Jan- & Jan- & Jan- & Jan- & Jan- & Jan- & Jan- & Jan- & Jan- \\
86 & 87 & 88 & 89 & 90 & 91 & 92 & 93 & 94 & 95 & 96 & 97 & 98 \\
& & & \multicolumn{4}{c}{ date }
\end{tabular}

No. avg. vol rate estimates removed $=$

During the analysis period, the average volume rate $=$ The standard deviation of the volume rate estimates =

For $\mathrm{Pd} / \mathrm{Pfa}=95 \% / 5 \%$ :

The mean volume rate is equivalent to $0 \mathrm{gal} / \mathrm{h}$

Threshold, T:

$-0.55 \mathrm{gal} / \mathrm{h}$

Min. Detectable Leak: $\quad-1.11 \mathrm{ga} / \mathrm{h}$
$-0.11 \mathrm{ga} / \mathrm{h}$

$0.29 \mathrm{gal} / \mathrm{h}$

For $\mathrm{Pd} / \mathrm{Pfa}=99 \% / 1 \%$ :

The mean volume rate is equivalent to $0 \mathrm{gal} / \mathrm{h}$ Threshold, T:

Min. Detectable Leak: $\quad-1.76 \mathrm{ga} / \mathrm{h}$
Gaussian Plots Not Representative Dute to small N....
Gaussian Plots Not Representative Due to small N.... 


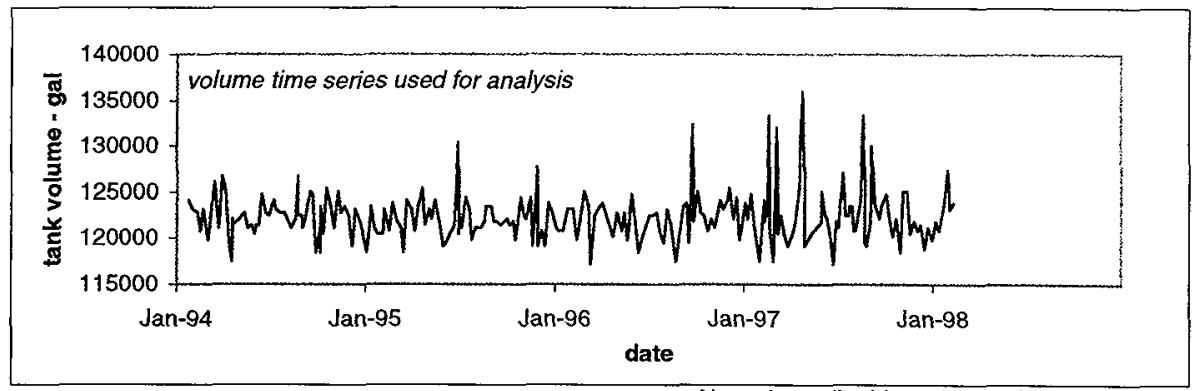

No. points edited from time series $=$

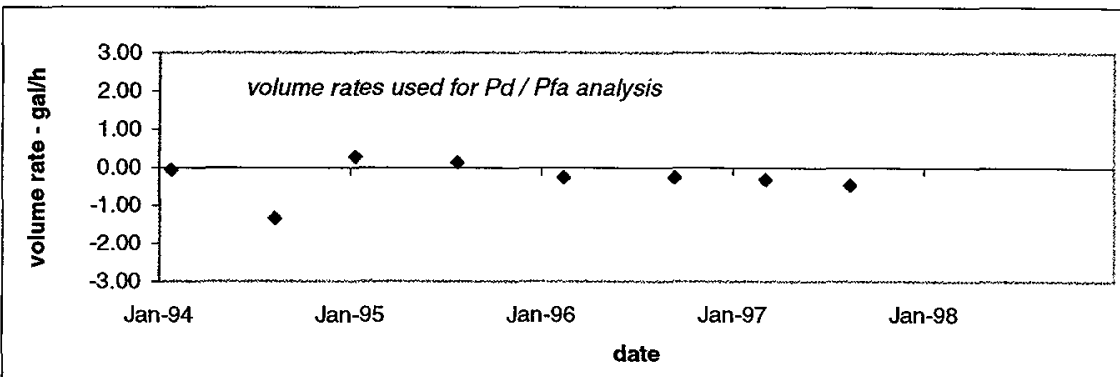

During the analysis period, the average volume rate = The standard deviation of the volume rate estimates =

For Pd $/ \mathrm{Pfa}=95 \% / 5 \%$ :

The mean volume rate is equivalent to $0 \mathrm{gal} / \mathrm{h}$

Threshold, T: $-0.93 \mathrm{gal} / \mathrm{h}$

Min. Detectable Leak: $\quad-1.85 \mathrm{gal} / \mathrm{h}$

Gaussian Plots Not Representative Due to small N....
No. avg. vol rate estimates removed $=$

$$
N=8
$$

$-0.29 \mathrm{ga} / \mathrm{h}$

$0.49 \mathrm{gal} / \mathrm{h}$

For $\mathrm{Pd} / \mathrm{Pfa}=99 \% / 1 \%$ :

The mean volume rate is equivalent to $0 \mathrm{gal} / \mathrm{h}$

Threshold, $\mathrm{T}$ :

$-1.47 \mathrm{gal} / \mathrm{h}$

Min. Detectable Leak: $\quad-2.93 \mathrm{gal} / \mathrm{h}$

Gaussian Plots Not Representative Due to small N.... 
Data File: B-110 Data is from sensor type: LOW

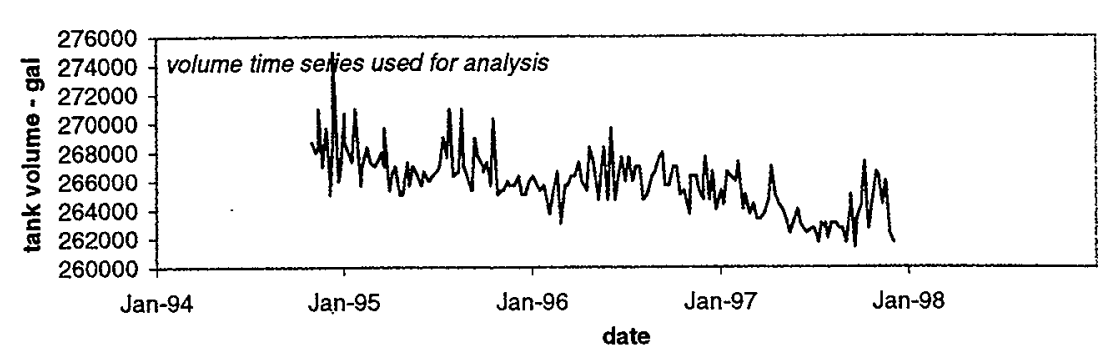

No. points edited from time series $=$

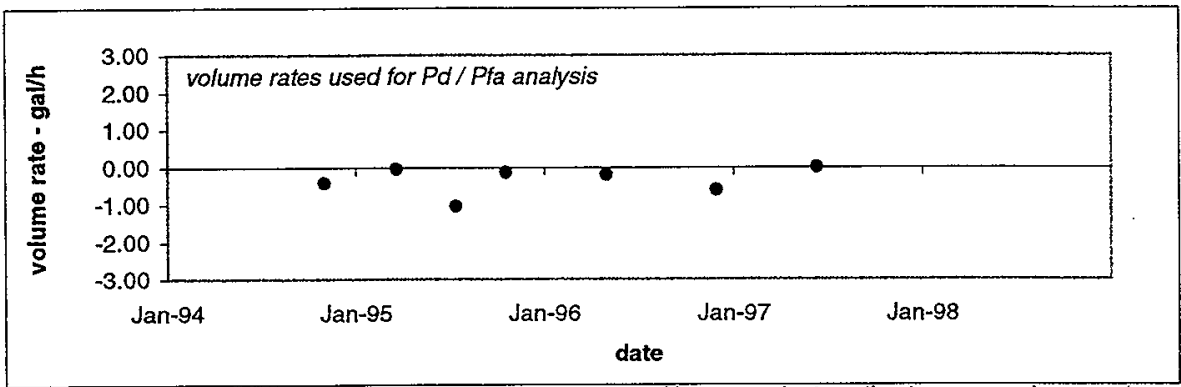

During the analysis period, the average volume rate $=$ The standard deviation of the volume rate estimates =

For $\mathrm{Pd} / \mathrm{Pfa}=95 \% / 5 \%$ :

The mean volume rate is NOT equivalent to $0 \mathrm{gal} / \mathrm{h}$ Threshold, T: Min. Detectable Leak: $\quad-1.49 \mathrm{ga} / \mathrm{h}$

Gaussian Plots Not Representative Due to smal! $N . .$.
No. avg. vol rate estimates removed $=$

$$
N=6
$$

$-0.41 \mathrm{gal} / \mathrm{h}$

$0.37 \mathrm{gaVh}$

For $\mathrm{Pd} / \mathrm{Pfa}=99 \% / 1 \%$ :

The mean volume rate is NOT equivalent to $0 \mathrm{gal} / \mathrm{h}$

Threshold, T:

$-0.86 \mathrm{gal} / \mathrm{h}$

Min. Detectable Leak: $\quad-1.73 \mathrm{gal} / \mathrm{h}$

Gaussian Plots Not Representative Due to small $\mathrm{N}$... 


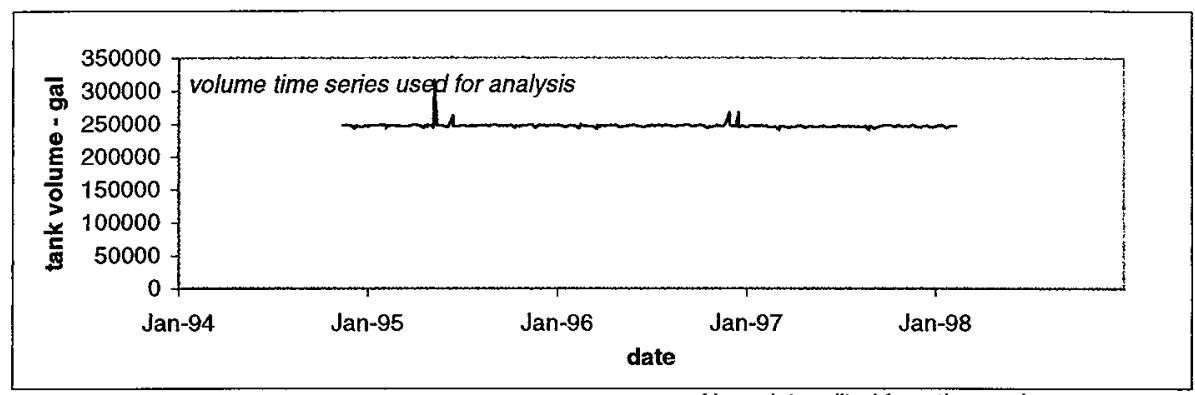

No. points edited from time series =

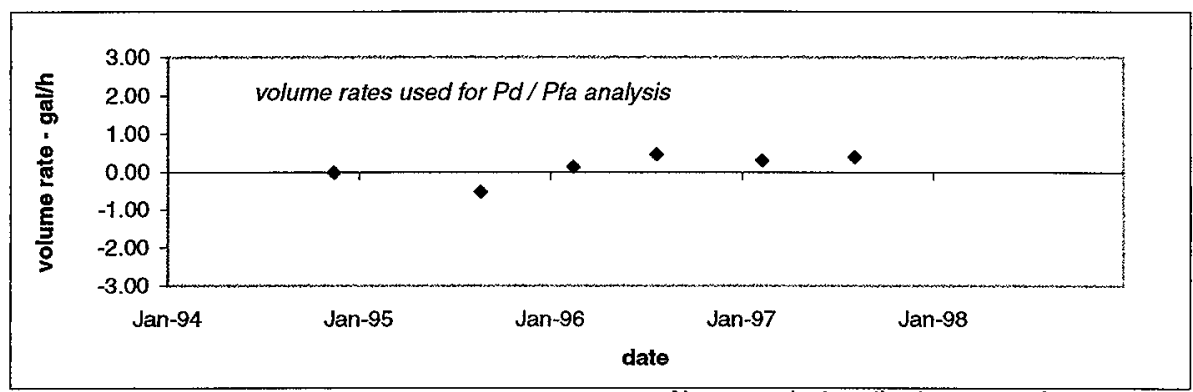

During the analysis period, the average volume rate $=$ The standard deviation of the volume rate estimates =

For $\mathrm{Pd} / \mathrm{Pfa}=\mathbf{9 5} \% / \mathrm{5 \%}$ :

The mean volume rate is equivalent to $0 \mathrm{gal} / \mathrm{h}$

Threshold, T: $\quad-0.73 \mathrm{gal} / \mathrm{h}$

Min. Detectable Leak: $\quad-1.45 \mathrm{gal} / \mathrm{h}$

Gaussian Plots Not Representative Due to small N...
No. avg. vol rate estimates removed $=$

$N=$

$0.12 \mathrm{gal} / \mathrm{h}$

$0.36 \mathrm{gal} / \mathrm{h}$

For $\mathrm{Pd} / \mathrm{Pfa}=\mathbf{9 9 \%} / \mathbf{1 \%}$ :

The mean volume rate is equivalent to $0 \mathrm{gal} / \mathrm{h}$

Threshold, T: $\quad-1.21 \mathrm{gal} / \mathrm{h}$

Min. Detectable Leak: $\quad-2.43 \mathrm{gal} / \mathrm{h}$ 


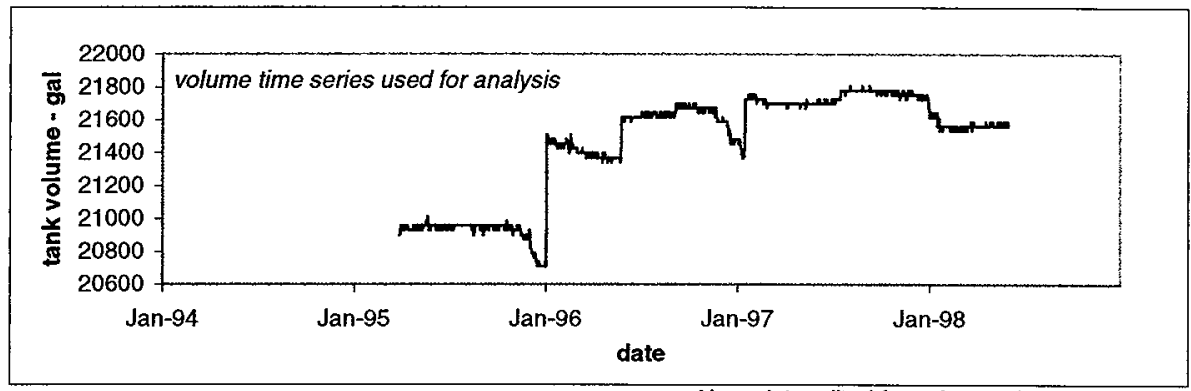

No. points edited from time series =

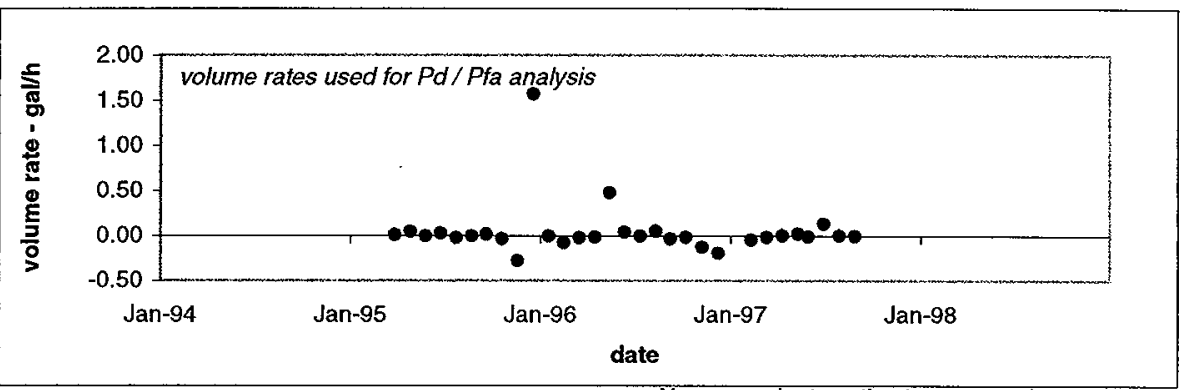

During the analysis period, the average volume rate = The standard deviation of the volume rate estimates =

For Pd $/ \mathrm{Pfa}=\mathbf{9 5} \% / \mathbf{5} \%$ :

The mean volume rate is equivalent to $0 \mathrm{gal} / \mathrm{h}$

Threshold, T: $\quad-0.53 \mathrm{gal} / \mathrm{h}$

Min. Detectable Leak: $\quad-1.05 \mathrm{gal} / \mathrm{h}$

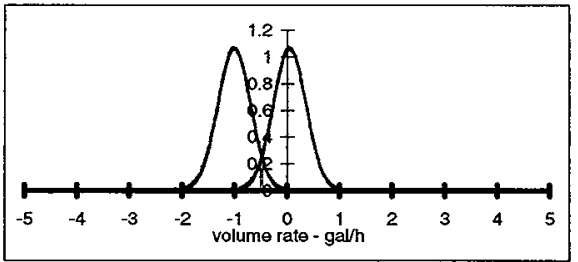

For this data, a threshold $=-0.98 \mathrm{gal} / \mathrm{h}$ will detect a tank release of The corresponding $\mathrm{Pfa}$ is $0.45 \%$
No. avg. vol rate estimates removed = $N=30$

$0.05 \mathrm{gal} / \mathrm{h}$

$0.31 \mathrm{gal} / \mathrm{h}$

For $\mathrm{Pd} / \mathrm{Pfa}=99 \% / 1 \%$ :

The mean volume rate is equivalent to $0 \mathrm{gal} / \mathrm{h}$ Threshold, T:

$-0.76 \mathrm{gal} / \mathrm{h}$

Min. Detectable Leak:

$-1.53 \mathrm{ga} / \mathrm{h}$

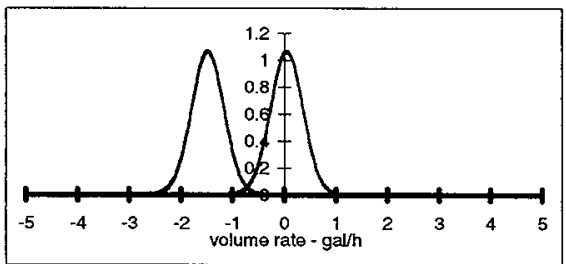

$1.53 \mathrm{ga} / \mathrm{h}$ at a $P d=95 \%$ 


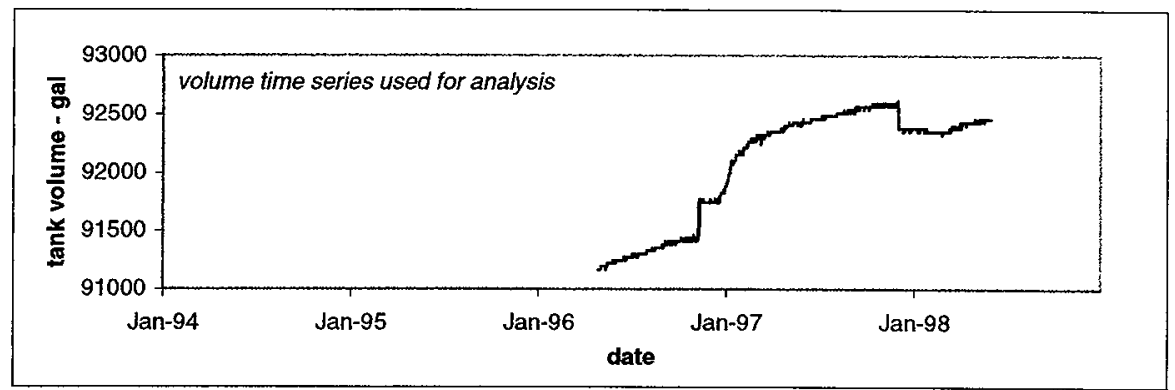

No. points edited from time series $=$

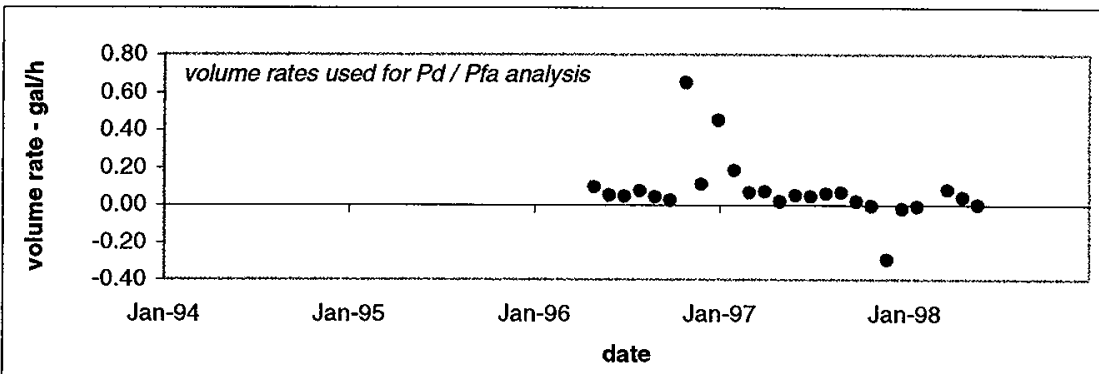

During the analysis period, the average volume rate = No. avg. vol rate estimates removed $=$

For Pd $/ \mathrm{Pfa}=95 \% / 5 \%$ :

The mean volume rate is NOT equivalent to $0 \mathrm{gal} / \mathrm{h}$ Threshold, T: $-0.29 \mathrm{gal} / \mathrm{h}$ Min. Detectable Leak: $\quad-0.58 \mathrm{gal} / \mathrm{h}$

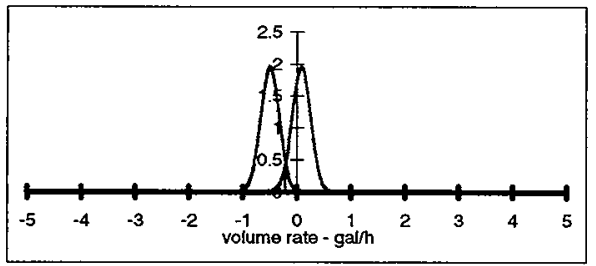

For $\mathrm{Pd} / \mathrm{Pfa}=\mathbf{9 9} \% / \mathbf{1 \%}$ :

The mean volume rate is equivalent to $0 \mathrm{gal} / \mathrm{h}$ Threshold, T: $-0.42 \mathrm{gal} / \mathrm{h}$ Min. Detectable Leak: $\quad-0.85 \mathrm{gal} / \mathrm{h}$

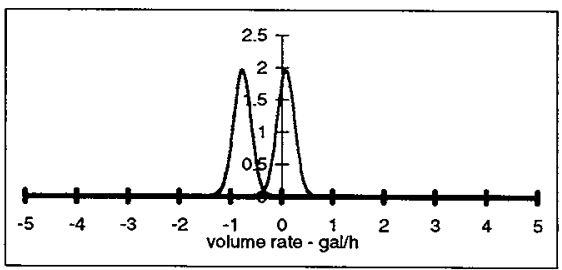

For this data, a threshold $=\quad-0.50 \mathrm{gal} / \mathrm{h}$ will detect a tank release of $\quad 0.85 \mathrm{gal} / \mathrm{h}$ at a $\mathrm{Pd}=95 \%$ The corresponding Pfa is $0.56 \%$ 


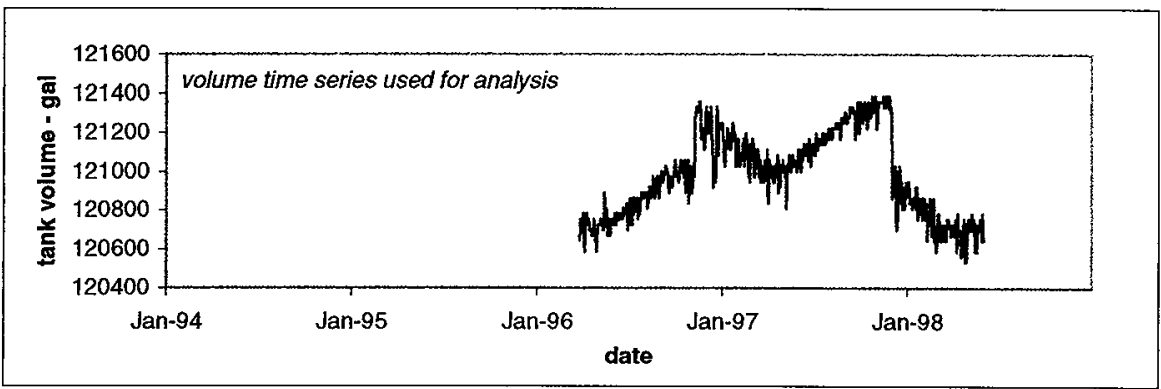

No. points edited from time series $=$

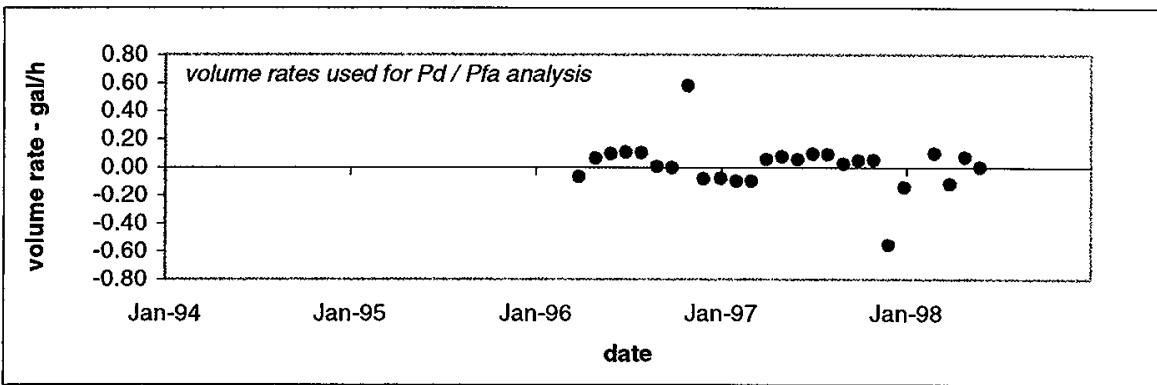

During the analysis period, the average volume rate =

No. avg. vol rate estimates removed $=$

$0.01 \mathrm{galh}$

$0.18 \mathrm{galh}$

For Pd $/$ Pfa $=99 \% / 1 \%$ :

The mean volume rate is equivalent to $0 \mathrm{gal} / \mathrm{h}$ Threshold, $\mathrm{T}$ : $\quad-0.45 \mathrm{gaV} / \mathrm{h}$ Min. Detectable Leak: $\quad-0.91 \mathrm{gal} / \mathrm{h}$

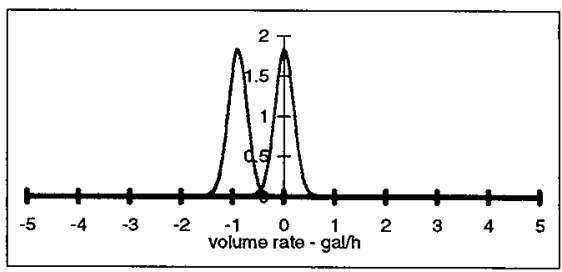

For this data, a threshold $=\quad-0.60 \mathrm{gal} / \mathrm{h}$ will detect a tank release of $\quad 0.91 \mathrm{gal} / \mathrm{h}$ at a $\mathrm{Pd}=95 \%$ The corresponding $\mathrm{Pfa}$ is $\quad 0.62 \%$ 


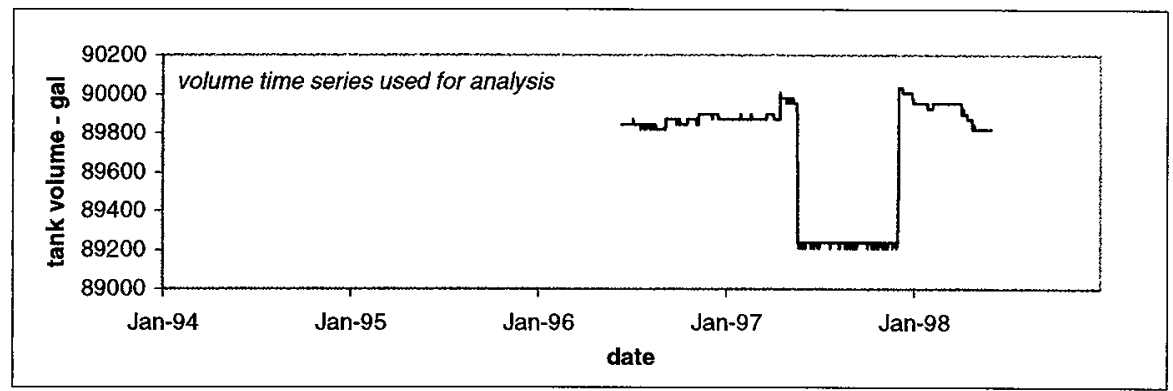

No. points edited from time series $=$

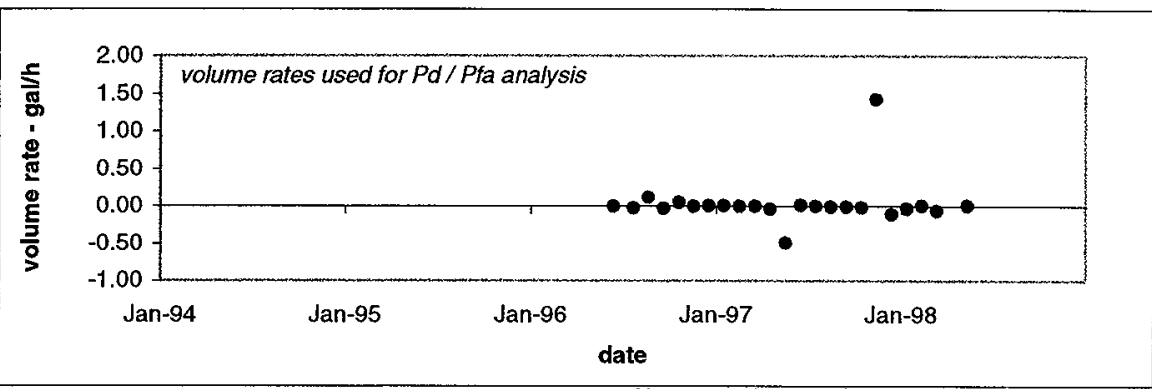

During the analysis period, the average volume rate $=$ The standard deviation of the volume rate estimates =

For Pd $/ \mathrm{Pfa}=95 \% / 5 \%$ :

The mean volume rate is equivalent to $0 \mathrm{gal} / \mathrm{h}$

Threshold, T: $\quad-0.57 \mathrm{gal} / \mathrm{h}$

Min. Detectable Leak: $\quad-1.14 \mathrm{gal} / \mathrm{h}$

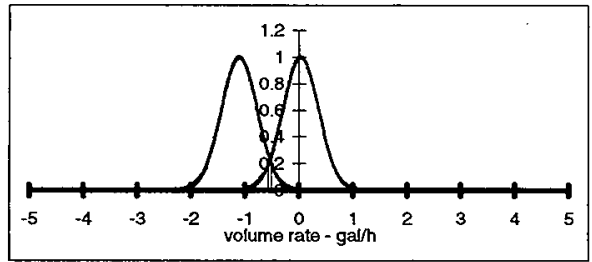

For this data, a threshold= The corresponding Pfa is
$-1.10 \mathrm{gal} / \mathrm{h}$ will detect a tank release of $1.67 \mathrm{gal} / \mathrm{h}$ at a $\mathrm{Pd}=95 \%$ $0.28 \%$
$N=22$

$0.03 \mathrm{gal} / \mathrm{h}$

$0.33 \mathrm{gal} / \mathrm{h}$

For Pd / Pfa = 99\% / 1\%:

The mean volume rate is equivalent to $0 \mathrm{gal} / \mathrm{h}$

Threshold, T:

$-0.83 \mathrm{gal} / \mathrm{h}$

Min. Detectable Leak: $\quad-1.67 \mathrm{gal} / \mathrm{h}$

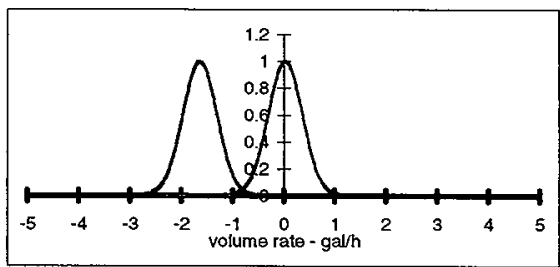




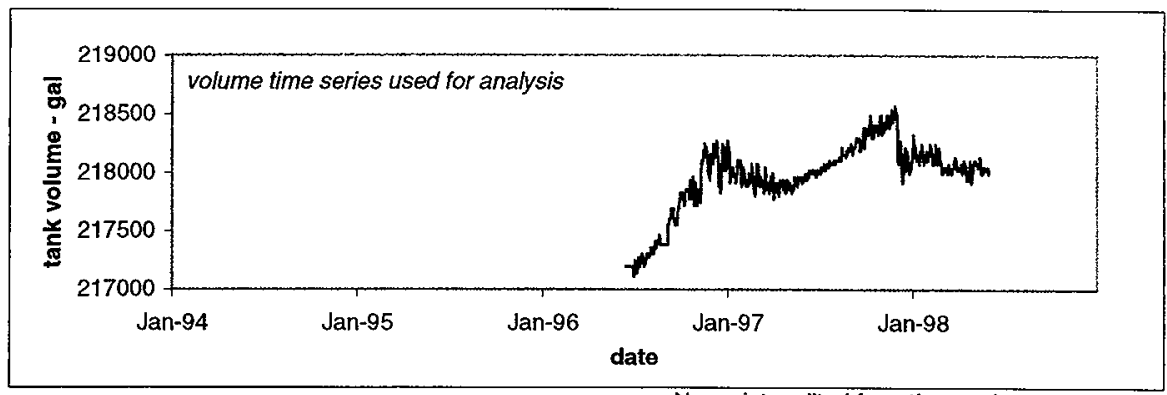

No. points edited from time series =

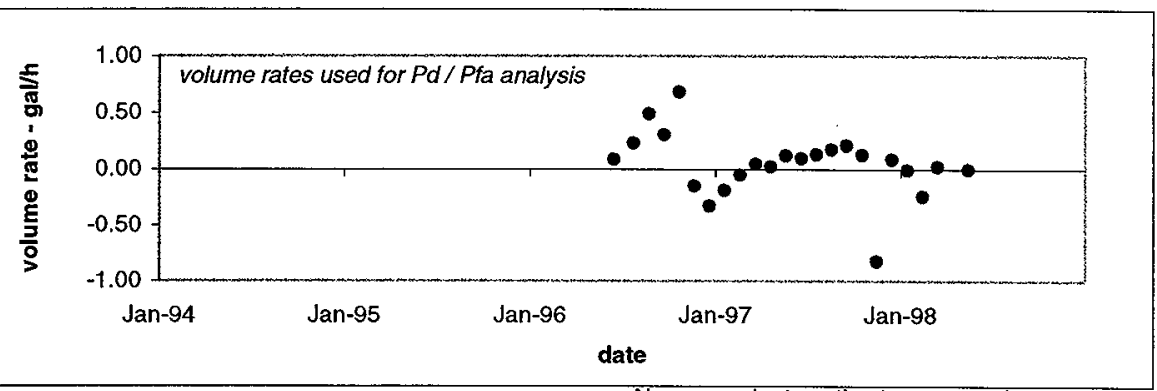

No. avg. vol rate estimates removed $=\quad \overline{8}$

During the analysis period, the average volume rate =

\section{$0.05 \mathrm{gal} / \mathrm{h}$}

$N=22$

The standard deviation of the volume rate estimates =

$0.30 \mathrm{gal} / \mathrm{h}$

For $\mathrm{Pd} / \mathrm{Pfa}=95 \% / 5 \%$ :

The mean volume rate is equivalent to $0 \mathrm{gal} / \mathrm{h}$

Threshold, T:

$-0.51 \mathrm{gal} / \mathrm{h}$

Min. Detectable Leak:

$-1.02 \mathrm{gal} / \mathrm{h}$

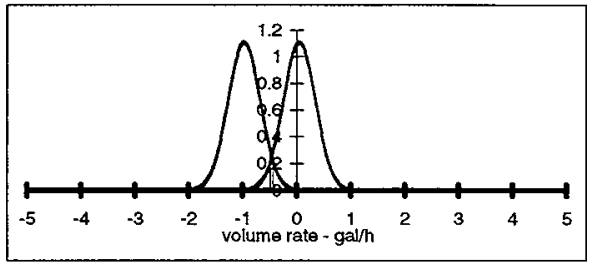

For $\mathrm{Pd} / \mathrm{Pfa}=99 \% / 1 \%$ :

The mean volume rate is equivalent to $0 \mathrm{gal} / \mathrm{h}$

Threshold, T:

$-0.75 \mathrm{gal} / \mathrm{h}$

Min. Detectable Leak:

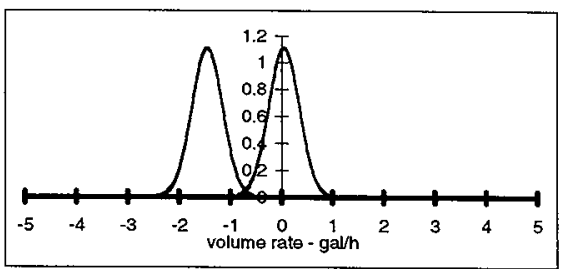

For this data, a threshold $=\quad-0.97 \mathrm{gal} / \mathrm{h}$ will detect a tank release of $1.50 \mathrm{gaVh}$ at a $\mathrm{Pd}=95 \%$ The corresponding $\mathrm{Pfa}$ is $0.32 \%$ 
Data File: BY-101 Data is from sensor type: NEUTRON ILL

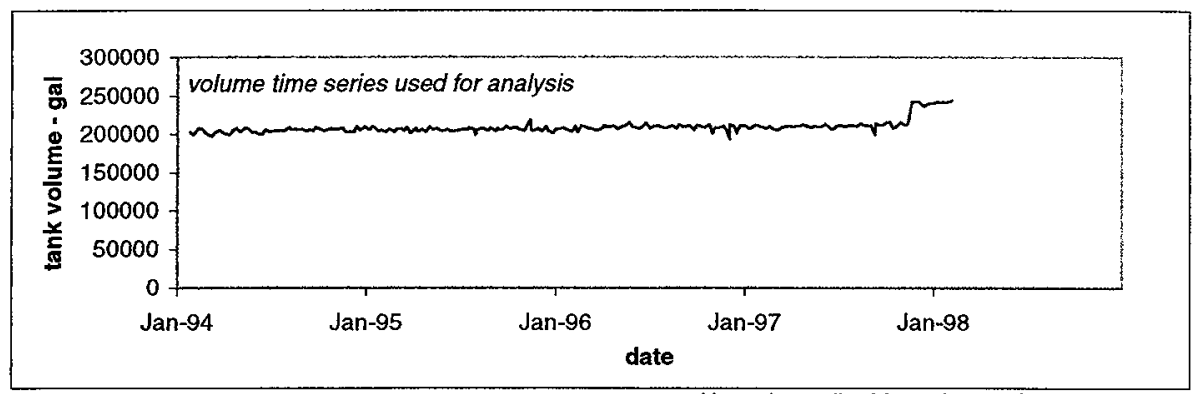

No. points edited from time series $=$

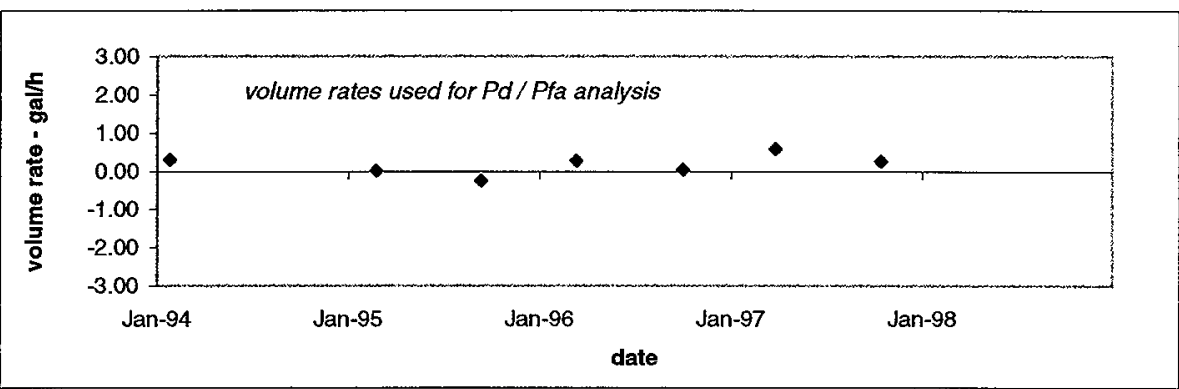

No. avg. vol rate estimates removed $=\quad 0$

During the analysis period, the average volume rate $=$ The standard deviation of the volume rate estimates =

For $\mathrm{Pd} / \mathrm{Pfa}=95 \% / 5 \%$ :

The mean volume rate is equivalent to $0 \mathrm{gal} / \mathrm{h}$ Threshold, T: $-4.37 \mathrm{gal} / \mathrm{h}$ Min. Detectable Leak: $\quad-8.74 \mathrm{gal} / \mathrm{h}$

\section{$0.98 \mathrm{gal} / \mathrm{h}$}

$2.31 \mathrm{gal} / \mathrm{h}$
For $\mathrm{Pd} / \mathrm{Pfa}=99 \% / 1 \%$ :

The mean volume rate is equivalent to $0 \mathrm{gal} / \mathrm{h}$ Threshold, T:

$-6.91 \mathrm{ga} / \mathrm{h}$

Min. Detectable Leak: $\quad-13.82 \mathrm{galh}$
Gaussian Plots Not Representative Due to small N....
Gaussian Plots Not Representative Due to small N.. 


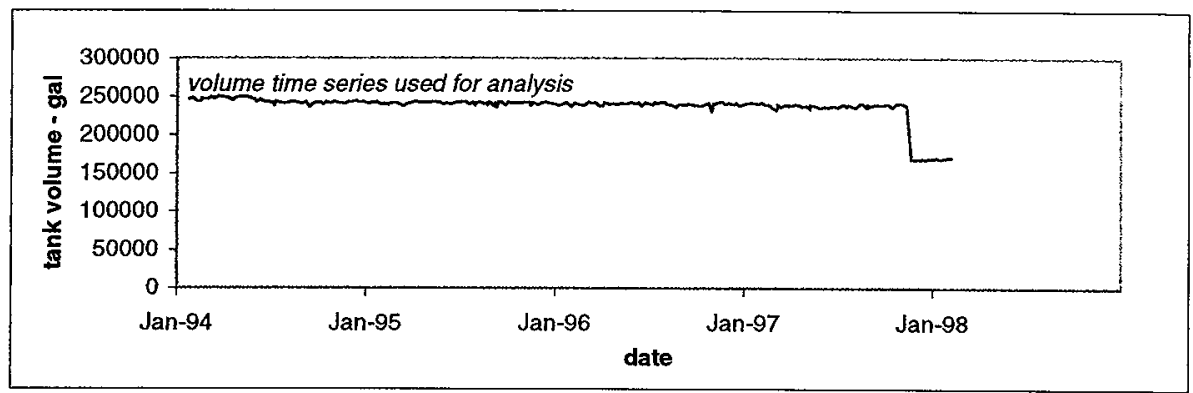

No. points edited from time series $=$

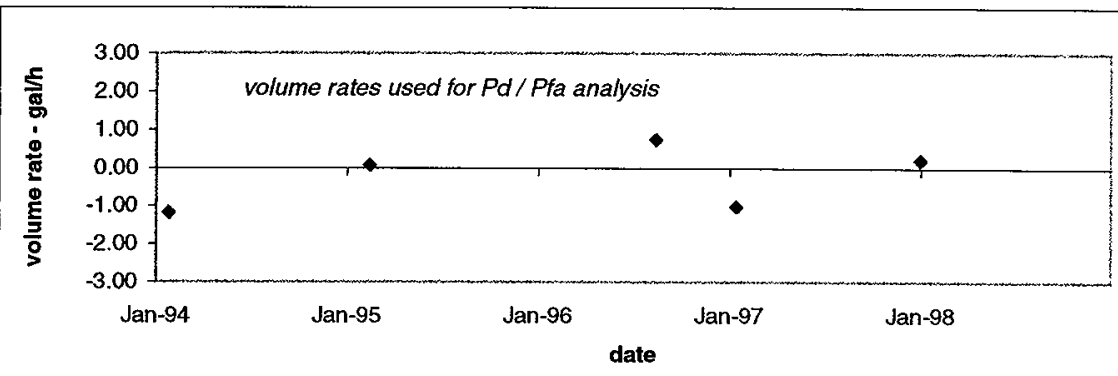

During the analysis period, the average volume rate $=$ The standard deviation of the volume rate estimates $=$

For $\mathrm{Pd} / \mathrm{Pfa}=\mathbf{9 5 \%} / \mathbf{5 \%}$ :

The mean volume rate is equivalent to $0 \mathrm{gal} / \mathrm{h}$ Threshold, T:

Min. Detectable Leak:

$-7.90 \mathrm{ga} / \mathrm{h}$

$-15.80 \mathrm{gal} / \mathrm{h}$

No. avg. vol rate estimates removed $=$ 1

$1.42 \mathrm{gal} / \mathrm{h}$

$$
N=8
$$

$4.17 \mathrm{gaV} / \mathrm{h}$

For Pd $/ \mathrm{Pfa}=99 \% / 1 \%$ :

The mean volume rate is equivalent to $0 \mathrm{gal} / \mathrm{h}$

Threshold, T: $\quad-12.50 \mathrm{gal} / \mathrm{h}$

Min. Detectable Leak: $\quad-25.00 \mathrm{gal} / \mathrm{h}$

Gaussian Plots Not Representative Due to small N.... 
Data File: BY-103 Data is from sensor type: NEUTRON ILL

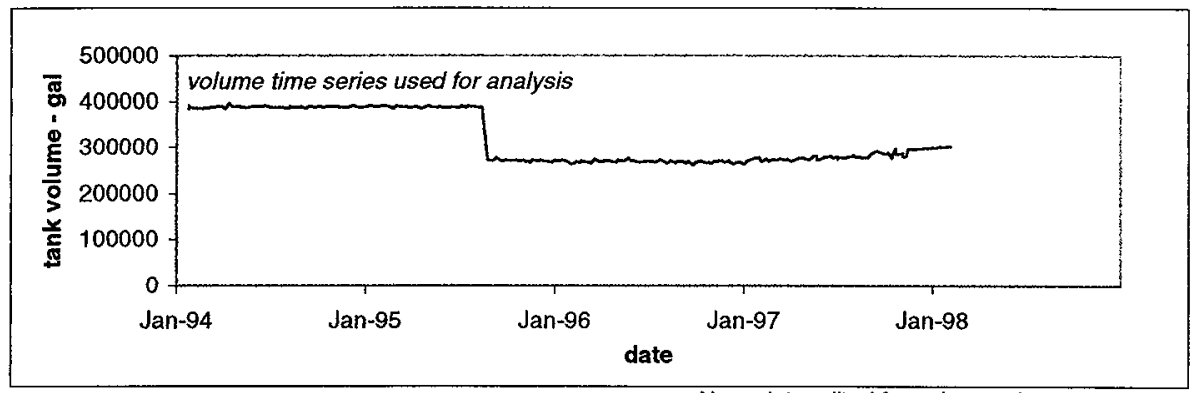

No. points edited from time series $=\quad 16$

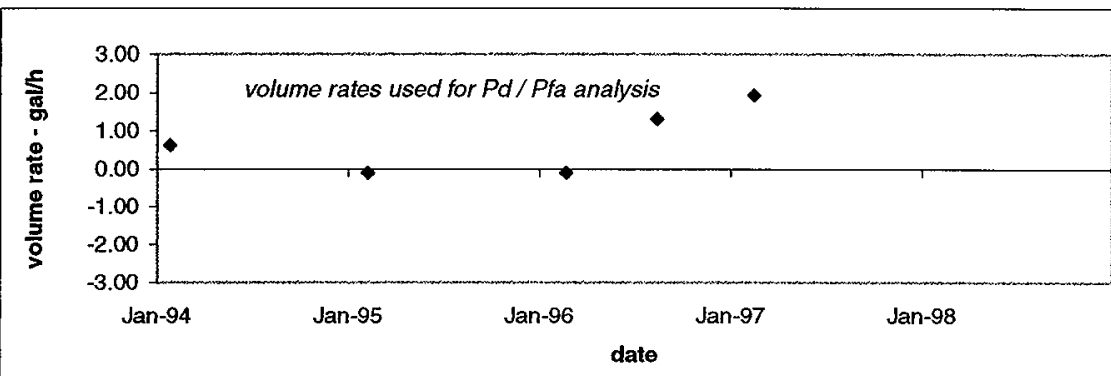

During the analysis period, the average volume rate $=$ The standard deviation of the volume rate estimates =

For Pd $/ \mathrm{Pfa}=95 \% / 5 \%$ :

The mean volume rate is equivalent to $0 \mathrm{gal} / \mathrm{h}$

Threshold, T: $\quad-1.90 \mathrm{gal} / \mathrm{h}$

Min. Detectable Leak: $\quad-3.81 \mathrm{gal} / \mathrm{h}$

Gaussian Plots Not Representative

Due to small $\mathbf{N} . .$.
No. avg. vol rate estimates removed $=$

$\mathrm{N}=$

$0.72 \mathrm{gal} / \mathrm{h}$

$0.89 \mathrm{gal} / \mathrm{h}$

For $\mathrm{Pd} / \mathrm{Pfa}=99 \% / 1 \%$ :

The mean volume rate is equivalent to $0 \mathrm{gal} / \mathrm{h}$

Threshold, T:

$-3.35 \mathrm{gal} / \mathrm{h}$

Min. Detectable Leak:
Gaussian Plots Not Representative Due to small N.... 
Data File: BY-104 Data is from sensor type: NEUTRON ILL

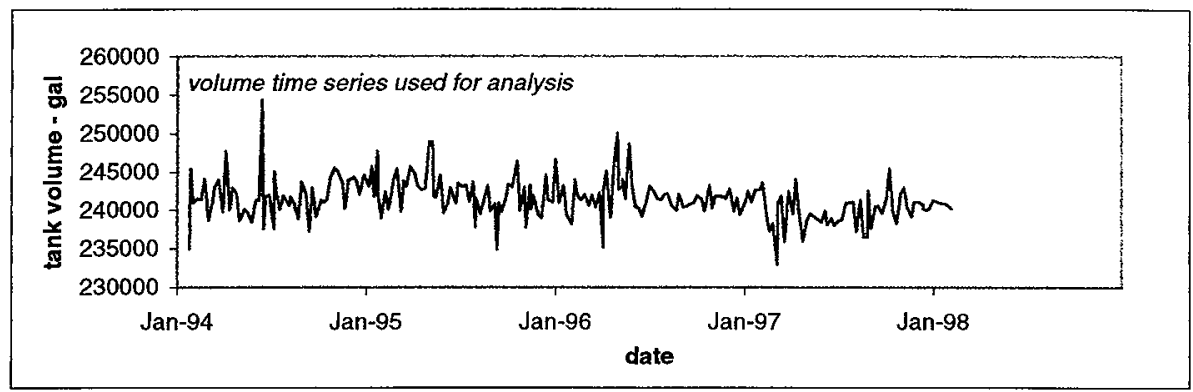

No. points edited from time series =

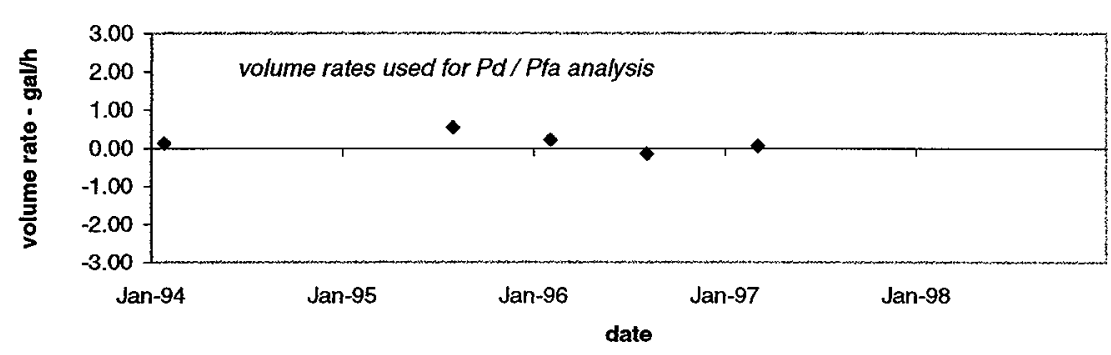

During the analysis period, the average volume rate = The standard deviation of the volume rate estimates =

For Pd $/ \mathrm{Pfa}=95 \% / 5 \%$ :

The mean volume rate is equivalent to $0 \mathrm{gal} / \mathrm{h}$

Threshold, T: $\quad-0.53 \mathrm{gal} / \mathrm{h}$

Min. Detectable Leak: $\quad-1.07 \mathrm{gal} / \mathrm{h}$

Gaussian Plots Not Representative Due to small N....
No. avg. vol rate estimates removed $=$

$\mathbf{N}=$

$0.15 \mathrm{gaV} / \mathrm{h}$

$0.25 \mathrm{gal} / \mathrm{h}$

For Pd $/ \mathrm{Pfa}=99 \% / 1 \%$ :

The mean volume rate is equivalent to $0 \mathrm{gal} / \mathrm{h}$

Threshold, $\mathrm{T}$ : $\quad-0.94 \mathrm{gal} / \mathrm{h}$

Min. Detectable Leak: $\quad-1.88 \mathrm{gal} / \mathrm{h}$
Gaussian Plots Not Representative Due to small N.... 
Data File: BY-105 Data is from sensor type: NEUTRON ILL

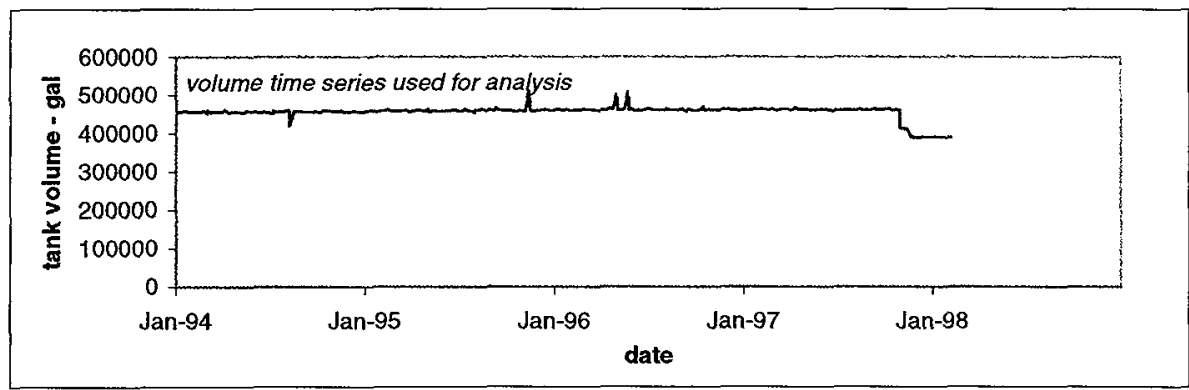

No. points edited from time series $=\quad 5$

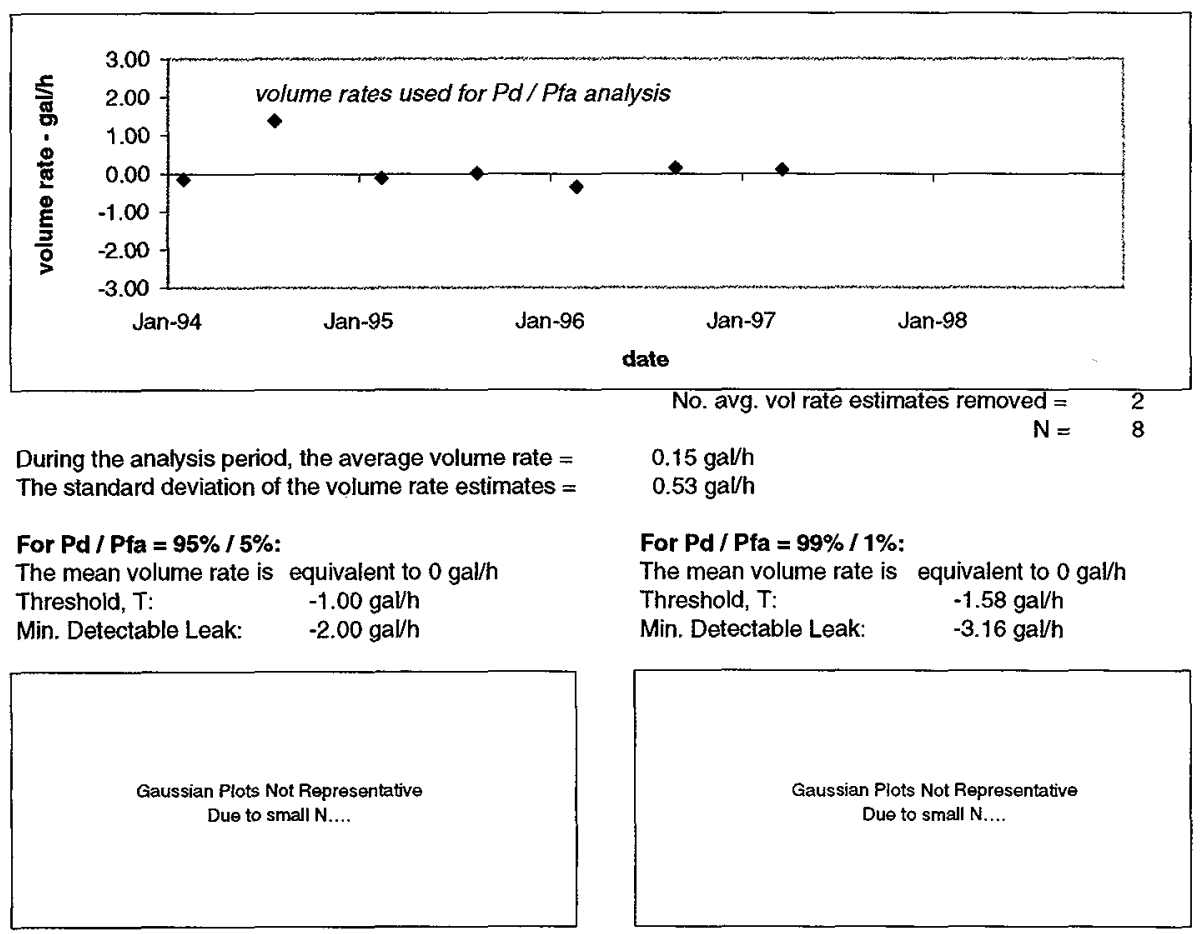




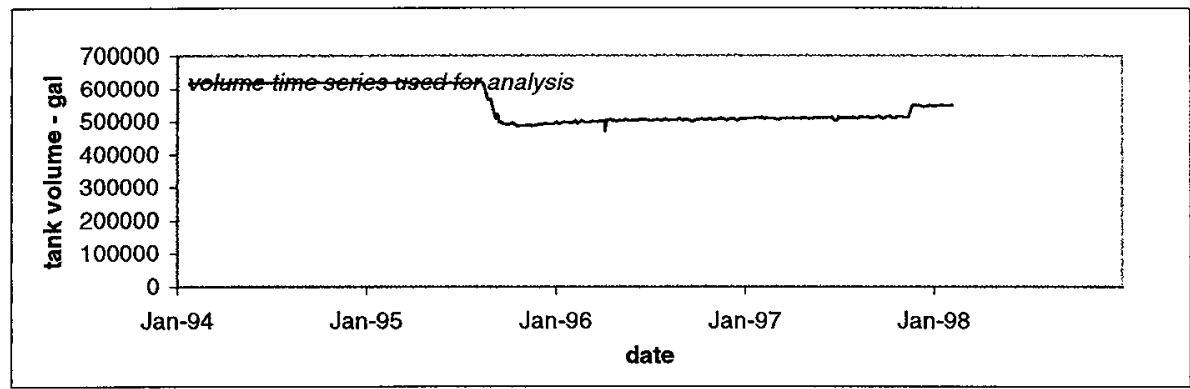

No. points edited from time series $=$

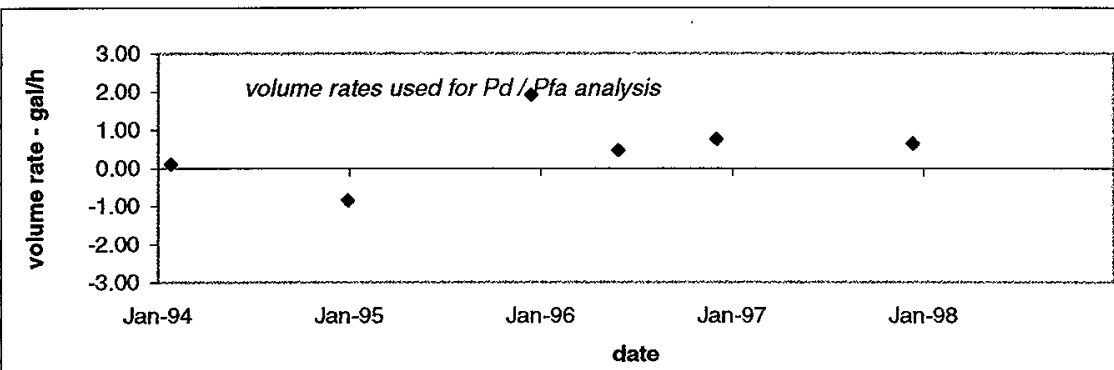

During the analysis period, the average volume rate =

No. avg. vol rate estimates removed $=$

$N=$ 3 The standard deviation of the volume rate estimates = $0.50 \mathrm{ga} / \mathrm{h}$
$0.90 \mathrm{ga} / \mathrm{h}$

For Pd $/ \mathrm{Pfa}=\mathbf{9 9} \% / \mathbf{1} \%$ :

For Pd / Pfa $=95 \% / 5 \%$ :

The mean volume rate is equivalent to $0 \mathrm{gal} / \mathrm{h}$

Threshold, T: $\quad-1.82 \mathrm{gal} / \mathrm{h}$

Min. Detectable Leak: $\quad-3.63 \mathrm{gal} / \mathrm{h}$

The mean volume rate is equivalent to $0 \mathrm{gal} / \mathrm{h}$

Threshold, $\mathrm{T}$ : $\quad-3.03 \mathrm{gal} / \mathrm{h}$

Min. Detectable Leak: $\quad-6.07 \mathrm{ga} / \mathrm{h}$ Due to small N.... 
Data File: BY-107 Data is from sensor type: NEUTRON ILL

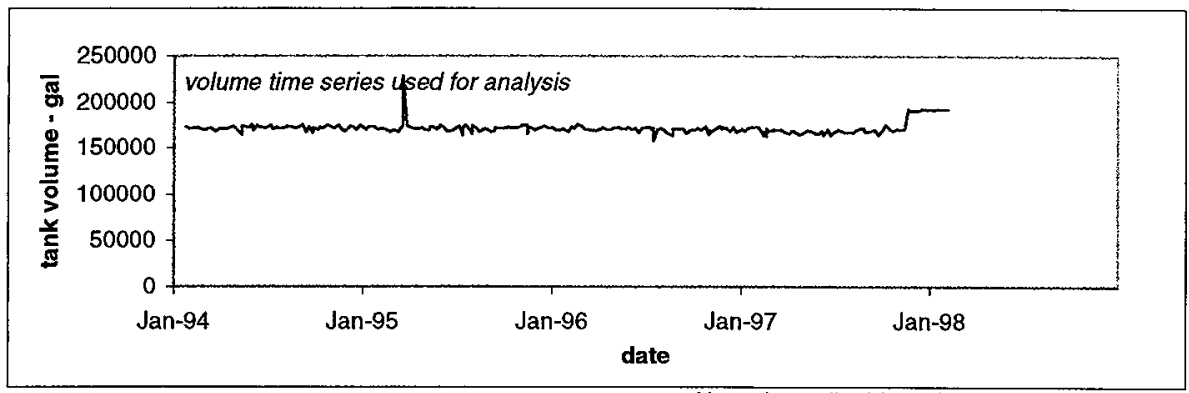

No. points edited from time series $=$

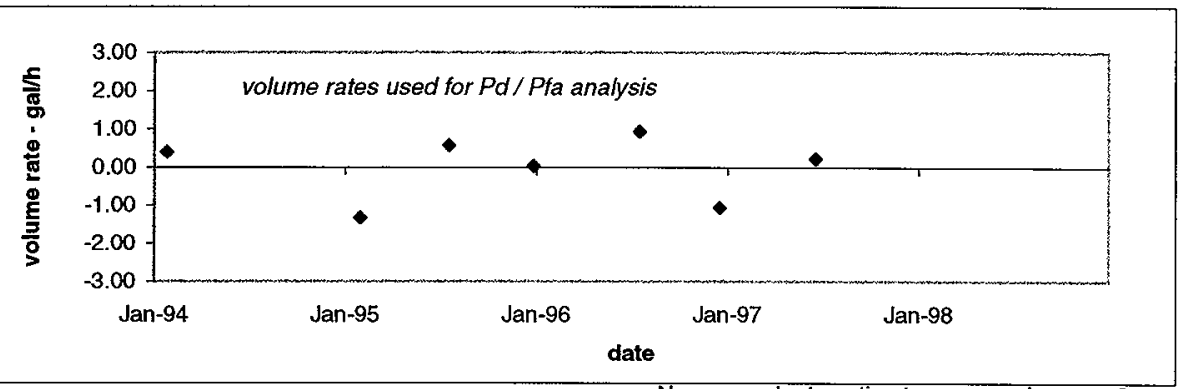

During the analysis period, the average volume rate $=$ The standard deviation of the volume rate estimates =

For Pd $/ \mathrm{Pfa}=95 \% / 5 \%$ :

The mean volume rate is equivalent to $0 \mathrm{gal} / \mathrm{h}$ Threshold, T:

Min. Detectable Leak: $\quad-3.28 \mathrm{gal} / \mathrm{h}$

Gaussian Plots Not Representative

Due to small $N$...
$-0.04 \mathrm{ga} / \mathrm{h}$

$N=7$
For $\mathrm{Pd} / \mathrm{Pfa}=99 \% / 1 \%$ :

The mean volume rate is equivalent to $0 \mathrm{gal} / \mathrm{h}$

Threshold, $\mathrm{T}$ : $\quad-2.65 \mathrm{gal} / \mathrm{h}$

Min. Detectable Leak: $\quad-5.31 \mathrm{ga} / \mathrm{h}$
Gaussian Plots Not Representative Due to small N... 
Data File: BY-109 Data is from sensor type: NEUTRON ILL

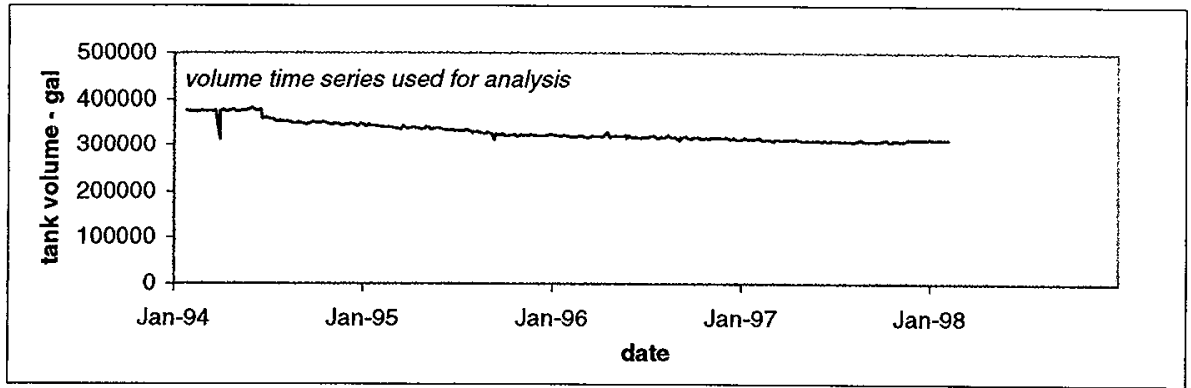

No. points edited from time series =

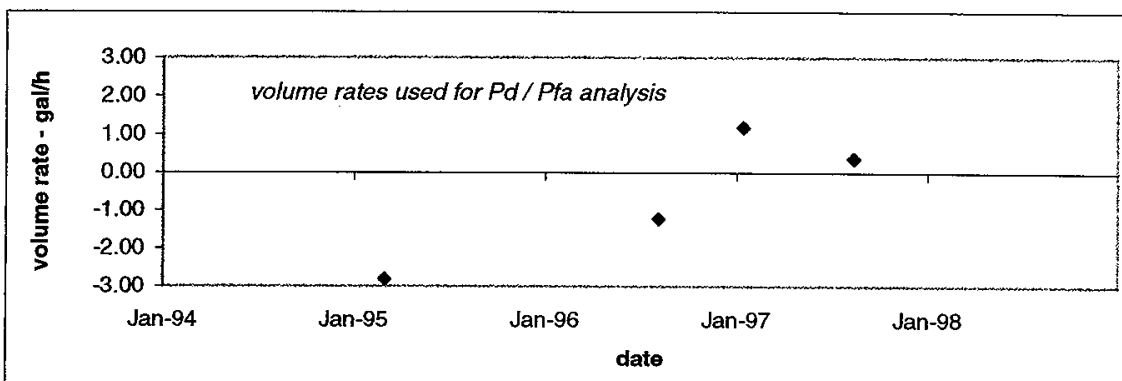

During the analysis period, the average volume rate $=$ The standard deviation of the volume rate estimates = $-0.62 \mathrm{gal} / \mathrm{h}$

No. avg. vol rate estimates removed $=4$

\section{$1.76 \mathrm{gal} / \mathrm{h}$}

For Pd $/ \mathrm{Pfa}=\mathbf{9 5 \%} / \mathbf{5 \%}$ :

The mean volume rate is equivalent to $0 \mathrm{gal} / \mathrm{h}$

Threshold, T:

$-4.14 \mathrm{gal} / \mathrm{h}$

Min. Detectable Leak: $\quad-8.28 \mathrm{gal} / \mathrm{h}$

For Pd $/$ Pfa $=99 \% / 1 \%$ :

The mean volume rate is equivalent to $0 \mathrm{gal} / \mathrm{h}$ Threshold, T:

$-7.99 \mathrm{gal} / \mathrm{h}$

Min. Detectable Leak: $\quad-15.97 \mathrm{gal} / \mathrm{h}$

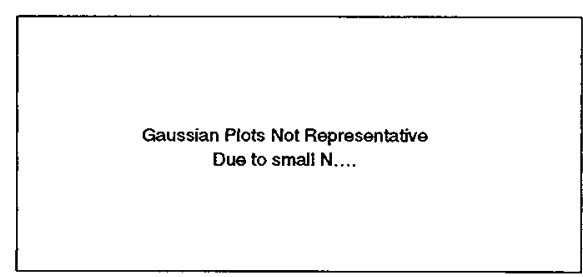

Gaussian Plots Not Representative Due to small N.... 


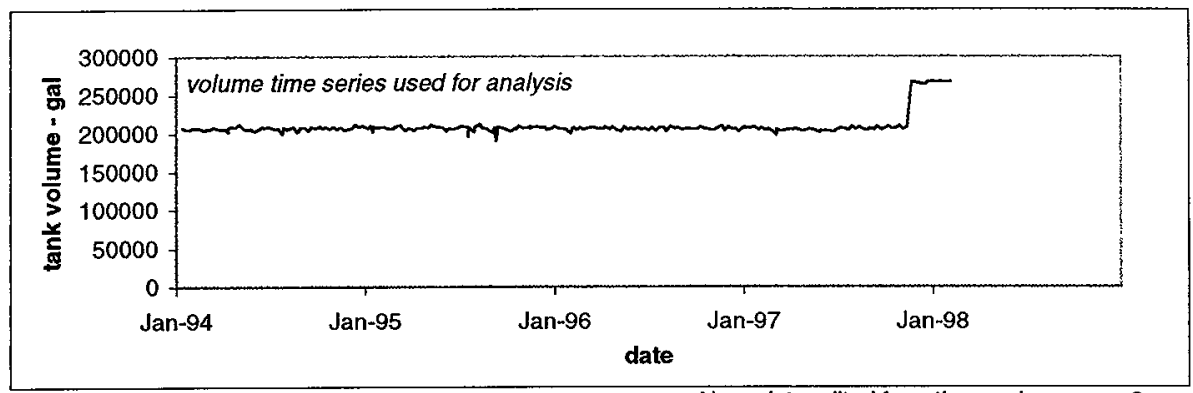

No. points edited from time series $=$

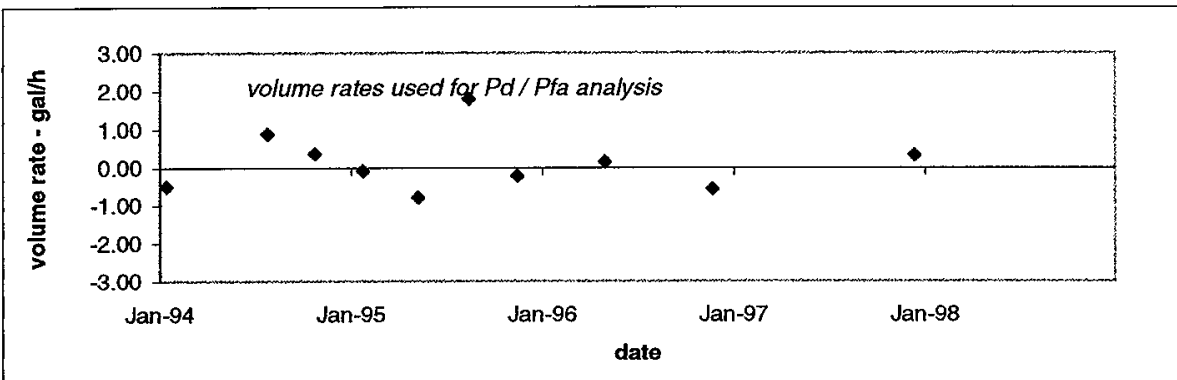

During the analysis period, the average volume rate $=$ The standard deviation of the volume rate estimates =

For Pd $/$ Pfa = 95\% / 5\%:

The mean volume rate is equivalent to $0 \mathrm{gal} / \mathrm{h}$ Threshold, $\mathrm{T}$ : $-1.41 \mathrm{gal} / \mathrm{h}$ Min. Detectable Leak: $\quad-2.82 \mathrm{gal} / \mathrm{h}$

Gaussian Plots Not Representative Due to small N....
No. avg. vol rate estimates removed =

$0.13 \mathrm{gal} / \mathrm{h}$

$0.77 \mathrm{gal} / \mathrm{h}$

For Pd / Pfa $=99 \% / 1 \%$ :

The mean volume rate is equivalent to $0 \mathrm{gal} / \mathrm{h}$ Threshold, T: $-2.17 \mathrm{gal} / \mathrm{h}$ Min. Detectable Leak: $\quad-4.33 \mathrm{gal} / \mathrm{h}$
Gaussian Plots Not Representative Due to small N.... 
Data File: BY-112 Data is from sensor type: NEUTRON ILL

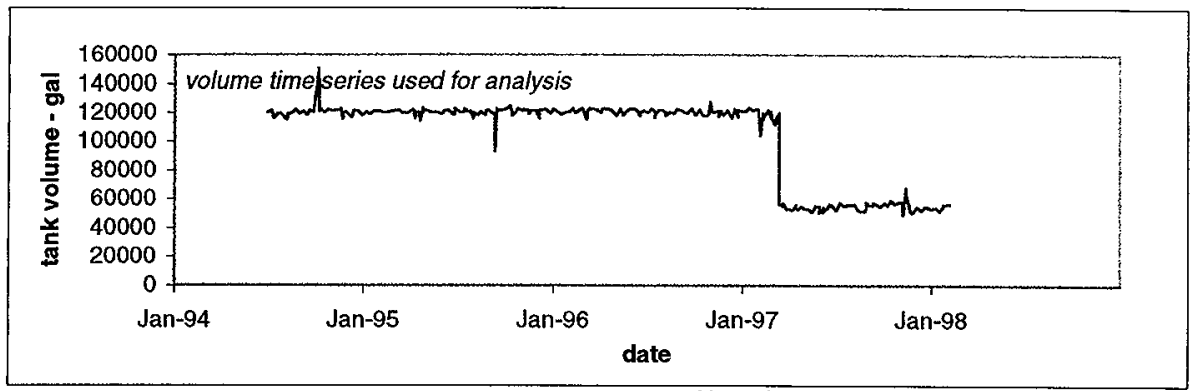

No. points edited from time series $=$ 10

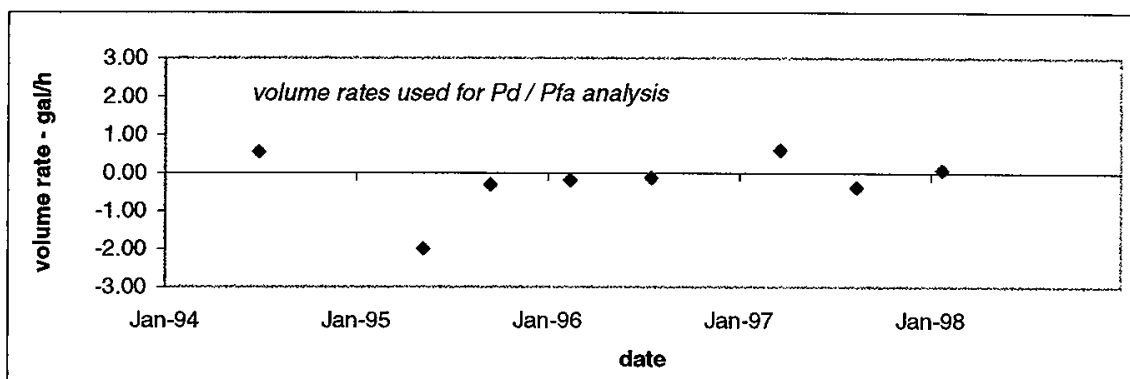

During the analysis period, the average volume rate =

No. avg. vol rate estimates removed $=$

$N=8$

The standard deviation of the volume rate estimates =

$-0.23 \mathrm{gal} / \mathrm{h}$

$0.80 \mathrm{gal} / \mathrm{h}$

For Pd / Pfa $=95 \% / 5 \%$ :

The mean volume rate is equivalent to $0 \mathrm{gal} / \mathrm{h}$

Threshold, $\mathrm{T}$ : $\quad-1.53 \mathrm{gal} / \mathrm{h}$

Min. Detectable Leak: $\quad-3.05 \mathrm{gal} / \mathrm{h}$

Gaussian Plots Not Representative Due to smal $\mathrm{N}$....
For $\mathrm{Pd} / \mathrm{Pfa}=\mathbf{9 9} \% / 1 \%$ :

The mean volume rate is equivalent to $0 \mathrm{gal} / \mathrm{h}$

Threshold, T:

$-2.41 \mathrm{gal} / \mathrm{h}$

Min. Detectable Leak: $\quad-4.83 \mathrm{gal} / \mathrm{h}$
Gaussian Plots Not Representative Due to small N... 
Data File: C-103 Data is from sensor type: Manual ENRAF

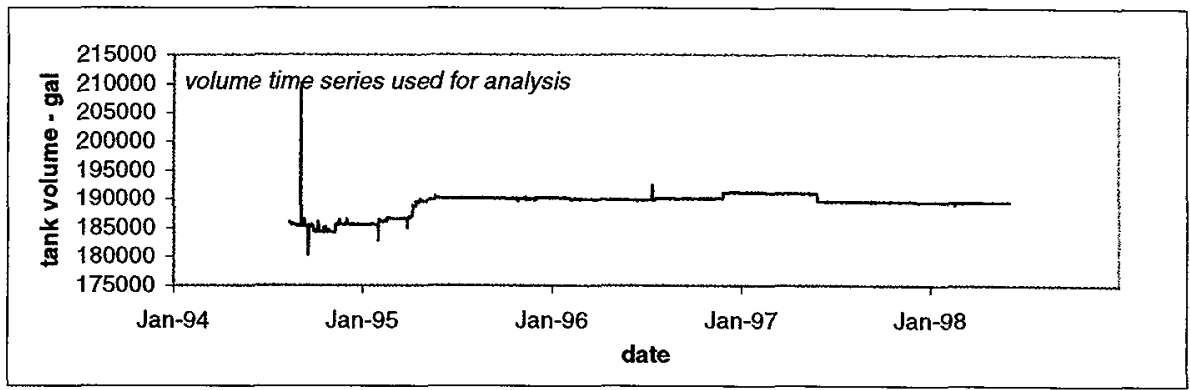

No. points edited from time series =

3

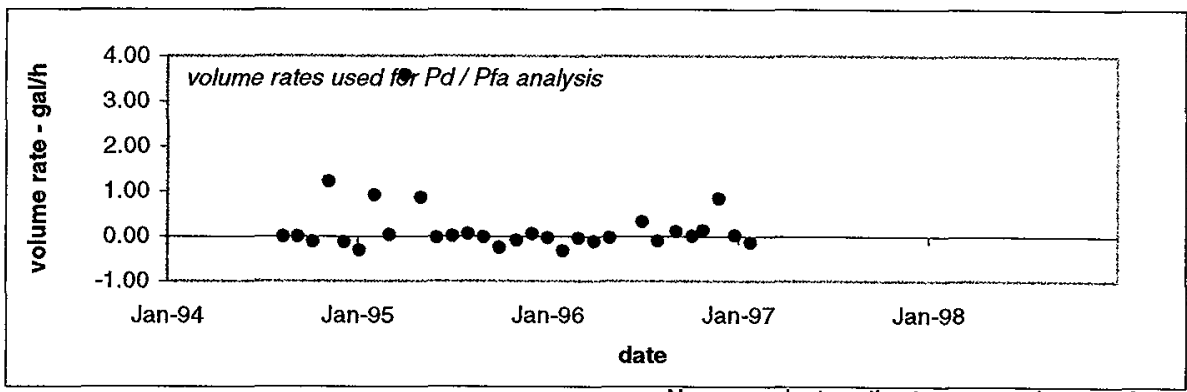

During the analysis period, the average volume rate = The standard deviation of the volume rate estimates =

For $\mathrm{Pd} / \mathrm{Pfa}=95 \% / 5 \%$ :

The mean volume rate is equivalent to $0 \mathrm{gal} / \mathrm{h}$ Threshold, T:

Min. Detectable Leak: $\quad-2.59 \mathrm{ga} / \mathrm{h}$

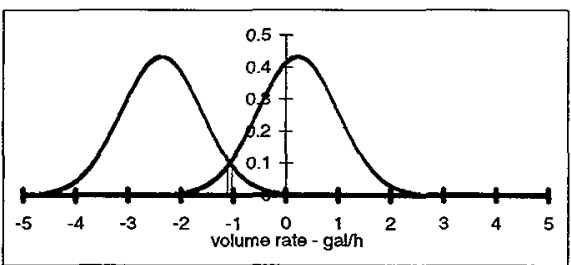

\section{$0.23 \mathrm{ga} / \mathrm{h}$}

$0.76 \mathrm{gal} / \mathrm{h}$
For Pd $/$ Pfa $=99 \% / 1 \%$ :

The mean volume rate is equivalent to $0 \mathrm{gal} / \mathrm{h}$

Threshold, $\mathrm{T}$ : $\quad-1.88 \mathrm{gal} / \mathrm{h}$

Min. Detectable Leak: $\quad-3.77 \mathrm{gal} / \mathrm{h}$

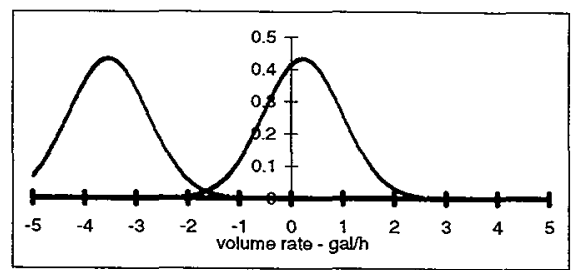

For this data, a threshold $=-2.03 \mathrm{galh}$ will detect a tank release of $\quad 3.77 \mathrm{galh}$ al a $\mathrm{Pd}=95 \%$ The corresponding Pfa is $0.52 \%$ 


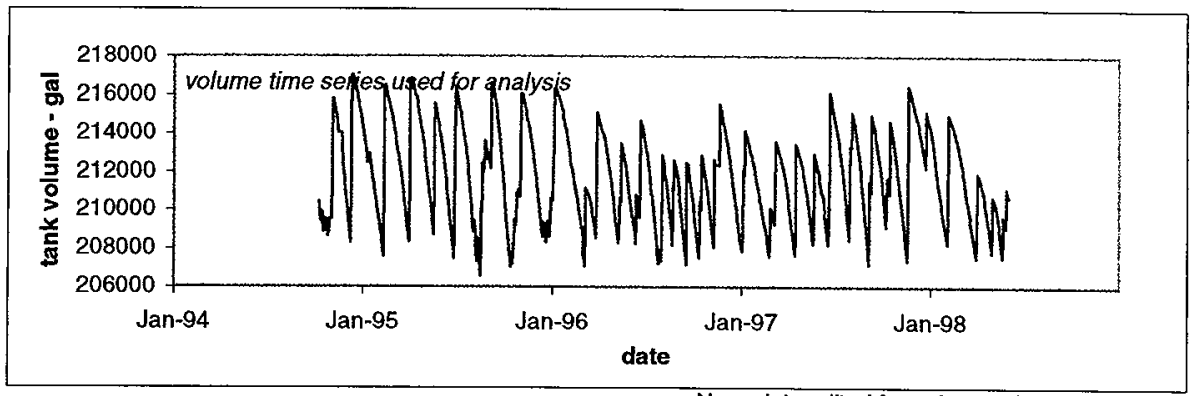

No. points edited from time series =

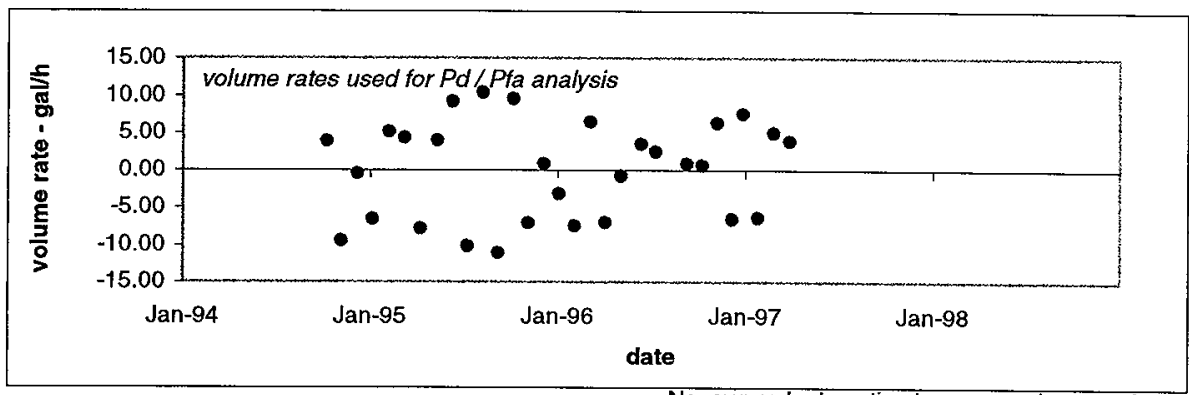

During the analysis period, the average volume rate = The standard deviation of the volume rate estimates =

For Pd $/ \mathrm{Pfa}=95 \% / 5 \%$ :

The mean volume rate is equivalent to $0 \mathrm{gal} / \mathrm{h}$

Threshold, $\mathrm{T}$ : $\quad-11.06 \mathrm{gal} / \mathrm{h}$

Min. Detectable Leak: $\quad-22.12 \mathrm{gal} / \mathrm{h}$

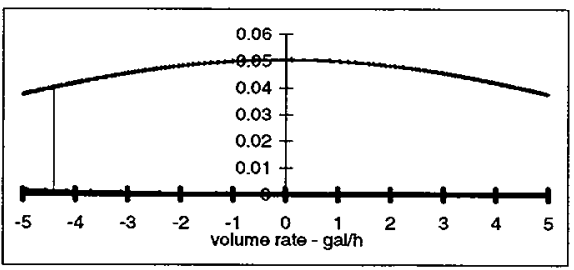

No. avg. vol rate estimates removed $=\quad 0$

$0.01 \mathrm{galh}$

$N=30$
For $\mathrm{Pd} / \mathrm{Pfa}=99 \% / 1 \%$ :

The mean volume rate is equivalent to $0 \mathrm{gal} / \mathrm{h}$ Threshold, T:

$-16.03 \mathrm{gal} / \mathrm{h}$ Min. Detectable Leak: $\quad-32.05 \mathrm{ga} / \mathrm{h}$

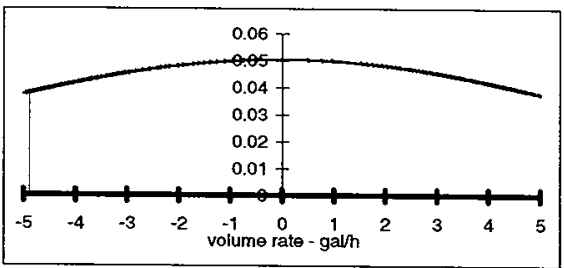

For this data, a threshold $=\quad 5.00 \mathrm{gal} / \mathrm{h}$ will detect a tank release of $\quad 32.05 \mathrm{gal} / \mathrm{h}$ at a Pd $=95 \%$ The corresponding $\mathrm{Pfa}$ is $\quad 3.76 \%$ 


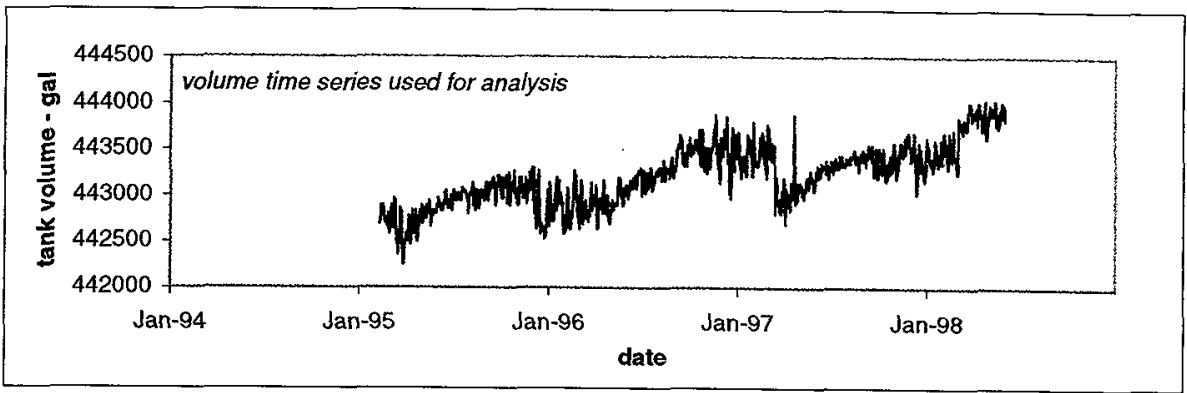

No. points edited from time series $=$

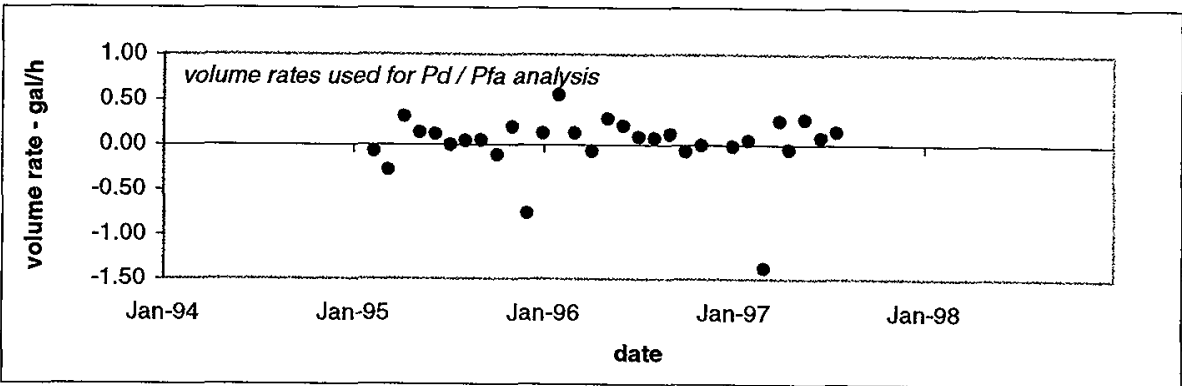

During the analysis period, the average volume rate $=$ The standard deviation of the volume rate estimates =

For $\mathrm{Pd} / \mathrm{Pfa}=95 \% / 5 \%$ :

The mean volume rate is equivalent to $0 \mathrm{gal} / \mathrm{h}$

Threshold, T: $\quad-0.58 \mathrm{ga} / \mathrm{h}$

Min. Detectable Leak: $\quad-1.17 \mathrm{gal} / \mathrm{h}$

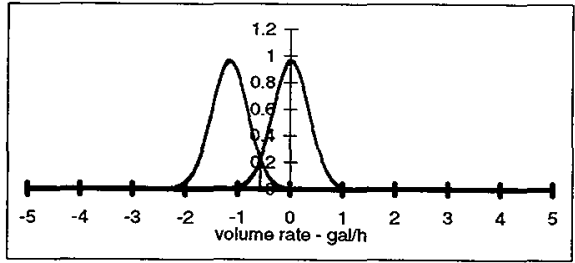

For this data, a threshold= $-1.12 \mathrm{gal} / \mathrm{h}$ will detect a tank release of The corresponding $\mathrm{Pfa}$ is $\quad 0.40 \%$

\section{$0.02 \mathrm{gal} / \mathrm{h}$}

$0.34 \mathrm{gal} / \mathrm{h}$
For Pd $/$ Pfa $=99 \% / 1 \%$ :

The mean volume rate is equivalent to $0 \mathrm{gal} / \mathrm{h}$ Threshold, $\mathrm{T}$ : Min. Detectable Leak: $-0.84 \mathrm{gal} / \mathrm{h}$ $-1.69 \mathrm{ga} / \mathrm{h}$

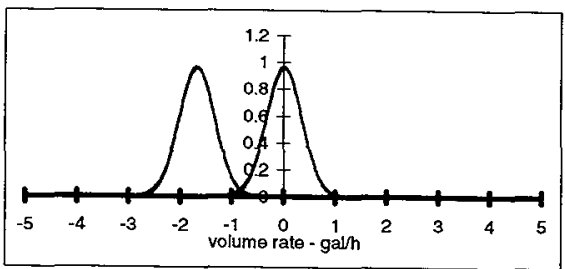

$1.69 \mathrm{gal} / \mathrm{h}$ at $\mathrm{Pd}=95 \%$ 


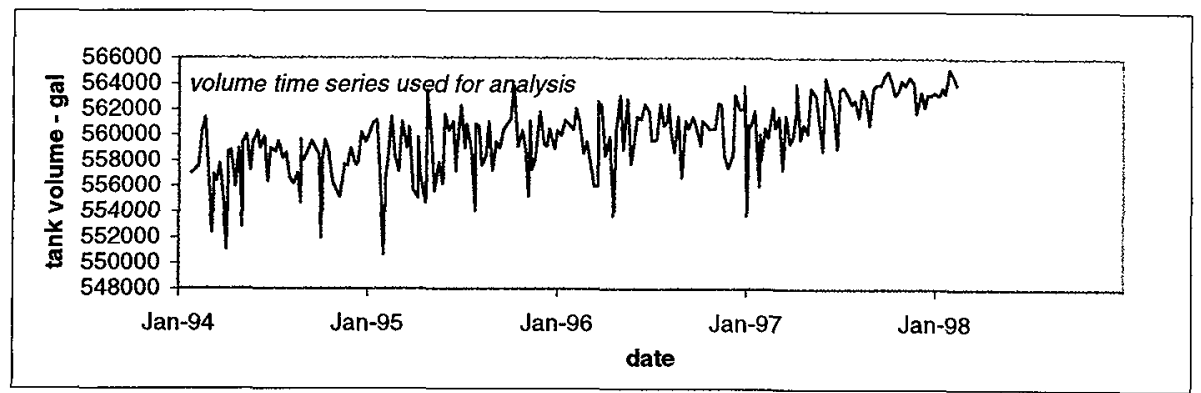

No. points edited from time series =

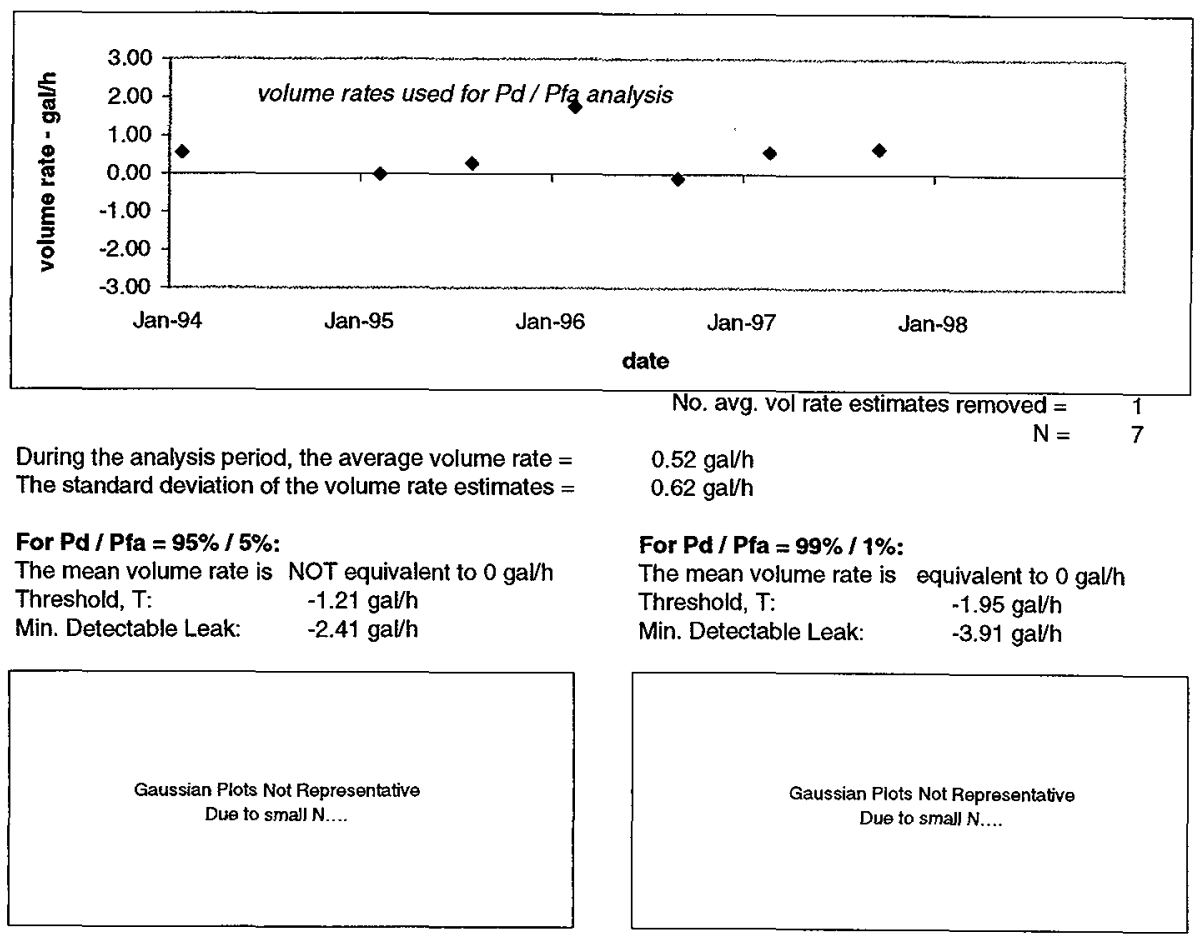




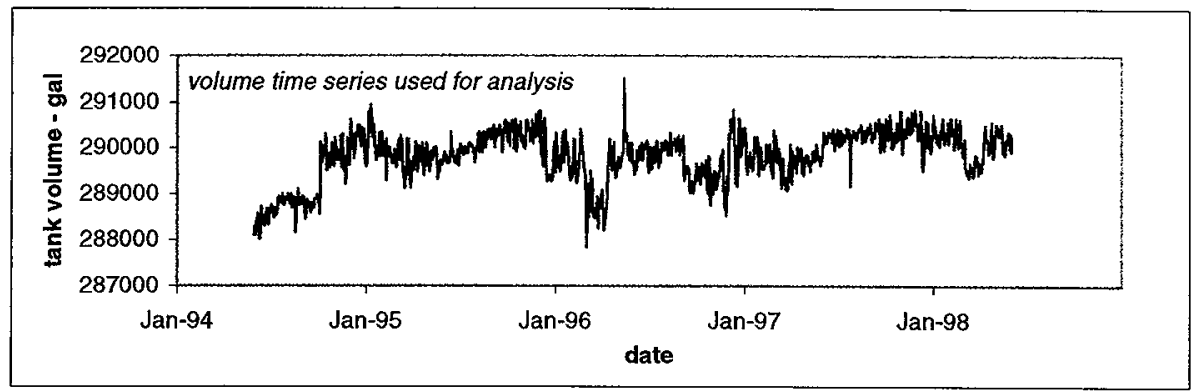

No. points edited from time series =

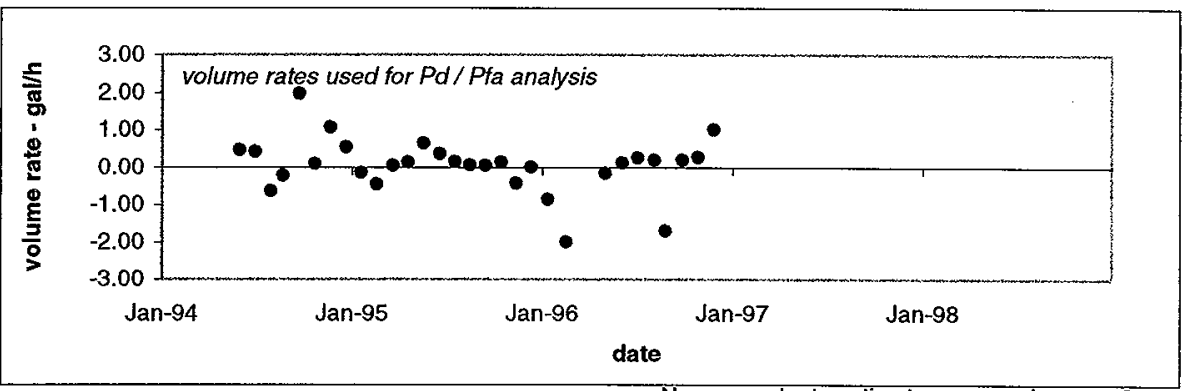

During the analysis period, the average volume rate = The standard deviation of the volume rate estimates =

For $\mathrm{Pd} / \mathrm{Pfa}=95 \% / 5 \%$ :

The mean volume rate is equivalent to $0 \mathrm{gal} / \mathrm{h}$

Threshold, $\mathrm{T}$ : $\quad-1.26 \mathrm{gal} / \mathrm{h}$

Min. Detectable Leak: $\quad-2.52 \mathrm{gal} / \mathrm{h}$

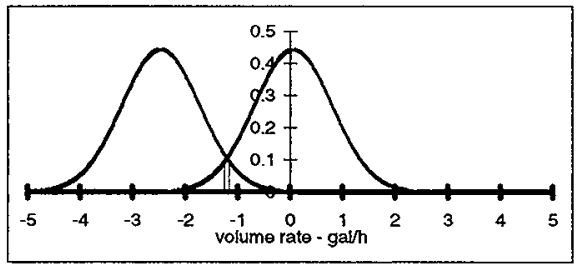

No. avg. vol rate estimates removed $=\quad 0$

$0.06 \mathrm{gal} / \mathrm{h}$

$0.74 \mathrm{gal} / \mathrm{h}$

For $\mathrm{Pd} / \mathrm{Pfa}=99 \% / 1 \%$ :

The mean volume rate is equivalent to $0 \mathrm{gal} / \mathrm{h}$

Threshold, $\mathrm{T}$ : $\quad-1.83 \mathrm{gal} / \mathrm{h}$

Min. Detectable Leak: $\quad-3.66 \mathrm{gal} / \mathrm{h}$

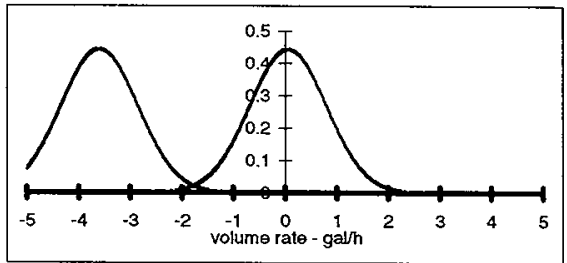

For this data, a threshold $=-2.10 \mathrm{galh}$ will detect a tank release of $\quad 3.66 \mathrm{gal} / \mathrm{h}$ at a $\mathrm{Pd}=95 \%$ The corresponding $\mathrm{Pfa}$ is $\quad 0.65 \%$ 


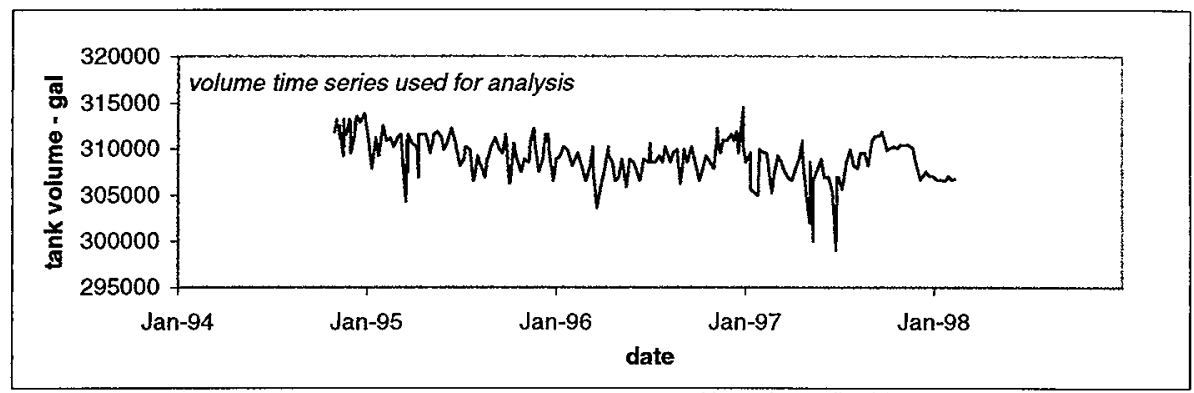

No. points edited from time series $=0$

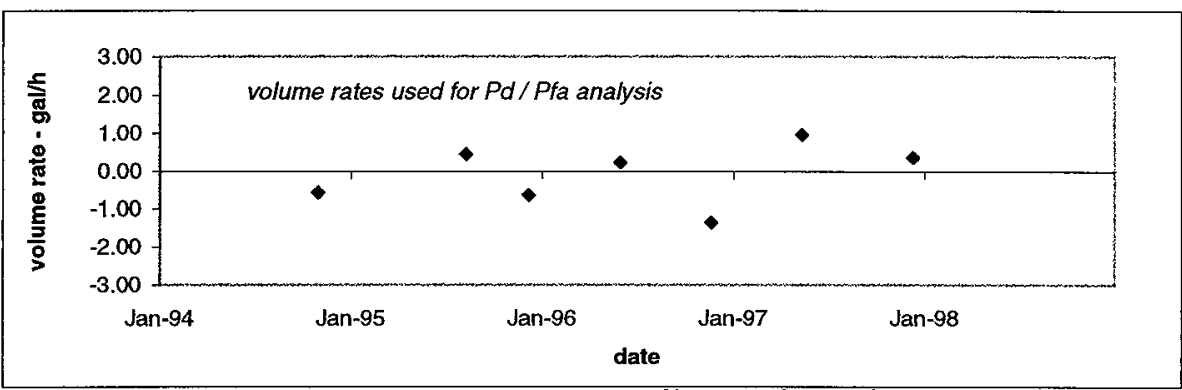

During the analysis period, the average volume rate = The standard deviation of the volume rate estimates =

For Pd / Pfa = 95\% / 5\%:

The mean volume rate is equivalent to $0 \mathrm{gal} / \mathrm{h}$

Threshold, T:

$-1.55 \mathrm{gal} / \mathrm{h}$

Min. Detectable Leak: $\quad-3.10 \mathrm{gal} / \mathrm{h}$

Gaussian Plots Not Representative Due to small N....
No. avg. vol rate estimates removed $=$

$$
\mathrm{N}=7
$$

$-0.09 \mathrm{gal} / \mathrm{h}$

$0.80 \mathrm{gal} / \mathrm{h}$

For Pd $/ \mathrm{Pfa}=99 \% / 1 \%$ :

The mean volume rate is equivalent to $0 \mathrm{gal} / \mathrm{h}$

Threshold, T:

$-2.50 \mathrm{ga} / \mathrm{h}$

Min. Detectable Leak: $\quad-5.01 \mathrm{gal} / \mathrm{h}$

Gaussian Plots Not Representative Due to small N.... 


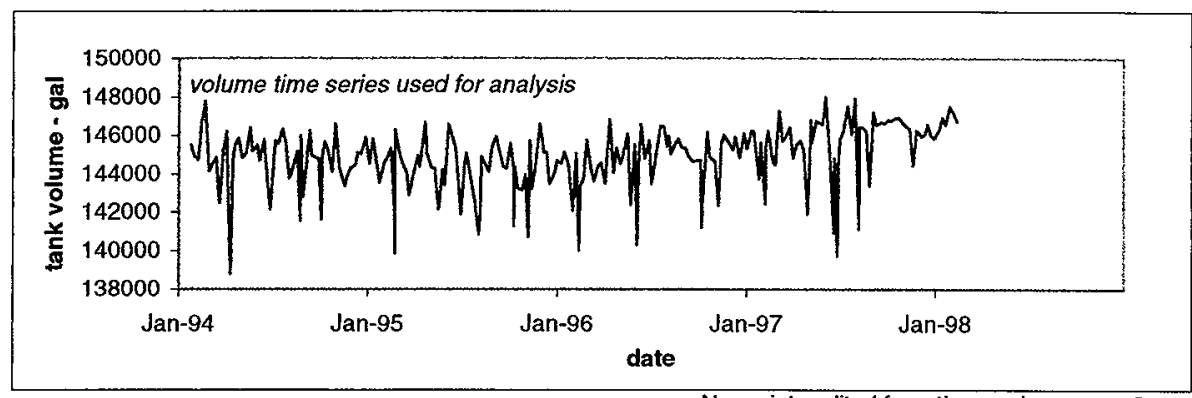

No. points edited from time series $=$

3

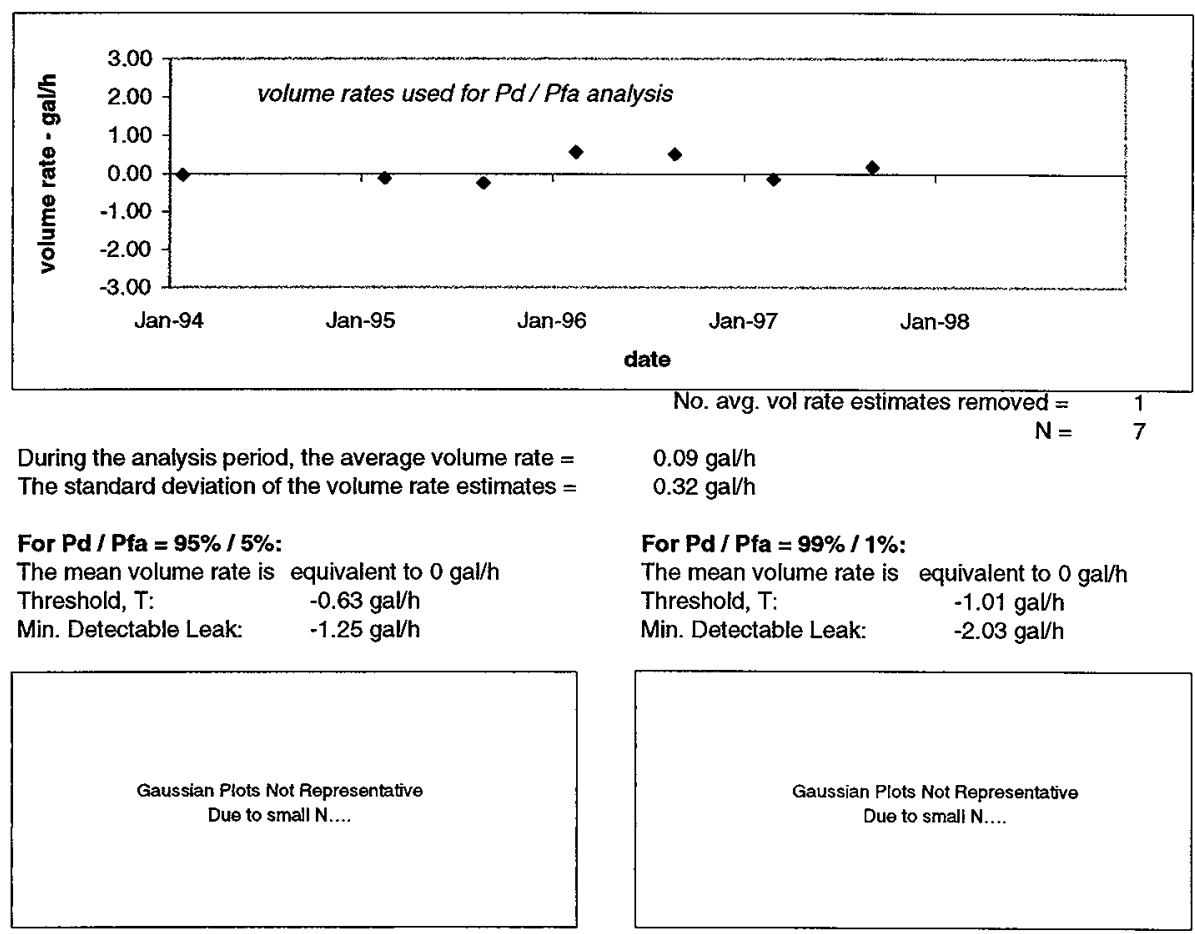




\section{Data File: S-108 Data is from sensor type: NEUTRON ILL}

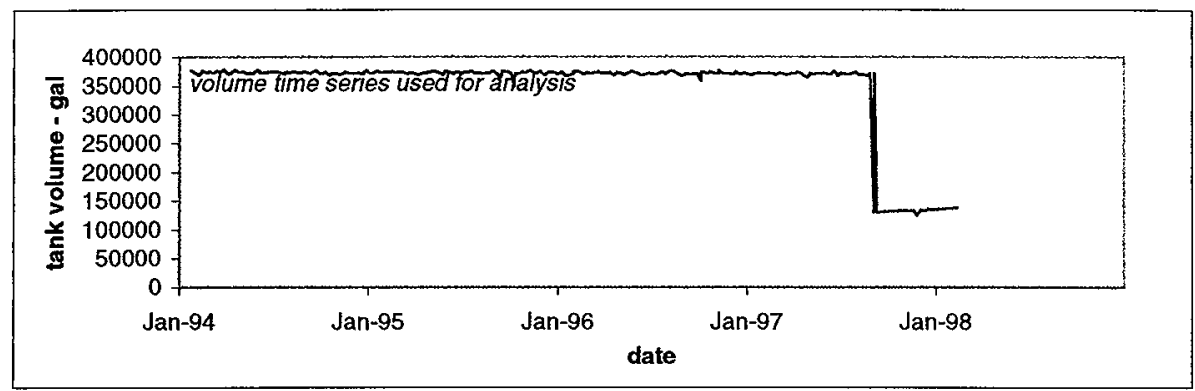

No. points edited from time series =

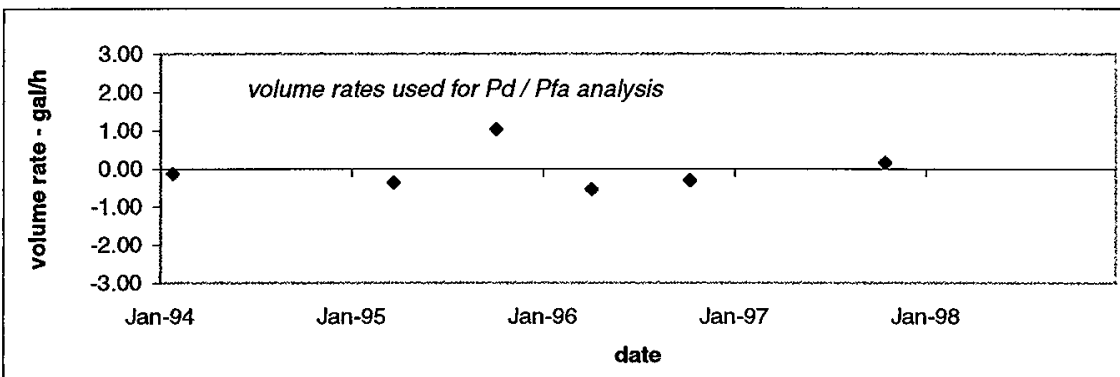

During the analysis period, the average volume rate = The standard deviation of the volume rate estimates =

For $\mathrm{Pd} / \mathrm{Pfa}=95 \% / 5 \%$ :

The mean volume rate is equivalent to $0 \mathrm{gal} / \mathrm{h}$

Threshold, T: $\quad-1.15 \mathrm{gal} / \mathrm{h}$

Min. Detectable Leak: $\quad-2.29 \mathrm{gal} / \mathrm{h}$

Gaussian Plots Not Representative Due to small $\mathbf{N}$...
No. avg. vol rate estimates removed $=$ $-0.03 \mathrm{gal} / \mathrm{h}$

$0.57 \mathrm{gal} / \mathrm{h}$

For $\mathrm{Pd} / \mathrm{Pfa}=99 \% / 1 \%$ :

The mean volume rate is equivalent to $0 \mathrm{gal} / \mathrm{h}$

Threshold, T: $\quad-1.91 \mathrm{gal} / \mathrm{h}$

Min. Detectable Leak: $\quad-3.83 \mathrm{ga} / \mathrm{h}$

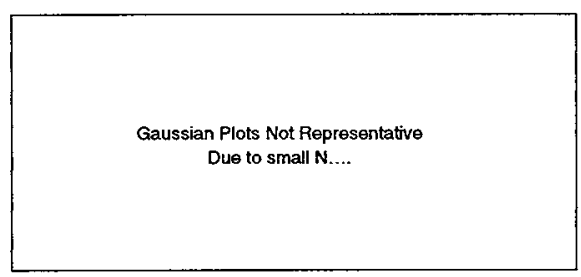

Gaussian Plots Not Representative Due to small $\mathrm{N}$.... 


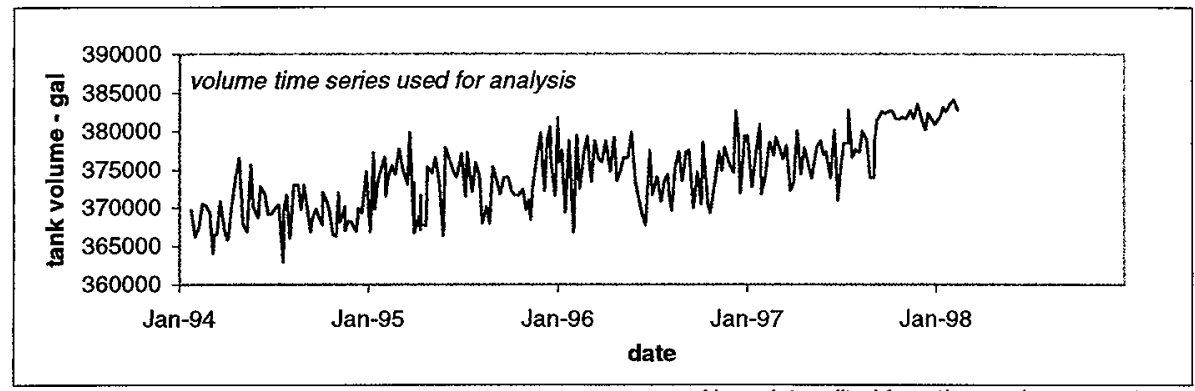

No. points edited from time series =

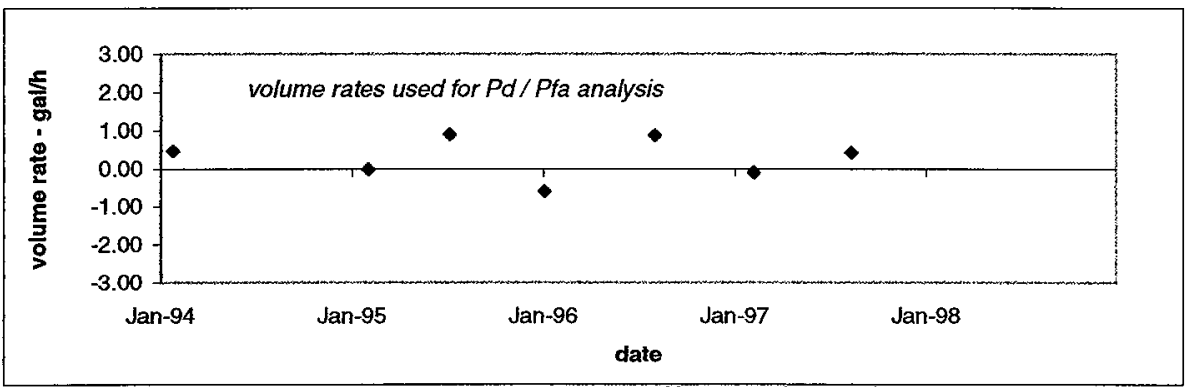

During the analysis period, the average volume rate = The standard deviation of the volume rate estimates =

For Pd $/ \mathrm{Pfa}=95 \% / 5 \%$ :

The mean volume rate is equivalent to $0 \mathrm{gal} / \mathrm{h}$ Threshold, T: $-1.07 \mathrm{gal} / \mathrm{h}$ Min. Detectable Leak: $\quad-2.13 \mathrm{gal} / \mathrm{h}$ $\begin{aligned} \text { No. avg. vol rate estimates removed } & =1 \\ \mathrm{~N}= & 7\end{aligned}$

$0.27 \mathrm{gal} / \mathrm{h}$

$0.55 \mathrm{gal} / \mathrm{h}$

For Pd / Pfa $=99 \% / 1 \%$ :

The mean volume rate is equivalent to $0 \mathrm{gal} / \mathrm{h}$

Threshold, T: $\quad-1.73 \mathrm{gal} / \mathrm{h}$

Min. Detectable Leak: $\quad-3.45 \mathrm{ga} / \mathrm{h}$
Gaussian Plots Not Representative Due to small N...
Gaussian Plots Not Representative Due to smali N... 
Data File: S-110 Data is from sensor type: NEUTRON ILL

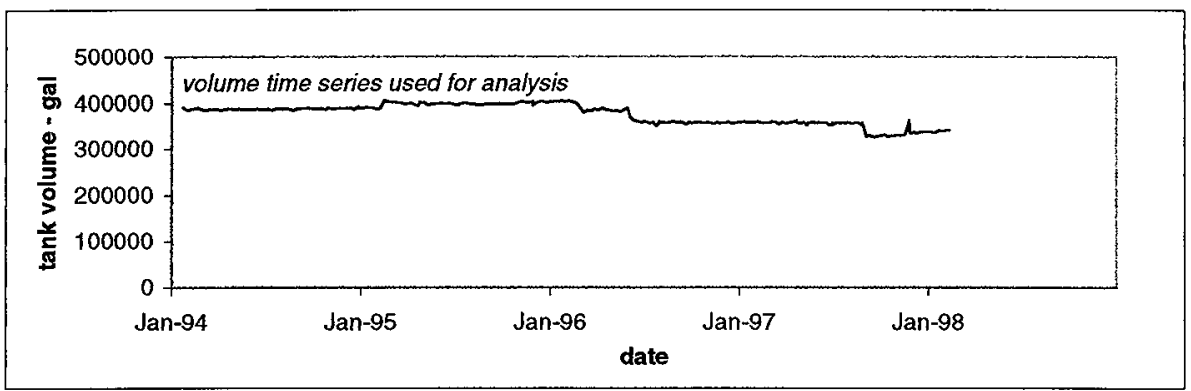

No. points edited from time series $=$

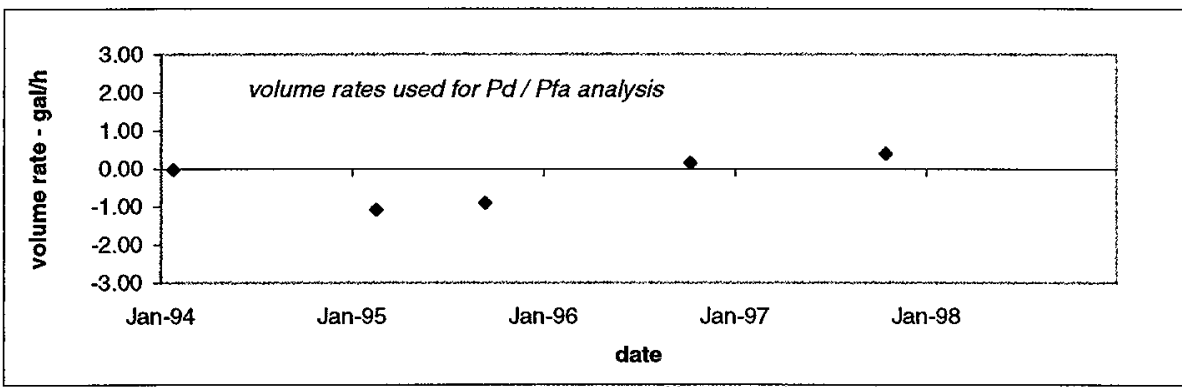

During the analysis period, the average volume rate $=$

No. avg. vol rate estimates removed = The standard deviation of the volume rate estimates = $-0.30 \mathrm{gal} / \mathrm{h}$

$N=5$

For $\mathrm{Pd} / \mathrm{Pfa}=95 \% / 5 \%$ :

The mean volume rate is equivalent to $0 \mathrm{gal} / \mathrm{h}$

Threshold, T:

$-1.41 \mathrm{gal} / \mathrm{h}$

Min. Detectable Leak: $\quad-2.81 \mathrm{gal} / \mathrm{h}$

Gaussian Plots Not Representative Due to small N...
Gaussian Plots Not Representative Due to small N... 


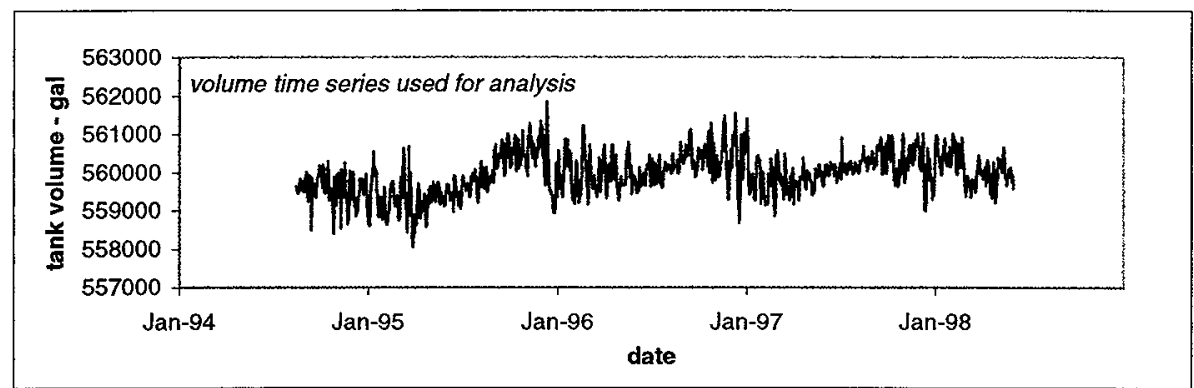

No. points edited from time series $=$

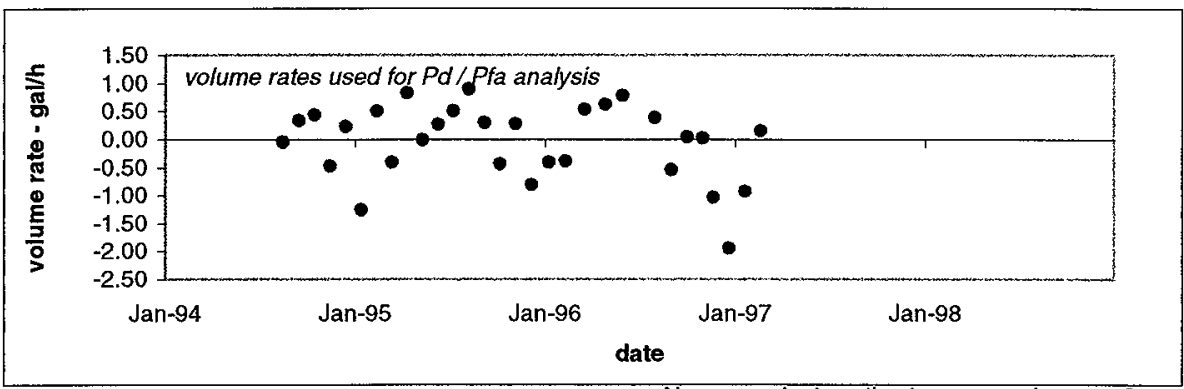

During the analysis period, the average volume rate =

No. avg. vol rate estimates removed $=$ 0

$-0.05 \mathrm{gal} / \mathrm{h}$

$0.67 \mathrm{gal} / \mathrm{h}$

For $\mathrm{Pd} / \mathrm{Pfa}=95 \% / 5 \%$ :

The mean volume rate is equivalent to $0 \mathrm{gal} / \mathrm{h}$

Threshold, $\mathrm{T}$ : $\quad-1.14 \mathrm{gal} / \mathrm{h}$

Min. Detectable Leak: $\quad-2.28 \mathrm{gal} / \mathrm{h}$

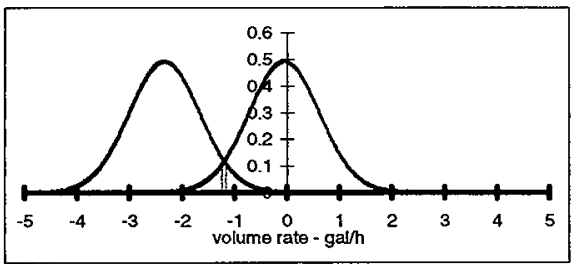

For this data, a threshold $=-2.22 \mathrm{ga} / \mathrm{h}$ will detect a tank release of The corresponding $\mathrm{Pfa}$ is $\quad 0.27 \%$
For $\mathrm{Pd} / \mathrm{Pfa}=99 \% / 1 \%$ :

The mean volume rate is equivalent to $0 \mathrm{gal} / \mathrm{h}$

Threshold, T: $\quad-1.65 \mathrm{gal} / \mathrm{h}$

Min. Detectable Leak: $\quad-3.31 \mathrm{gal} / \mathrm{h}$

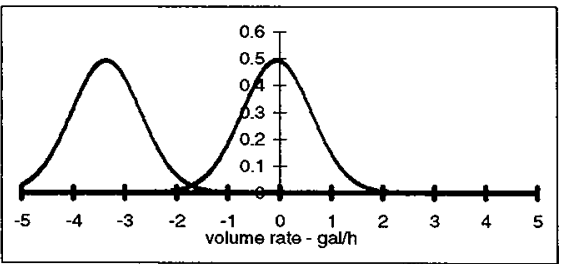

$3.31 \mathrm{ga} / \mathrm{h}$ at a $\mathrm{Pd}=95 \%$ 
Data File: $\mathbf{S - 1 1 2}$ Data is from sensor type: NEUTRON ILL

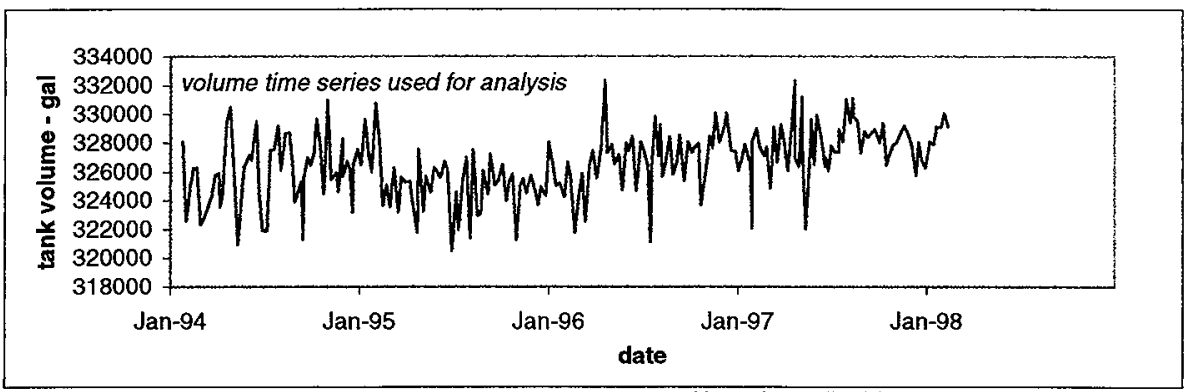

No. points edited from time series $=$

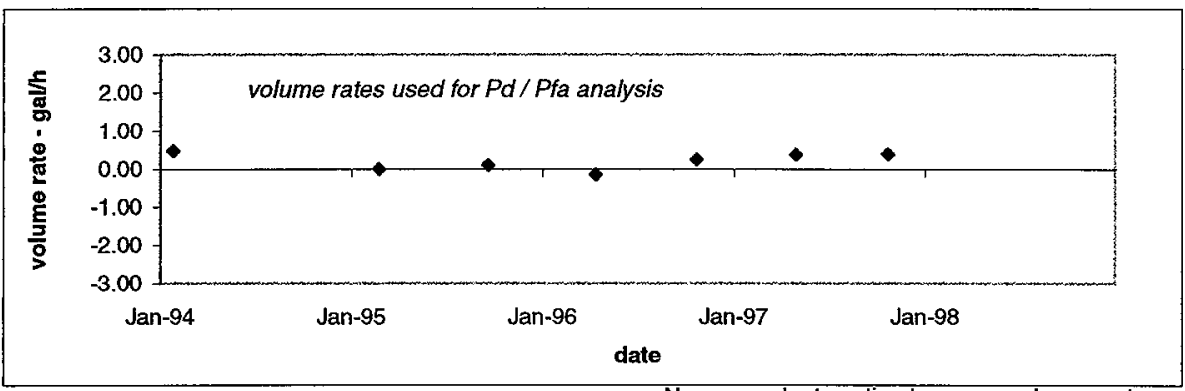

During the analysis period, the average volume rate = The standard deviation of the volume rate estimates =

For $\mathrm{Pd} / \mathrm{Pfa}=95 \% / 5 \%$ :

The mean volume rate is NOT equivalent to $0 \mathrm{gal} h$

Threshold, T:

$-0.44 \mathrm{gal} / \mathrm{h}$

Min. Detectable Leak: $\quad-0.89 \mathrm{gal} / \mathrm{h}$

Gaussian Plots Not Representative Due to smali N....

\section{$0.20 \mathrm{gal} / \mathrm{h}$ \\ $0.23 \mathrm{gal} / \mathrm{h}$}

$\mathbf{N}=$ 7

For Pd $/ \mathrm{Pfa}=99 \% / 1 \%$ :

The mean volume rate is equivalent to $0 \mathrm{gal} / \mathrm{h}$

Threshold, T:

$-0.72 \mathrm{gal} / \mathrm{h}$

Min. Detectable Leak:
Gaussian Plots Not Representative Due to small N.... 


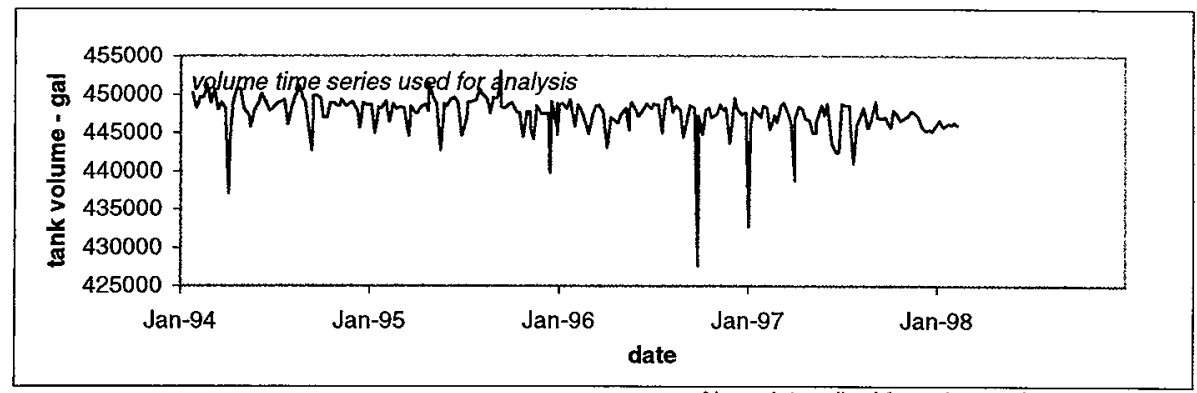

No. points edited from time series $=$

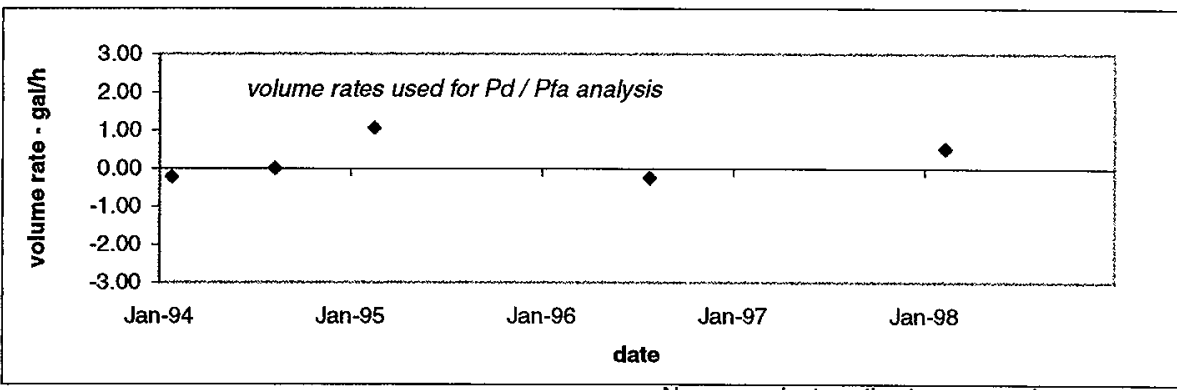

During the analysis period, the average volume rate $=$ The standard deviation of the volume rate estimates =

For Pd / Pfa = 95\% / 5\%:

The mean volume rate is equivalent to $0 \mathrm{gal} / \mathrm{h}$

Threshold, T: $-5.94 \mathrm{gal} / \mathrm{h}$

Min. Detectable Leak: $\quad-11.88 \mathrm{gal} / \mathrm{h}$

Gaussian Plots Not Representative Due to small N....
$1.49 \mathrm{gal} / \mathrm{h}$

$$
\mathbf{N}=5
$$

For Pd $/ \mathrm{Pfa}=99 \% / 1 \%$ :

The mean volume rate is equivalent to $0 \mathrm{gal} / \mathrm{h}$ Threshold, T:

$-10.44 \mathrm{gal} / \mathrm{h}$

Min. Detectable Leak: $\quad-20.88 \mathrm{gal} / \mathrm{h}$
Gaussian Plots Not Representative Due to small N... 
Data File: SX-102 Data is from sensor type: NEUTRON ILL

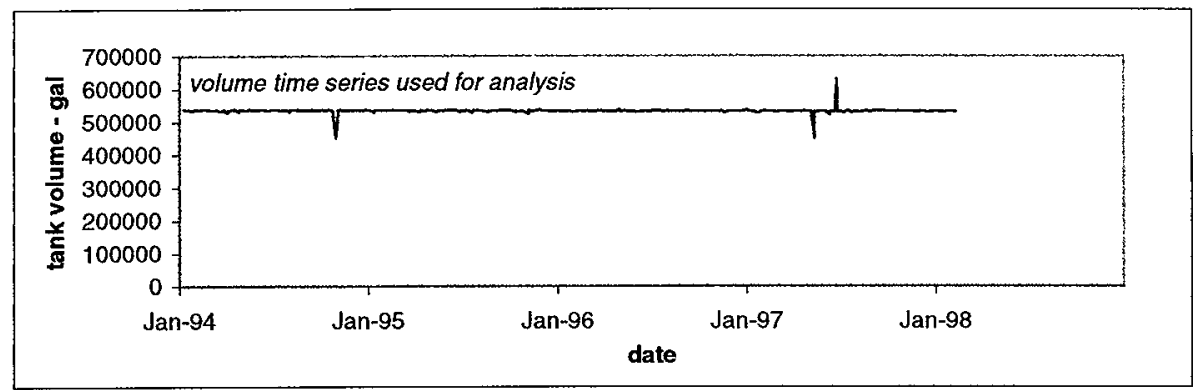

No. points edited from time series =

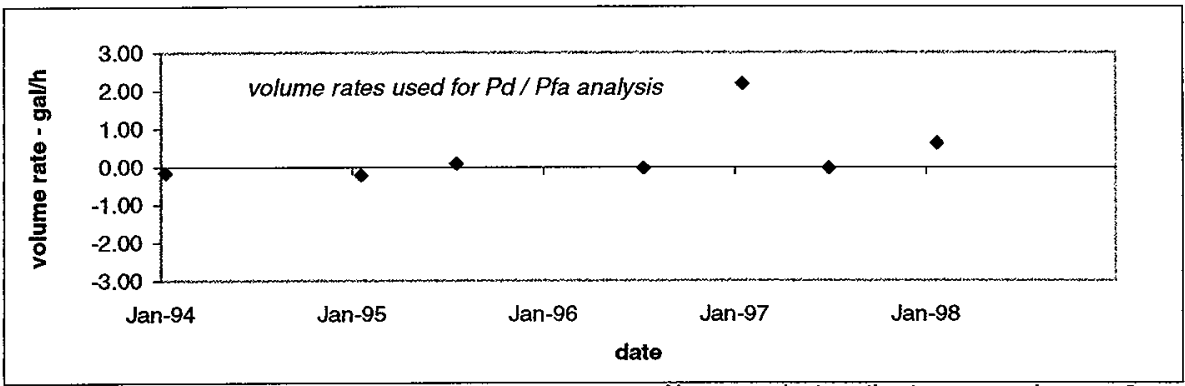

During the analysis period, the average volume rate $=$ The standard deviation of the volume rate estimates $=$

For $\mathrm{Pd} / \mathrm{Pfa}=95 \% / 5 \%$ :

The mean volume rate is equivalent to $0 \mathrm{gal} / \mathrm{h}$

Threshold, T:

$-1.67 \mathrm{gal} / \mathrm{h}$

Min. Detectable Leak: $\quad-3.34 \mathrm{ga} / \mathrm{h}$

Gaussian Plots Not Representative Due to small N...
No. avg. vol rate estimates removed $=$

$\mathbf{N}=$

$0.35 \mathrm{gal} / \mathrm{h}$

$0.86 \mathrm{gaVh}$

For $\mathrm{Pd} / \mathrm{Pfa}=99 \% / 1 \%$ :

The mean volume rate is equivalent to $0 \mathrm{gal} / \mathrm{h}$ Threshold, T:

$-2.70 \mathrm{gal} / \mathrm{h}$

Min. Detectable Leak:

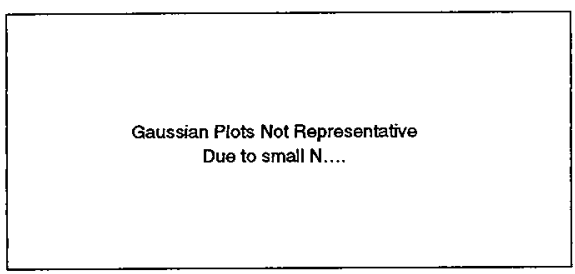

Gaussian Plots Not Representative Due to small $\mathrm{N}$.... 
Data File: SX-103 Data is from sensor type: NEUTRON ILL

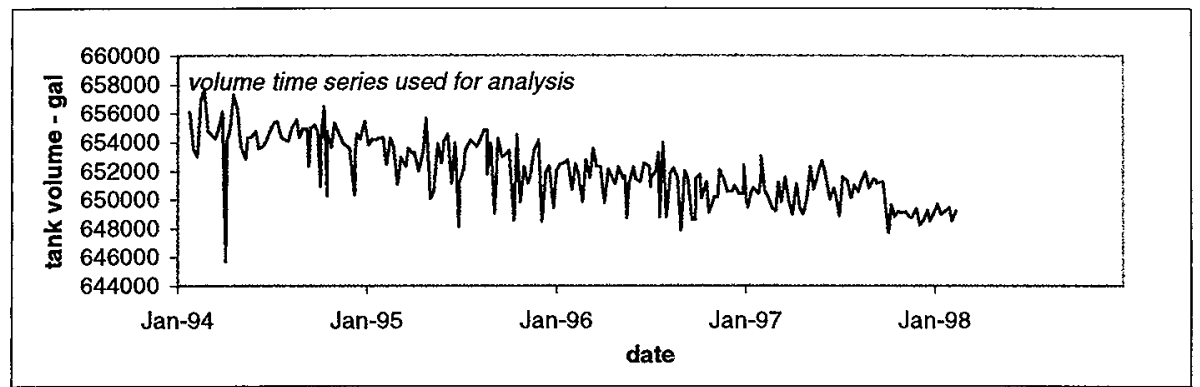

No. points edited from time series $=$

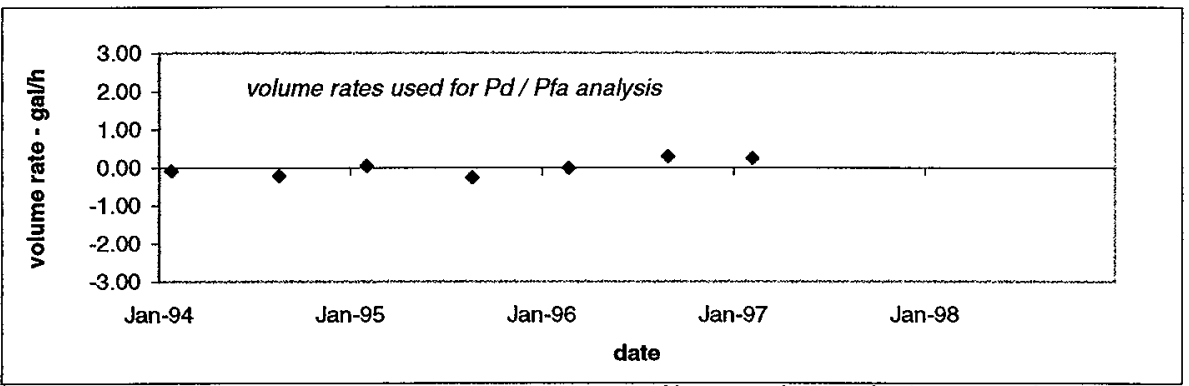

During the analysis period, the average volume rate $=$

No. avg. vol rate estimates removed $=$

$N=7$

The standard deviation of the volume rate estimates =

$-0.01 \mathrm{gal} / \mathrm{h}$

$0.21 \mathrm{gal} / \mathrm{h}$

For Pd $/ \mathrm{Pfa}=95 \% / 5 \%$ :

The mean volume rate is equivalent to $0 \mathrm{gal} / \mathrm{h}$

Threshold, T: $\quad-0.41 \mathrm{gal} / \mathrm{h}$

Min. Detectable Leak: $\quad-0.82 \mathrm{gal} / \mathrm{h}$
For Pd $/ \mathrm{Pfa}=99 \% / 1 \%$ :

The mean volume rate is equivalent to $0 \mathrm{gal} / \mathrm{h}$

Threshold, $\mathrm{T}$ : $\quad-0.66 \mathrm{gal} / \mathrm{h}$

Min. Detectable Leak: $\quad-1.33 \mathrm{gal} / \mathrm{h}$
Gaussian Plots Not Representative Due to small N....
Gaussian Plots Not Representative Due to small N.... 
Data File: $\quad$ SX-104 Data is from sensor type: NEUTRON ILL.

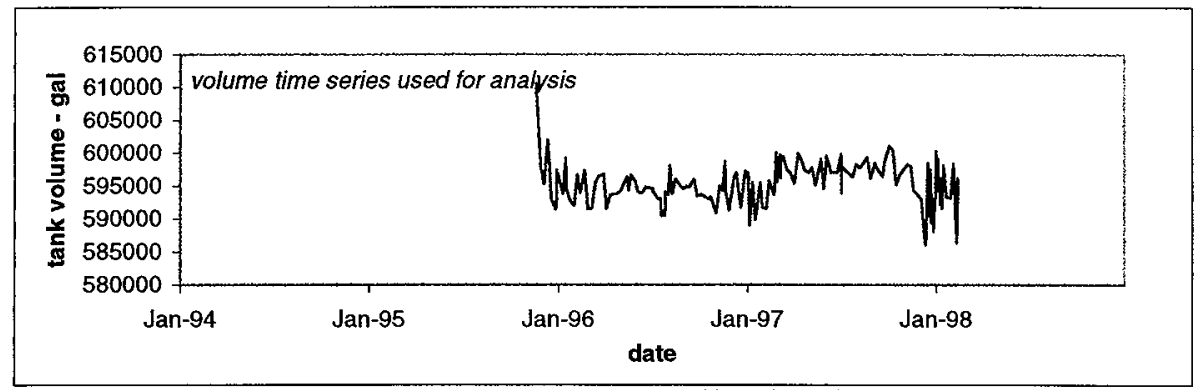

No. points edited from time series $=$

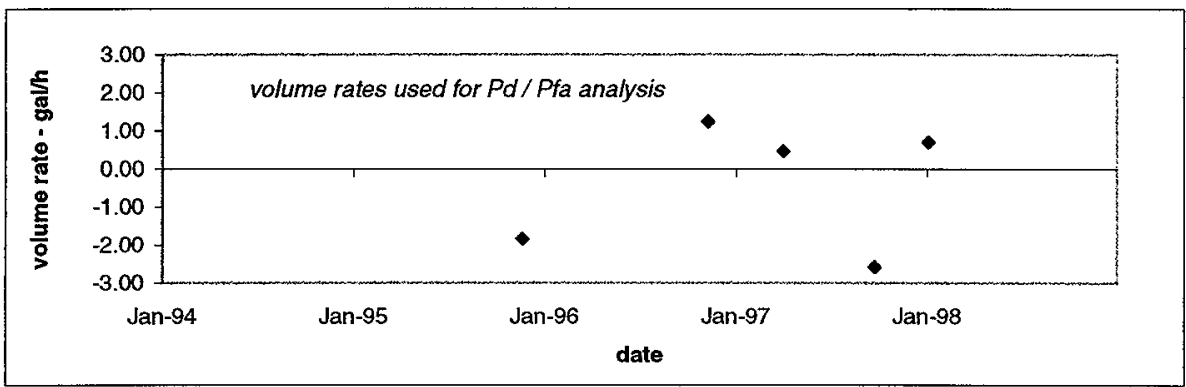

During the analysis period, the average volume rate = The standard deviation of the volume rate estimates =

For Pd / Pfa $=95 \% / 5 \%$ :

The mean volume rate is equivalent to $0 \mathrm{gal} / \mathrm{h}$

Threshold, T:

$-3.60 \mathrm{gal} / \mathrm{h}$

Min. Detectable Leak: $\quad-7.20 \mathrm{ga} / \mathrm{h}$
$-0.41 \mathrm{gal} / \mathrm{h}$

$N=5$
For Pd $/ \mathrm{Pfa}=\mathbf{9 9} \% / 1 \%$ :

The mean volume rate is equivalent to $0 \mathrm{gal} / \mathrm{h}$

Threshold, T:

$-6.32 \mathrm{gal} / \mathrm{h}$

Min. Detectable Leak: $\quad-12.65 \mathrm{gal} / \mathrm{h}$
Gaussian Plots Not Representative Due to small N....
Gaussian Plots Not Representative Due to small $N . .$. 


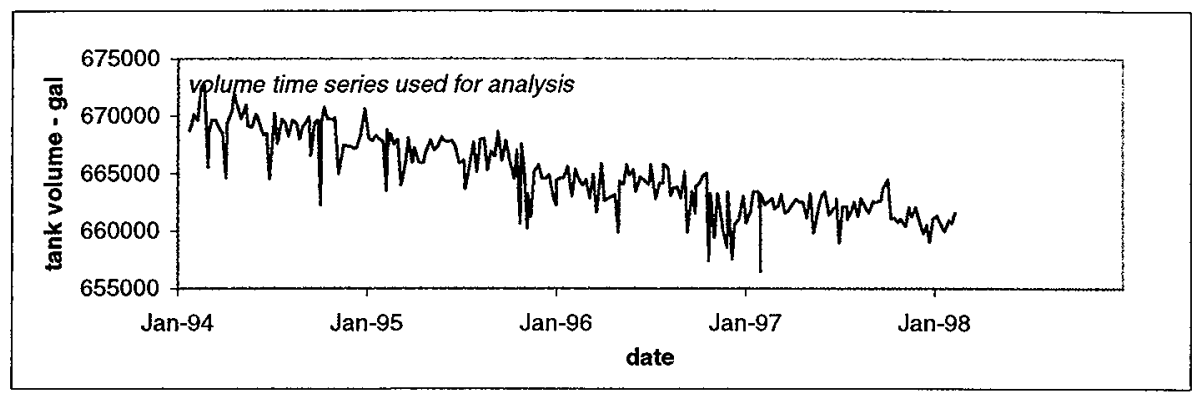

No. points edited from time series $=$

8

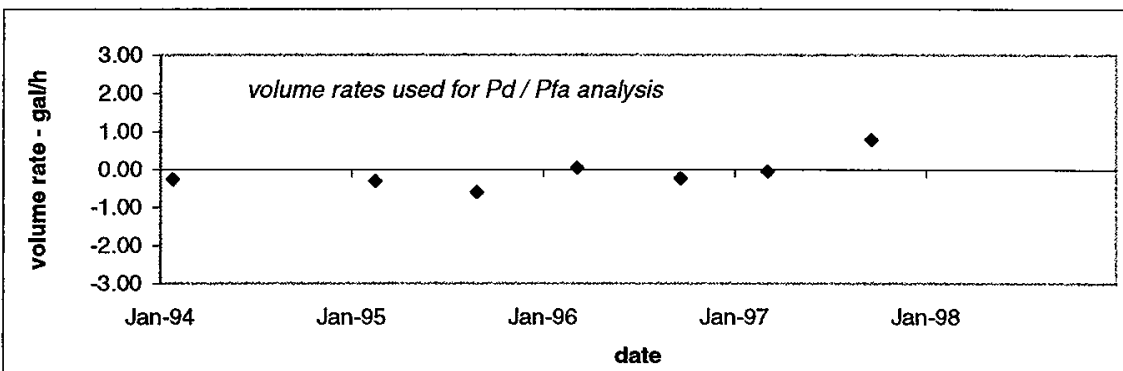

During the analysis period, the average volume rate $=$ The standard deviation of the volume rate estimates =

For $\mathrm{Pd} / \mathrm{Pfa}=95 \% / 5 \%$ :

The mean volume rate is equivalent to $0 \mathrm{gal} / \mathrm{h}$

Threshold, $\mathrm{T}$ : $\quad-0.84 \mathrm{gal} / \mathrm{h}$

Min. Detectable Leak: $\quad-1.68 \mathrm{gal} / \mathrm{h}$

Gaussian Plots Not Representative Due to smail $\mathbf{N}$....
No. avg. vol rate estimates removed $=$

$$
N=7
$$

$-0.10 \mathrm{gal} / \mathrm{h}$

$0.43 \mathrm{gal} / \mathrm{h}$

For $\mathrm{Pd} / \mathrm{Pfa}=99 \% / 1 \%$ :

The mean volume rate is equivalent to $0 \mathrm{gal} / \mathrm{h}$

Threshold, $\mathrm{T}$ : $\quad-1.36 \mathrm{gal} / \mathrm{h}$

Min. Detectable Leak: $\quad-2.72 \mathrm{gal} / \mathrm{h}$

Gaussian Plots Not Representative Due to small N.... 


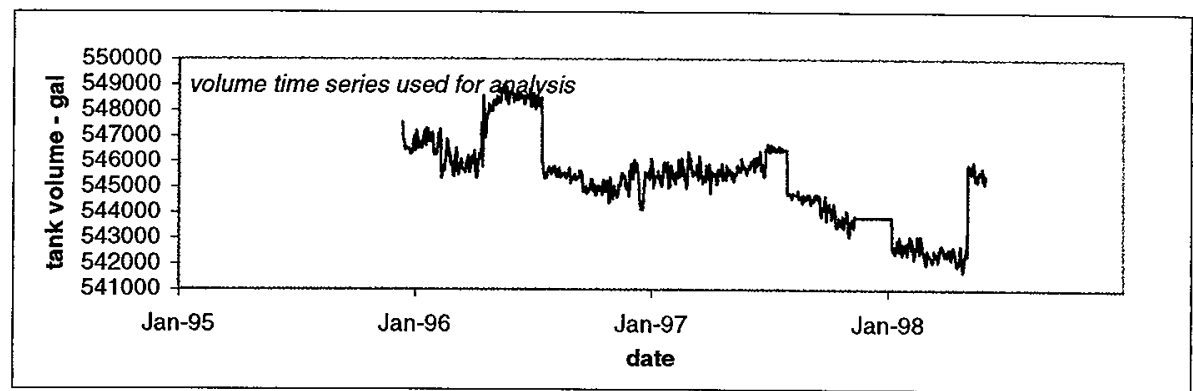

No. points edited from time series =

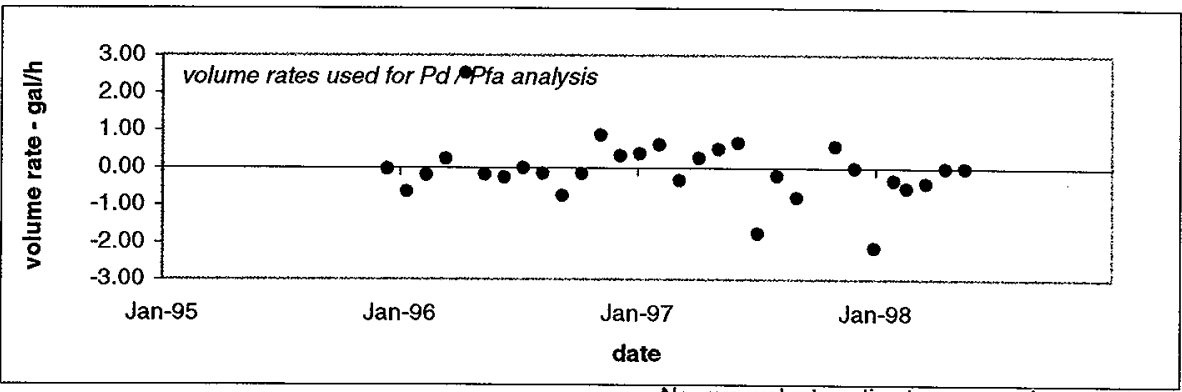

During the analysis period, the average volume rate = $-0.08 \mathrm{gal} / \mathrm{h}$

$N=26$

The standard deviation of the volume rate estimates =

$0.87 \mathrm{gal} / \mathrm{h}$

For Pd $/ \mathrm{Pfa}=95 \% / 5 \%$ :

The mean volume rate is equivalent to $0 \mathrm{gal} / \mathrm{h}$ Threshold, T: $-1.49 \mathrm{gal} / \mathrm{h}$ Min. Detectable Leak: $\quad-2.97 \mathrm{gal} / \mathrm{h}$

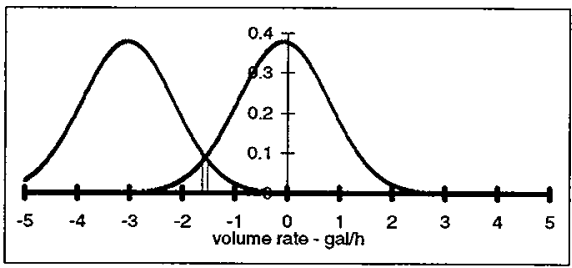

For this data, a threshold $=5.00 \mathrm{gal} / \mathrm{h}$ will detect a tank release of The corresponding $\mathrm{Pfa}$ is
For $\mathrm{Pd} / \mathrm{Pfa}=99 \% / 1 \%$ :

The mean volume rate is equivalent to $0 \mathrm{gal} / \mathrm{h}$

Threshold, $\mathrm{T}$ : $\quad-2.16 \mathrm{gal} / \mathrm{h}$

Min. Detectable Leak: $\quad-4.32 \mathrm{ga} / \mathrm{h}$

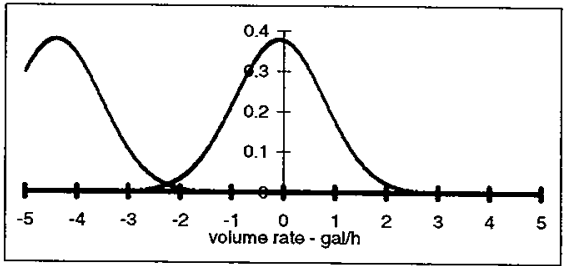

$4.32 \mathrm{gal} / \mathrm{h}$ at a $\mathrm{Pd}=95 \%$ 


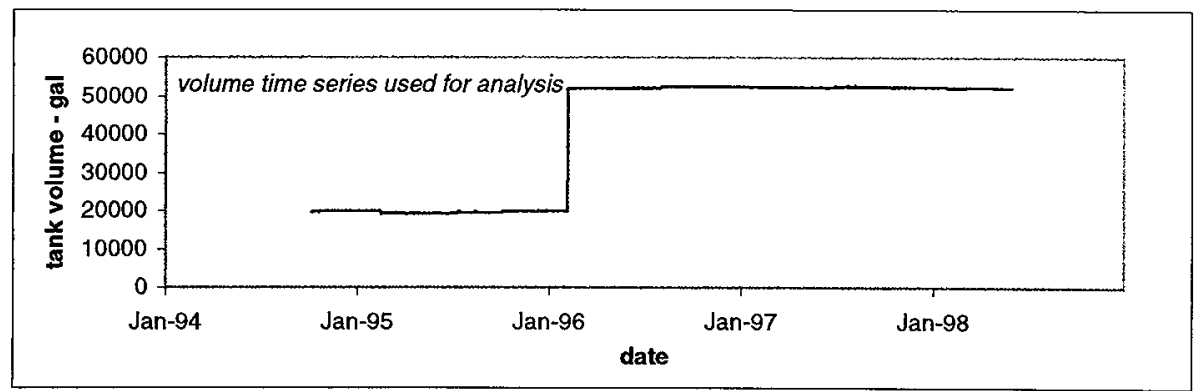

No. points edited from time series $=$

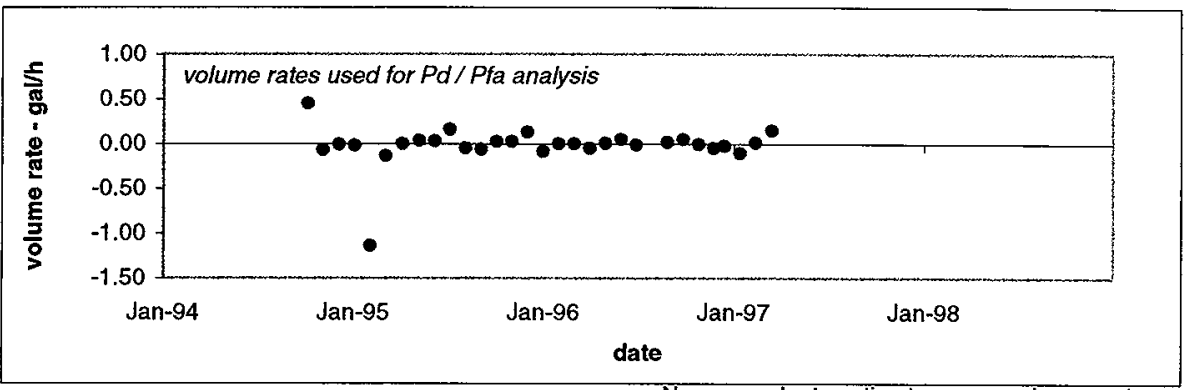

During the analysis period, the average volume rate $=$

No. avg. vol rate estimates removed =

For Pd $/ \mathrm{Pfa}=95 \% / 5 \%$ :

The mean volume rate is equivalent to $0 \mathrm{gal} / \mathrm{h}$

Threshold, T:

$-0.41 \mathrm{gal} / \mathrm{h}$

Min. Detectable Leak: $\quad-0.81 \mathrm{gal} / \mathrm{h}$

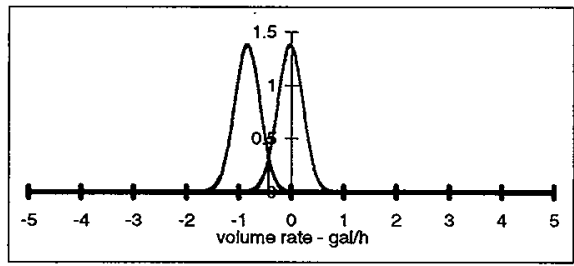

For this data, a threshold $=-0.82 \mathrm{galh}$ will detect a tank release of The corresponding Pfa is
$0.24 \mathrm{gal} / \mathrm{h}$

For $\mathrm{Pd} / \mathrm{Pfa}=99 \% / 1 \%$ :

The mean volume rate is equivalent to $0 \mathrm{gal} / \mathrm{h}$ Threshold, $\mathrm{T}$ : $\quad-0.59 \mathrm{gal} / \mathrm{h}$ Min. Detectable Leak: $\quad-1.18 \mathrm{gal} / \mathrm{h}$

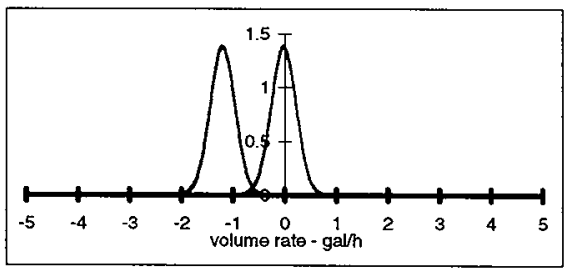

$1.18 \mathrm{galh}$ at $\mathrm{Pd}=95 \%$ 


\section{Data File: T-104 Data is from sensor type: NEUTRON ILL}

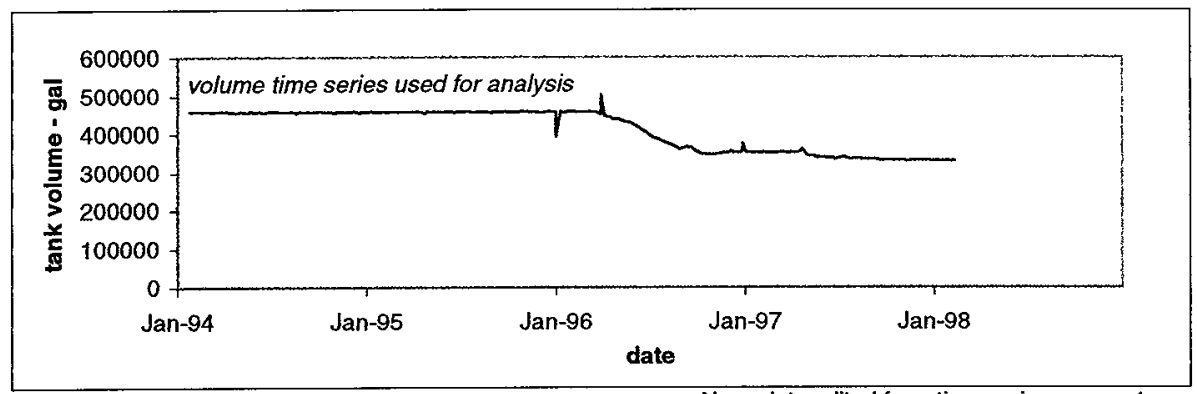

No. points edited from time series $=$

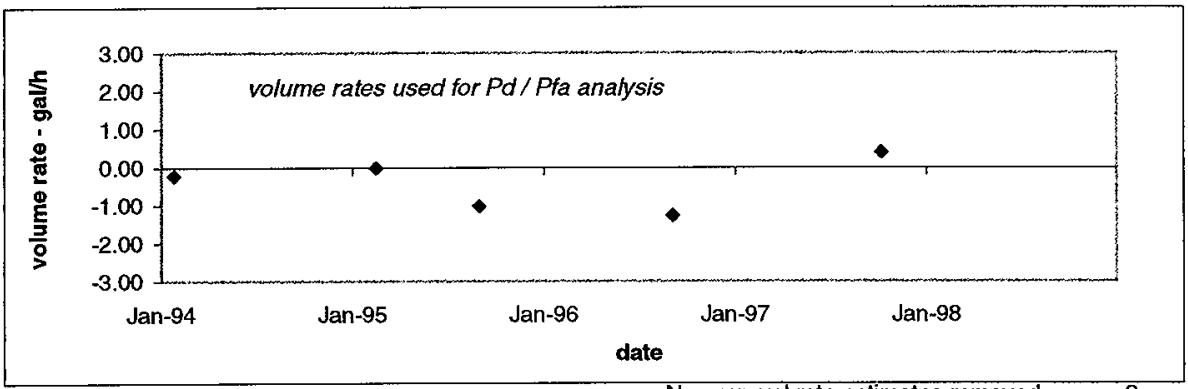

During the analysis period, the average volume rate $=$ The standard deviation of the volume rate estimates =

For Pd $/ \mathrm{Pfa}=95 \% / 5 \%$ :

The mean volume rate is equivalent to $0 \mathrm{gal} / \mathrm{h}$ Threshold, $\mathrm{T}$ : $-1.48 \mathrm{gal} / \mathrm{h}$ Min. Detectable Leak: $\quad-2.96 \mathrm{gal} / \mathrm{h}$

Gaussian Plots Not Representative Due to small N....
No. avg. vol rate estimates removed =

$-0.43 \mathrm{gal} / \mathrm{h}$

$\mathrm{N}=5$
For Pd / Pfa = 99\% / 1\%:

The mean volume rate is equivalent to $0 \mathrm{gal} / \mathrm{h}$

Threshold, T:

$-2.60 \mathrm{ga} / \mathrm{h}$

Min. Detectable Leak: $\quad-5.20 \mathrm{gal} / \mathrm{h}$
Gaussian Plots Not Representative Due to small N... 
Data File: T-111 Data is from sensor type: NEUTRON ILL

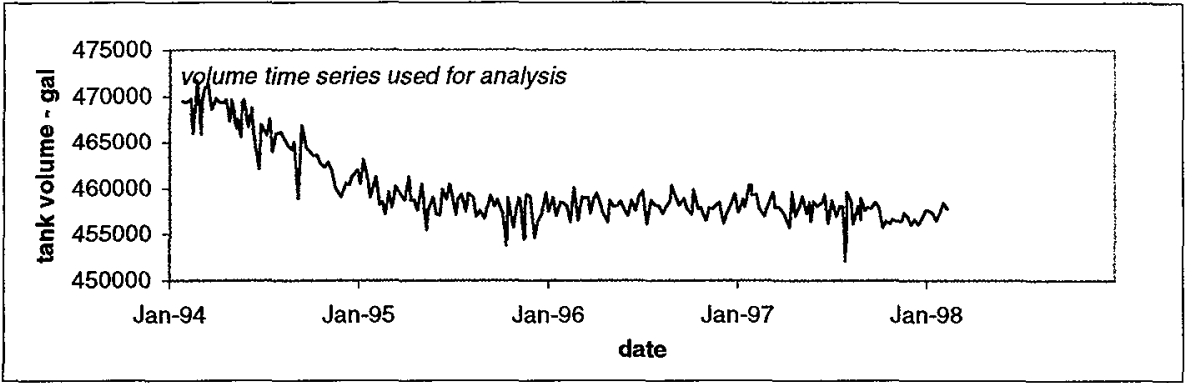

No. points edited from time series $=$

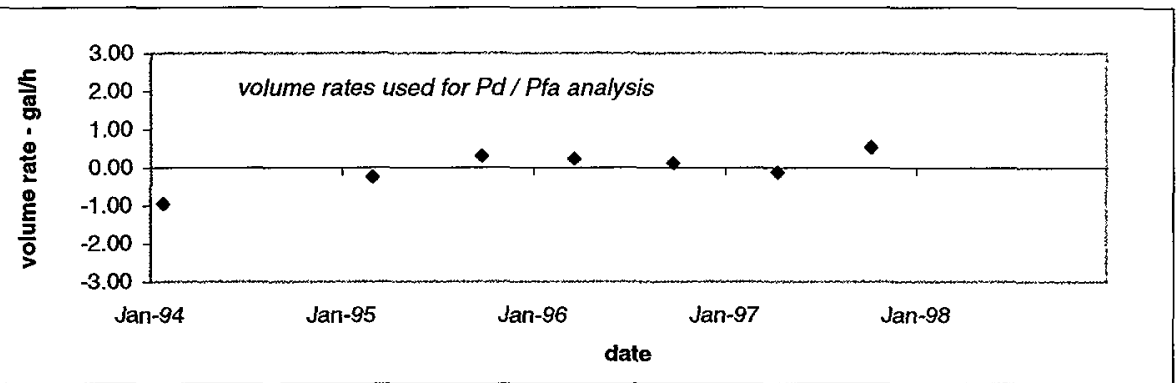

During the analysis period, the average volume rate =

No. avg. vol rate estimates removed $=1$

The standard deviation of the volume rate estimates =

$-0.02 \mathrm{gal} / \mathrm{h}$

$N=7$

For $\mathrm{Pd} / \mathrm{Pfa}=\mathbf{9 5} \% / 5 \%$ :

The mean volume rate is equivalent to $0 \mathrm{gal} / \mathrm{h}$

Threshold, T:

Min. Detectable Leak: $\quad-1.90 \mathrm{gal} / \mathrm{h}$
$0.49 \mathrm{ga} / \mathrm{h}$

For $\mathrm{Pd} / \mathrm{Pfa}=99 \% / 1 \%$ :

The mean volume rate is equivalent to $0 \mathrm{gal} / \mathrm{h}$

Threshold, T:

$-1.53 \mathrm{ga} / \mathrm{h}$

Min. Detectable Leak:
$-3.07 \mathrm{gal} / \mathrm{h}$

Gaussian Plots Not Representative Due to smal! N.... 
Data File: T-110 Data is from sensor type: NEUTRON ILL

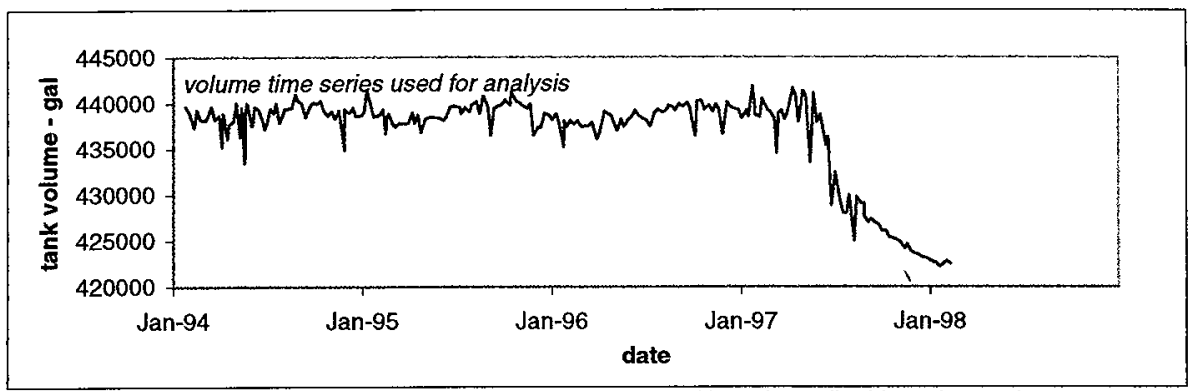

No. points edited from time series $=$

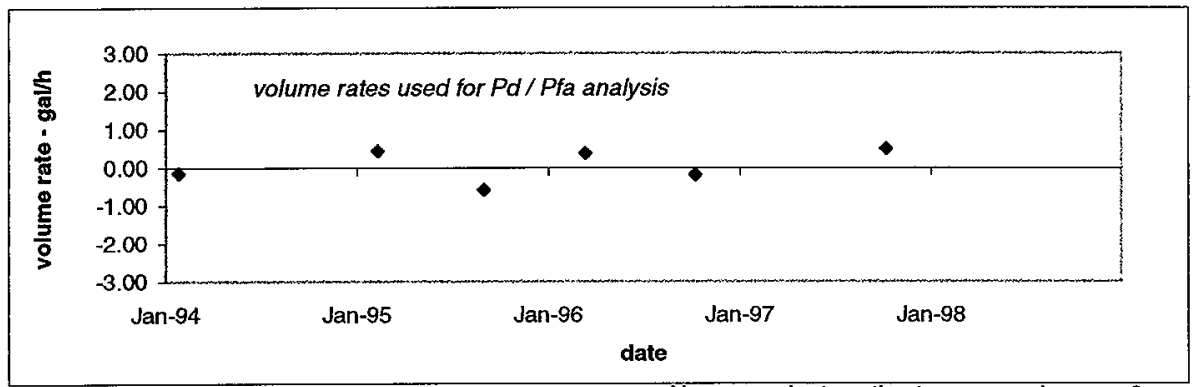

During the analysis period, the average volume rate $=$ The standard deviation of the volume rate estimates =

For Pd $/ \mathrm{Pfa}=95 \% / 5 \%$ :

The mean volume rate is equivalent to $0 \mathrm{gal} / \mathrm{h}$ Threshold, T: $-0.88 \mathrm{gal} / \mathrm{h}$ Min. Detectable Leak: $\quad-1.76 \mathrm{ga} / \mathrm{h}$

Gaussian Plots Not Representative Due to small N....
No. avg. vol rate estimates removed $=\quad 2$

$0.06 \mathrm{gal} / \mathrm{h}$

$N=6$ $0.44 \mathrm{gal} / \mathrm{h}$

For Pd $/ \mathrm{Pfa}=99 \% / 1 \%$ :

The mean volume rate is equivalent to $0 \mathrm{gal} / \mathrm{h}$

Threshold, T:

$-1.47 \mathrm{gal} / \mathrm{h}$

Min. Detectable Leak: $\quad-2.94 \mathrm{gal} / \mathrm{h}$
Gaussian Plots Not Representative Due to small N... 


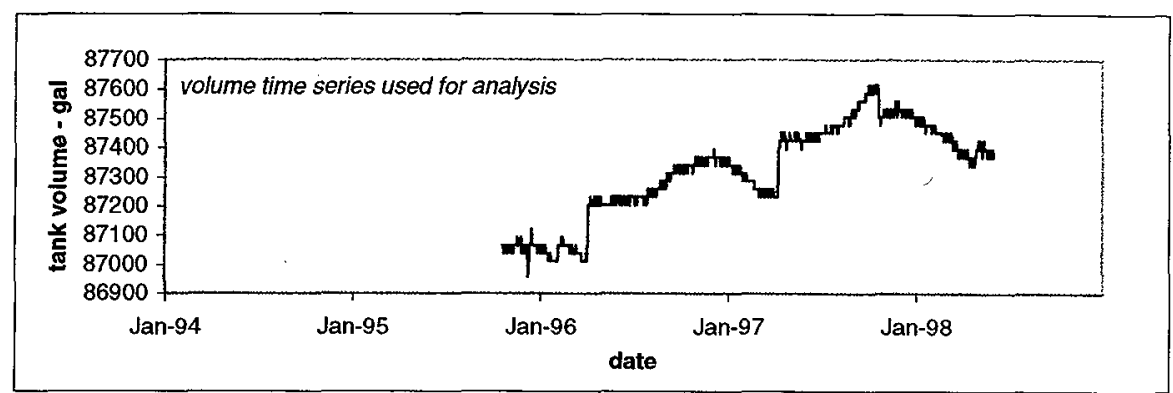

No. points edited from time series =

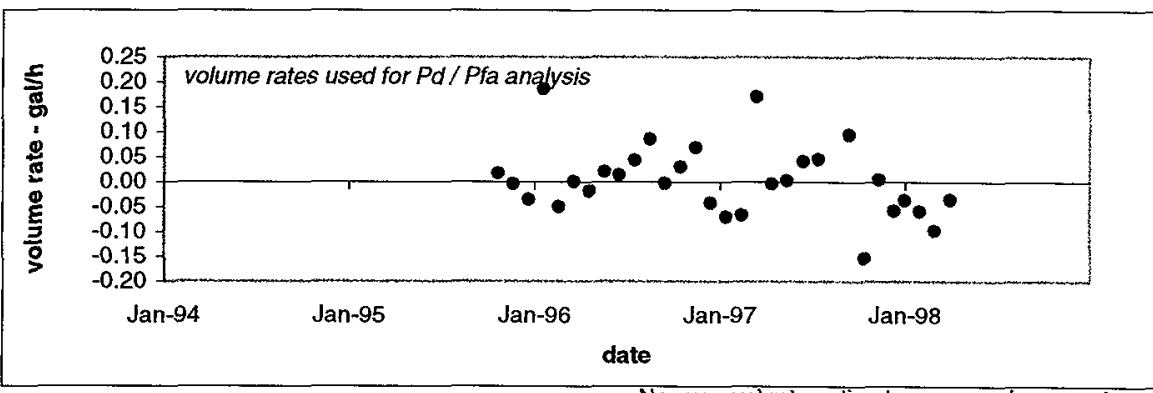

During the analysis period, the average volume rate =

No. avg. vol rate estimates removed $=\quad 1$ The standard deviation of the volume rate estimates =

$$
0.00 \mathrm{gal} / \mathrm{h}
$$$$
\mathrm{N}=29
$$

For Pd $/ \mathrm{Pfa}=95 \% / 5 \%$ :

The mean volume rate is equivalent to $0 \mathrm{gal} / \mathrm{h}$

Threshold, T:

$-0.12 \mathrm{gal} / \mathrm{h}$

Min. Detectable Leak:

$-0.25 \mathrm{gal} / \mathrm{h}$

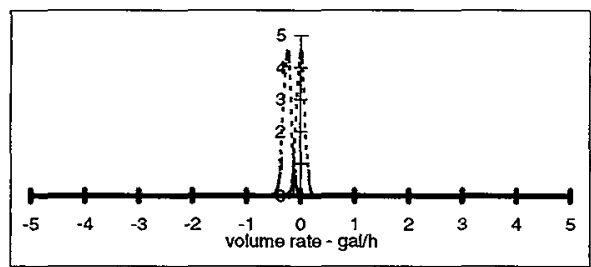

For Pd $/$ Pfa $=99 \% / 1 \%$ :

The mean volume rate is equivalent to $0 \mathrm{gal} / \mathrm{h}$ Threshold, $\mathrm{T}$ : $\quad-0.18 \mathrm{gal} / \mathrm{h}$ Min. Detectable Leak: $\quad-0.36 \mathrm{gal} / \mathrm{h}$

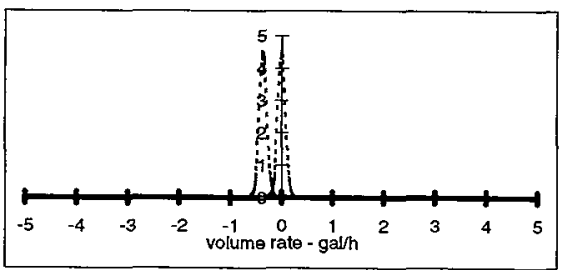

For this data, a threshold $=-0.25 \mathrm{gal} / \mathrm{h}$ will detect a tank release of $0.36 \mathrm{gal} / \mathrm{h}$ at a $\mathrm{Pd}=95 \%$ The corresponding Pfa is $\quad 1.11 \%$ 


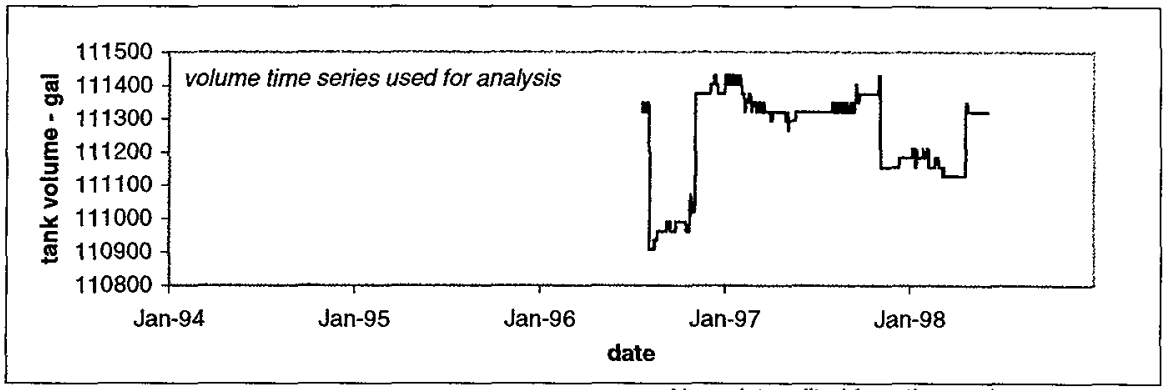

No. points edited from time series =

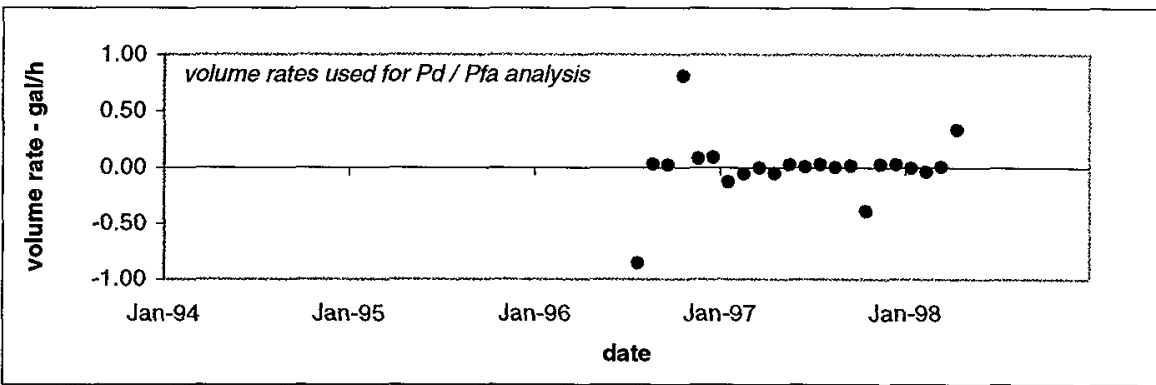

During the analysis period, the average volume rate $=$

No. avg. vol rate estimates removed = 8 The standard deviation of the volume rate estimates =

$-0.01 \mathrm{gal} / \mathrm{h}$

$N=22$

For Pd $/ \mathrm{Pfa}=95 \% / 5 \%$ :

The mean volume rate is equivalent to $0 \mathrm{gal} / \mathrm{h}$

Threshold, T: $\quad-0.49 \mathrm{gal} / \mathrm{h}$

Min. Detectable Leak: $\quad-0.98 \mathrm{ga} / \mathrm{h}$

$0.28 \mathrm{gal} / \mathrm{h}$

For $\mathrm{Pd} / \mathrm{Pfa}=\mathbf{9 9 \%} / \mathbf{1 \%}$ :

The mean volume rate is equivalent to $0 \mathrm{gal} / \mathrm{h}$

Threshold, T: $\quad-0.71 \mathrm{gal} / \mathrm{h}$

Min. Detectable Leak: $\quad-1.43 \mathrm{gal} / \mathrm{h}$
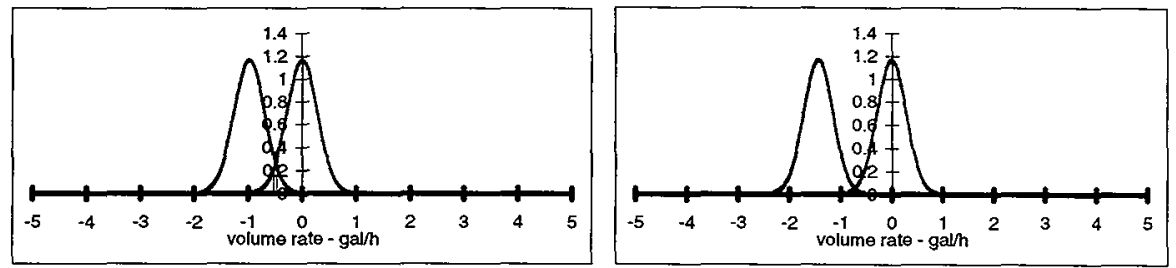

For this data, a threshold $=\quad-0.98 \mathrm{gal} / \mathrm{h}$ will detect a tank release of $1.43 \mathrm{galh}$ at a $\mathrm{Pd}=95 \%$ The corresponding Pfa is $\quad 0.32 \%$ 
Data File: TX-102 Data is from sensor type: NEUTRON ILL

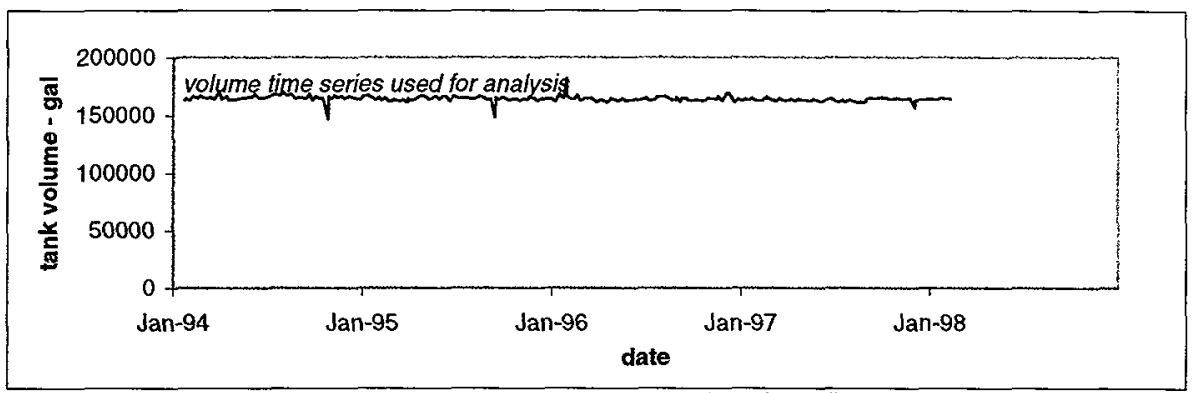

No. points edited from time series $=$

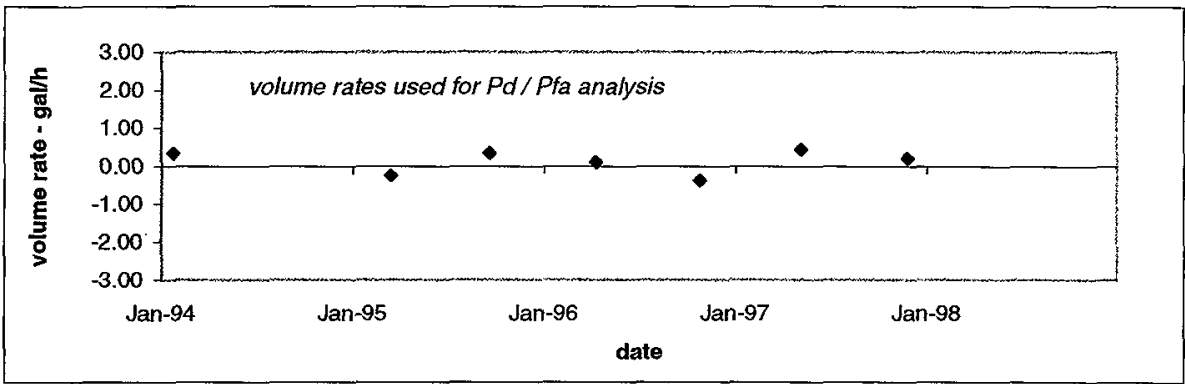

No. avg. vol rate estimates removed $=-1$

During the analysis period, the average volume rate $=$ $0.10 \mathrm{gal} / \mathrm{h}$

$N=7$

The standard deviation of the volume rate estimates =

For $\mathrm{Pd} / \mathrm{Pfa}=99 \% / 1 \%$ :

For $\mathrm{Pd} / \mathrm{Pfa}=95 \% / 5 \%$ :

The mean volume rate is equivalent to $0 \mathrm{gal} / \mathrm{h}$

Threshold, T: $\quad-0.60 \mathrm{gal} / \mathrm{h}$

Min. Detectable Leak: $\quad-1.20 \mathrm{gal} / \mathrm{h}$

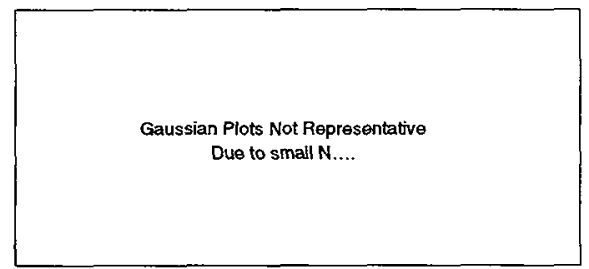

The mean volume rate is equivalent to $0 \mathrm{gal} / \mathrm{h}$

Threshold, T: $\quad-0.97 \mathrm{gaVh}$

Min. Detectable Leak: $\quad-1.94$ gallh
Gaussian Plots Not Representative Due to small $\mathrm{N}$... 
Data File: TX-106 Data is from sensor type: NEUTRON ILL

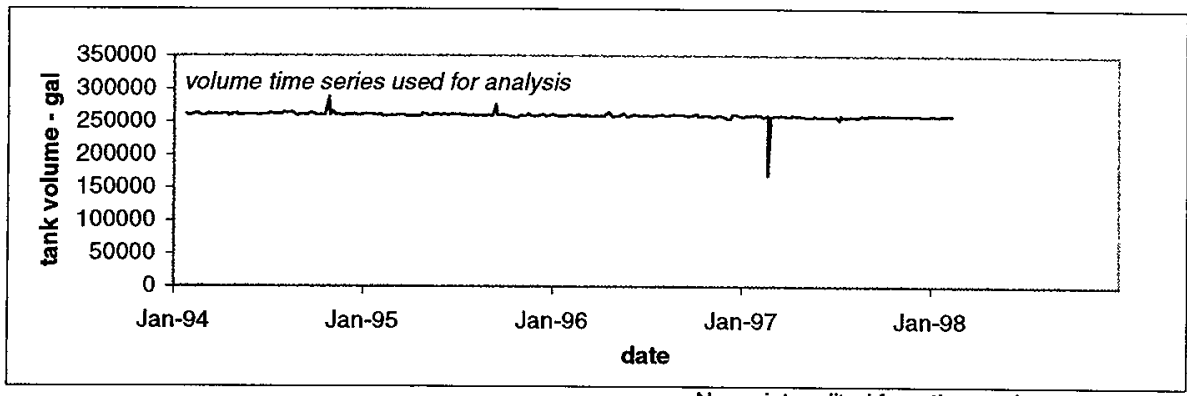

No. points edited from time series $=$

4

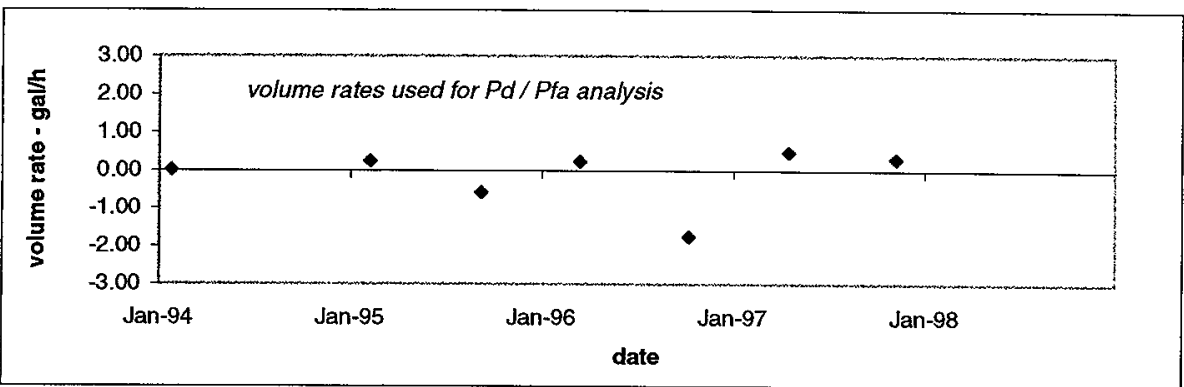

During the analysis period, the average volume rate $=$

No. avg. vol rate estimates removed $=$ 1 The standard deviation of the volume rate estimates = $-0.16 \mathrm{gal} / \mathrm{h}$ $N=7$

For Pd $/$ Pfa $=95 \% / 5 \%$ :

The mean volume rate is equivalent to $0 \mathrm{gal} / \mathrm{h}$

Threshold, T: $\quad-1.52 \mathrm{gal} / \mathrm{h}$

Min. Detectable Leak: $\quad-3.04 \mathrm{gal} / \mathrm{h}$

Gaussian Plots Not Representative Due to small N....
Gaussian Plots Not Representative Due to small N.... 
Data File: TX-109 Data is from sensor type: NEUTRON ILL

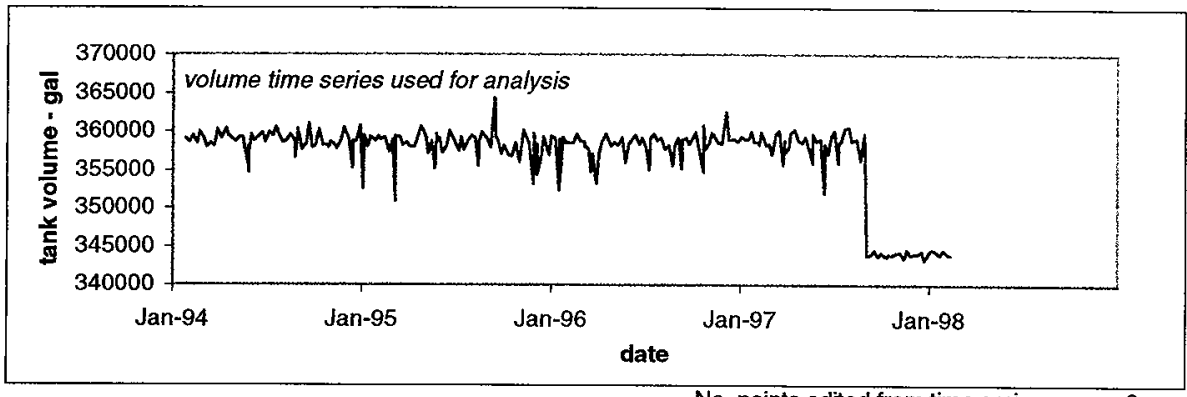

No. points edited from time series =

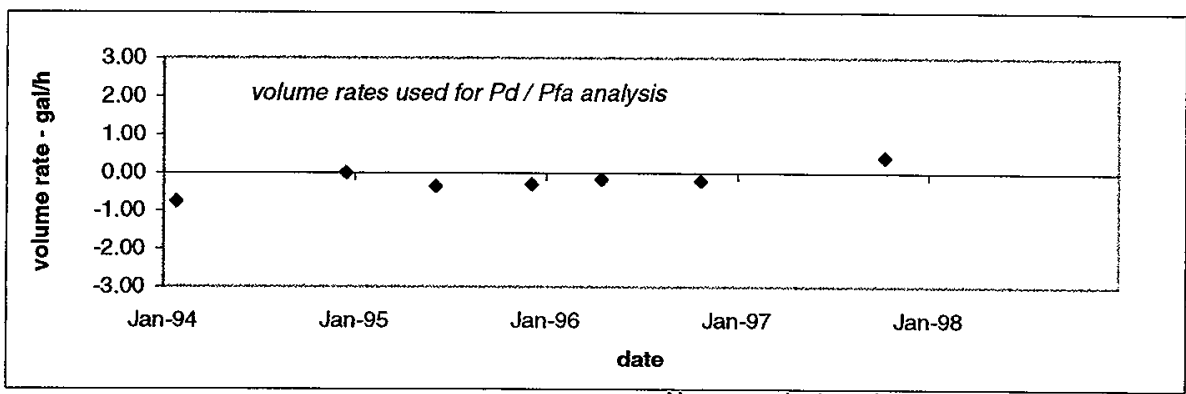

During the analysis period, the average volume rate = The standard deviation of the volume rate estimates =

For $\mathrm{Pd} / \mathrm{Pfa}=95 \% / 5 \%$ :

The mean volume rate is equivalent to $0 \mathrm{gal} / \mathrm{h}$

Threshold, T: $\quad-0.69 \mathrm{gal} / \mathrm{h}$

Min. Detectable Leak: $\quad-1.38 \mathrm{gal} / \mathrm{h}$

Gaussian Plots Not Representative Due to small N...
No. avg. vol rate estimates removed $=$

$\mathrm{N}=7$

$-0.21 \mathrm{gal} / \mathrm{h}$

$0.36 \mathrm{gal} / \mathrm{h}$

For Pd / Pfa $=99 \% / 1 \%$ :

The mean volume rate is equivalent to $0 \mathrm{gal} / \mathrm{h}$

Threshold, T:

$-1.12 \mathrm{ga} / \mathrm{h}$

Min. Detectable Leak:
Gaussian Plots Not Representative Due to smail N... 
Data File: TX-110 Data is from sensor type: NEUTRON ILL

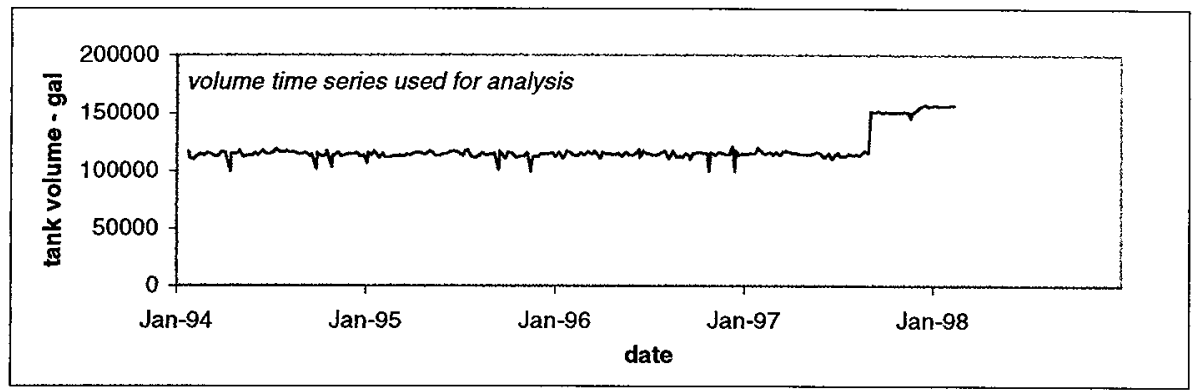

No. points edited from time series $=2$

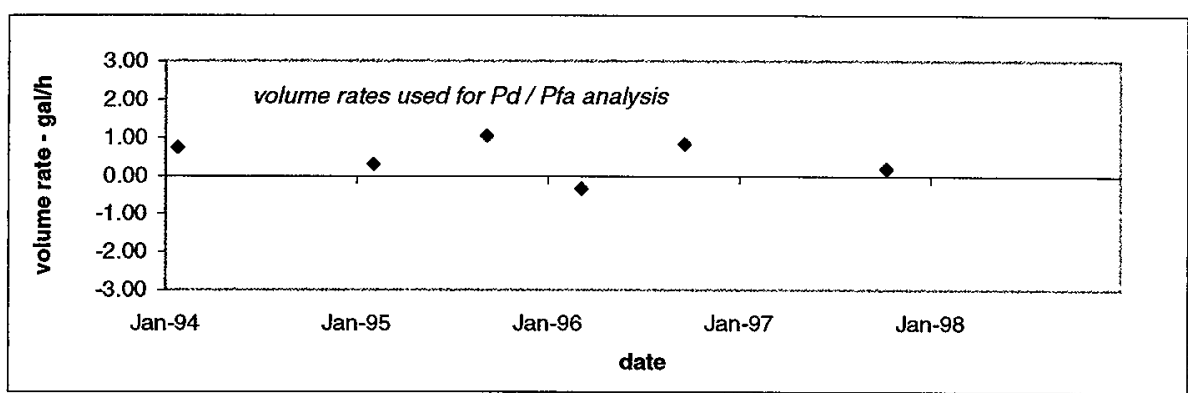

During the analysis period, the average volume rate = The standard deviation of the volume rate estimates =

For $\mathrm{Pd} / \mathrm{Pfa}=95 \% / 5 \%$ :

The mean volume rate is NOT equivalent to $0 \mathrm{gal} / \mathrm{h}$ Threshold, T: $-1.02 \mathrm{gal} / \mathrm{h}$ Min. Detectable Leak: $\quad-2.04 \mathrm{gal} / \mathrm{h}$

Gaussian Plots Not Representative Due to small N....
No. avg. vol rate estimates removed $=$

$$
N=
$$

$0.46 \mathrm{gal} / \mathrm{h}$

$0.51 \mathrm{gal} / \mathrm{h}$

For $\mathrm{Pd} / \mathrm{Pfa}=\mathbf{9 9 \%} / \mathbf{1 \%}$ :

The mean volume rate is equivalent to $0 \mathrm{gal} / \mathrm{h}$ Threshold, T:

$-1.71 \mathrm{gal} / \mathrm{h}$

Min. Detectable Leak:
Gaussian Plots Not Representative Due to small $\mathrm{N}$.... 
Data File: TX-111 Data is from sensor type: NEUTRON ILL

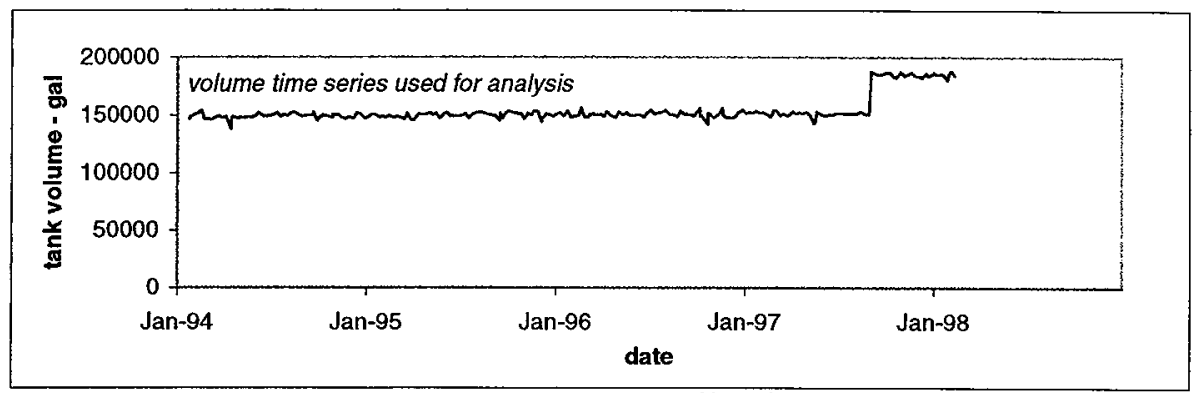

No. points edited from time series $=\quad 6$

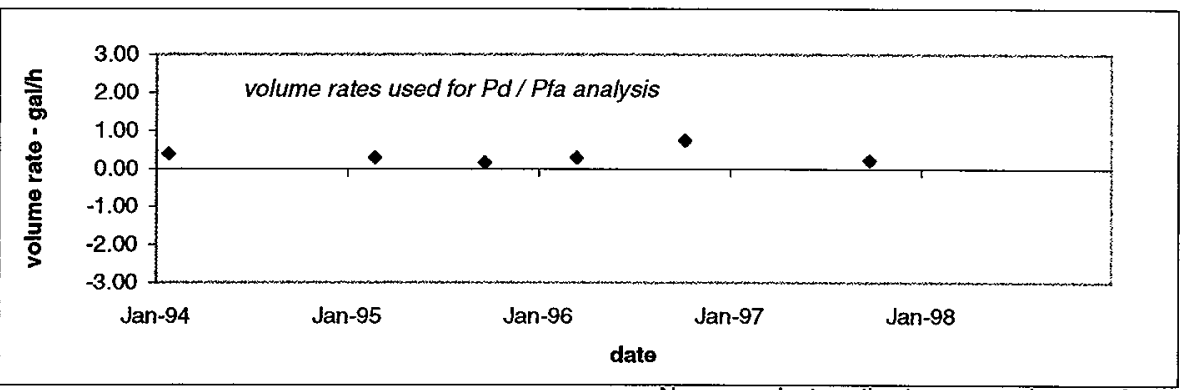

During the analysis period, the average volume rate = The standard deviation of the volume rate estimates = $0.34 \mathrm{gal} / \mathrm{h}$

For $\mathrm{Pd} / \mathrm{Pfa}=\mathbf{9 5} \% / \mathbf{5} \%$ :

The mean volume rate is NOT equivalent to $0 \mathrm{gal} / \mathrm{h}$ Threshold, T: $-0.42 \mathrm{gal} / \mathrm{h}$ Min. Detectable Leak: $\quad-0.83 \mathrm{gal} / \mathrm{h}$
For $\mathrm{Pd} / \mathrm{Pfa}=99 \% / 1 \%$ :

The mean volume rate is NOT equivalent to $0 \mathrm{gal} / \mathrm{h}$ Threshold, T: $-0.69 \mathrm{gal} / \mathrm{h}$ Min. Detectable Leak: $\quad-1.39 \mathrm{ga} / \mathrm{h}$
Gaussian Plots Not Representative Due to small $N . .$.
Gaussian Plots Not Representative Due to smail N.... 


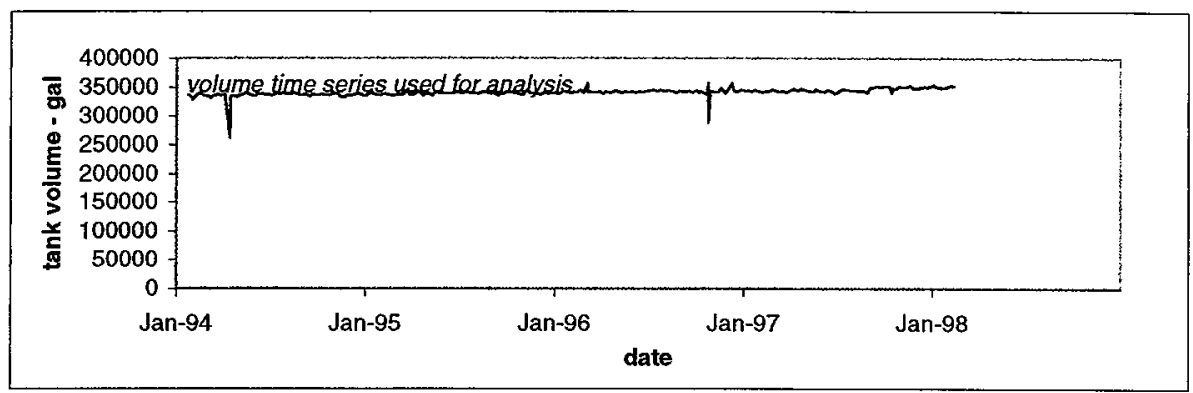

No. points edited from time series =

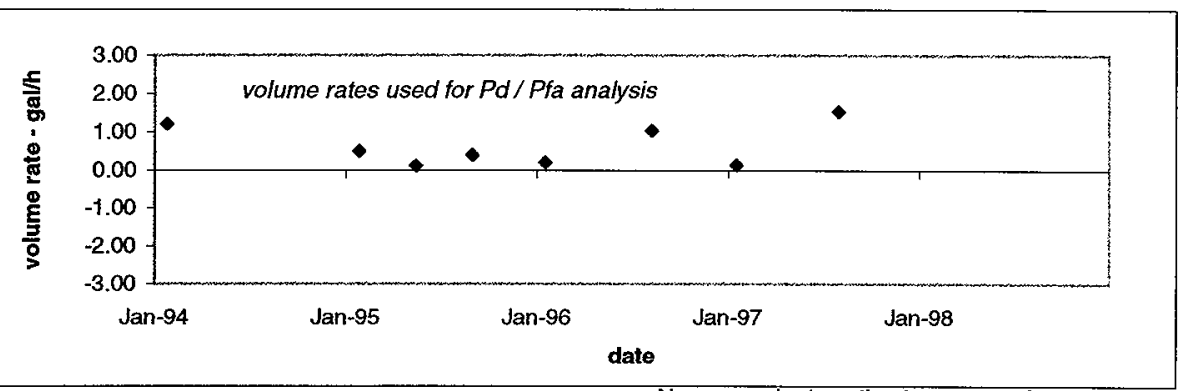

During the analysis period, the average volume rate $=$ The standard deviation of the volume rate estimates =

For Pd $/$ Pfa $=95 \% / 5 \%$ :

The mean volume rate is NOT equivalent to $0 \mathrm{gal} / \mathrm{h}$

Threshold, T: $\quad-1.04 \mathrm{gal} / \mathrm{h}$

Min. Detectable Leak: $\quad-2.08 \mathrm{gal} / \mathrm{h}$
No. avg. vol rate estimates removed =

$\mathrm{N}=$

$0.63 \mathrm{gal} / \mathrm{h}$

$0.55 \mathrm{gal} / \mathrm{h}$

For $\mathrm{Pd} / \mathrm{Pfa}=99 \% / 1 \%$ :

The mean volume rate is NOT equivalent to $0 \mathrm{gaVh}$ Threshold, T:

$-1.64 \mathrm{gal} / \mathrm{h}$

Min. Detectable Leak:
Gaussian Plots Not Representative Due to small N....
Gaussian Plots Not Representative Due to small N.. 


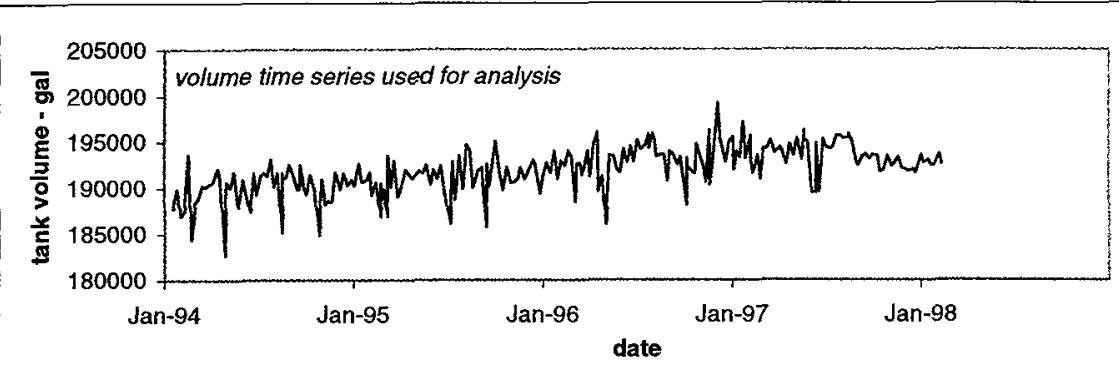

No. points edited from time series $=$

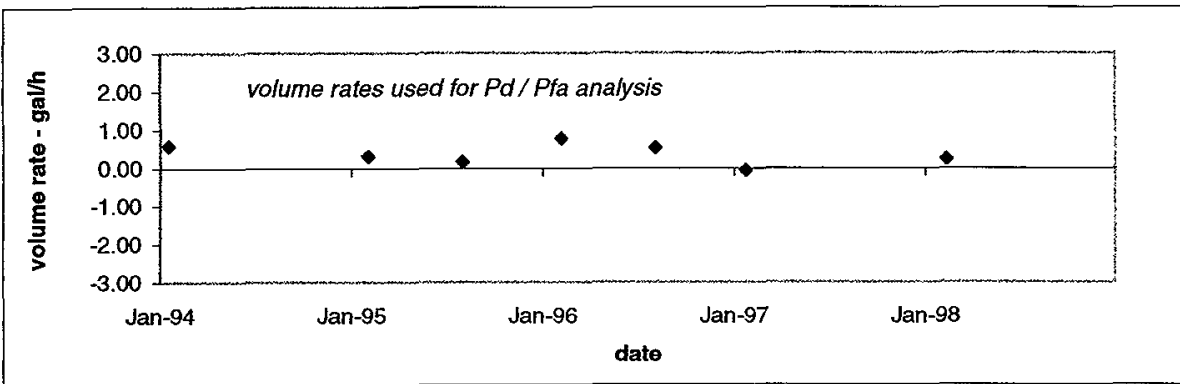

During the analysis period, the average volume rate $=$ The standard deviation of the volume rate estimates =

\section{For Pd $/ \mathrm{Pfa}=95 \% / 5 \%$ :}

The mean volume rate is NOT equivalent to $0 \mathrm{gal} / \mathrm{h}$

Threshold, T: $-0.55 \mathrm{gal} / \mathrm{h}$ Min. Detectable Leak: $\quad-1.11 \mathrm{ga} / \mathrm{h}$

Gaussian Plots Not Representative Due to small N....
No. avg. vol rate estimates removed =

$\mathbf{N}=$

$0.35 \mathrm{gal} / \mathrm{h}$

$0.28 \mathrm{gal} / \mathrm{h}$

For $\mathrm{Pd} / \mathrm{Pfa}=99 \% / 1 \%$ :

The mean volume rate is NOT equivalent to $0 \mathrm{gal} / \mathrm{h}$ Threshold, T:

$-0.89 \mathrm{gal} / \mathrm{h}$

Min. Detectable Leak:
Gaussian Plots Not Representative Due to smail N... 
Data File: TX-114 Data is from sensor type: NEUTRON ILL

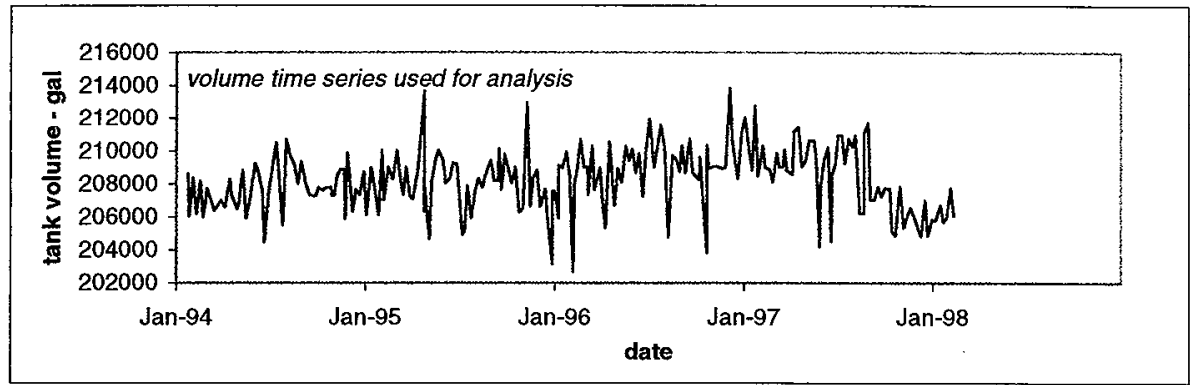

No. points edited from time series $=$

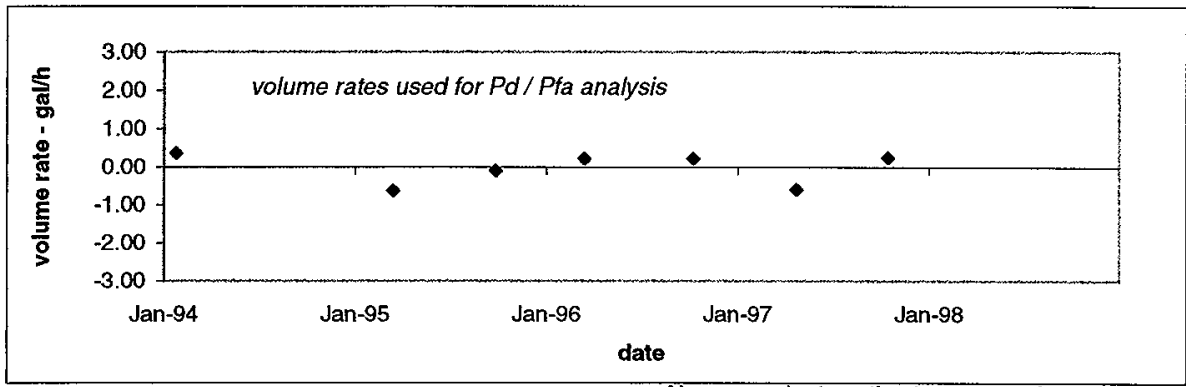

During the analysis period, the average volume rate = The standard deviation of the volume rate estimates =

For $\mathrm{Pd} / \mathrm{Pfa}=95 \% / 5 \%$ :

The mean volume rate is equivalent to $0 \mathrm{gal} / \mathrm{h}$ Threshold, T: $-0.81 \mathrm{gal} / \mathrm{h}$ Min. Detectable Leak: $\quad-1.61 \mathrm{gal} / \mathrm{h}$

Gaussian Plots Not Representative Due to small $N . .$. .
No. avg. vol rate estimates removed $=1$ $-0.05 \mathrm{gal} / \mathrm{h}$

$N=7$
For Pd / Pfa = 99\% / 1\%:

The mean volume rate is equivalent to $0 \mathrm{gal} / \mathrm{h}$ Threshold, T: $-1.30 \mathrm{gal} / \mathrm{h}$ Min. Detectable Leak: $\quad-2.61 \mathrm{ga} / \mathrm{h}$
Gaussian Plots Not Representative Due to small N.... 


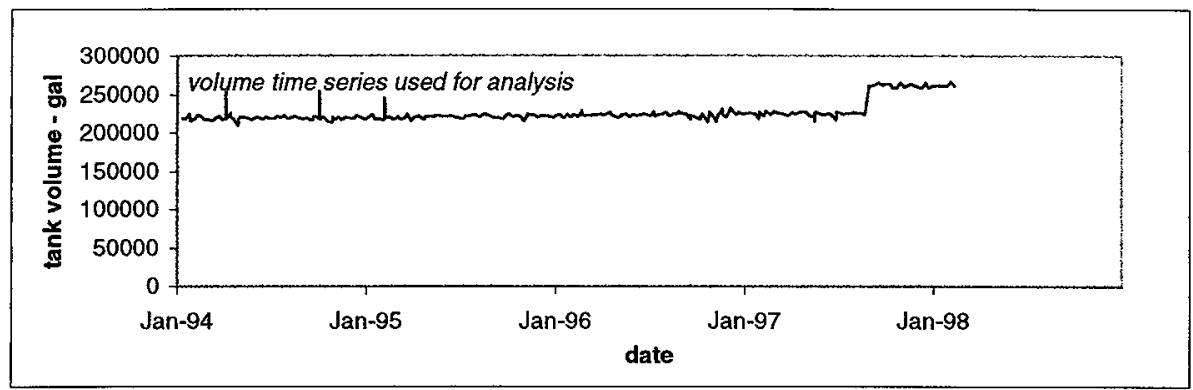

No. points edited from time series $=$

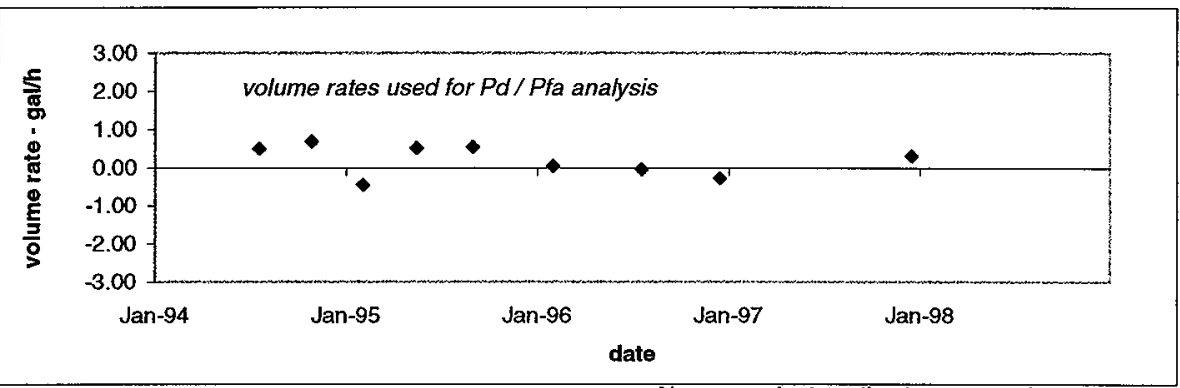

During the analysis period, the average volume rate $=$ The standard deviation of the volume rate estimates =

For Pd $/ \mathrm{Pfa}=95 \% / 5 \%$ :

The mean volume rate is equivalent to $0 \mathrm{gal} / \mathrm{h}$

Threshold, T: $\quad-0.74 \mathrm{gal} / \mathrm{h}$

Min. Detectable Leak: $\quad-1.48 \mathrm{gal} / \mathrm{h}$

Gaussian Plots Not Representative Due to small $\mathbf{N} . .$.
$0.19 \mathrm{gal} / \mathrm{h}$

$0.40 \mathrm{ga} / \mathrm{h}$

$\mathbf{N}=$
For Pd $/ \mathrm{Pfa}=99 \% / 1 \%$ :

The mean volume rate is equivalent to $0 \mathrm{gal} / \mathrm{h}$ Threshold, T:

$-1.15 \mathrm{gal} / \mathrm{h}$

Min. Detectable Leak:
Gaussian Plots Not Representative Due to small N.... 


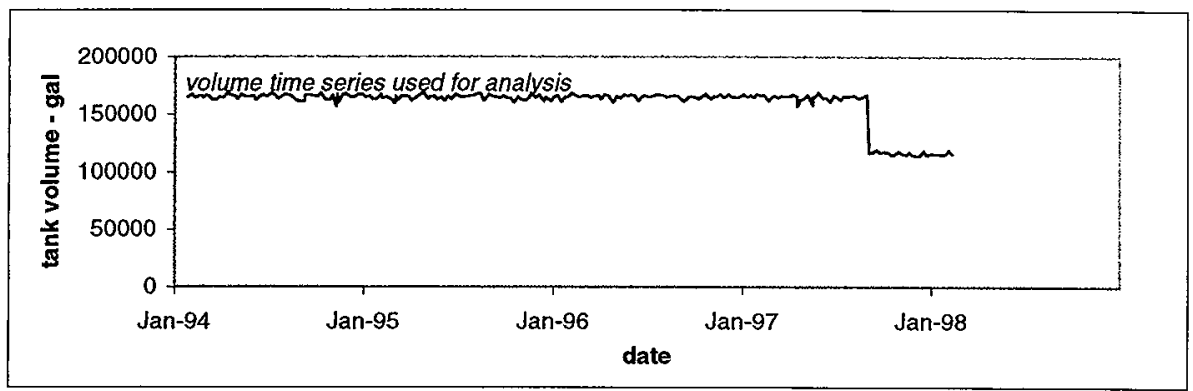

No. points edited from time series $=$

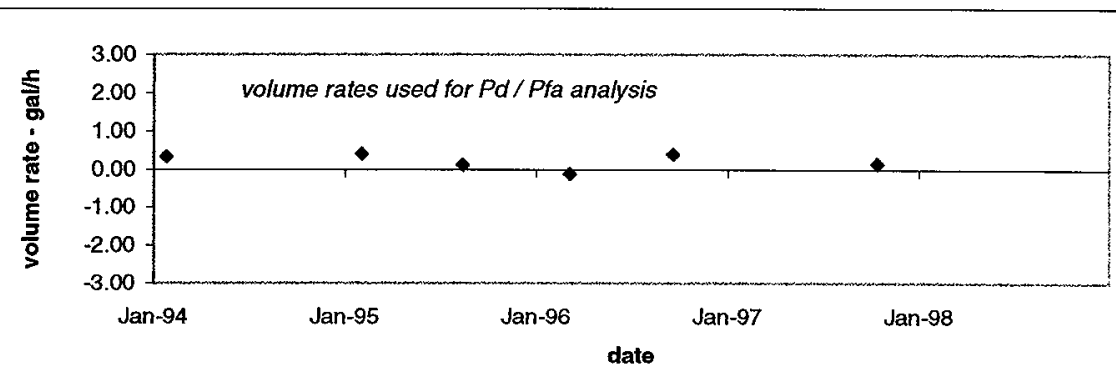

During the analysis period, the average volume rate $=$ The standard deviation of the volume rate estimates =

For Pd / Pfa = 95\% / 5\%:

The mean volume rate is NOT equivalent to $0 \mathrm{gal} / \mathrm{h}$ Threshold, T:

Min. Detectable Leak:

$-0.40 \mathrm{gal} / \mathrm{h}$

$-0.81 \mathrm{gal} / \mathrm{h}$

No. avg. vol rate estimates removed =

$$
\mathrm{N}=
$$
2

$0.20 \mathrm{gal} / \mathrm{h}$

$0.20 \mathrm{gal} / \mathrm{h}$

For $\mathrm{Pd} / \mathrm{Pfa}=99 \% / 1 \%$ :

The mean volume rate is equivalent to $0 \mathrm{gal} / \mathrm{h}$ Threshold, T:

$-0.67 \mathrm{gal} / \mathrm{h}$

Min. Detectable Leak:

Gaussian Plots Not Representative Due to smail N....
Gaussian Plots Not Representative Due to small N... 
Data File: TX-118 Data is from sensor type: NEUTRON ILL

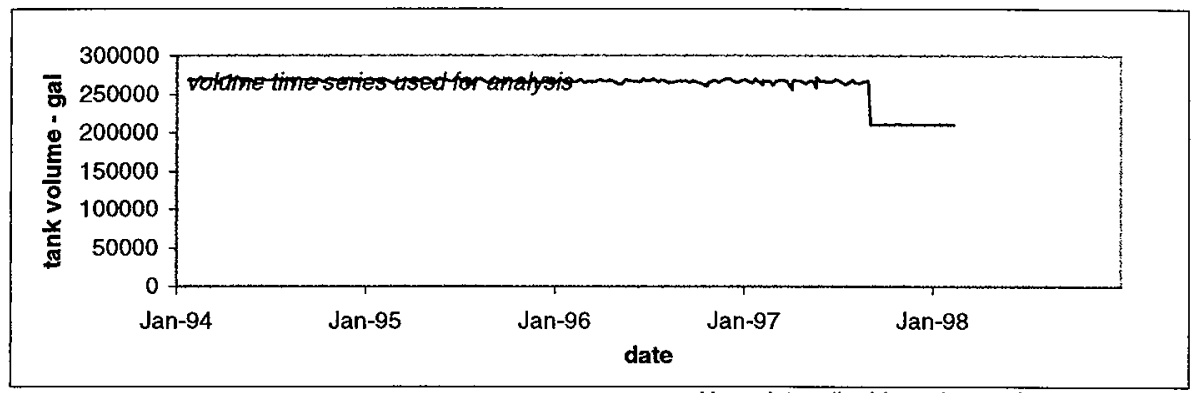

No. points edited from time series $=$

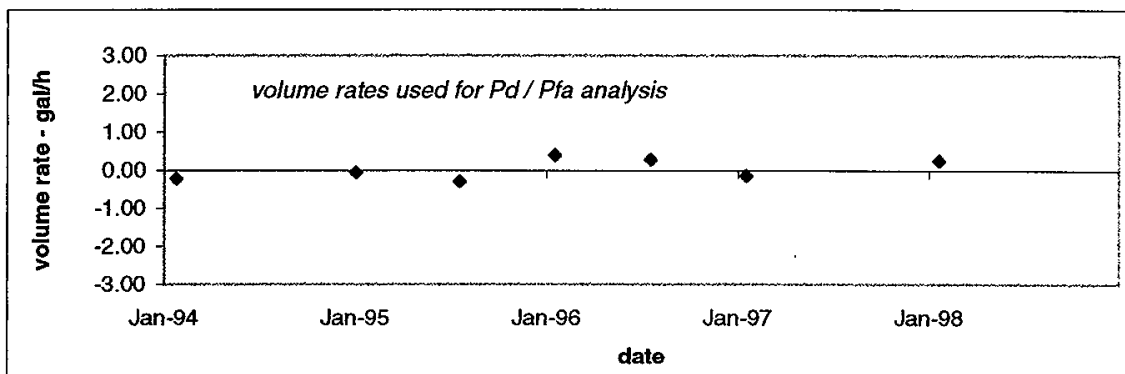

During the analysis period, the average volume rate = The standard deviation of the volume rate estimates =

For Pd $/ \mathrm{Pfa}=95 \% / 5 \%$ :

The mean volume rate is equivalent to $0 \mathrm{gal} / \mathrm{h}$

Threshold, T: $\quad-0.52 \mathrm{gal} / \mathrm{h}$

Min. Detectable Leak: $\quad-1.05 \mathrm{gal} / \mathrm{h}$
No. avg. vol rate estimates removed $=$ 2

$N=7$ $0.03 \mathrm{gal} / \mathrm{h}$

$0.27 \mathrm{gal} / \mathrm{h}$

For Pd / Pfa $=99 \% / 1 \%$ :

The mean volume rate is equivalent to $0 \mathrm{gal} / \mathrm{h}$

Threshold, T: $\quad-0.85 \mathrm{ga} / \mathrm{h}$

Min. Detectable Leak: $\quad-1.69 \mathrm{ga} / \mathrm{h}$
Gaussian Plots Not Representative Due to small N....
Gaussian Plots Not Representative Due to small $\mathrm{N}$... 


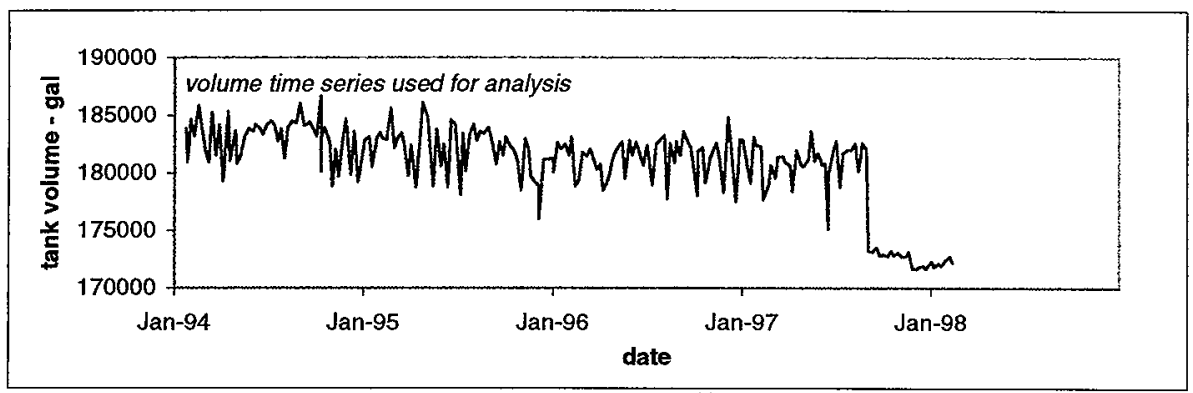

No. points edited from time series $=$

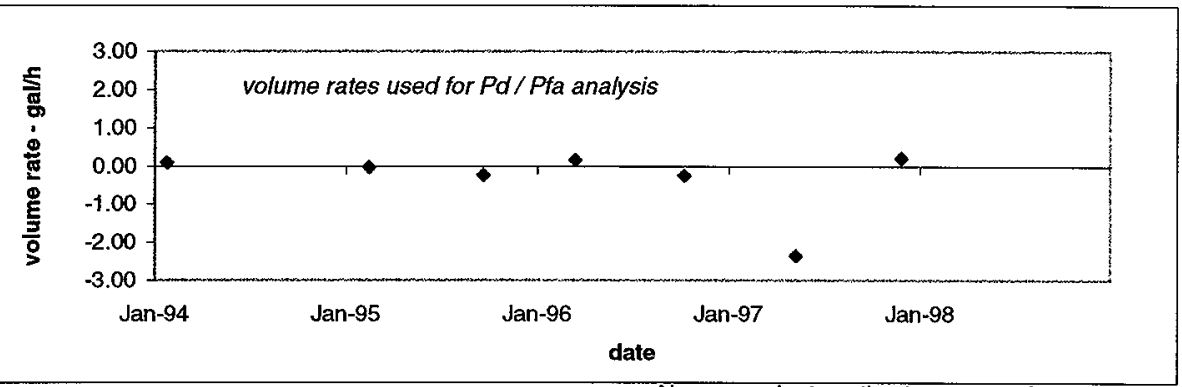

During the analysis period, the average volume rate $=$ The standard deviation of the volume rate estimates =

For Pd $/ \mathrm{Pfa}=95 \% / 5 \%$ :

The mean volume rate is equivalent to $0 \mathrm{gal} / \mathrm{h}$

Threshold, $\mathrm{T}$ : $\quad-1.76 \mathrm{gal} / \mathrm{h}$

Min. Detectable Leak: $\quad-3.52 \mathrm{gal} / \mathrm{h}$

Gaussian Plots Not Representative Due to small N...
$-0.35 \mathrm{gal} / \mathrm{h}$

$$
N=7
$$

For Pd $/ \mathrm{Pta}=99 \% / 1 \%$ :

The mean volume rate is equivalent to $0 \mathrm{gal} / \mathrm{h}$

Threshold, T: $\quad-2.85 \mathrm{gal} / \mathrm{h}$

Min. Detectable Leak: $\quad-5.69 \mathrm{gal} / \mathrm{h}$

\begin{tabular}{c}
\hline Gaussian Plots Not Representative \\
Due to small N.... \\
\hline
\end{tabular}

Gaussian Plots Not Representative Due to small N... 


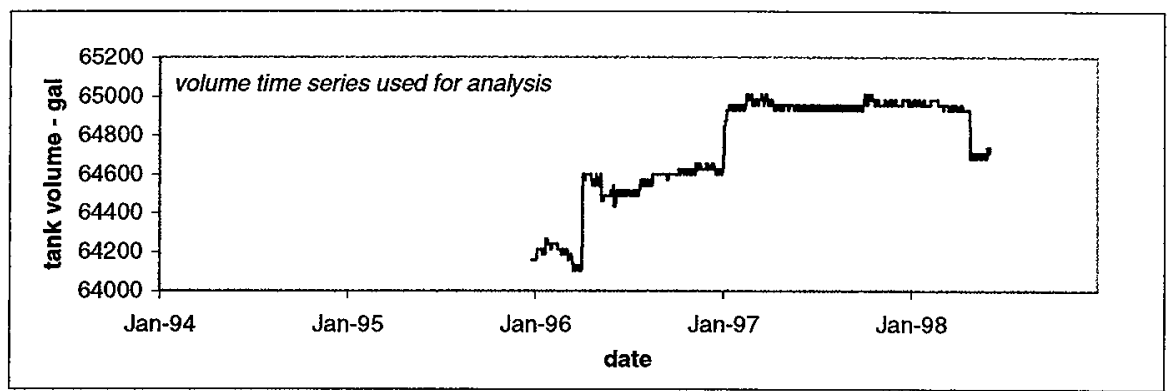

No. points edited from time series $=$

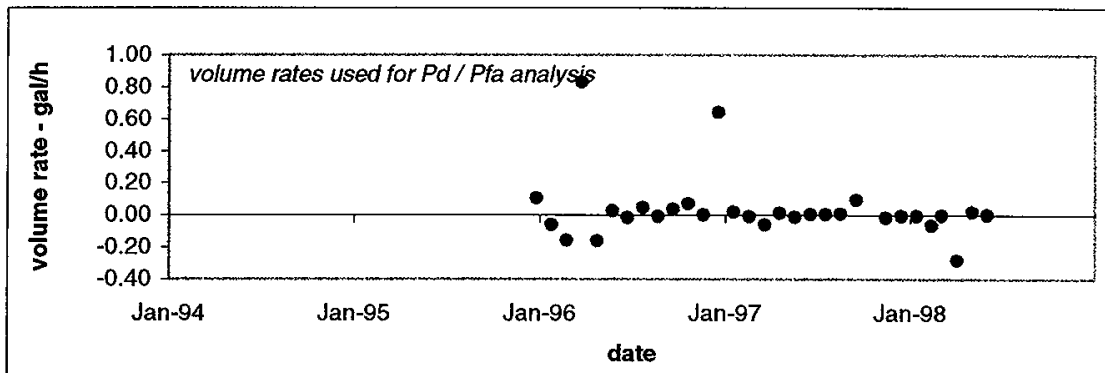

During the analysis period, the average volume rate $=$

No. avg. vol rate estimates removed =

For $\mathrm{Pd} / \mathrm{Pfa}=95 \% / 5 \%$ :

The mean volume rate is equivalent to $0 \mathrm{gal} / \mathrm{h}$ Threshold, T:

$-0.36 \mathrm{gal} / \mathrm{h}$

Min. Detectable Leak:

$-0.71 \mathrm{gal} / \mathrm{h}$

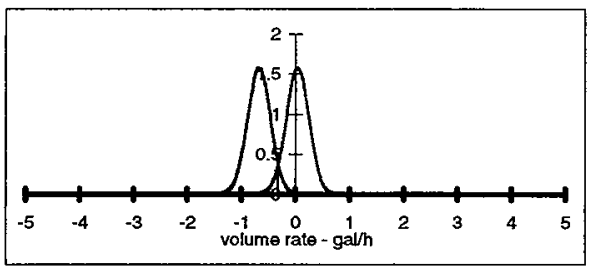

For $\mathrm{Pd} / \mathrm{Pfa}=99 \% / 1 \%$ :

The mean volume rate is equivalent to $0 \mathrm{gal} / \mathrm{h}$

Threshold, T: $\quad-0.52 \mathrm{gal} / \mathrm{h}$

Min. Detectable Leak: $\quad-1.04 \mathrm{gal} / \mathrm{h}$

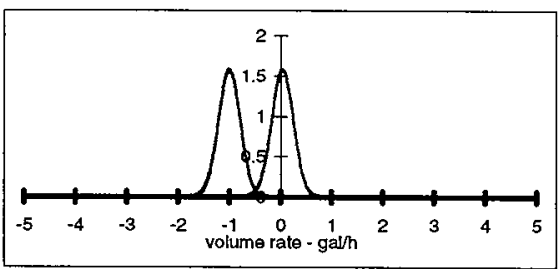

For this data, a threshold $=\quad-0.66 \mathrm{ga} / \mathrm{h}$ will detect a tank release of $1.04 \mathrm{gal} / \mathrm{h}$ at a $\mathrm{Pd}=95 \%$ The corresponding Pfa is $\quad 0.64 \%$ 


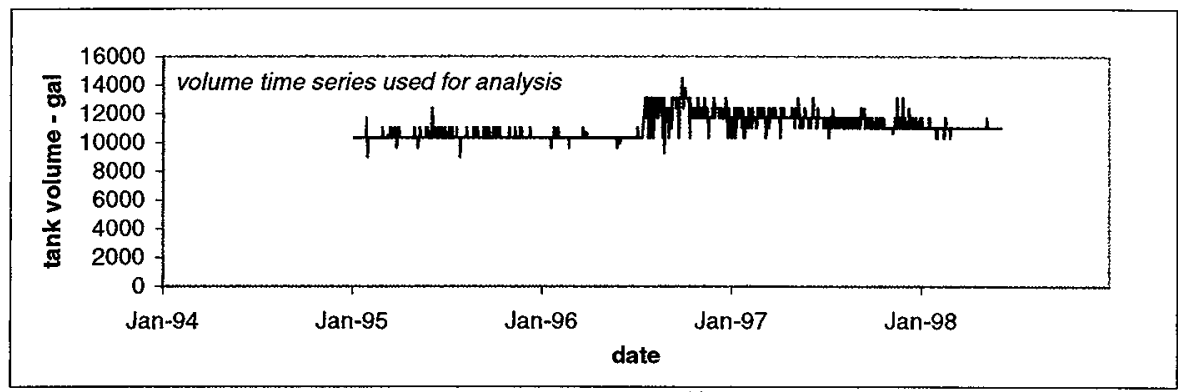

No. points edited from time series =

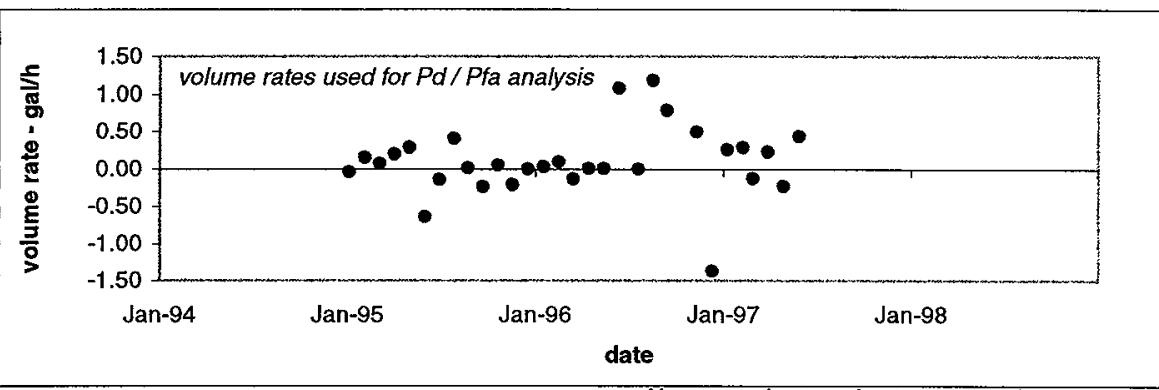

During the analysis period, the average volume rate $=$

No. avg. vol rate estimates removed $=$

For $\mathrm{Pd} / \mathrm{Pfa}=95 \% / 5 \%$ :

The mean volume rate is equivalent to $0 \mathrm{gal} / \mathrm{h}$ Threshold, T:

$-0.82 \mathrm{gal} / \mathrm{h}$

Min. Detectable Leak: $\quad-1.65 \mathrm{gal} / \mathrm{h}$

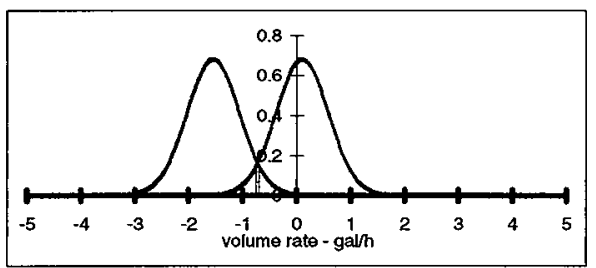

For this data, a threshold=

The corresponding $\mathrm{Pfa}$ is

$-1.51 \mathrm{gal} / \mathrm{h}$ will detect a tank release of $0.27 \%$
For Pd $/ \mathrm{Pfa}=99 \% / 1 \%$ :

The mean volume rate is equivalent to $0 \mathrm{gal} / \mathrm{h}$

Threshold, T: $\quad-1.20 \mathrm{gal} / \mathrm{h}$

Min. Detectable Leak: $\quad-2.40 \mathrm{ga} / \mathrm{h}$

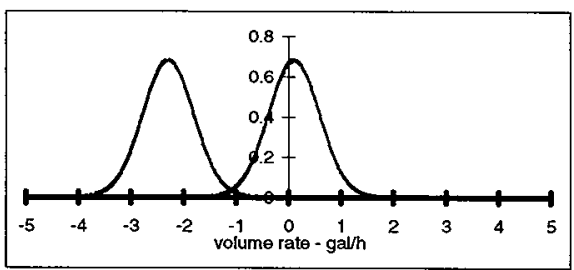

$2.40 \mathrm{gal} / \mathrm{h}$ at $\mathrm{Pd}=95 \%$ 


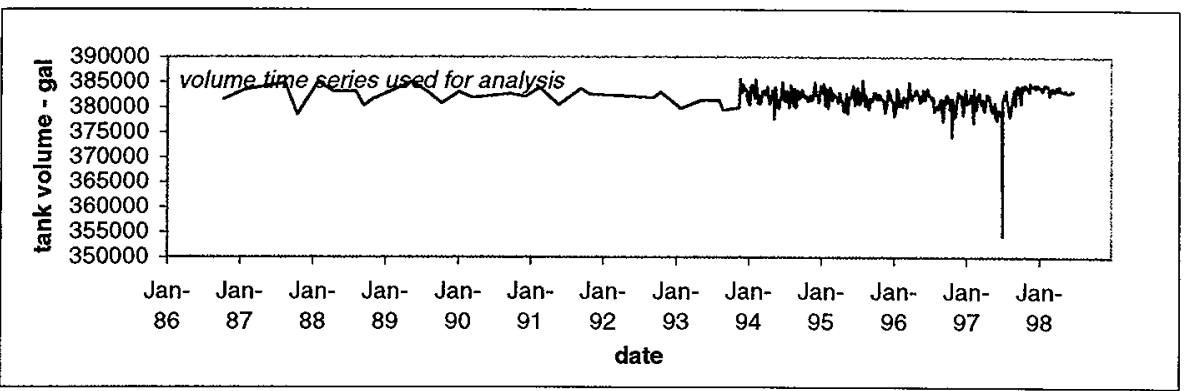

No. points edited from time series $=$

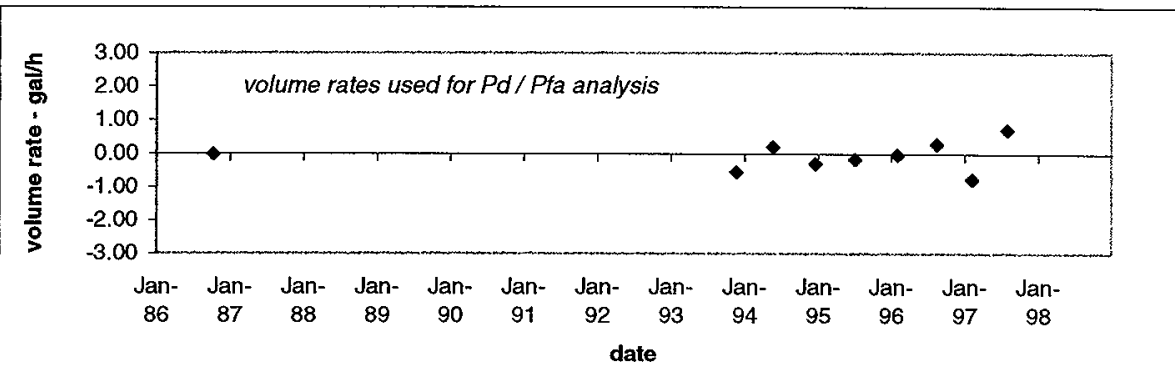

During the analysis period, the average volume rate = The standard deviation of the volume rate estimates =

For Pd / Pfa $=95 \% / 5 \%$ :

The mean volume rate is equivalent to 0 gal $/ \mathrm{h}$

Threshold, T:

$-0.83 \mathrm{gal} / \mathrm{h}$

Min. Detectable Leak: $\quad-1.66 \mathrm{ga} / \mathrm{h}$

Gaussian Plots Not Representative Due to small N...
$-0.08 \mathrm{gal} / \mathrm{h}$

No. avg. vol rate estimates removed $=$

$N=9$

For Pd $/ \mathrm{Pfa}=99 \% / 1 \%$ :

The mean volume rate is equivalent to $0 \mathrm{gal} / \mathrm{h}$ Threshold, T: Min. Detectable Leak: $\quad-2.59 \mathrm{gal} / \mathrm{h}$
Gaussian Plots Not Representative Due to small $\mathrm{N}$... 


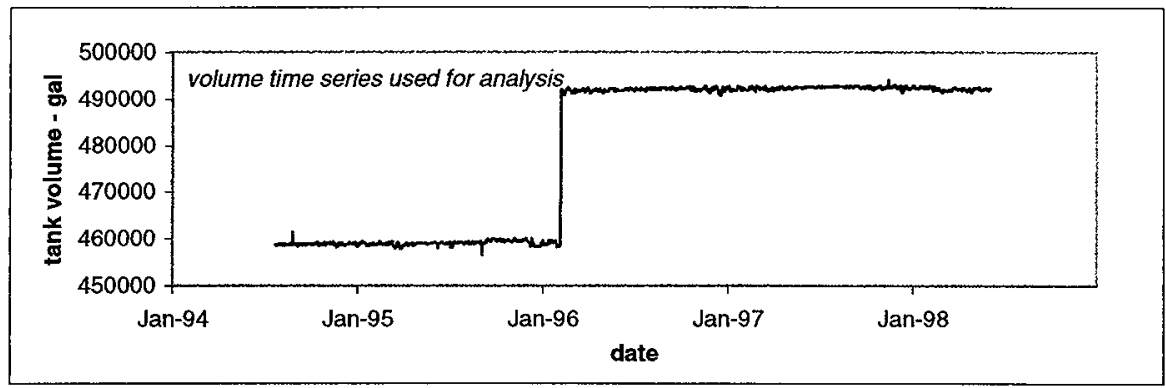

No. points edited from time series =

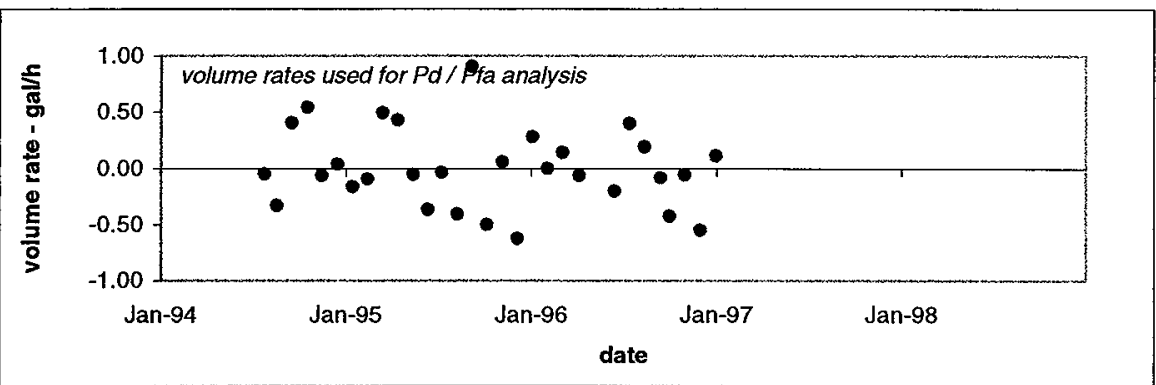

During the analysis period, the average volume rate $=$ The standard deviation of the volume rate estimates =

For $\mathrm{Pd} / \mathrm{Pfa}=95 \% / 5 \%$ :

The mean volume rate is equivalent to $0 \mathrm{gal} / \mathrm{h}$ Threshold, T:

$-0.61 \mathrm{ga} / \mathrm{h}$

Min. Detectable Leak:

$-1.23 \mathrm{gal} / \mathrm{h}$

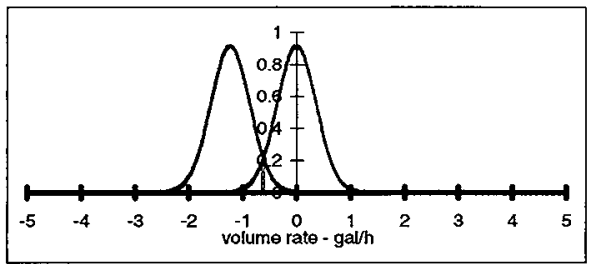

No. avg. vol rate estimates removed =

$N=29$

$$
\begin{aligned}
& 0.00 \mathrm{gal} / \mathrm{h} \\
& 0.36 \mathrm{gal} / \mathrm{h}
\end{aligned}
$$

For Pd $/ \mathrm{Pfa}=99 \% / 1 \%$ :

The mean volume rate is equivalent to $0 \mathrm{gal} / \mathrm{h}$ Threshold, T

$-0.89 \mathrm{ga} / \mathrm{h}$

Min. Delectable Leak: $\quad-1.78 \mathrm{gal} / \mathrm{h}$

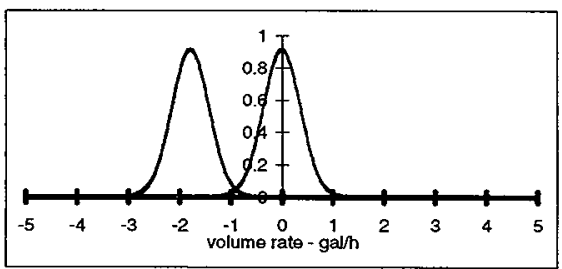

For this data, a threshold $=-1.20 \mathrm{gal} / \mathrm{h}$ will detect a tank release of $1.78 \mathrm{ga} / \mathrm{h}$ at a $\mathrm{Pd}=95 \%$ The corresponding Pfa is $\quad 0.38 \%$ 


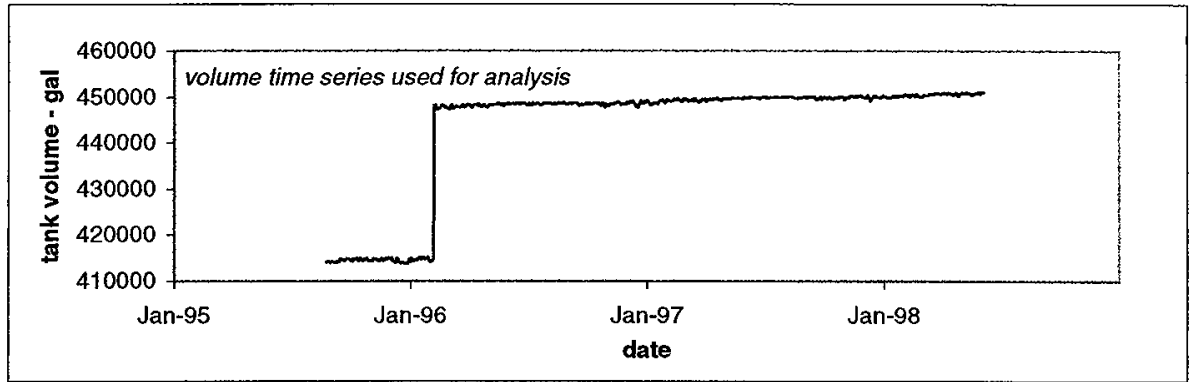

No. points edited from time series $=$

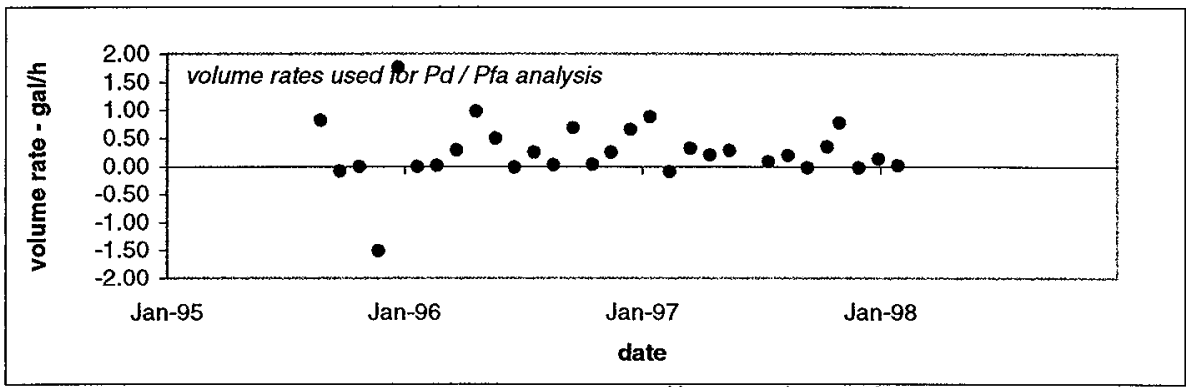

During the analysis period, the average volume rate $=$ The standard deviation of the volume rate estimates =

For Pd $/ \mathrm{Pfa}=95 \% / 5 \%$ :

The mean volume rate is NOT equivalent to $0 \mathrm{gal} / \mathrm{h}$ Threshold, $\mathrm{T}$ : $\quad-0.92 \mathrm{gal} / \mathrm{h}$ Min. Detectable Leak: $\quad-1.83 \mathrm{gal} / \mathrm{h}$

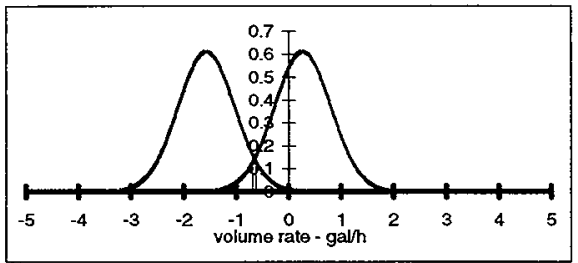

No. avg. vol rate estimates removed $=$

$$
N=
$$
29

For this data, a threshold= $-1.52 \mathrm{gal} / \mathrm{h}$ will detect a tank release of $\quad 2.66 \mathrm{gal} / \mathrm{h}$ at a $\mathrm{Pd}=95 \%$ The corresponding Pfa is $\quad 0.25 \%$

For $\mathrm{Pd} / \mathrm{Pfa}=99 \% / 1 \%$ :

The mean volume rate is NOT equivalent to $0 \mathrm{gal} / \mathrm{h}$ Threshold, T: $\quad-1.33 \mathrm{gal} / \mathrm{h}$ Min. Detectable Leak: $\quad-2.66 \mathrm{gal} / \mathrm{h}$

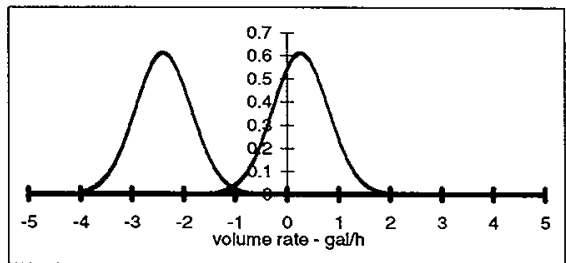

$0.27 \mathrm{gal} / \mathrm{h}$

$0.54 \mathrm{gal} / \mathrm{h}$ 


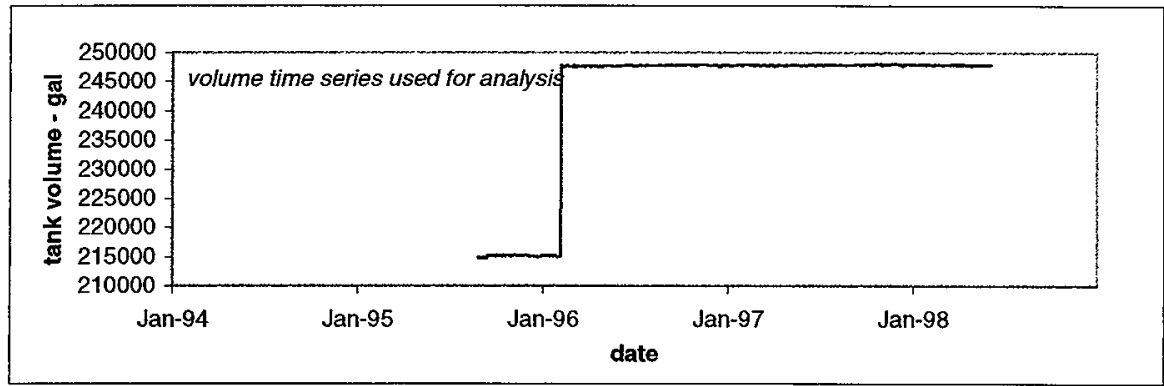

No. points edited from time series $=$

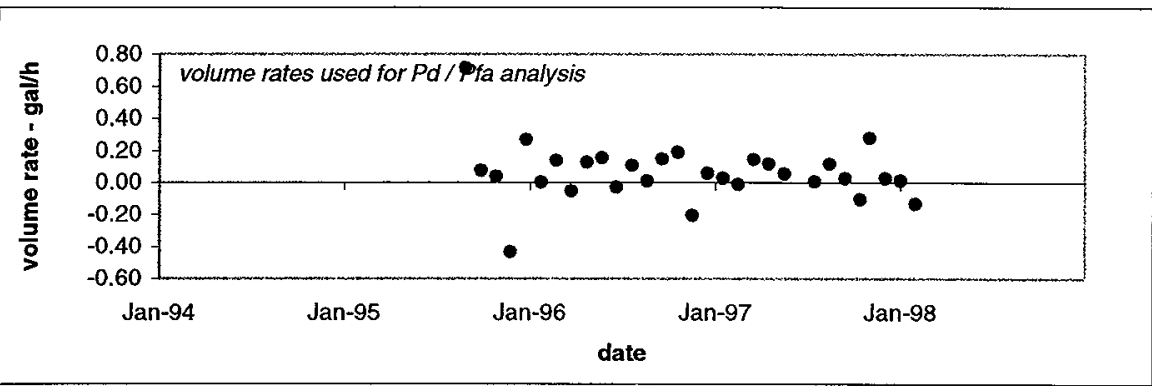

During the analysis period, the average volume rate $=$ The standard deviation of the volume rate estimates =

For Pd / Pfa = 95\% / 5\%:

The mean volume rate is NOT equivalent to $0 \mathrm{gal} / \mathrm{h}$ Threshold, $T$ : $-0.32 \mathrm{gal} / \mathrm{h}$ Min. Detectable Leak: $\quad-0.64 \mathrm{ga} / \mathrm{h}$

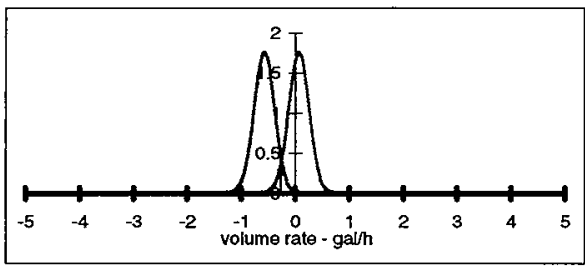

No. avg. vol rate estimates removed $=$

$0.06 \mathrm{gal} / \mathrm{h}$

$0.19 \mathrm{gal} / \mathrm{h}$

For Pd $/ \mathrm{Pfa}=99 \% / 1 \%$ :

The mean volume rate is equivalent to $0 \mathrm{gal} / \mathrm{h}$

Threshold, T: $\quad-0.46 \mathrm{gal} / \mathrm{h}$

Min. Detectable Leak: $\quad-0.93 \mathrm{ga} / \mathrm{h}$

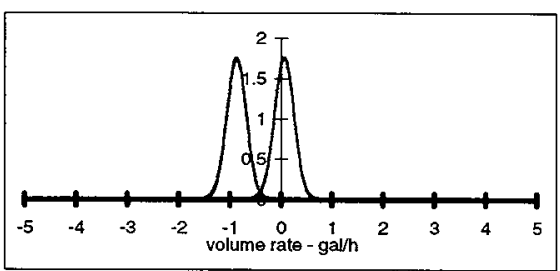

For this data, a threshold $=\quad-0.57 \mathrm{gal} / \mathrm{h}$ will detect a tank release of $\quad 0.93 \mathrm{galh}$ at a $\mathrm{Pd}=95 \%$ The corresponding Pfa is $\quad 0.61 \%$ 


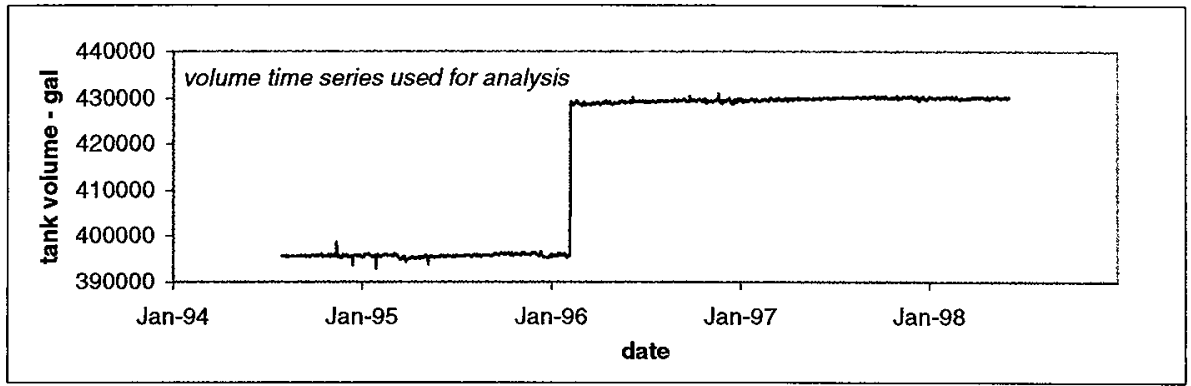

No. points edited from time series =

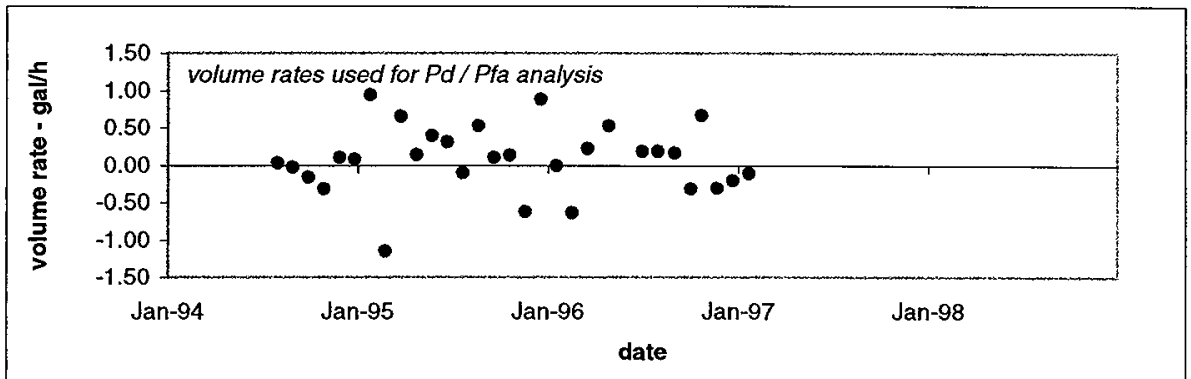

During the analysis period, the average volume rate $=$ The standard deviation of the volume rate estimates =

For Pd $/ \mathrm{Pfa}=95 \% / 5 \%$ :

The mean volume rate is equivalent to $0 \mathrm{gal} / \mathrm{h}$

Threshold, T: $\quad-0.78 \mathrm{gal} / \mathrm{h}$

Min. Detectable Leak: $\quad-1.56 \mathrm{gal} / \mathrm{h}$

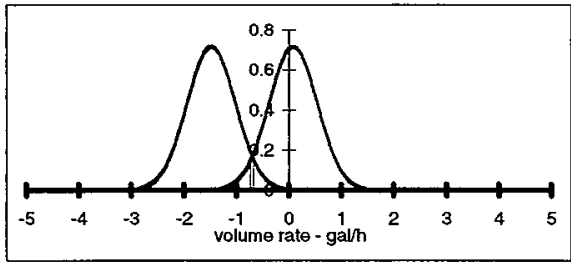

For this data, a threshold $=-1.44 \mathrm{gal} / \mathrm{h}$ will detect a tank release of The corresponding Pfa is
No. avg. vol rate estimates removed $=$

$N=29$

$0.08 \mathrm{gal} / \mathrm{h}$

$0.46 \mathrm{gal} / \mathrm{h}$

For Pd $/ \mathrm{Pfa}=99 \% / 1 \%$ :

The mean volume rate is equivalent to $0 \mathrm{gal} / \mathrm{h}$

Threshold, T: $\quad-1.13 \mathrm{ga} / \mathrm{h}$

Min. Detectable Leak: $\quad-2.26 \mathrm{gal} / \mathrm{h}$

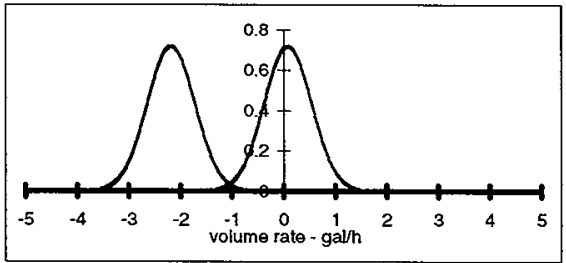

$2.26 \mathrm{gal} / \mathrm{h}$ at a $\mathrm{Pd}=95 \%$ 


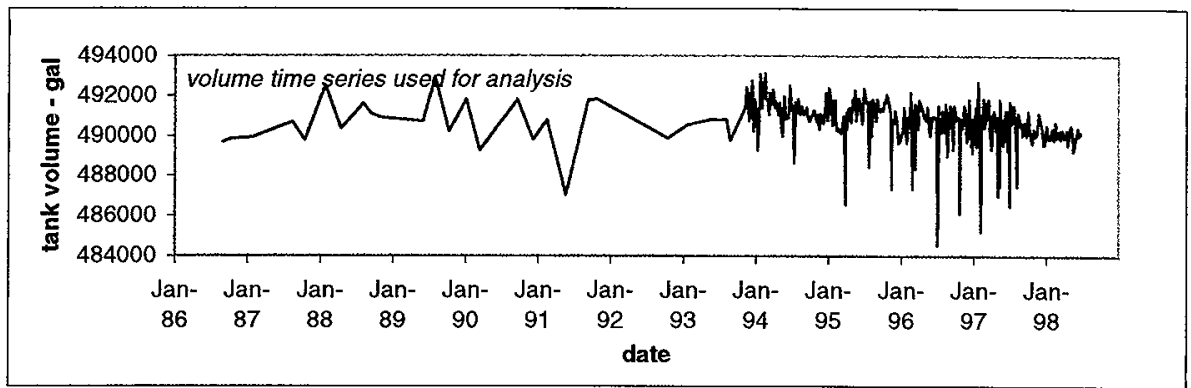

No. points edited from time series =

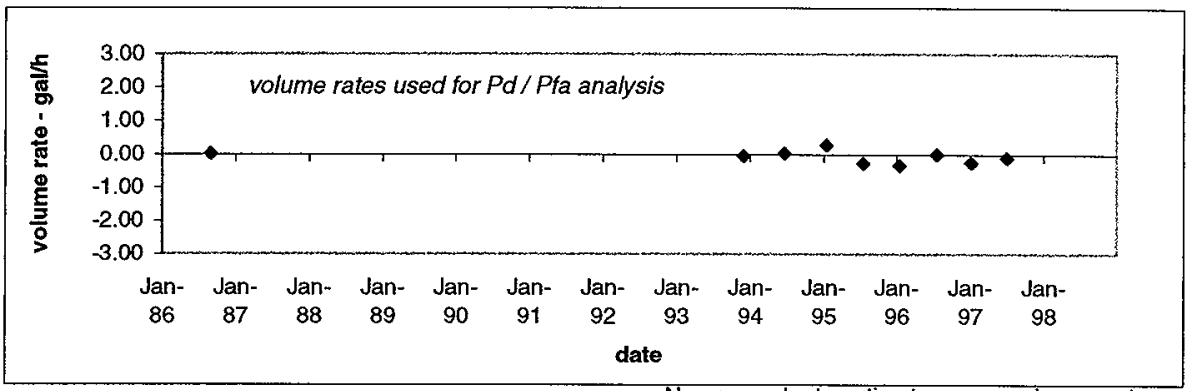

During the analysis period, the average volume rate = The standard deviation of the volume rate estimates =

For $\mathrm{Pd} / \mathrm{Pfa}=\mathbf{9 5} \% / 5 \%$ :

The mean volume rate is equivalent to $0 \mathrm{gal} / \mathrm{h}$

Threshold, T: $\quad-0.35 \mathrm{gal} / \mathrm{h}$

Min. Detectable Leak: $\quad-0.71 \mathrm{ga} / \mathrm{h}$

Gaussian Plots Not Representative Due to small $N$..
No. avg. vol rate estimates removed $=1$ $-0.08 \mathrm{gal} / \mathrm{h}$

$\mathrm{N}=9$
For $\mathrm{Pd} / \mathrm{Pfa}=99 \% / 1 \%$ :

The mean volume rate is equivalent to $0 \mathrm{gal} / \mathrm{h}$

Threshold, $\mathrm{T}$ : $\quad-0.55 \mathrm{gal} / \mathrm{h}$

Min. Detectable Leak: $\quad-1.10 \mathrm{gal} / \mathrm{h}$
Gaussian Plots Not Representative Due to small N.... 


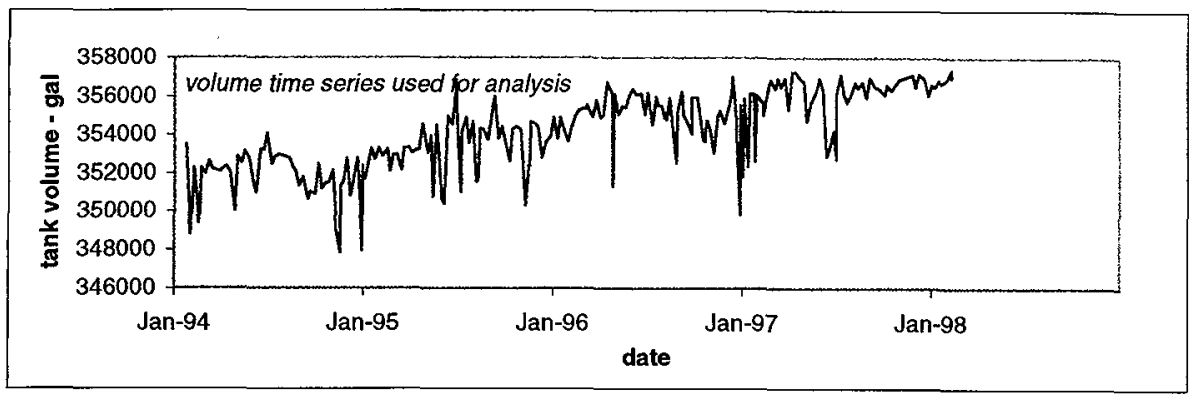

No. points edited from time series =

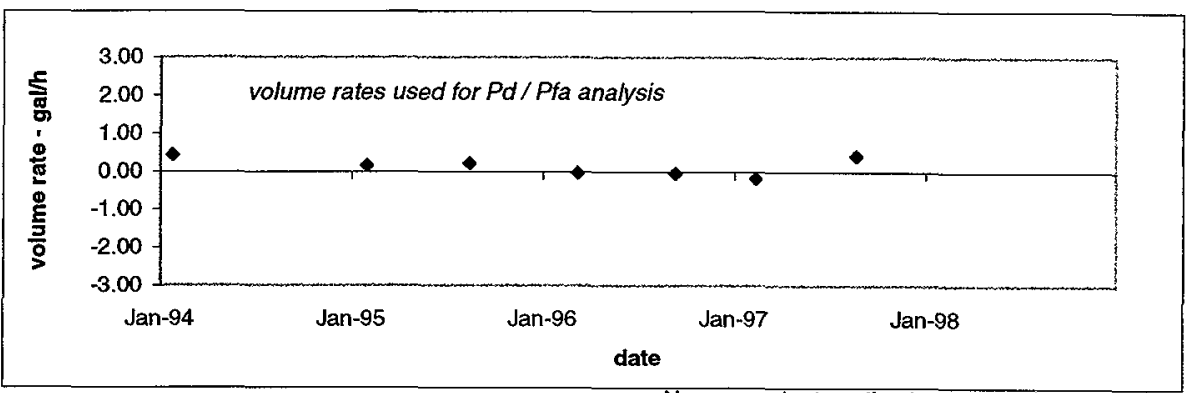

During the analysis period, the average volume rate =

$$
0.13 \mathrm{gal} / \mathrm{h}
$$$$
N=7
$$

The standard deviation of the volume rate estimates $=$

$$
0.24 \mathrm{gal} / \mathrm{h}
$$

For Pd $/ \mathrm{Pfa}=95 \% / 5 \%$ :

The mean volume rate is equivalent to $0 \mathrm{gal} / \mathrm{h}$

Threshold, T:

$-0.46 \mathrm{ga} / \mathrm{h}$

Min. Detectable Leak: $\quad-0.92 \mathrm{gal} / \mathrm{h}$

Gaussian Plots Not Representative Due to small N...
For $\mathrm{Pd} / \mathrm{Pfa}=99 \% / 1 \%$ :

The mean volume rate is equivalent to $0 \mathrm{gal} / \mathrm{h}$ Threshold, T:

Min. Detectable Leak:
$-0.74 \mathrm{gal} / \mathrm{h}$

$-1.49 \mathrm{gal} / \mathrm{h}$
Gaussian Plots Not Representative Due to small N... 


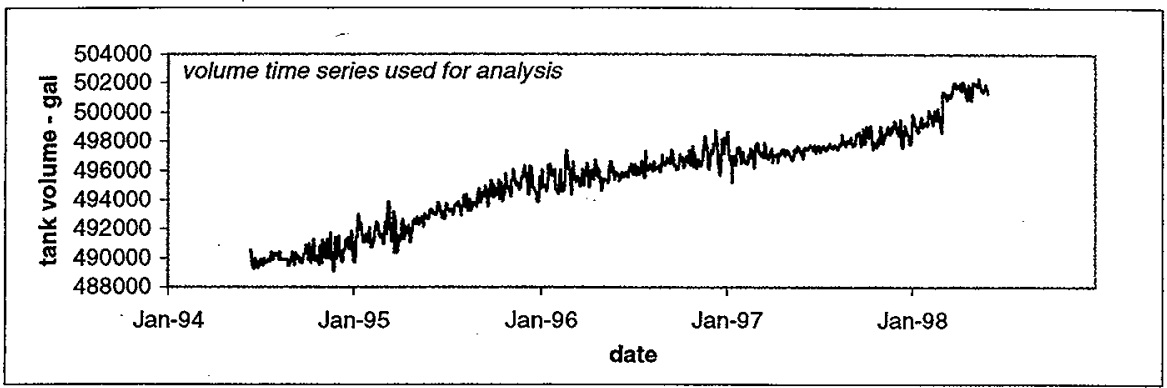

No. points edited from time series $=$

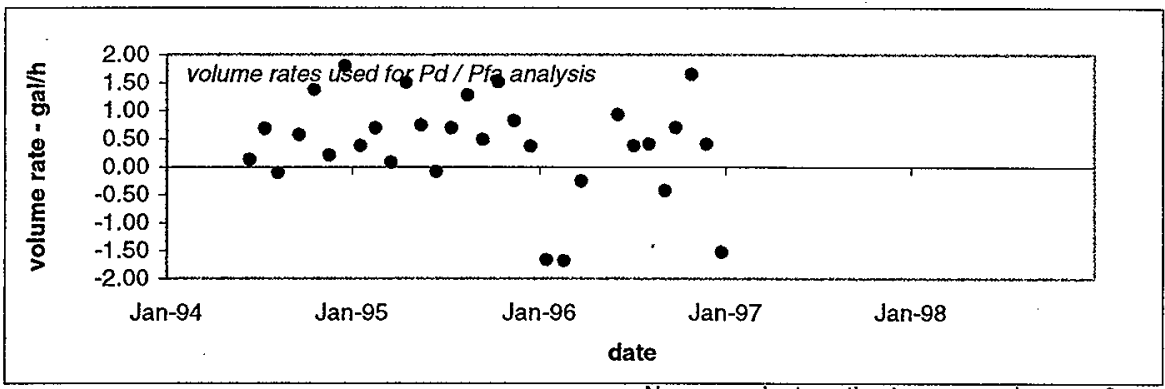

During the analysis period, the average volume rate = The standard deviation of the volume rate estimates =

For Pd $/ \mathrm{Pfa}=95 \% / 5 \%$ :

The mean volume rate is NOT equivalent to $0 \mathrm{gal} / \mathrm{h}$ Threshold, T:

Min. Detectable Leak: $-1.50 \mathrm{gal} / \mathrm{h}$ $-3.00 \mathrm{gal} / \mathrm{h}$

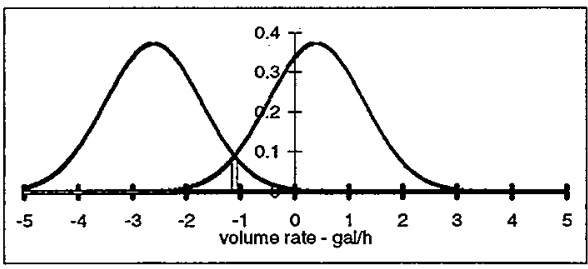

$0.40 \mathrm{gal} / \mathrm{h}$

$$
N=30
$$

For Pd $/ \mathrm{Pfa}=99 \% / 1 \%$ :

The mean volume rate is equivalent to $0 \mathrm{gal} / \mathrm{h}$

Threshold, T: $\quad-2.18 \mathrm{gal} / \mathrm{h}$ Min. Detectable Leak: $\quad-4.35 \mathrm{gal} / \mathrm{h}$
For this data, a threshold= The corresponding $\mathrm{Pfa}$ is
$5.00 \mathrm{gal} / \mathrm{h}$ will detect a tank release of $4.35 \mathrm{gal} / \mathrm{h}$ at a $\mathrm{Pd}=95 \%$ $0.00 \%$

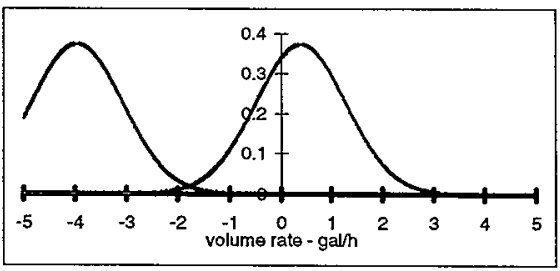




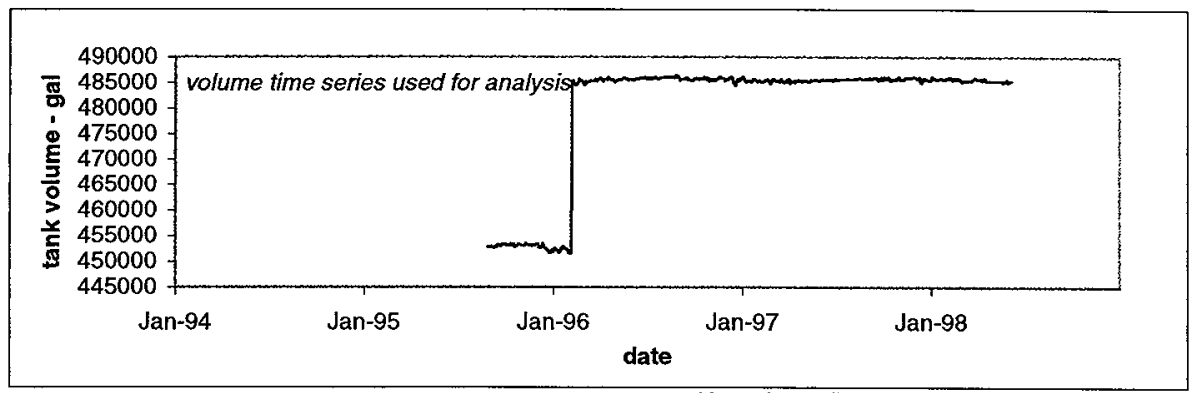

No. points edited from time series $=2$

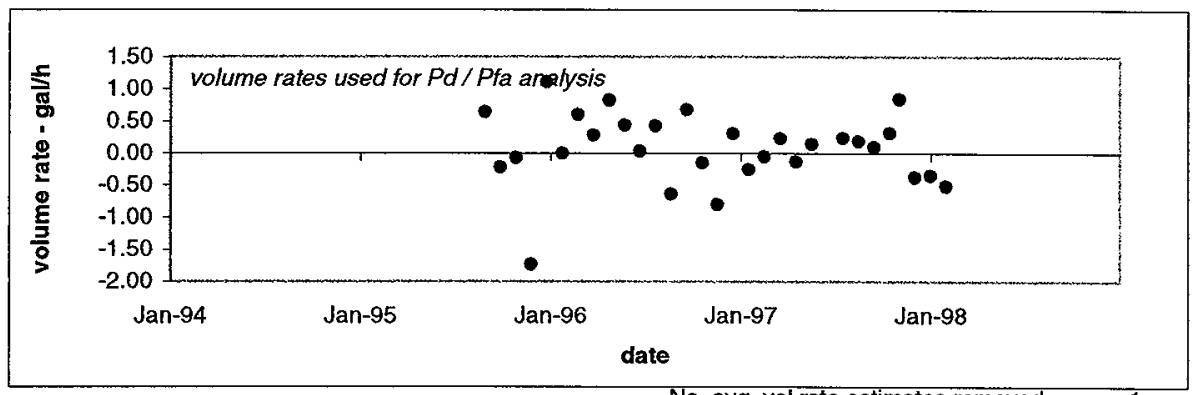

During the analysis period, the average volume rate $=$ The standard deviation of the volume rate estimates =

For $\mathrm{Pd} / \mathrm{Pfa}=95 \% / 5 \%$ :

The mean volume rate is equivalent to $0 \mathrm{gal} / \mathrm{h}$

Threshold, T: $\quad-0.98 \mathrm{gal} / \mathrm{h}$

Min. Detectable Leak: $\quad-1.96 \mathrm{gal} / \mathrm{h}$

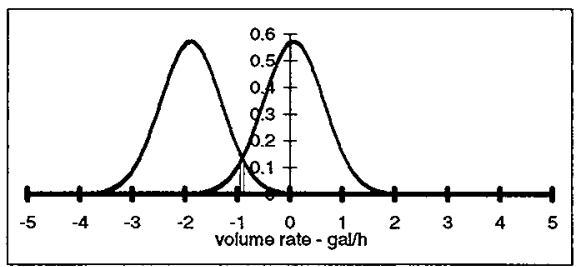

No. avg. vol rate estimates removed $=$

$$
N=29
$$

$0.07 \mathrm{gal} / \mathrm{h}$

$0.58 \mathrm{gal} / \mathrm{h}$

For $\mathrm{Pd} / \mathrm{Pfa}=99 \% / 1 \%$ :

The mean volume rate is equivalent to $0 \mathrm{gal} / \mathrm{h}$

Threshold, T:

$-1.42 \mathrm{gal} / \mathrm{h}$

Min. Detectable Leak: $\quad-2.84 \mathrm{gal} / \mathrm{h}$

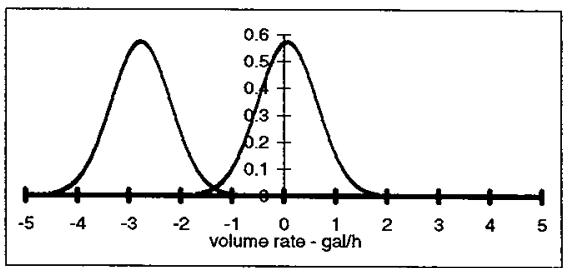

For this data, a threshold= $-1.83 \mathrm{gal} / \mathrm{h}$ will detect a tank release of $\quad 2.84 \mathrm{gal} / \mathrm{h}$ at a $\mathrm{Pd}=95 \%$ The corresponding $\mathrm{Pfa}$ is $\quad 0.24 \%$ 


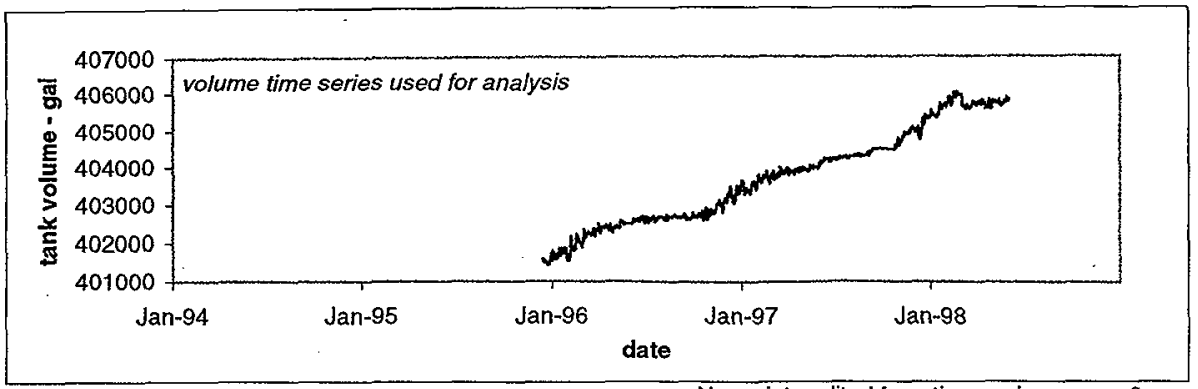

No. points edited from time series $=$

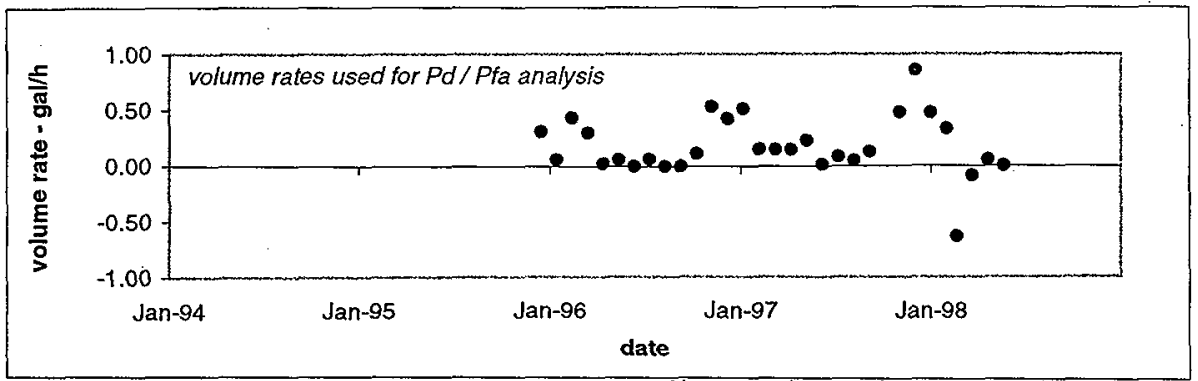

During the analysis period, the average volume rate = The standard deviation of the volume rate estimates =

For $\mathrm{Pd} / \mathrm{Pfa}=95 \% / 5 \%$ :

The mean volume rate is NOT equivalent to $0 \mathrm{ga} / \mathrm{h}$ Threshold, T: $-0.46 \mathrm{gal} / \mathrm{h}$ Min. Detectable Leak: $\quad-0.92 \mathrm{galh}$

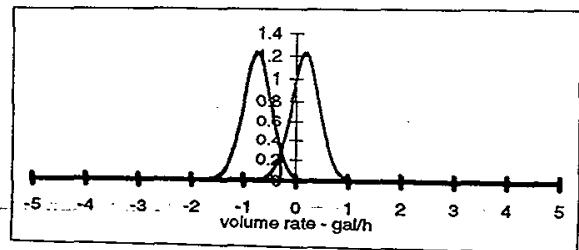

For this data, a threshold The corresponding Pfa is $-0.72 \mathrm{gaVh}$ will detect a tank release of

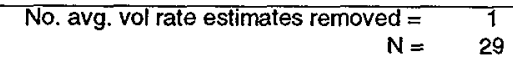

$0.18 \mathrm{ga} / \mathrm{h}$

$0.27 \mathrm{gal} / \mathrm{h}$

For Pd $/$ Pfa $=99 \% / 1 \%$ :

The mean volume rate is NOT equivalent to $0 \mathrm{ga} / \mathrm{h}$ Threshold, T: $-0.67 \mathrm{gal} / \mathrm{h}$ Min. Detectable Leak: $-1.33 \mathrm{gaV} / \mathrm{h}$

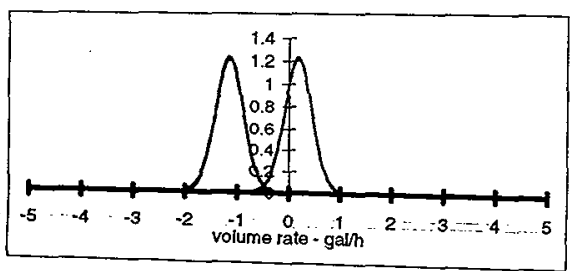

$1.33 \mathrm{gal} / \mathrm{h}$ at $\mathrm{a} \mathrm{Pd}=95 \%$ 


\section{Appendix F}

\section{Calculation of Potential Leaks}




\begin{tabular}{|c|c|c|c|c|c|c|c|c|c|}
\hline Tank & 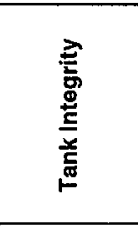 & 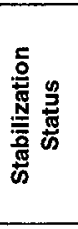 & 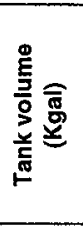 & 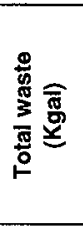 & 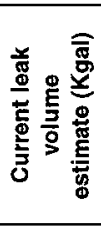 & 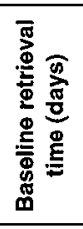 & 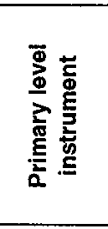 & 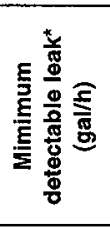 & 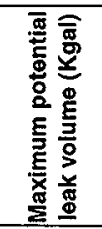 \\
\hline $\mathrm{A}-101(\mathrm{~T}, \mathrm{H}, \mathrm{O})$ & SOUND & $/ \mathrm{PI}$ & 1000 & 953 & 0 & 570 & LOW & 3.83 & 52 \\
\hline$A-102(T)$ & SOUND & IS/PI & 1000 & 41 & 0 & 123 & ENRAF & No Data & No Data \\
\hline $\mathrm{A}-103(\mathrm{~T})$ & ASMD LKR & IS/II & 1000 & 371 & 5.5 & 295 & ENRAF & 2.00 & 14 \\
\hline A-104 (T) & ASMD LKR & IS/II & 1000 & 28 & 2.5 & 104 & No Data & No Data & No Data \\
\hline A-105 & ASMD LKR & IS/II & 1000 & 19 & 277 & 84 & No Data & No Data & No Data \\
\hline $\mathrm{A}-106(\mathrm{~T})$ & SOUND & IS/II & 1000 & 125 & 0 & 179 & LOW & No Data & No Data \\
\hline$A X-101(T, H)$ & SOUND & /PI & 1000 & 748 & 0 & 473 & LOW & No Data & No Data \\
\hline$A X-102(T, H)$ & ASMD LKR & IS/II & 1000 & 39 & 3 & 121 & No Data & No Data & No Data \\
\hline$A X-103(H)$ & SOUND & IS/II & 1000 & 112 & 0 & 172 & LOW & No Data & No Data \\
\hline$A X-104(T)$ & ASMD LKR & IS/II & 1000 & 7 & 0 & 36 & No Data & No Data & No Data \\
\hline $\mathrm{B}-101(\mathrm{~T})$ & ASMD LKR & IS/II & 500 & 113 & 0 & 112 & No Data & No Data & No Data \\
\hline $\mathrm{B}-102(\mathrm{~T})$ & SOUND & IS/II & 500 & 32 & 0 & 72 & ENRAF & 0.37 & 1 \\
\hline $\mathrm{B}-103(\mathrm{~T})$ & ASMD LKR & IS/II & 500 & 59 & 0 & 87 & No Data & No Data & No Data \\
\hline B-104 & SOUND & IS/II & 500 & 371 & 0 & 234 & ENRAF & No Data & No Data \\
\hline B-105 & ASMD LKR & $|S / I|$ & 500 & 306 & 0 & 204 & LOW & 1.85 & 9 \\
\hline B-106 & SOUND & IS/II & 500 & 117 & 0 & 114 & ENRAF & No Data & No Data \\
\hline B-107 & ASMD LKR & $|S / I|$ & 500 & 165 & 8 & 137 & No Data & No Data & No Data \\
\hline B-108 & SOUND & $\mid S / I I$ & 500 & 94 & 0 & 103 & LOW & No Data & No Data \\
\hline B-109 & SOUND & IS/II & 500 & 127 & 0 & 119 & No Data & No Data & No Data \\
\hline$B-110(T)$ & ASMD LKR & IS/II & 500 & 246 & 10 & 175 & LOW & 1.49 & 6 \\
\hline B-111 & ASMD LKR & IS/II & 500 & 237 & 0 & 171 & LOW & 1.45 & 6 \\
\hline $\mathrm{B}-112(\mathrm{~T})$ & ASMD LKR & IS/II & 500 & 33 & 2 & 73 & ENRAF & 1.05 & 2 \\
\hline B-201 & ASMD LKR & IS/II & 55 & 29 & 1.2 & 19 & No Data & No Data & No Data \\
\hline $\mathrm{B}-202(\mathrm{~T})$ & SOUND & IS/II & 55 & 27 & 0 & 18 & No Data & No Data & No Data \\
\hline B-203 & ASMD LKR & $|S /| \mid$ & 55 & 51 & 0.3 & 29 & No Data & No Data & No Data \\
\hline B-204 & ASMD LKR & IS/II & 55 & 50 & 0.4 & 29 & No Data & No Data & No Data \\
\hline $\mathrm{BX}-101(\mathrm{~T})$ & ASMD LKR & IS/II & 500 & 43 & 0 & 79 & No Data & No Data & No Data \\
\hline$B X-102(T)$ & ASMD LKR & IS/II & 500 & 96 & 70 & 104 & No Data & No Data & No Data \\
\hline $\mathrm{BX}-103$ & SOUND & IS/II & 500 & 68 & 0 & 91 & ENRAF & 0.58 & 1 \\
\hline$B X-104(T)$ & SOUND & IS/II & 500 & 99 & 0 & 106 & ENRAF & 0.62 & 2 \\
\hline $\mathrm{BX}-105(\mathrm{~T})$ & SOUND & IS/II & 500 & 51 & 0 & 83 & ENRAF & 1.14 & 2 \\
\hline$B X-106(T)$ & SOUND & $|P|$ & 500 & 38 & 0 & 76 & No Data & No Data & No Data \\
\hline BX-107 & SOUND & $|\mathrm{S} / \mathrm{P}|$ & 500 & 345 & 0 & 222 & No Data & No Data & No Data \\
\hline$B X-108$ & ASMD LKR & IS/II & 500 & 26 & 2.5 & 67 & No Data & No Data & No Data \\
\hline$B X-109$ & SOUND & $\mid \mathrm{S} / \mathrm{PI}$ & 500 & 193 & 0 & 150 & No Data & No Data & No Data \\
\hline$B X-110$ & ASMD LKR & IS/PI & 500 & 207 & 0 & 157 & ENRAF & 1.02 & 4 \\
\hline$B X-111$ & ASMD L.KR & /PI & 500 & 162 & 0 & 136 & No Data & No Data & No Data \\
\hline$B X-112$ & SOUND & IS/PI & 500 & 165 & 0 & 137 & No Data & No Data & No Data \\
\hline
\end{tabular}




\begin{tabular}{|c|c|c|c|c|c|c|c|c|c|}
\hline Tank & 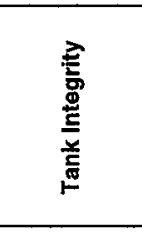 & 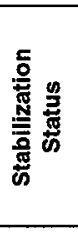 & 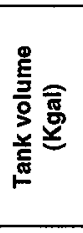 & 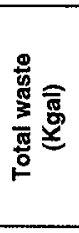 & 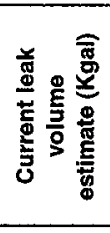 & 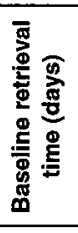 & 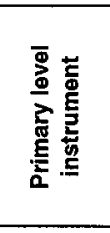 & 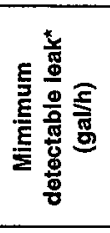 & 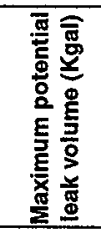 \\
\hline$B Y-101$ & SOUND & IS/II & 750 & 387 & 0 & 272 & LOW & 8.74 & 57 \\
\hline$B Y-102$ & SOUND & $/ \mathrm{PI}$ & 750 & 277 & 0 & 220 & LOW & 15.80 & 83 \\
\hline $\mathrm{BY}-103(\mathrm{~T}, \mathrm{Fe})$ & ASMD LKR & $/ \mathrm{PI}$ & 750 & 414 & 5 & 285 & LOW & 3.81 & 26 \\
\hline $\mathrm{BY}-104(\mathrm{~T}, \mathrm{Fe})$ & SOUND & IS/II & 750 & 406 & 0 & 281 & LOW & 1.07 & 7 \\
\hline BY-105 (T, Fe) & ASMD LKR & $/ \mathrm{PI}$ & 750 & 503 & 0 & 327 & LOW & 2.00 & 16 \\
\hline BY-106 & ASMD LKR & $/ \mathrm{PI}$ & 750 & 642 & 0 & 393 & LOW & 9.37 & 88 \\
\hline $\mathrm{BY}-107(\mathrm{Fe})$ & ASMD LKR & $|S /| \mid$ & 750 & 266 & 15.1 & 215 & LOW & 3.28 & 17 \\
\hline BY $-108(F e)$ & ASMD LKR & IS/II & 750 & 228 & 5 & 197 & No Data & No Data & No Data \\
\hline BY-109 & SOUND & /PI & 750 & 290 & 0 & 226 & LOW & 8.28 & 45 \\
\hline$B Y-110(F e)$ & SOUND & IS/II & 750 & 398 & 0 & 277 & LOW & 2.82 & 19 \\
\hline $\mathrm{BY}-111(\mathrm{Fe})$ & SOUND & $|S /| \mid$ & 750 & 459 & 0 & 306 & No Data & No Data & No Data \\
\hline $\mathrm{BY}-112(\mathrm{Fe})$ & SOUND & $|S / I|$ & 750 & 291 & 0 & 227 & LOW & 3.05 & 17 \\
\hline C-101 (T) & ASMD LKR & IS/II & 500 & 88 & 20 & 101 & No Data & No Data & No Data \\
\hline $\mathrm{C}-102(\mathrm{~T}, \mathrm{O})$ & SOUND & IS/IP & 500 & 316 & 0 & 208 & No Data & No Data & No Data \\
\hline $\mathrm{C}-103(\mathrm{~T}, \mathrm{O})$ & SOUND & /PI & 500 & 195 & 0 & 151 & ENRAF & 2.59 & 9 \\
\hline C-104 (T) & SOUND & IS/II & 500 & 295 & 0 & 198 & No Data & No Data & No Data \\
\hline $\mathrm{C}-105(\mathrm{Sn}, \mathrm{T})$ & SOUND & IPI & 500 & 134 & 0 & 122 & No Data & No Data & No Data \\
\hline C-106 (T, HL) & SOUND & $/ P I$ & 500 & 229 & 0 & 167 & ENRAF & 22.10 & 89 \\
\hline $\mathrm{C}-107(\mathrm{~T})$ & SOUND & IPI & 500 & 237 & 0 & 171 & No Data & No Data & No Data \\
\hline $\mathrm{C}-108(\mathrm{~T}, \mathrm{Fe})$ & SOUND & IS/II & 500 & 66 & 0 & 90 & No Data & No Data & No Data \\
\hline $\mathrm{C}-109(\mathrm{Fe})$ & SOUND & IS/II & 500 & 66 & 0 & 90 & No Data & No Data & No Data \\
\hline $\mathrm{C}-110(T)$ & ASMD LKR & $\mid \mathrm{PI}$ & 500 & 178 & 2 & 143 & No Data & No Data & No Data \\
\hline $\mathrm{C}-111(\mathrm{~T})$ & ASMD LKR & IS/II & 500 & 57 & 5.5 & 86 & No Data & No Data & No Data \\
\hline $\mathrm{C}-112(\mathrm{~T})$ & SOUND & $\mid \mathrm{S} / \mathrm{PI}$ & 500 & 104 & 0 & 108 & No Data & No Data & No Data \\
\hline C-201 & ASMD LKR & IS/II & 55 & 2 & 0.55 & 5 & No Data & No Data & No Data \\
\hline C-202 & ASMD LKR & $|S /| \mid$ & 55 & 1 & 0.45 & 4 & No Data & No Data & No Data \\
\hline C-203 & ASMD LKR & IS/II & 55 & 5 & 0.4 & 7 & No Data & No Data & No Data \\
\hline C-204 & ASMD LKR & IS/II & 55 & 3 & 0.35 & 6 & No Data & No Data & No Data \\
\hline S-101 (T) & SOUND & $/ \mathrm{Pl}$ & 750 & 427 & 0 & 291 & ENRAF & 1.17 & 8 \\
\hline $\mathrm{S}-102(\mathrm{H}, \mathrm{O})$ & SOUND & $/ \mathrm{PI}$ & 750 & 549 & 0 & 349 & LOW & 2.41 & 20 \\
\hline S-103 & SOUND & $/ P I$ & 750 & 248 & 0 & 206 & ENRAF & 2.52 & 12 \\
\hline S-104 (T) & ASMD LKR & IS/II & 750 & 294 & 24 & 228 & LOW & 3.10 & 17 \\
\hline S-105 & SOUND & IS/II & 750 & 456 & 0 & 305 & LOW & 1.25 & 9 \\
\hline S-106 & SOUND & /PI & 750 & 479 & 0 & 316 & ENRAF & 3.00 & 23 \\
\hline S-107 (T) & SOUND & $/ \mathrm{PI}$ & 750 & 376 & 0 & 267 & ENRAF & 0.92 & 6 \\
\hline S-108 & SOUND & $\mid \mathrm{PI}$ & 750 & 450 & 0 & 302 & LOW & 2.29 & 17 \\
\hline$S-109$ & SOUND & $/ \mathrm{PI}$ & 750 & 568 & 0 & 358 & LOW & 2.13 & 18 \\
\hline
\end{tabular}




\begin{tabular}{|c|c|c|c|c|c|c|c|c|c|}
\hline Tank & 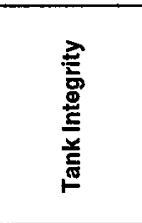 & 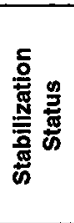 & 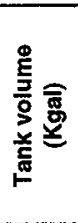 & 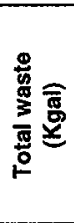 & 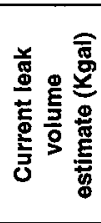 & 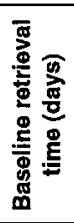 & 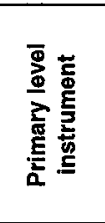 & 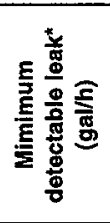 & 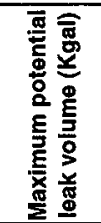 \\
\hline S-110 & SOUND & $/ \mathrm{PI}$ & 750 & 390 & 0 & 274 & LOW & 2.81 & 18 \\
\hline S-111 $(H, O)$ & SOUND & /PI & 750 & 540 & 0 & 345 & ENRAF & 2.28 & 19 \\
\hline $\mathrm{S}-112(\mathrm{~T}, \mathrm{H})$ & SOUND & $/ \mathrm{PI}$ & 750 & 523 & 0 & 337 & LOW & 0.89 & 7 \\
\hline SX-101 (T) & SOUND & $/ \mathrm{PI}$ & 1000 & 456 & 0 & 335 & LOW & 11.88 & 96 \\
\hline SX-102 (H) & SOUND & $/ \mathrm{PI}$ & 1000 & 543 & 0 & 376 & LOW & 3.34 & 30 \\
\hline$S X-103(T, H, O)$ & SOUND & $/ \mathrm{PI}$ & 1000 & 652 & 0 & 428 & LOW & 0.82 & 8 \\
\hline SX-104 (T) & ASMD LKR & $/ \mathrm{PI}$ & 1000 & 614 & 6 & 410 & LOW & 7.20 & 71 \\
\hline $\mathrm{SX}-105(\mathrm{~T}, \mathrm{H})$ & SOUND & $/ \mathrm{PI}$ & 1000 & 683 & 0 & 443 & LOW & 1.68 & 18 \\
\hline$S X-106(T, H)$ & SOUND & $|P|$ & 1000 & 538 & 0 & 374 & ENRAF & 2.97 & 27 \\
\hline$S X-107(T)$ & ASMD LKR & IS/II & 1000 & 104 & 5 & 169 & No Data & No Data & No Data \\
\hline$s X-108(T)$ & ASMD LKR & IS/II & 1000 & 87 & 35 & 160 & No Data & No Data & No Data \\
\hline$S X-109(T)$ & ASMD LKR & $|\mathrm{S} / \mathrm{|}|$ & 1000 & 244 & 10 & 235 & No Data & No Data & No Data \\
\hline$S X-110(T)$ & ASMD LKR & IS/II & 1000 & 62 & 5.5 & 144 & No Data & No Data & No Data \\
\hline$S X-111(T)$ & ASMD LKR & IS/II & 1000 & 125 & 2 & 179 & No Data & No Data & No Data \\
\hline$S X-112(T)$ & ASMD LKR & IS/II & 1000 & 92 & 30 & 163 & No Data & No Data & No Data \\
\hline$S X-113(T)$ & ASMD LKR & IS/II & 1000 & 26 & 15 & 100 & No Data & No Data & No Data \\
\hline$S X-114(T)$ & ASMD LKR & IS/II & 1000 & 181 & 0 & 205 & No Data & No Data & No Data \\
\hline$S X-115(T)$ & ASMD LKR & IS/II & 1000 & 12 & 50 & 61 & No Data & No Data & No Data \\
\hline$T-101(T)$ & ASMD LKR & IS/PI & 500 & 102 & 7.5 & 107 & No Data & No Data & No Data \\
\hline$T-102$ & SOUND & IS/II & 500 & 32 & 0 & 72 & ENRAF & 0.81 & 1 \\
\hline$T-103$ & ASMD LKR & $|S /| \mid$ & 500 & 27 & 1 & 68 & No Data & No Data & No Data \\
\hline$T-104$ & SOUND & $/ \mathrm{Pl}$ & 500 & 343 & 0 & 221 & LOW & 2.96 & 16 \\
\hline$T-105(T)$ & SOUND & IS/II & 500 & 98 & 0 & 105 & No Data & No Data & No Data \\
\hline T-106 (T) & ASMD LKR & IS/II & 500 & 21 & 115 & 62 & No Data & No Data & No Data \\
\hline $\mathrm{T}-107$ & ASMD LKR & $/ \mathrm{PI}$ & 500 & 173 & 0 & 141 & No Data & No Data & No Data \\
\hline$T-108$ & ASMD LKR & IS/II & 500 & 44 & 1 & 80 & No Data & No Data & No Data \\
\hline $\mathrm{T}-109$ & ASMD LKR & IS/II & 500 & 58 & $i$ & 86 & No Data & No Data & No Data \\
\hline $\mathrm{T}-110(\mathrm{~T}, \mathrm{H})$ & SOUND & $/ \mathrm{Pl}$ & 500 & 369 & 0 & 233 & LOW & 1.76 & 10 \\
\hline$T-111$ & ASMD LKR & $/ \mathrm{PI}$ & 500 & 446 & 1 & 270 & LOW & 0.83 & 5 \\
\hline $\mathrm{T}-112(\mathrm{~T})$ & SOUND & IS/II & 500 & 67 & 0 & 91 & No Data & No Data & No Data \\
\hline$T-201$ & SOUND & IS/II & 55 & 29 & 0 & 19 & No Data & No Data & No Data \\
\hline$T-202$ & SOUND & IS/II & 55 & 21 & 0 & 15 & No Data & No Data & No Data \\
\hline$T-203$ & SOUND & IS/II & 55 & 35 & 0 & 22 & No Data & No Data & No Data \\
\hline$T-204$ & SOUND & IS/II & 55 & 38 & 0 & 23 & No Data & No Data & No Data \\
\hline TX-101 & SOUND & $1 S / 11$ & 750 & 87 & 0 & 130 & ENRAF & 0.98 & 3 \\
\hline TX-102 & SOUND & $\mid \mathrm{S} / \mathrm{I}$ & 750 & 217 & 0 & 192 & LOW & 1.20 & 6 \\
\hline$T X-103$ & SOUND & IS/II & 750 & 157 & 0 & 163 & No Data & No Data & No Data \\
\hline$T X-104$ & SOUND & IS/II & 750 & 65 & 0 & 120 & No Data & No Data & No Data \\
\hline
\end{tabular}




\begin{tabular}{|c|c|c|c|c|c|c|c|c|c|}
\hline Tank & 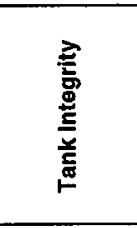 & 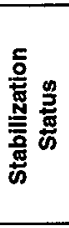 & 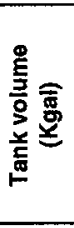 & 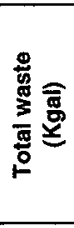 & 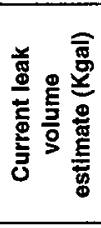 & 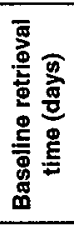 & 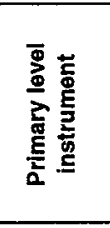 & 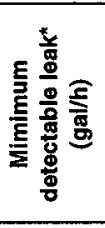 & 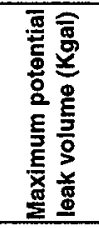 \\
\hline TX-105(O) & ASMD LKR & IS/II & 750 & 609 & 0 & 377 & No Data & No Data & No Data \\
\hline TX-106 & SOUND & IS/II & 750 & 453 & 0 & 303 & LOW & 3.04 & 22 \\
\hline TX-107 & ASMD LKR & $|S / I|$ & 750 & 36 & 2.5 & 98 & No Data & No Data & No Data \\
\hline TX-108 & SOUND & IS/II & 750 & 134 & 0 & 153 & No Data & No Data & No Data \\
\hline$T X-109(T)$ & SOUND & IS/II & 750 & 384 & 0 & 271 & LOW & 1.38 & 9 \\
\hline $\mathrm{TX}-110$ & ASMD LKR & IS/II & 750 & 462 & 0 & 308 & LOW & 2.04 & 15 \\
\hline TX-111 & SOUND & IS/II & 750 & 370 & 0 & 264 & No Data & No Data & No Data \\
\hline TX-112 & SOUND & IS/II & 750 & 649 & 0 & 396 & LOW & 2.08 & 20 \\
\hline$T X-113$ & ASMD LKR & IS/II & 750 & 607 & 0 & 376 & LOW & 1.11 & 10 \\
\hline$T X-114$ & ASMD LKR & IS/II & 750 & 535 & 0 & 342 & LOW & 1.61 & 13 \\
\hline$T X-115$ & ASMD LKR & IS/li & 750 & 640 & 0 & 392 & LOW & 1.48 & 14 \\
\hline TX-116 & ASMD LKR & $|S| I \mid$ & 750 & 631 & 0 & 388 & No Data & No Data & No Data \\
\hline TX-117 & ASMD LKR & IS/II & 750 & 626 & 0 & 385 & LOW & 0.81 & 7 \\
\hline$T X-118(T)$ & SOUND & IS/II & 750 & 347 & 0 & 253 & LOW & 1.05 & 6 \\
\hline$T Y-101(T)$ & ASMD LKR & IS/II & 750 & 118 & 1 & 145 & No Data & No Data & No Data \\
\hline TY-102 & SOUND & IS/II & 750 & 64 & 0 & 119 & No Data & No Data & No Data \\
\hline$T \gamma-103(T)$ & ASMD LKR & IS/II & 750 & 162 & 3 & 166 & LOW & 3.52 & 14 \\
\hline TY-104 (O) & ASMD LKR & IS/II & 750 & 46 & 1.4 & 107 & ENRAF & 0.71 & 2 \\
\hline TY-105 & ASMD LKR & IS/II & 750 & 231 & 35 & 198 & No Data & No Data & No Data \\
\hline TY-106 & ASMD LKR & IS/HI & 750 & 17 & 20 & 70 & No Data & No Data & No Data \\
\hline U-101 & ASMD LKR & IS/II & 500 & 25 & 30 & 66 & ENRAF & 1.65 & 3 \\
\hline$U-102$ & SOUND & $/ \mathrm{PI}$ & 500 & 374 & 0 & 236 & No Data & No Data & No Data \\
\hline $\mathrm{U}-103(\mathrm{H}, \mathrm{O})$ & SOUND & /PI & 500 & 468 & 0 & 280 & ENRAF & 1.23 & 8 \\
\hline $\mathrm{U}-104$ & ASMD LKR & $1 S / 11$ & 500 & 122 & 55 & 117 & No Data & No Data & No Data \\
\hline U-105 $(H, O)$ & SOUND & /PI & 500 & 418 & 0 & 257 & ENRAF & 1.83 & 11 \\
\hline $\mathrm{U}-106(0)$ & SOUND & $/ \mathrm{PI}$ & 500 & 226 & 0 & 166 & ENRAF & 0.64 & 3 \\
\hline U-107 (T, O) & SOUND & $/ \mathrm{P} \mathbf{i}$ & 500 & 406 & 0 & 251 & ENRAF & 1.56 & 9 \\
\hline$U-108(H)$ & SOUND & $/ \mathrm{PI}$ & 500 & 468 & 0 & 280 & No Data & No Data & No Data \\
\hline$U-109(H)$ & SOUND & /PI & 500 & 463 & 0 & 278 & ENRAF & 1.96 & 13 \\
\hline $\mathrm{U}-110(\mathrm{~T})$ & ASMD LKR & $|S / P|$ & 500 & 186 & 8.1 & 147 & No Data & No Data & No Data \\
\hline U-111 (O) & SOUND & /PI & 500 & 329 & 0 & 215 & LOW & 0.92 & 5 \\
\hline U-112 & ASMD LKR & IS/II & 500 & 49 & 8.5 & 82 & No Data & No Data & No Data \\
\hline U-201 & SOUND & IS/II & 55 & 5 & 0 & 7 & No Data & No Data & No Data \\
\hline U-202 (O) & SOUND & IS/II & 55 & 5 & 0 & 7 & No Data & No Data & No Data \\
\hline U-203 (O) & SOUND & $|S / I|$ & 55 & 3 & 0 & 6 & No Data & No Data & No Data \\
\hline U-204 (O) & SOUND & IS/II & 55 & 3 & 0 & 6 & No Data & No Data & No Data \\
\hline
\end{tabular}

